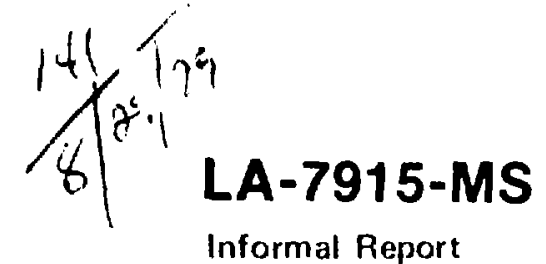

Informal Report
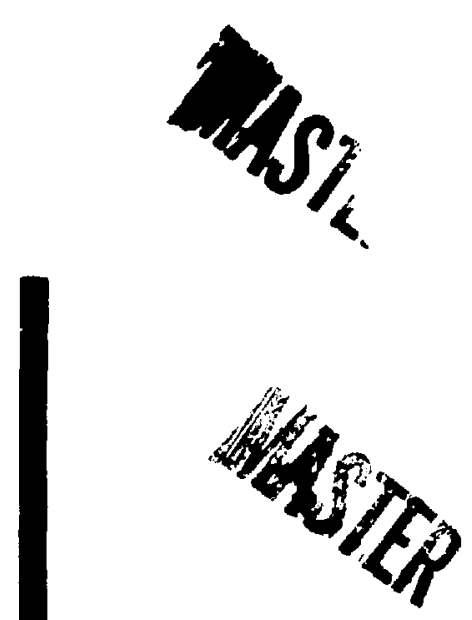

LAMPF 805-MHz Accelerator

\section{Structure Tuning and Its Relation to Fabrication and Installation}



$\frac{7}{0}$

$\stackrel{2}{\frac{2}{5}}$ 
LA-7915-MS

Informal Repo:t

UC-28

Issued: July 1979

\title{
LAMPF 805-MHz Accelerator \\ Structure Tuning and Its Relation to \\ Fabrication and Installation
}

\author{
G. R. Swain
}
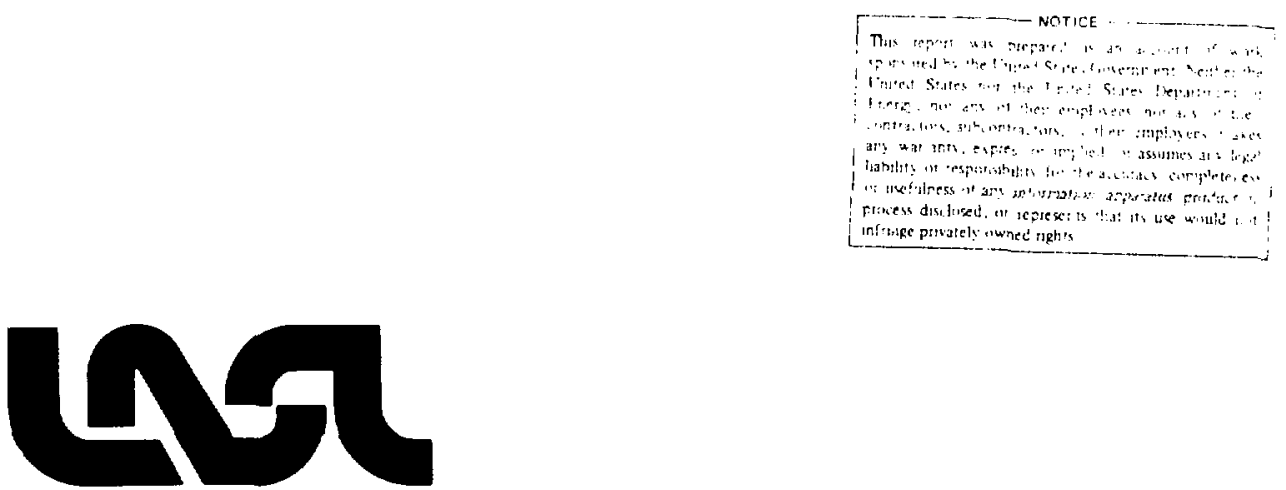
I. TNTRODUCTION

A. Scope of This Report 1

B. A Prief look at Design Consiclerations 2

11. PRE-INSTALLATION TLNLNG PROCEIJ)RE 3

n. Tank Sections 3

1. Crude Initial Segment Half Cap Determined 5

2. Initial Segment Noses Machined 7

3. Improved Segment Half Gap and Clamshell Hall Giap Determined 9

4. Segment Noses Machined 9

5. Initial Ciamshell Bosses Machined 9

6. Remaining Clamshe11 Bosses Machined and All (') amshells Brazed 9

7. Segments for a Tank Machined y

8. ldentilication Marks and Scgmont Fose Radius hpplied 10

9. Cap Set and identification Stamed on Coupiing Cavities 10

10. Final Scgment Half Cap Determined 10

11. Segment Suses Yachined to Final Halr rap 11

12. Section Parts Brazed Together 11

13. Pi/2-mode and Acecerating Cavity Frerunencies Measured 11

14. Required Accelerating: Cavity Frequencies Calculated is

15. Accelerating Cavities Which Are low in Frequency runed 13

16. Flats Cut for Cooling Tubes 13

17. Sections leak checked 13

18. Cooljng Tubes Installeci, Sections Cleaned Up and Stored J3

B. Bridge Couplers 13

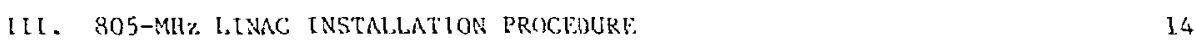

A. Initial Installation and Checkout 14

1. Piers, Rails, Monuments 14

2. Tunnel Wiring, Sector Water Systems 16

3. R.F. Cluster Building Racks and Wiring 16

4. Module Installation 16

5. Reference Drive Line 16

6. Safety, Communications Systems 16

7. Capacitor Bank, Local Klystron Controls and Connections 16

$\begin{array}{ll}\text { 8. Plumbing } & 17\end{array}$

9. Resonance Controllers 17

10. Klystron Units 17

11. Final Cavity Tuning 17

12. Bridge Coupler Tuning and Module Field Flattening 17

13. Monitor Loops 18

14. Vacuum Manifolds 18

15. Ion Pumps 18

16. Temporary E-Probes 18

17. RF Window 18 
1.s. leak Check, kepair lields 18

19. "lumbing For RF rindow, Bridge Coupler Posts 19

20. Stopband Check 19

21. Module Conditioning 19

22. High-Power Test 19

23. Magnets and Beam Trquipment 19

24. Leak Cleck and Pumpdown 20

25. RF Sustem Sotup and Calibration 20

B. Laker I.inac Modifications 20

1. Bridge Coupler length Correction 20

2. Mlignment liork 22

3. $\because$ iscollaneous changes 23

a. Current Monitors 23

b. Beam Position Monitors 23

c. Benm Steering Configuration ?3

d. Vacuum 23

IV. 805-MIH LINAC FINAL. TLNING PRUCEDURES

A. Coupling Cavity Pretuning 23

1. Physical Conditions 23

2. Set Frequency 23

B. Accelerating Cavity Tuning 24

1. Determine Distances 24

2. Check Temperature 26

3. Measure Cavity Frequencies 26

4. Measure Pi/2-Mode Frequency Before Tuning 26

5. Calculate Frequencies 26

6. Tune Interior Cavities 26

a. Septum Bending 26

b. Dinging 30

c. Nose Stretching 30

7. Tune End Accelerating Cavities 31

8. Measure Pi/2-Mode Frequency After Tuning 31

C. Final Tank Tuning Checks 31

1. Stopband Check 31

2. Preliminary Bridge Coupler Tuning 32

3. Preliminary Beadpull and Field Flattening 32

4. Frequency and Stopband Under Vacuum 33

D. Bridge Coupler Tur.ing and H-Probe Calibration 33

1. Cut Iris to Initial Size 33

2. Install Adjustable Posts 33

3. Adjust Center Post Penetration 36

4. Drill For Additional Posts If Required 37

5. Install Trial Posts 38 
ConTE:WS, cont'd.

6. Find Approximate Center Post penceration 38

7. Install Contier Post 38

8. Measuru VSWR 38

9. Finlarise iris 39

10. Insta11 Permanent Fixed Posts 39

11. Adjust find limers 39

12. Adjust Compling Cavities 39

13. Nojust Platse 'Bith find-End Irive 39

14. Cheret Phase bith center brive 40

15. Recheref Frequency and thasing 40)

16. Mcissure stophand 40)

17. Cherek VSibR 40)

Ir. Cat fermanont find Tuners 40

1\%. Make fimal lhase check 40

20. Reroord Final Mageiurrinents 40

21. Sot H-probess 40)

L. Folule Fiold Fralization 4 ?

1. Mu Varium Bcadpull 42

$\therefore$ cherek scatter bithin lanks $\quad 42$

3. Rotate Bridgo Coupler conter losts 42

4. Record Data 4 ?

F. Final Low-Power Stupband Cherk 42

V. TUNTMG THCHNIOUES AND THOLS 43

A. Frequency Measurement Technigues 43

1. Resionant Frequency 43

2. Pi/2-Mode Identification 43

3. Stophand 46

4. Possihlo Pitralls in Frequency Measurements 46

a. Poor Contact by Shorting Pin 46

b. Iris to Bridge Coupler Fnd Tuner Prohe Interaction 47

c. Apparatus Too close to Iris 47

d. Humidity bffects 47

e. Temperature Drift 48

B. Calculation of Desired Cavity Frequencies 48

1. Coupling Cavities 48

2. Accelerating Cavities 48

C. Tuning probes $\quad 49$

1. Coupling Cavity Probe 49

a. Histo: ical Note 49

b. Description of the Probe and Method of Use 50

c. Additional Refinements 52 
CONTENTS, concl'a.

2. Accelerating Cavity Tuning Probe 52

a. Historical Note 52

b. Description of the Probe 53

1). Tuning touls 53

I. Septum Bonding Toul 53

$\therefore$ Siste tretching Tool

3. Dinging Tnol 56

4. Sose Shaving Tool 56

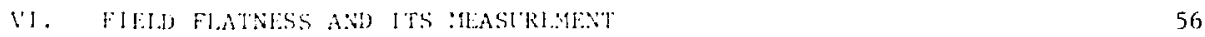

a. (Iverviluw

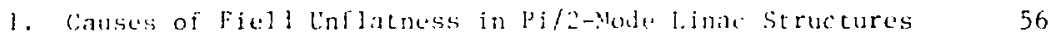

2. Fireld bistribution Measurememts 57

B. Computerized Frequency Bealpuld Techniques 58

1. Electrical Considerations 58

2. Yechanical Consideralions 59

3. Softwore and aperating comeiderations bl

$\therefore$ Cheide of thasurement parameters and Accuracy 63

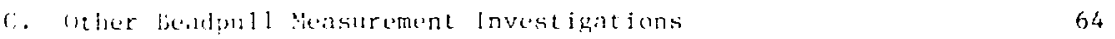

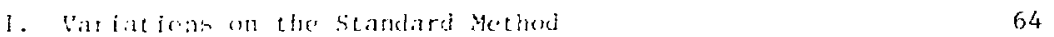

$\therefore$ [nther Topes of healpul] 65

3. Effect of bendpull Pickup point 66

1). (Hbserved long-Term Stabilit: of Field bistributions 66

$\begin{array}{lr}\text { ACKNOWLFDCYIENTS } & 68\end{array}$

APPENDIXES:

A. DESIGN PARLYETERS FOR THE 805-MHZ LINAC

B. MEASUREJ AND roUIVALENT CIRCUIT PARAMFTERS

1. Introduction to the Tiables 73

11. Index to Parameters in the Tables 74

C. CORPUTER PROGRM l.ISTINGS $\quad 87$

D. COUPLING OF DRIVE I.LNE TO BRIDGF COUPLER CAVITY 99

E. TUNING CONDITIONS FROM COUPLED RESONATOR THEORY 100

F. FIELD DISTRIBUTION DEPENDENCE ON BEAM LOADINr. 102

G. STOPBAND AND HIGH-POWER STABILITY 104

11. READPULL MEASUREMENT EQULPMENT AND OPTIONS 106

I. Equipment Notes 106

II. Electrical Connections 106

III. Controls and Options 107

IV. Paper Tape Format 110

1. BEADPULL ERROR FROM DRIVE-TO-PICKUP SEPARATION 110

J. ESTIMATE OF NEAREST NEIGHBOR COLPLING, FROM MODE SPACINC 112 
LAMPF: 305-\$HIZ ACCHLIRATOR STRIUTURI: TUNING;

AND ITS RFLATION TO FABRICATION NNI INSTAIIATION

by

C. R. Skian

ABSTRACT

In the course of construction of the $805-\mathrm{Mli}$ linac, it was necessary to set 10000 resonant cavities to precise frequencies and to check, and in some cases, to adjust the field distribution along the beam axis of the $104 \mathrm{rf}$ tanks composing the 1 inac. Since this was the first proton 1 inac of the side-coupled type ever built, it was necessary to develop new techniques and instrumentation for structure tuning. An outline of the fabrication and installation process is given, showing how the tuning operations were interwoven with the fabrication steps and indicating the re] ation of tuning to other installation and check-out activities. The steps of the tuning procedure are then examined in detail. Tools for tuning by dinging, nose-stretching, and septum bending are described. Techniques for frequency measurements and for beadpull measurements of field distribution are discussed. The section on ficld distribution measurement includes results of research on measurement procedure and theory and observations confirming the low-power stability of field distributions for a three-year period.

Selected results from the theory of chains of coupled resonators are given. Coupled resonator model parameters and various measured parameters for the 805-Miz linac are tabulated.

\section{INTRODUCTION}

A. Scope of This Report

The 805-Miz linac at the Los $M 1$ amos C1inton $P$. Anderson Meson Physics Facility (LAMPF) was the first proton linac employing a side-coupled standing wave structure. The linac is approximately 0.8 $\mathrm{km}$ long, and is used for the energy range 100 to $800 \mathrm{MeV}$. The $805-\mathrm{MJz}$ linac is supplied with particles by three ion sources with Cockcroft-Walton power supplies (for $\mathrm{H}^{-}, \mathrm{H}^{+}$, and polarized $\mathrm{H}^{-}$beams) and a four-tank drift-tube linac for acceleration from 0.75 to $100 \mathrm{MeV}$. A general description of LAMPF and its early history are given by Livingston (1972).

This report presents one aspect of the construction of the $805-\mathrm{MHz}$ linac: structure tuning. The process of structure tuning consisted of the steps in the design, fabrication, and initial adjustment of the approximately $10000 \mathrm{rf}$ cavities making up the linac such that the proper resonant frequencies and field distributions were obtained. As such a linac had not been built before, it was necessary to develop new technjques and instrumentation (as well as make minor revisions in the design of the accelerator itself in a few cases) as the work progressed.

The structure tuning operations for the 805$M l z$ linac were very much interlaced with the fabrication process. Thus it is appropriate that this report present an outline of the structure fabrication process and then show how the tuning procedures were embedded in it. The relation of structure tuning to other installation and checkout activities will be shown. However, the report will not attempt to describe the construction of the if system, the control system, the beam switchyard, etc.; nor give details of auxiliary systems such as vacuum or cooling systems, except as they impinged upon the tuning process. 
The report begins by briefly reviewing how the 805-NA = linac was designed, and how certain parameter values and tolerances came out of that design process. Later sections of the report give outlines of the fabrication and tuning procedures (parts $I i$ and 111 ), describe in detail the final tuning procedures used (part IV), ard give details of the tuning tools and field adjustment procedures (parts $V$ and $V I)$. The section on field distribution measurement in part li includes results of research on measurement procedure and theory as well as a description of the standard computerized procedure adopted for the tuning of the linac. The observed stability of the low-power field distribution within Iinac tanks over a three-year period is also discussed. Summaries of 805-MHz linac design and measured parameters are given ir. the tables in Appendixes $A$ and $B$. Included are coupled resonator model parameters for each tank in the 805-MHz 1inac. In aldition, selected results from the theory of coupled resonators useful in this report are deve1oped in the appendixes.

B. A Bricf Look a: lesign Considerations

Initial Jesign considerations involved the balancing of desirable beam pen formance against capitil and operating costs. It was desired to have an intense beam with small energy spread but with low beam lose along the machine to keep activation levels low. The choice of the frequencies 201.25 and $805.00 \mathrm{bll}:$ for the drift-tube and side-coupled linacs was based on the technology of drift-tube linacs and the availability of rf drive equipment. Also beam dynamics calculations indicated that the bunch coming out of the drift-tube 1 inac would be compact enough to be accepted by a side-coupled linac operating at four times the frequency. (The factor of 4 was decided upon before it was decided to accelerate both positive and negative beams. An odd factor, such as 3 , would have simplified the design of the transition area (Swenson 1972) between the linacs.)

From the point of view of the linac structure, the operating efficiency nay be rated by the parameter called effective shunt impedance, $2 \mathrm{~T}^{2}$, given by

$$
z T^{2}=(\Delta \varepsilon)^{2} /\left(Q^{2} L P\right),
$$

where $Z$ is the shunt impedance per unit length of structure, $T$ is the transit time factor, $q$ is the charge of the accelerated particle, $P$ is the power loss and $i c$ is the particle energy gain in a length L. For the side-coupled linac, the shunt impedance is strongly influenced by accelerating cavity geometry and beam-hole size. Calculations were made using a computer code named LALA (Hoyt et al. 1966, Engel 1968a, Rich and Mackoberts 1969). Mesh calculations were performed for a cylindrically symmetric model. Simple iris-loaded waveguide geometries were analyed first. Then features such as rounded outside corners and nose cones around the beam holes were added, resulting in an improved shunt impedance. A series of calculations was run to optimize the cavity geometry for a given frequency, particle velocity, and beam-hole size. The predicted shunt impedances and $Q$ 's were checked against the performance of various prototype linac models (E. Knapp et al. 1968). These tests and calculations (Jacobson 1963) indicated that, based on shunt impedance, the appropriate energy to change from the drifttube structure to the side-coupled structure was 100 yel. The danger of beam pulse shortening duc to excitation of transverse cavity modes was estimated to be small (Gluckstern 1964, Potter 1966). Beam dynamics calculations indicated that it was reasonable to use a $3.175 \mathrm{~cm}$ ( 1.250 inch) diameter beam hole for $100-21 \mathrm{MeV}$ and a $3.810 \mathrm{~cm}$ (1.500 inch) hole for 211-800 Mel, and that it was reasonable to use a stepped-beta structure. (Cality length is uniform within each of the 104 tanks.) Beam dynamics calculations were also used to explore the types of focusing systems that could be used, and to determine the effects of structure or focusing magnet misorientation, of stray magnetic field, of focusing field strength errors, of tank field unflatness, and of space charge (Jacobson and Visscher 1964, Jakobson et al. 1964, Crandall 1967a, Swenson and Crandall 1968, Jameson et al. 1970, Crandall et a 1. 1971). The effect of accelerating structure length or spacing errors will be discussed in part III.B.1. of this report.

The energy gain per unit length was limited to about $1.1 \mathrm{MeV}$ per meter in order to avoid cooling and $\mathrm{rf}$ arcing problems in the $805 \mathrm{MHz}$ 1inac. Perhaps this was an overly conservative choice, since side-coupled structures have been successfully operated at over $10 \mathrm{MeV}$ per meter for electron acceleration in commercial units (Livingston 1972, p. 29). 
The economy of drive increased with size; the largest practical drive source was selected to be about 1 megawatt. These considerations thus determined the length of side-coupled structure that could be poliered from one drive source, and hence how many sources nere needed. The tank lengths and spacings and the design particle energy and phase at the input and output of each tank were then calculated using an iterative procedure (Crandall l974b).

The final 805 wa linac configuration was based on K. R. Crandall's computer printout (kov. 2, 1967, see Appendix i) giving number of accelerating cavities per tank, carity lengths, and spacings between tanks. Additional specifications (horstell 1968a) were based on economic considerations of the fabrication process and on the need for cooling for high duty factor operation. Janks were made in sections small enough to fit in a tall $(2.13 \mathrm{~m}$, or 84 inches brazing furnace. Diagrams presenting the nomenclatare and illustrating the sequence of assembly of s01-1liz linac parts are siven by kocaan et al. $\left(19^{-3}\right)$. The wall thickness between cavities was made large enough to easily transmit the heat from the nose regions near the beam to the outside diameter, where water-cooling tubes were attached. Based on a balance between copper costs and dic costs, it was decided to use nine die sets for forging the accelerating cavity segments, nine more for the c) am-shells (coupling cavity halves), and two sets for tank heads. Twelve different thicknesses of coupling cavitics were used to provide for the required coupling and to maintain clearance at the section joint flanges. A tabulation of geometrical and electromagnetic parameturs for acceleratirg and coupling cavitics has prepared (Engel 1968b) using the optimum LALA results as a guide. Figs. 1 and 2 show examples from this tabulation.

In order to keep the work force at Lith at a reasonable size, but yet accomplish the fabrication of the $805 \mathrm{kHz}$ linat in a reasonable time, it was decided to subcontract as much as possible r.f the forging and crude nuchining to outside firms, but to do all the critical work of finishing, final assembly, and precision tuning at LuPF. It was also decicied to obtain brazing furn ces for the asscmbly of sections at LAMPF. Among the factors involyed in making this decision were problems of transportation, engineering supervision, and the special brazing troatments required (Worstell 1963a-b, 1970, 1971, Worstell et al. 1966).

In order to check certain asperts of the 805MHz linac design fairly early in the fabrication process, Vodule 5, the first module of this linac, was first set up and operated with full rf energy (but without beam) at the Equipment Test Laboratory Building (Fig. 3). This permitted some evaluation of the tuning techniques, the module cooling system and the $\mathrm{rf}$ contro systems (Jameson and Wallace et al. 1970, Jameson and Swain et al. 1970, Swain et al. 1971). The initial development of the computerized beadpull measurement of field distribution also kas done during this time. In March 1971, Vodule 5 was mored in two pieces to its permanent position in the beam tunnel.

Calculations for coupled resonator equivalent circuits were used to investigate the effect of beam loading and the tolerances on frequency and coupling for structure tuning (E. Knapp 1964b, B. knapp et al. 1965, Swain 1966d, Jameson and Swain et al. 1970). Further discussions of the tuning tolerances used are found in sections III.A.11. and 12, and IV. (particulariy IV.C.) of this report.

Some later modifications of the LNMPF 805MHz linac from its original design will be outlined in part III.B. of this report.

\section{I . PRI:-INSTMLLATION TUNING PROCEDURE}

The tanks of the $805-1 \mathrm{~Hz}$ Iinac are made up from two or four sections (Fig. 4). This report section deals with the fabrication and tuning steps which occurred before the linac sections and bridge couplers vere installed on their support rails in the beam channel. (See koczan et al. 1973 and references therein, horstell 1971). Diaglams and nomenclature for the various parts are given by koczan et al. (19:5).

\section{A. Tank Sections}

The copper forging and initial machining work were perforned by outside shops. As the machined copper forgings for segments and clamshells were received at the Equipment rest Laboratory Building (ETLB), they were gaged by the inspectio. crew. Those which did not meet the specifications were assigned for rework as necessary. A number of spares of each type were ordered, and unused spares of any type could generally be reworked for use as any previous type, since the parts became larger as 


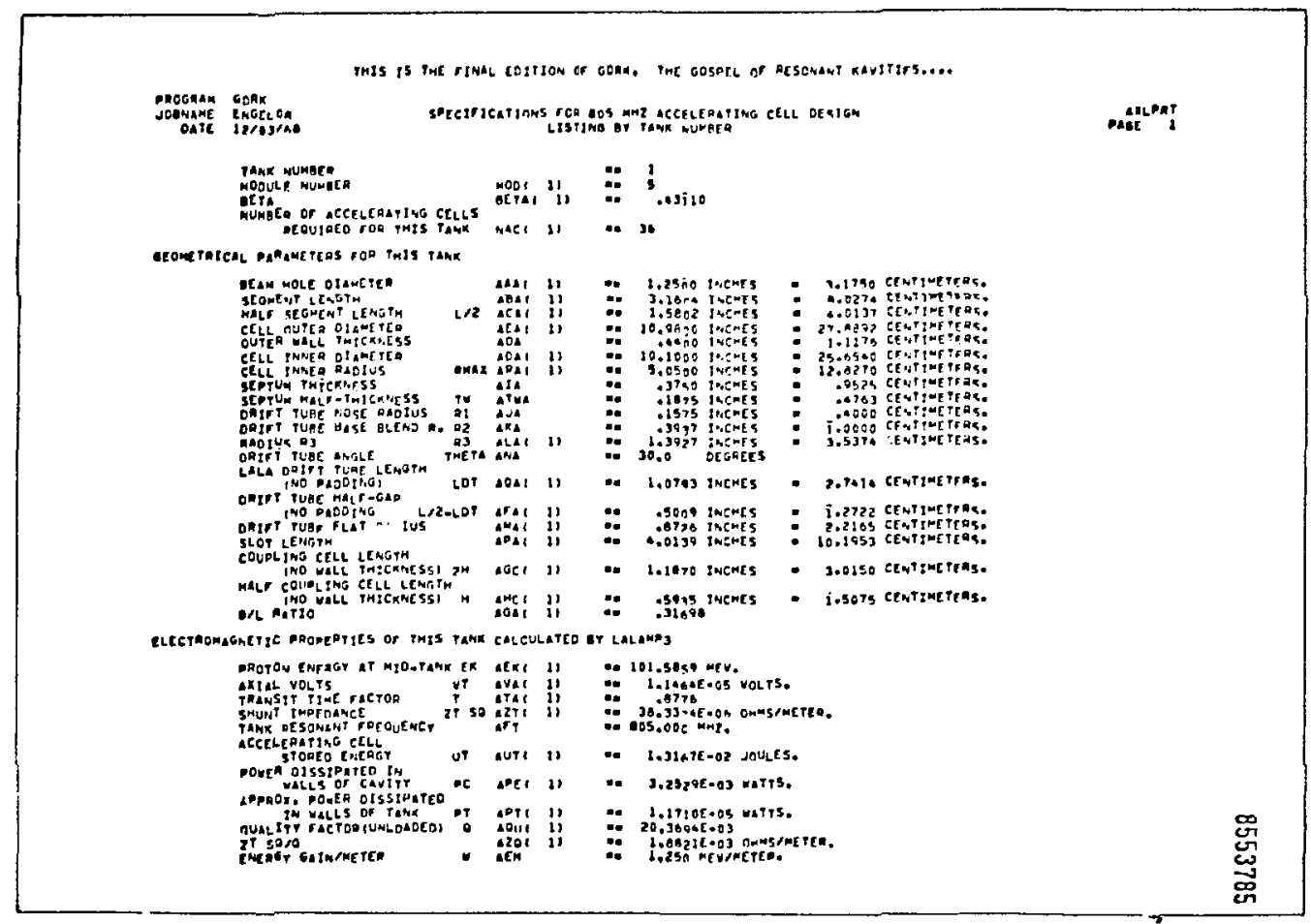

Fig. 1. wxample of tabulation of accelerating cavity parameters.

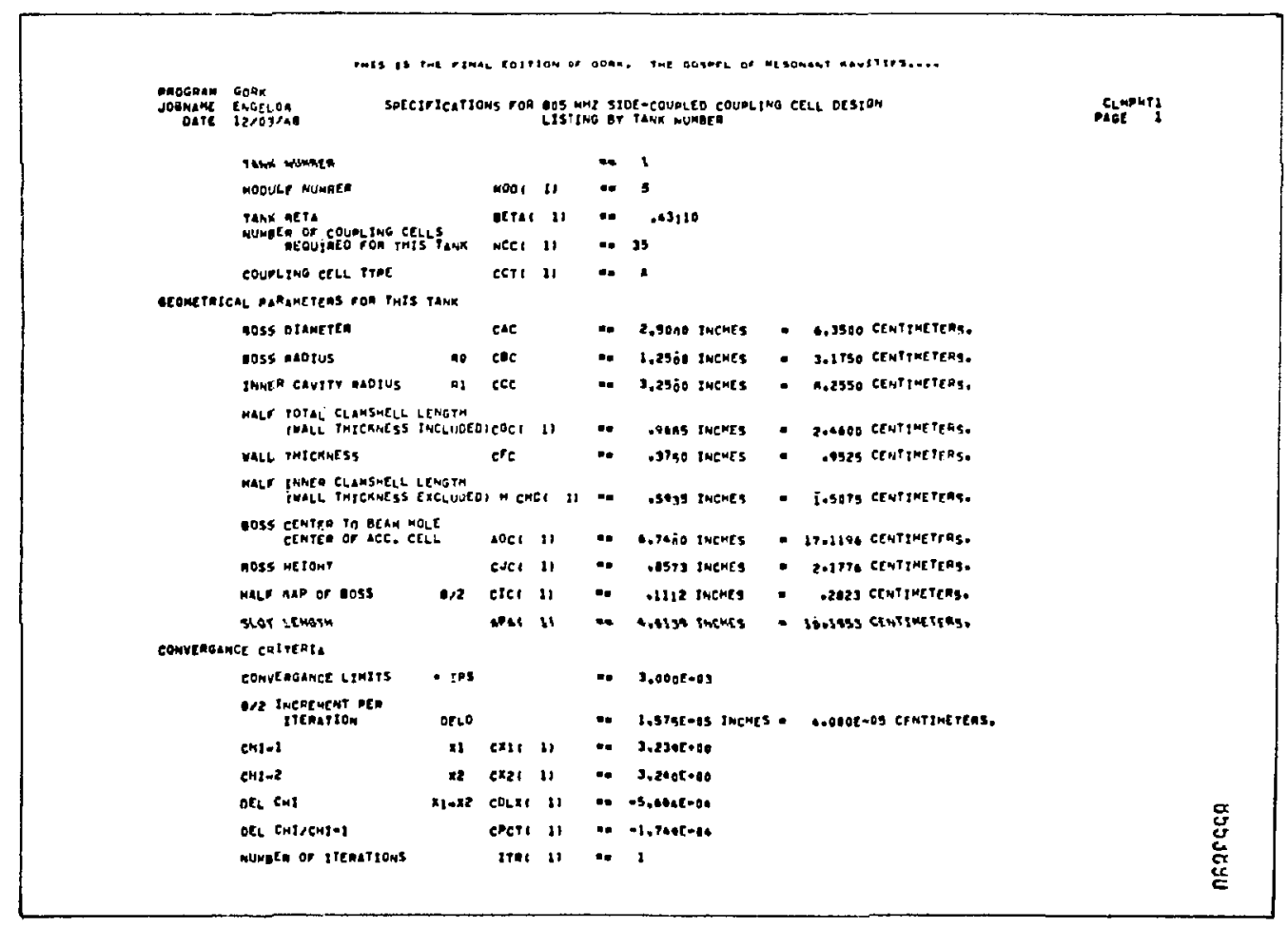

Fig. 2. Example of tabulation of coupling cavity parameters. 


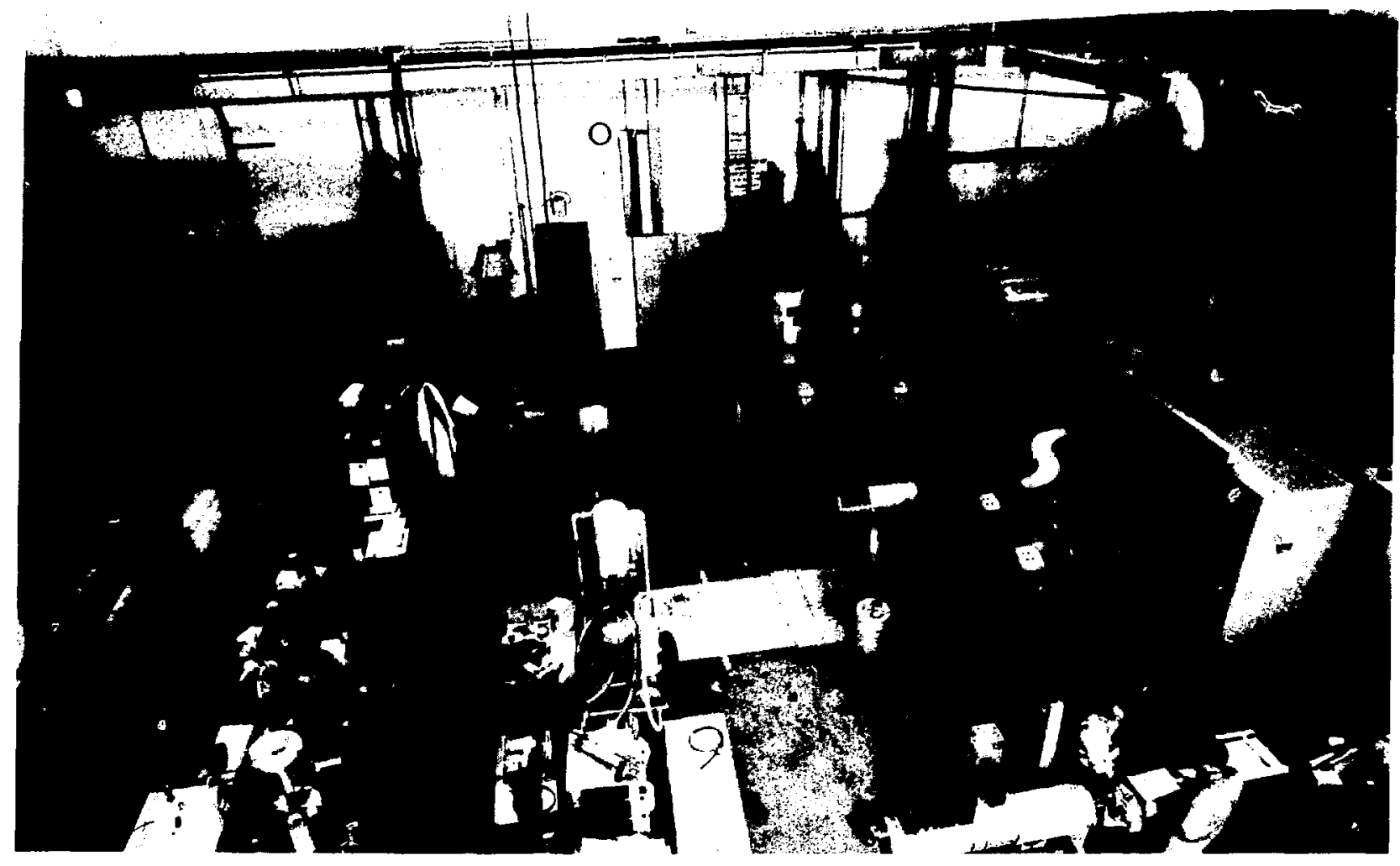

Fig. 3. Module 5 under test at ETLB. Module 5 is at the far left, and its drive klystron is at the upper right. Several partly completed modulator assembiies are at right center.

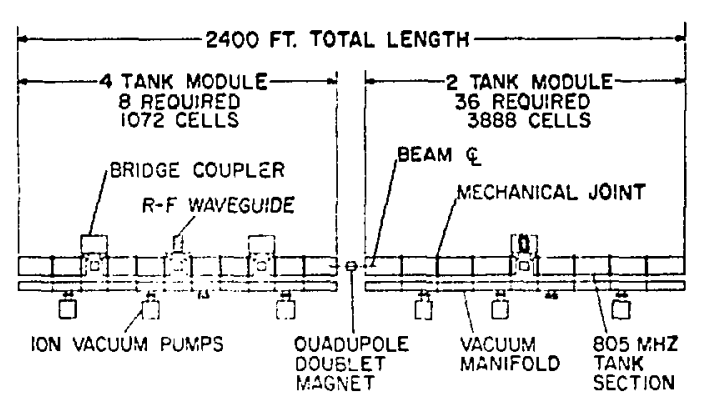

Fig. 4. Schematic of 805-injz linac modular concept.

une proceeded downstream along the machine. As received by the tuning section at E'TLB, the outer radius of each cavity had been machined in the segment or clamshell to the specified final dimensions, but the nose or boss had been left long (Engel $1968 \mathrm{~b}$, pp. 1-2) to allow the tuning process to compensate for possible dimensional variations elsewhere in the cavity. (Accelerating segment noses were about $2 \mathrm{~mm}$ long and clamshell bosses were about $0.7 \mathrm{~mm}$ long.) The segment noses did not have a radius at their tips at this time. The flow of parts in the pre-installation fabrication and tuning process was as shown in Fig. 5. Parts for the first tank of a now coupling cavity type were handled differently from those for subsequent tanks of the same coupling cavity type. The procedure for subsequent tank segments began at Step 7 below.

\section{Crude Initial Segment Half Gap Determined} (ETL Tuning Lab.). Approximately eight segments were used to determine the initial segment halfgap dimension. The nose cones of these eight segments were cut back (as will be explained in step 2) to give a resonant frequency in the range from 800 to $802 \mathrm{MH}$ - for each cavity formed between two segments as measured in the two-segment fixture. This fixture allowed two segments without coupling cavities to be clamped between aluminum end plates faced with plastic (Fig. 6). Two probes on hinged nonconducting blocks were raised to cover the coupling cavity slots, one on each segment, thereby placing the probes in a suitable position to introduce and pick up a rf signal in the cavity formed between the two segments (Fig. 7). For 


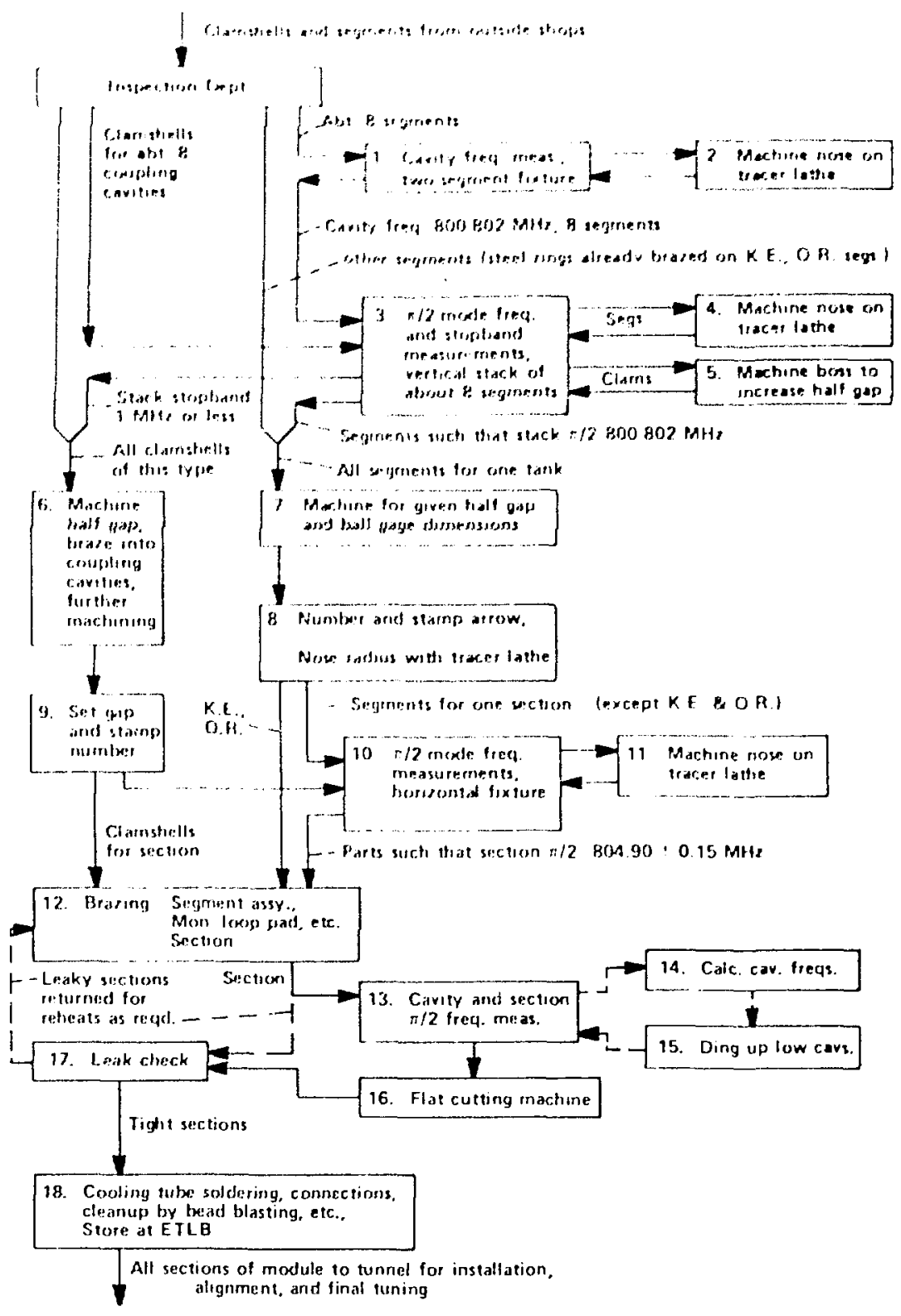

Fig. 5. Flow of tank section parts in pre-installation fabrication and tuning processes. (Box numbers correspond to the steps described in Section IA $\mathrm{A}$ ) 

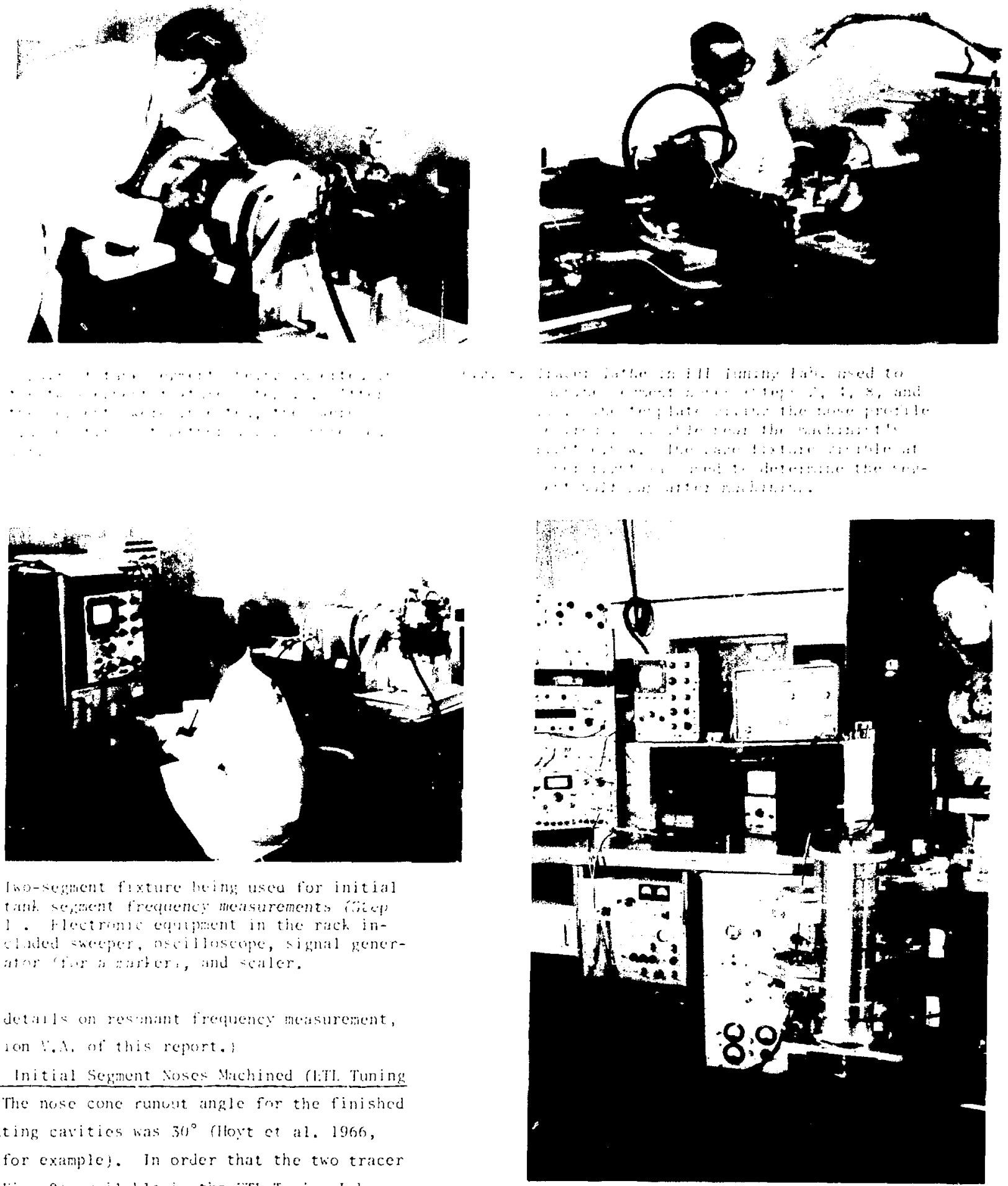

firticer deta11 on resmant frequency measurement,

sece Section $\because 2$. of this report,

\section{Initial segment woses Yachined flatl Tuning}

lat. 1 The nose cone runout angle for the finished accelerating cavities was $30^{\circ}$ fltoy et al. 1966 , I.ig. 1, for example). In order that the two tracer lathes (1ig. 81 arallable in the i:rl Tuning Lab. take off copper on!y from the tip region of the noses, the tracer lathe templates used had a runout of $35^{\circ}$. Since the initial eight segments required that considerable copper be removed from the noses,

:ig. 9. Prototype Model !: tuning equipment in 1965. The vertical stack of segments clamped together with steel bands is similar to the stack used in Step 3 of the LAMpF tank sections procedures. 


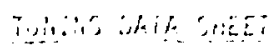 \\ crect list: iarir 91 _. isection}

Main cell nalf gap o $800-4 i+12$. celis to shov.

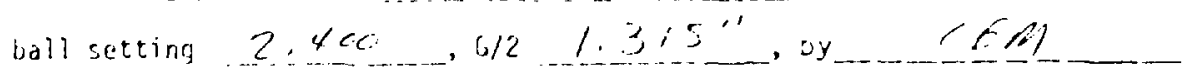
on (iate) -

Rverage freçuency two cell reading ............ Mhtz.

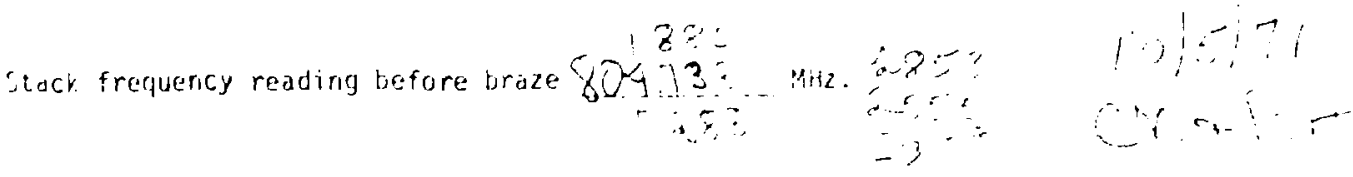

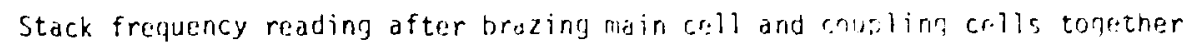

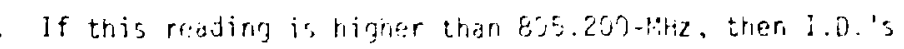
should be re-cut so that stiack frequency is $=205.600-14 \mathrm{H} z$. Hew reading litiz.

If the stack frequency after tank section is brazed is below $804.95 \mathrm{~J}-1.9 \mathrm{~Hz}$. then this tank should be Dinged. liew reading $\mathrm{PHH}$.

Final coupling cell gap 93511

Final main cell hali gap. $1.333^{\text {at }}$.

Final check: (Date)

Sent to tunnel by

Fig. 10. Data record for ETL Tuning Lab. measurements on parts of a tank section. Such records were filed in module notebooks. 


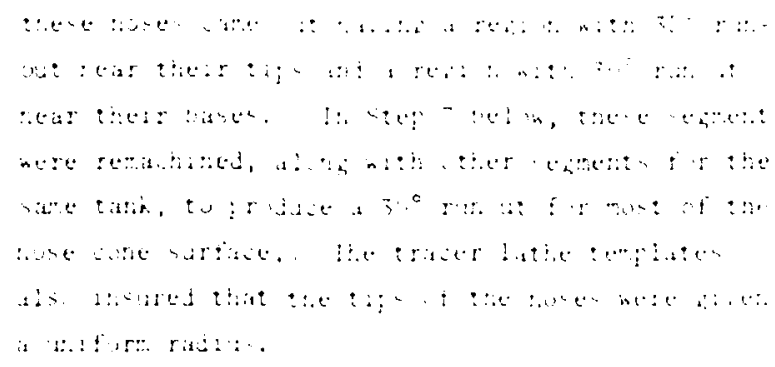
pensate for the drop a reanant frequenc: cabout

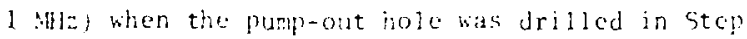
6. Lither procedure was sat isfactury, since the coupling cavities were casy to adjust in frequency later (step 9, etc.). The sensititity of resonant frequency to change in the gap was about 40 lifyz per $\mathrm{mm}$ ( $1 \mathrm{MHz} / \mathrm{mil})$. The final coupling cavity gap was recorded on the Tuning llata shect.

4. Segment loses Machined (ETL Tuning Lab.) Copper was removed from the tips of the initial segment noses with a tracer lathe as in step 2 .

5. Initial Clamshell Bosses Machined (ETL Shop). In order to raise the frequency of coupling cavities, copper was machined of the flat end of the clamshell reentrant boss, thus increasing the clamshell half-gap dimension.

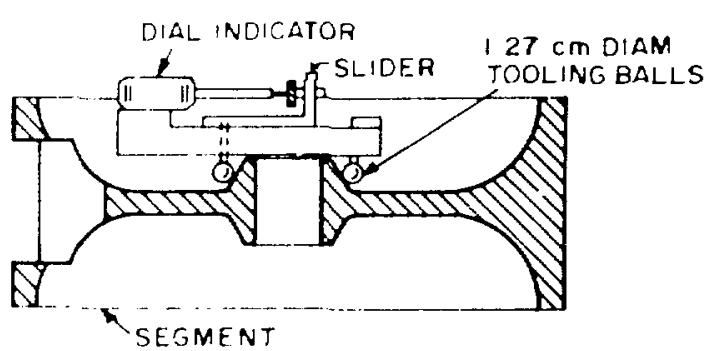

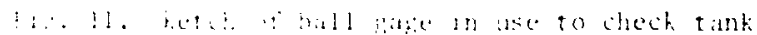

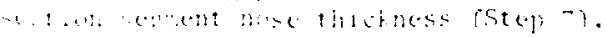

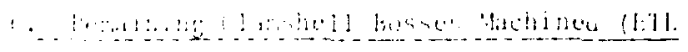

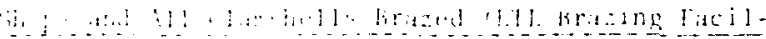

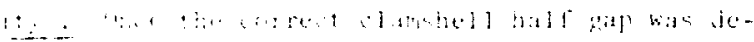

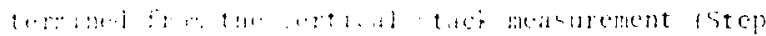

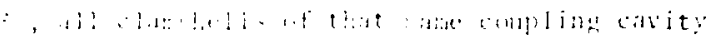

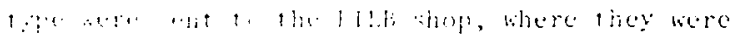

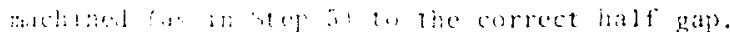

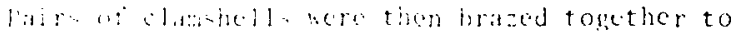

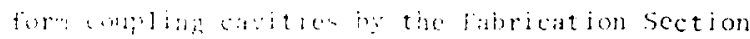

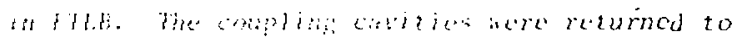
the lllly shog for further wishining. The cavities sere contoured to math the outside dianeter of the heyments conly three different outside diameters were used for segments of the sos ats linac), a pum-ont hole was bored, and one of the tho dowel pin loles was drillod. Tho lowed pins were used for aligment in Step 12, when the coupling carities were brazed to their mating segments. The other lowel pin hole was not drilled until after the coupling cality gaps were adjusted in step 9.) The couling cavitics were then sent to the Juning Lab.

\section{$\therefore$ Segments For 1 Tank Yachined (ETL Shop).} lor the initial tank of a given coupling cavity type, the segment half-gap dimension had been determined in step 3 above. For other tanks with the same coupling cavity type, the half-gap dimension to be used was extrapolated from that of the previous tank, using the tabulation (Fig. 1, p. 4) of the calculated dimensions as a guide (Engel 1968b) and reducing the projected half gap by $0.38 \mathrm{~mm}$ 
(0.015"). (This procedure left a $0.38 \mathrm{~mm}$ pad of copper on the noses to be available as necessary to compensate for variations in other cayty dimensions.) In either case, all segments for a given tank now had their noses machined off lleaving a flat tip) to the required half gap, and had the sides of the noses machined to give a uniform nose thickness. (The latter operation removed the region of $35^{\prime \prime}$ runout left in the initial segments by Steps 2 and 4 , lcaving all noses with a uniform $30^{\circ}$ runout.) The thickness of the noses was checked us ing a ball gage arrangement. A sketch of the gage is use is shown in Fig. 11. The ball gage dimensions used were $5.486 \mathrm{~cm}\left(2.160^{\prime \prime}\right)$ for segments with a $3.175 \mathrm{~cm}\left(1.25^{\prime \prime}\right)$ diameter beam hole and $6.096 \mathrm{~cm}\left(2.400^{\prime \prime}\right)$ for segments with a $3.810 \mathrm{~cm}$ (1.50") diameter beam hole. The segments also had their outside diameter michined to mate with the coupling cavity contour. Two dowel pin holes were drilled in each segment to be wised later (Step 12) in aligning the coupling cavity over the coupling slot in the segment. The segments were then returned to the Tuning Lab.

\section{Identification Marks and Segment Nose} Radius Applied (FTL Tuning Lab.) Segments were stamped with a permanent segment number (which indicated the tank number and relative position within the tank) and an arrow indicating the bean direction. After this time, all frequency measurements would be made with the segments arranged in their final sequence, but not necessarily with the coupling cavities that each would eventually rereive. Segments not needed were put aside for possible use as spares.

One of the tracer lathes was used to put the radius on the tip of the nose on each side of the segments. Since this did not shurten the noses appreciably, this did not leave the segments with any significant tapered surface with the $35^{\circ}$ runout of the tracer lathe template.

9. Gap Set and Identification Stamped On Coupling Cavities (ETL Tuning Lab.). The gap of coupling cavities was set to the dimension found in the vertical stack measurement in step 3. The copper was soft enough that this was done by tapping on the sides with a mallet to bring the bosses together or tapping in a phenolic wedge inserted between the bosses to force them apart. Figure 12 shows

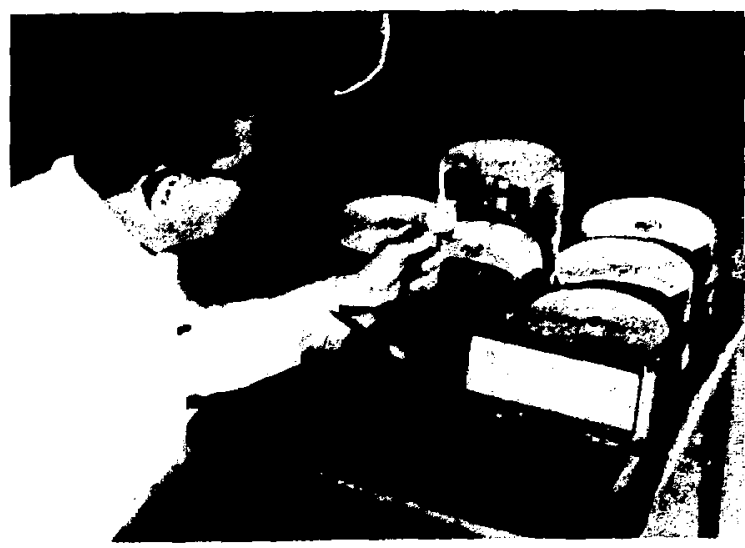

Fig. 12. Checking coupling cavity (clamshell) gap after halves brazed together and gap set, Step 9.

coupling cavities being checked after this adjustment.

Each coupling cavity was stamped with a permanent identification number which agreed with that of the segment to which it would be joined.

10. Final Segment Half Gap Determined (ETL Tuning Lab.). Frequency measurements were made for a long stack using the long horizontal fixture. A long stack consisted of all the segments, excluding knife-edge and 0 -ring segments, of a given tank section held together in order by the fixture and with the coupling cavities clamped on. The long horizontal fixture employed a pair of support rails faced with plastic upon which a set of segments could be placed (Fig. 13). The segments were clamped between a fixed aluminum end plate at one end of the rails and a movable aluminum end plate at the other. A set of special clamps was used to hold a coupling cavity in position at the proper side of each segment. (Although the segments were placed in their correct final order and relative orientation, the coupling cavities used for the measurement were not necessarily the same cavities the segments would eventually receive. )

In the Tuning Lab., the temperature was held at $22.2^{\circ} \mathrm{C}\left(72^{\circ} \mathrm{F}\right)$ and the humidity was controlled in order to make precise frequency measurements possible. The $\pi / 2$-mode frequency of the long stack was adjusted to $804.90 \pm 0.15 \mathrm{MHz}$. This figure was arrived at after considerable experience with the effects of the brazing process was obtained. It was 


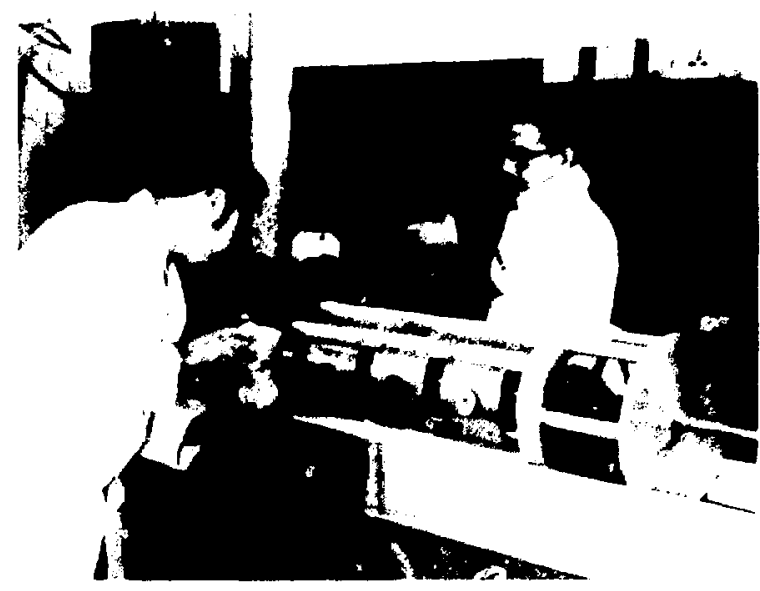

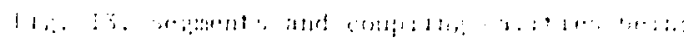

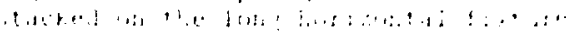

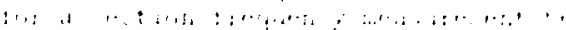

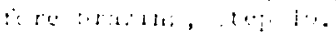

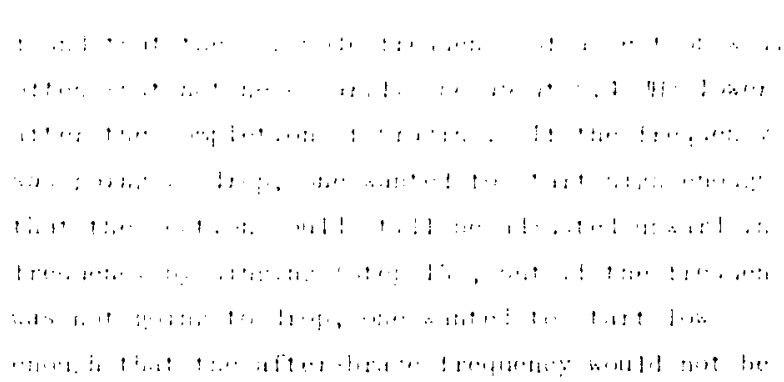

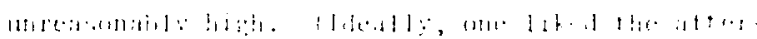

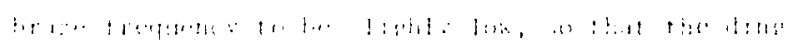

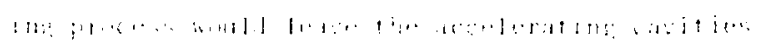

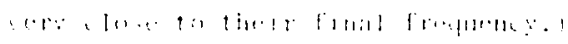

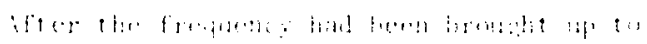

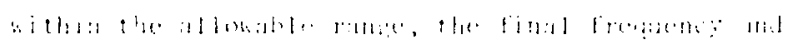

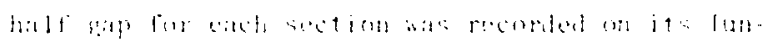

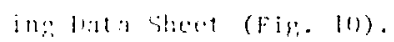

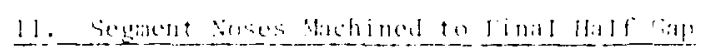

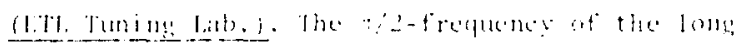

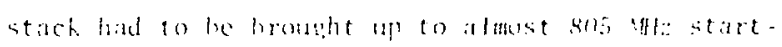
ing from somelwere in the range sos-80.t infe. The

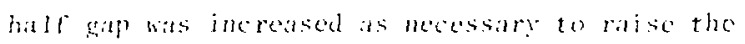
frecuency hy mehining enper oft the ends of the segment noses with one of the tracer lathes. The sensitivity to change in gip was ahout $8 \mathrm{~g}, \mathrm{~m} / \mathrm{mm}$ (200 kHz/mil) for the small segments, decroasing to acout $4 \mathrm{MHz} / \mathrm{mm}(100 \mathrm{kHz} / \mathrm{ni} 1)$ for the larger oncs. If the frequency had to be reduced, the segment inside diameter was sometimes swept. This was almost as sensitive. Making the segment shorter was used to reduce the frequency in a few cases. This had a sensitivity of about $0.2 \mathrm{MHz} / \mathrm{mm}$ ( $5 \mathrm{kHz} / \mathrm{mil}$ ).

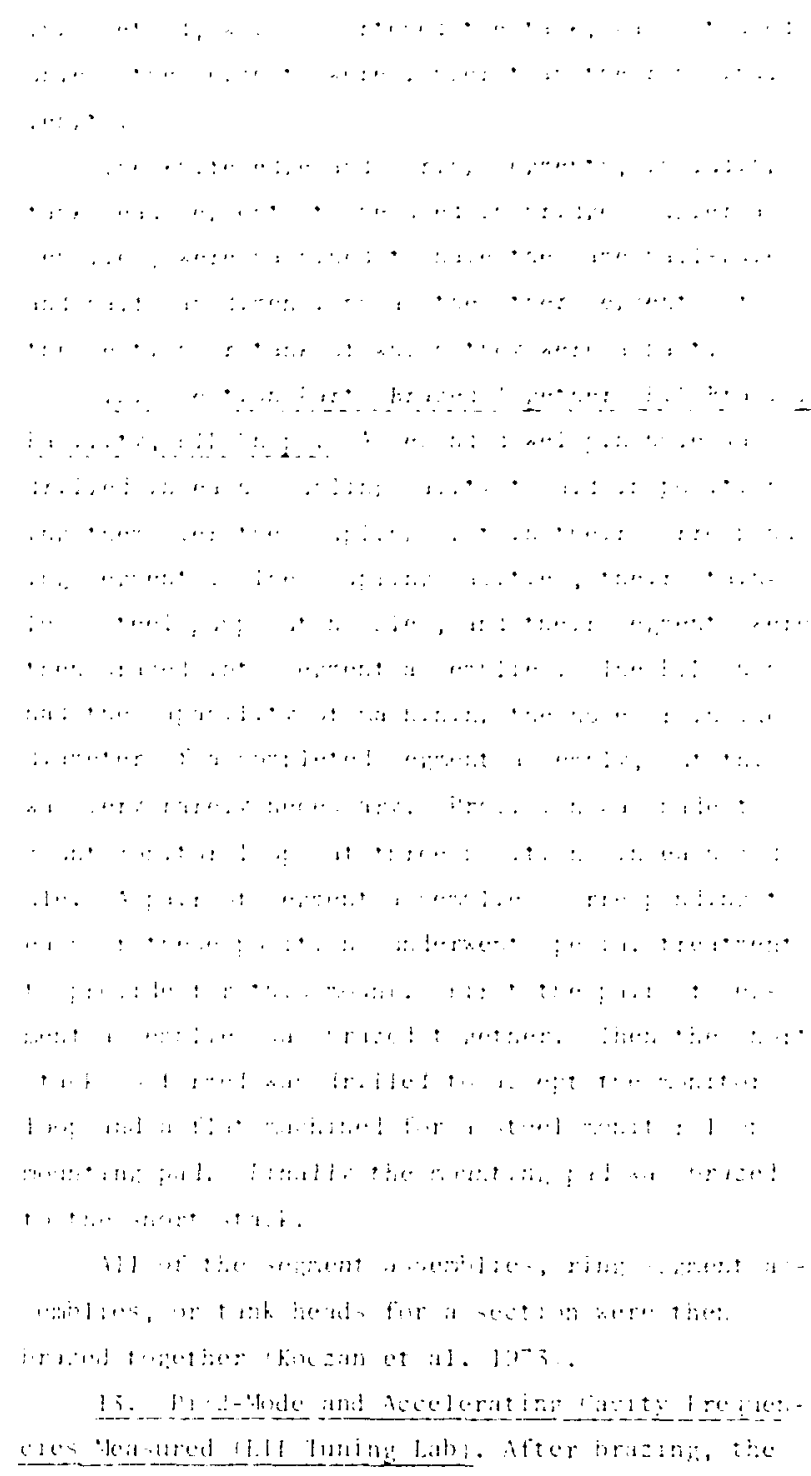

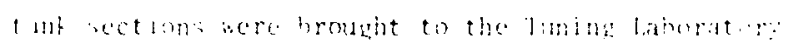

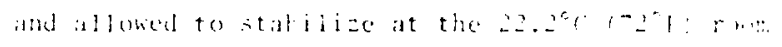

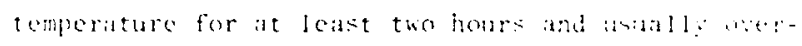
night. The "/a-mode frequency was motsured as and i probes on the bearn line to inject and pich al simat for each end of the section that was mot a tand head, the end coupling carity was shorted with one of the H-probe and short assemblies (sec Section V.c...). (lor calculation purposes it has desired to deal it ith a section of structure that started and cnded ith an accelerating cavity.] Individua! accelcrating cavity frequencies lere then measurcd, with $H$ probes used to inject and pick up the signal. Accelcrating cavities adjacent to the one being measured were shorted out by means of an aluminum cylinder or disconnected E probe inserted along the beam hole in 


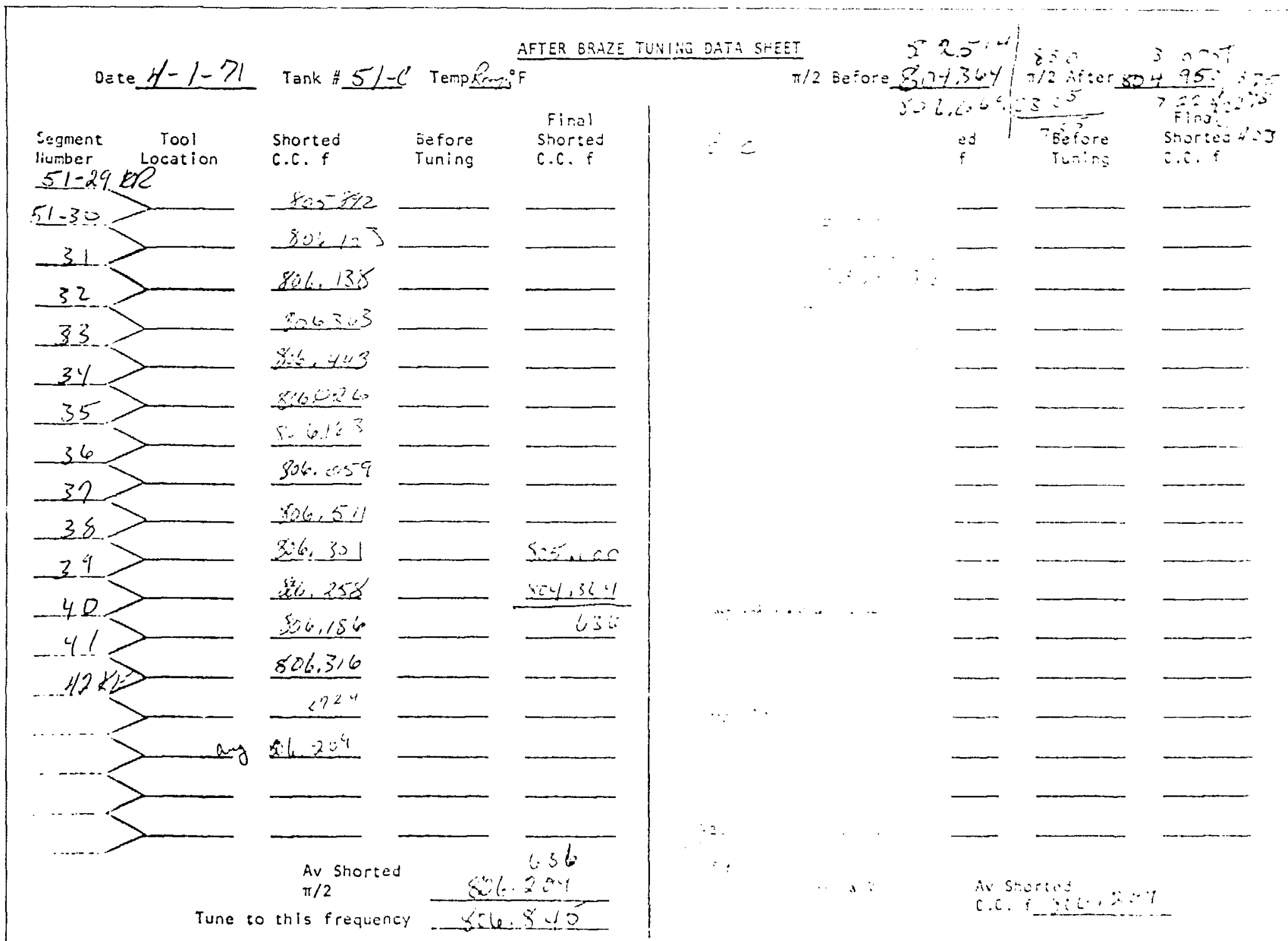

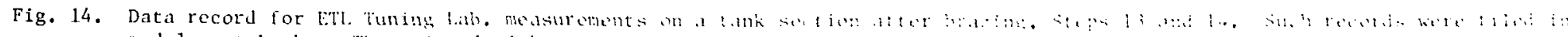

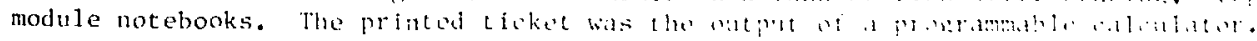




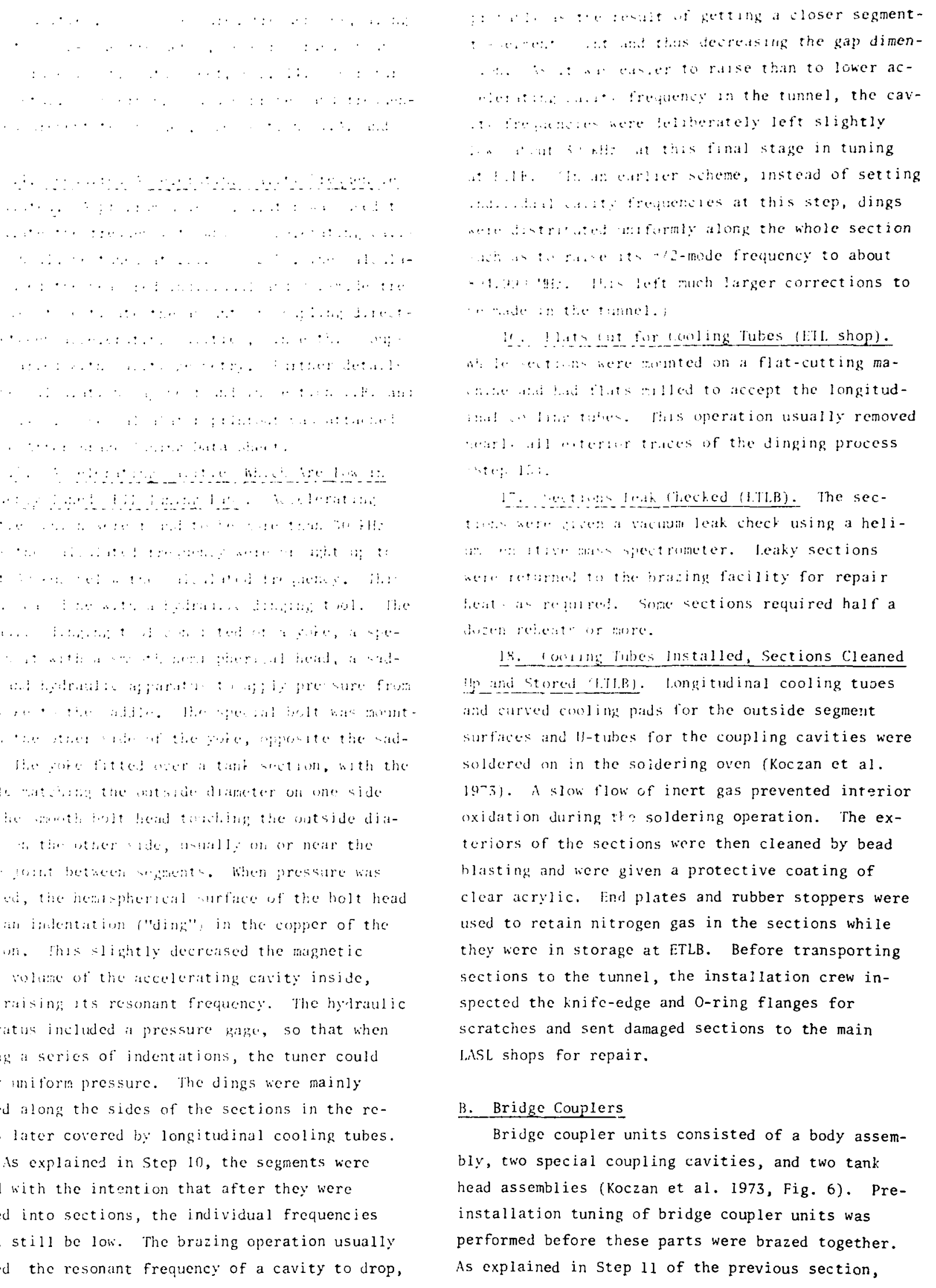




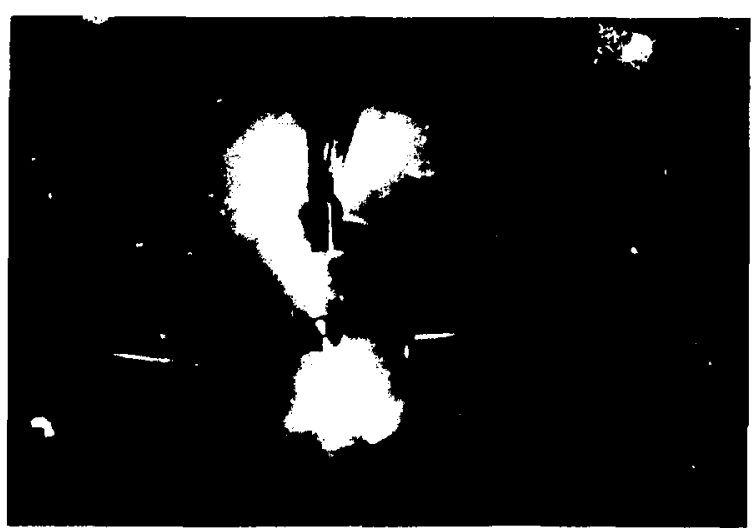

1.is. 15. Interior of bridge coupler with iris after final assembly and installation. Three of the severn post's ased for mode suppression and field stabijizition aro vistole, two en the side and once near the far top of the sast ity. The bar bsed (a) compensite for the shift in resenant frequem: rased by the drive iris is acen at the sope hiso visible are one of the end tancer wases in the centers of the ciatity ends and one of the coupling shots at the bot tom of the carity where it forlas to the tanks belos via it special

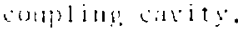

the labe lank head schments had the ir noses mat whined fo hatre the sime half-pal dimension as the werants of the tamb they were to mate.

is received be the taning section at Filde, the bedy ar it had fust tunce ports, end tuner holes, and end slots for foining to the coupling carities already mathined. The tuning procedure differed depending upon whether the bridge coupler had an iris for rif are or not. If the bridge coupler had an iris, the following steps were done:

1. The tamk head segments and coupling cavities were clamped to the bridge coupler body.

$\therefore$ Plates with lf-probes (pickup loops) were at tached to the tank head flamges. (Care was tathen not to seratch or nick the knife-edge o-ring joint area.)

3. Each coupl ing cavity frequenc; has neasured with all other cavities (two half accelerating cavities, the body cavity, and the other coupling cavity) shorted. The H-probe in the cavity below and an F-probe (electric pickup probe) inserted in the probe hole in the coupling cavity were used to inject and pick up the rf signal. (For further details of frequency measurements, see Section V.A.)
1. The conaling cay ity gap vias adjusted uratil the coupling: ciat $\%$ resonant frequency was near gos 4flyz as deterinined in Step 3.

3. The resonint frequency of the whole assembly withest shorts wis deterinined, using the H-probes to inject and pick up the rf signai. At this stage, most of the bridge coupler units had an $8.89 \mathrm{~cm}$ f.s.j" daweter circular iris. for the last few modules of the acceleratur, the bridge coupler rad an $8.8 .1 \times 12.711$ clit $(3.5 \times 5 \%)$ racetrack-shaped iris at this stage. The iris lovered the resonant frequency, and a length of round copper bar was to be brazed in the tur of the bridge coupler (lig. 15) to bring its resonint frequency back up to about 808.5 :fla. For this macutament the bridge coupler was upside down, and thus a length of bar could be ladd in the body unit. ine proper length of bar was deterained by trial. (see Lisl laboratory

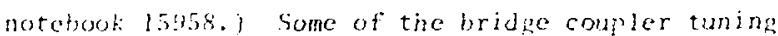
diata is given in ipperdix B.

llater when the completed bridge coupler wa, installed in the tunnel and the iris enlarged in proper coupling to the input waveguide, end tuners were inserted in the bridge coupler body cavity to bring the resonant froquency down to 805.0 :111z.)

In the cise of a bridge coupler without an iris, the resonant frequency was checked to make sure that it was above 805 . $91 z$, and that was all.

There were no further pre-installation frequency checks after the bridge coupler assembly parts were brazed together (koczan et al. 1973, Hig. 51).

\section{HIT. SO5-IHE I.WM: INSTMLLTTON PROCIIUUR:}

At this point we shift our attention from the manufacturing processes which took place at outside shops and at the Equipment Test Laboratory Building to the installation and checkout processes which took place in the LMPF beam tunnel and in the cluster of buildings above it. Fig. 16 gives a hint of the many activities taking place within the installation and checkout processes. The final tuning procedures, shown as Step: 11,12 , and 20 in the figure, will be discussed briefly in the sections to follow and again in greater detail in Section IV. See also Swenson (1968) and Tregellas (1969). A. Initial Installation and Checkout

1. Piers, Rails, Monuments, Piers were bolted to metal plates provided for them in the floor of 


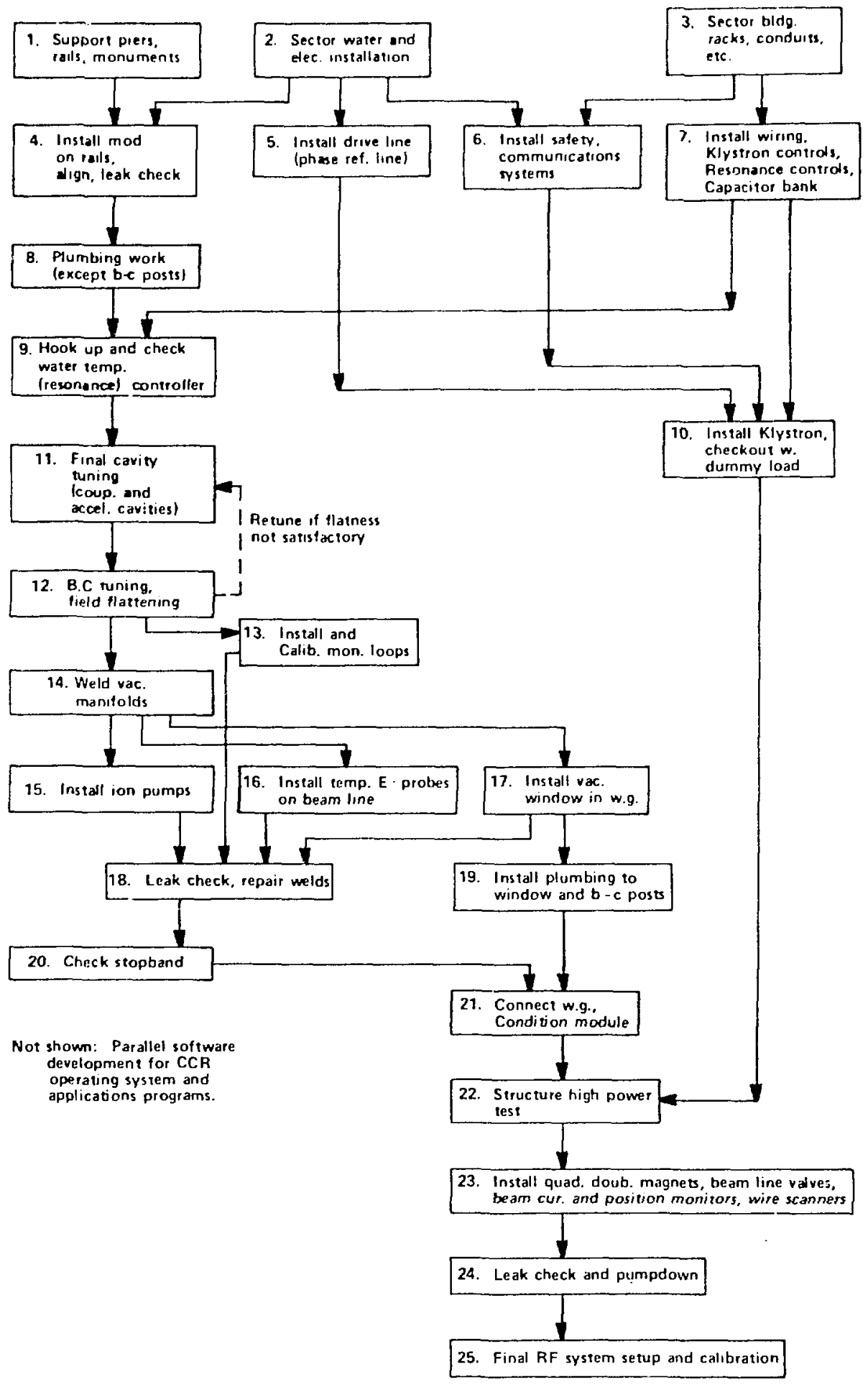

Fig. 16. Installation and checkout procedures for 805-xliz linac. (Box numbers correspond to the steps described in section Iil. 1. ) 


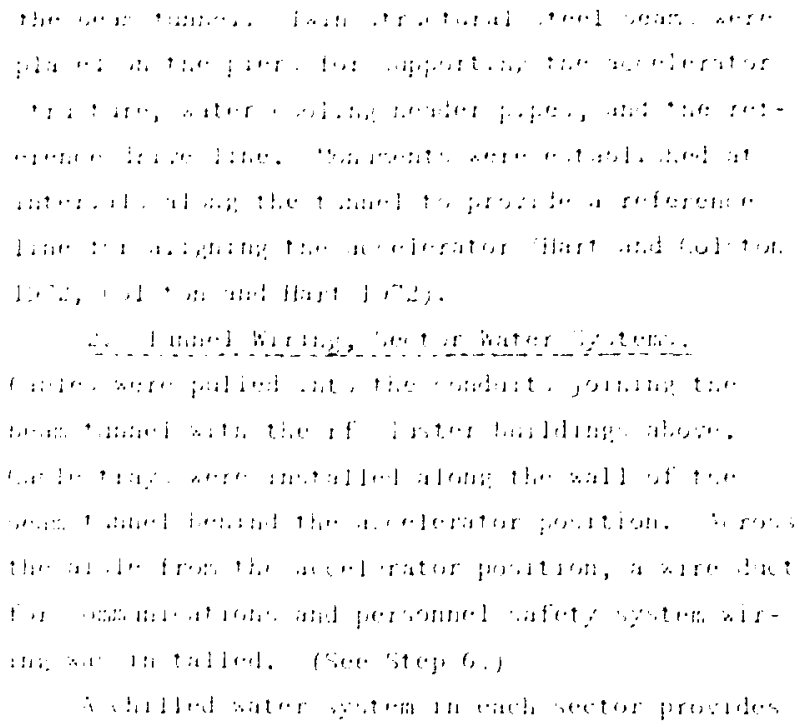

3. R. H. Eluster Building Racks and Hi ring. Cable trays were provided along the service at ile joining the r.f. cluster huildings with each other and with the central control room (CCR) (Case and Parher 1008, littlo 1969b). Racks were installed in the r.f. cluster buildings for the local portions of the control systems, and cabincts put in place for the klystron water cooling systems (lboss 1971 a). Ixtensive use was made of the local control positions during the installation phase for checkout and initial operation. Normal operation of the accelerator at later times was almost exclusively done using the control computer and the remote consoles in CCR (Butler 1967, 1973, 1975. Butler et a1. 1971, Gore 1968, liartway et al. 1975, Mr Div. 1971b рг. 21-26, Neber 1969.)

4. Module Installation. When completed tank sections and bridge coupler assemblies were available at the Equipment Test Laboratory Building (I:TLB) for one or more complete nodules, these would be

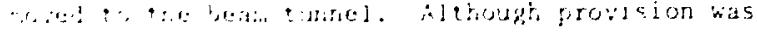

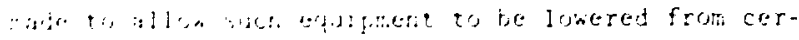

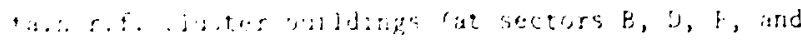

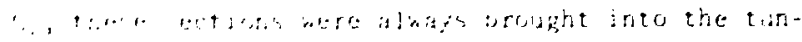

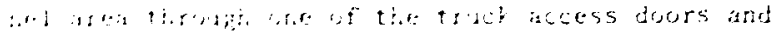

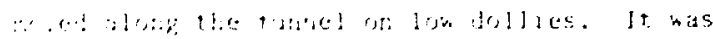

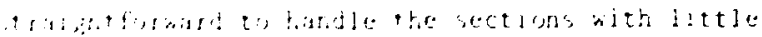

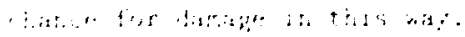

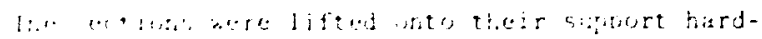

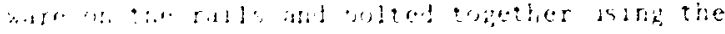

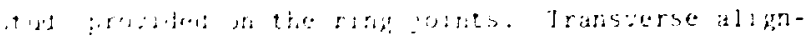

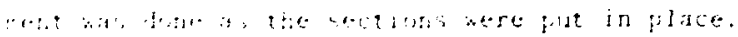

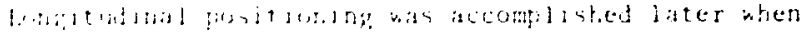

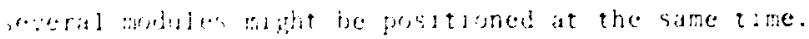

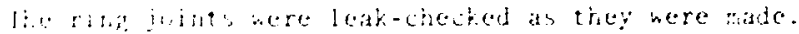
In :Ha a.ent that the bnife-rodge lid not mate a

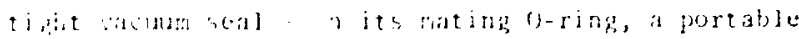

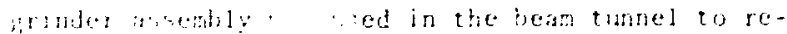

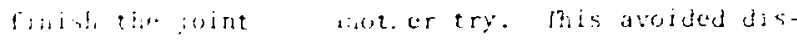
a, iemal: af provicasly installed sectiuns and poswhle damate in transporting sections to the WASt.

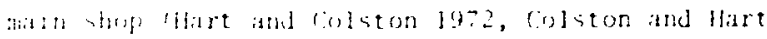
$1: 1,2$

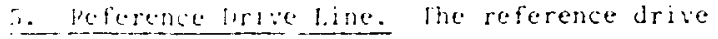
lone was a grects on microwate line along the acceleratur to frovide an $805-40$ e reference signal for phase control. This line was installed along the biate of the accelerator support rails (MP live l969d

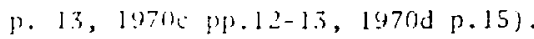

1. Siff:ty, Communications Systems. Wiring and equipment wis installed for the following systems: Beam spill monjtors and area radiaton monitors (Parker 19686, 1970, 1971a, 1974, Parker et a1. 1971, 1972), personnel safety system (warning signs, scram buttons, interlock switches on personnel access Joors) (Core 1969, Little 1971b), interphones (Hartway 1969, 1971, Putnam 1968), closed-circuit tolevision (Parker 1968a, 1969), and rf pulse viewing ("video") system (Criscuolo 1970a, Van Buren and Maddocks 1969. Schaller 1974).

7. Capacitor Bank, Local Klystron Controls and Connections. A capacitor bank used by all the klystrons in each r.f. cluster building was installed in each capacitor room (Doss 1971a). Chassis of control equipment, some of which were mounted in NIM bins, were installed in the racks. Electrical, air, and water connections for the klystron units were put in. 


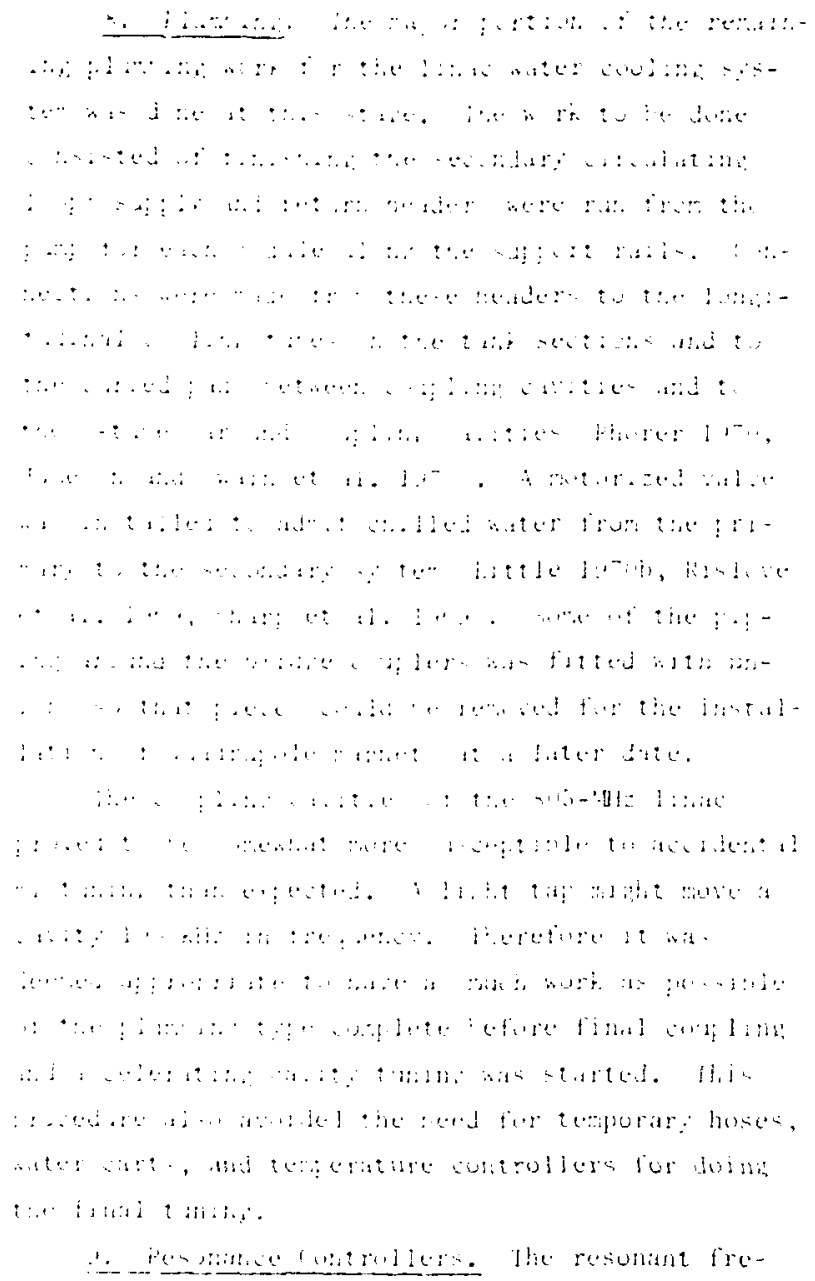

Occasionally a connector would be knocked loose or some such event would cause the control sistem to fail during final tuning. The tuning technicians checked glass thermometers on the linac structure occasionally, but worked an appreciable length of time in some instances before they realized the temperature was no longer correct. In retrospect, it appears that having some audible alarm available if the temperature went out of bounds would have been a good idea.

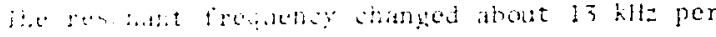

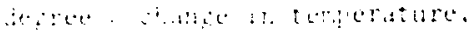

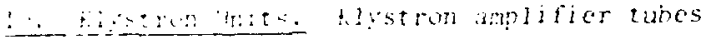

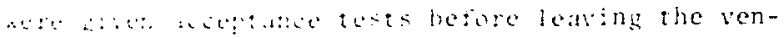

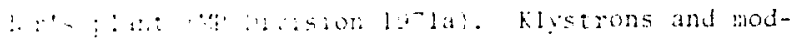

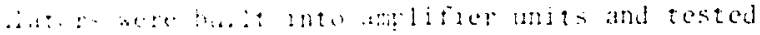

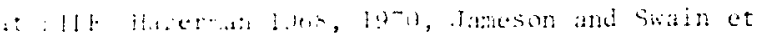

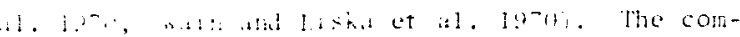

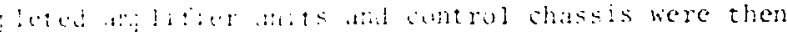

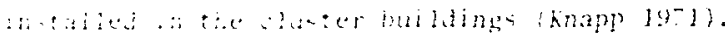

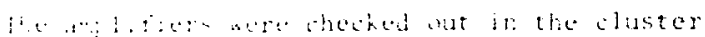

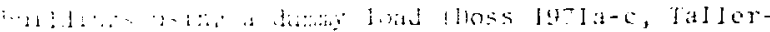

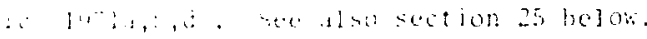

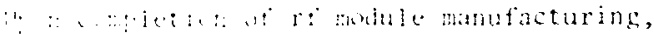

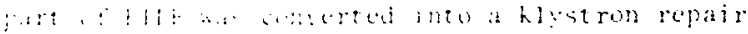

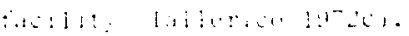

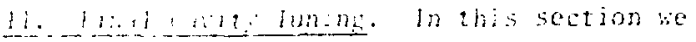

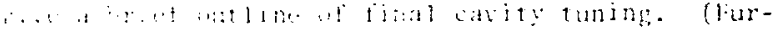

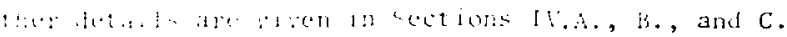

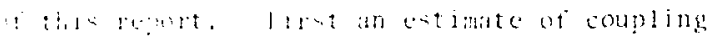

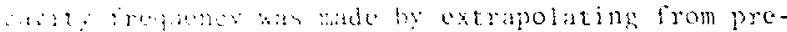

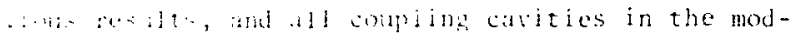
wh were at in that frequency. Sext the frequenacs to all aceleratume cariti s in the rodule, a's nell as the "is-mode frequencies of each tank in the module, nere measured. This dat a was used to calcalate the correet acederating cavity frequencies for interior and and cavities, and the cavities tece tuncd acoordingly. The resonant frequencies were changed using three different types of tools: dinging tools raised the frequency, nose-stretching tools lovered the frequency, and septum-bending tools were used for cavities inaccessible to the other tools or for use in correcting the field distribution within a tank. After the accelerating cavitics were tuned, the tank $\pi / 2$-mode frequencies and stopbands were determined. The coupling cavities were then retuned such that the stopband was in the range 0 to $+30 \mathrm{kHz}$. (The stopband had a tendency to decrease at first, dropping perhaps $30 \mathrm{kllz}$ over the first counle months after turing.,

12. Bridge Coupler Tuning and Module Flattening. In this section lie rive a brief outline of bridge coupler tuning and module field flattening. fFurther details are given in sections IV.D. and $E$. of this report,) The tuning operations on the bridge coupler had the following abjectives:

(a) The module $\pi / 2$-mode frequency was made to 


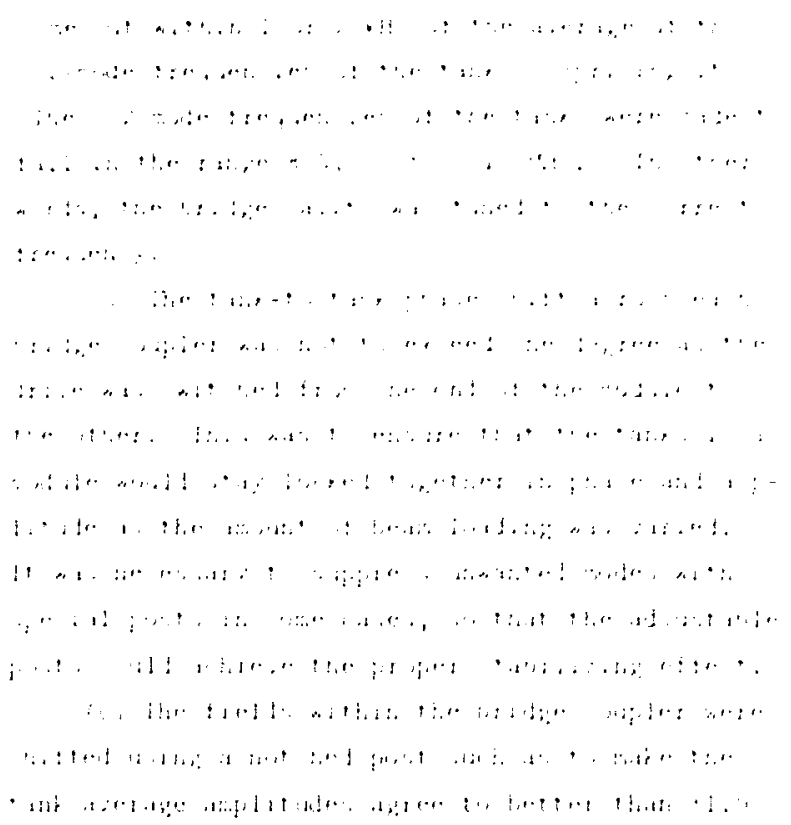

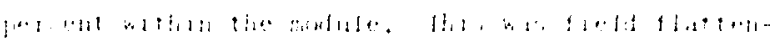

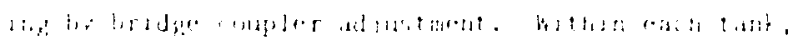

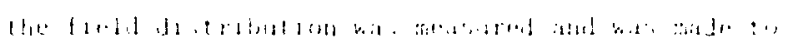

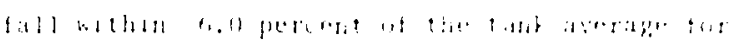

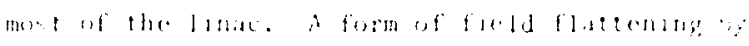

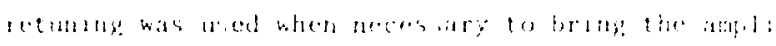

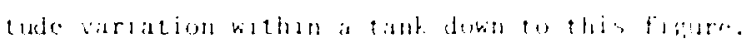

some nowet technegues were develuped te ripidly

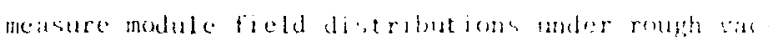
mun cenditions.

(d) lor bribge conplers with a drive iris, the iras wate endarged such that the with th the in

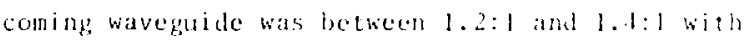
the iris overcoupled. linis wats to lnsure a reacomably good impedance match between the module amal the drive line when the linac was operated with beam. (See also Append $i x$ o.)

the rour types of adjustinent $(a)-(d)$ interacted fairly strongly, and an itcrative procedure (usually taking 3 or fewer itcrations) was devised to converge upon the four criteria simultancously.

13. Monitor loops. Magnetic probes were provided at three or more points on each modulc to provide a feedback signal for the amplitude and phase control systems and to provide signals for determining the stability of the ficld distribution during initial high-power testing and checkout. These probes were adjusted to deliver approximately $10 \mathrm{~W}$ of peak power when the tanks were at design field strength (Cady 1972). The nominal coupling factor was $-48.5 \mathrm{~dB}$.

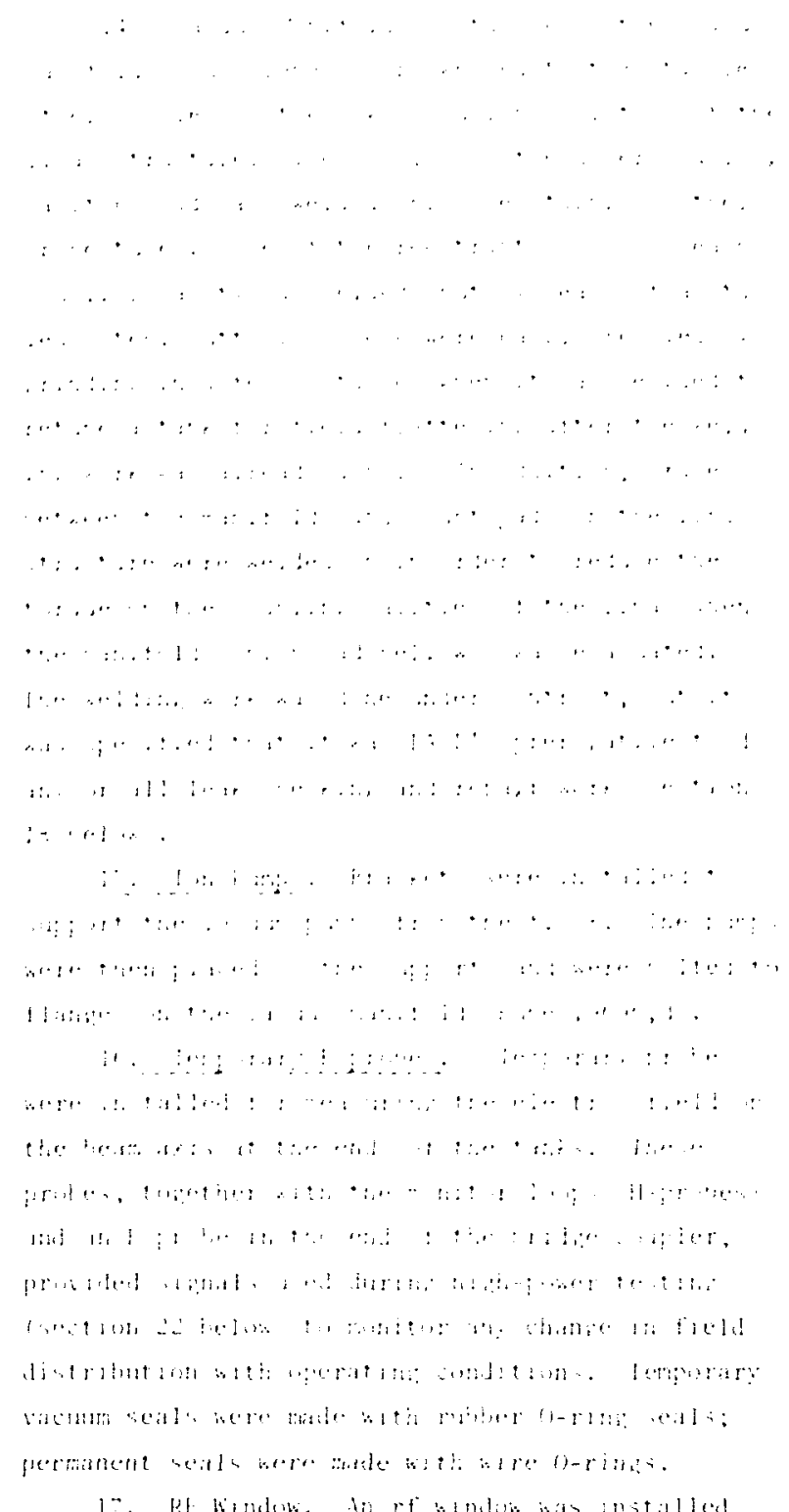

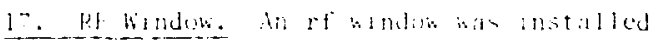

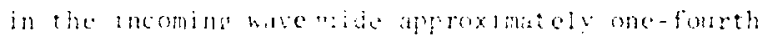
watelength back rom the irin in the drenen bridge compler in cace findule ot the linas the window separates the pressuriated saveride from the cracuated linac structure. The metal housing of the window has a passiget for water wooljng.

Initially it was planned to use feneral lasetric units with an aluminum oxide window held in place with an indium-lead alloy. These proved to be short-lived under high-power conditions, and Varjan windows were substituted fancson and Swain et al. 1970, Swain 1970b, Liska 1971a-b, Shlacr 1971, Jameson 1972).

18. Leak Check, Repair Welds. The integrity of the structure and all welded joints was checked 


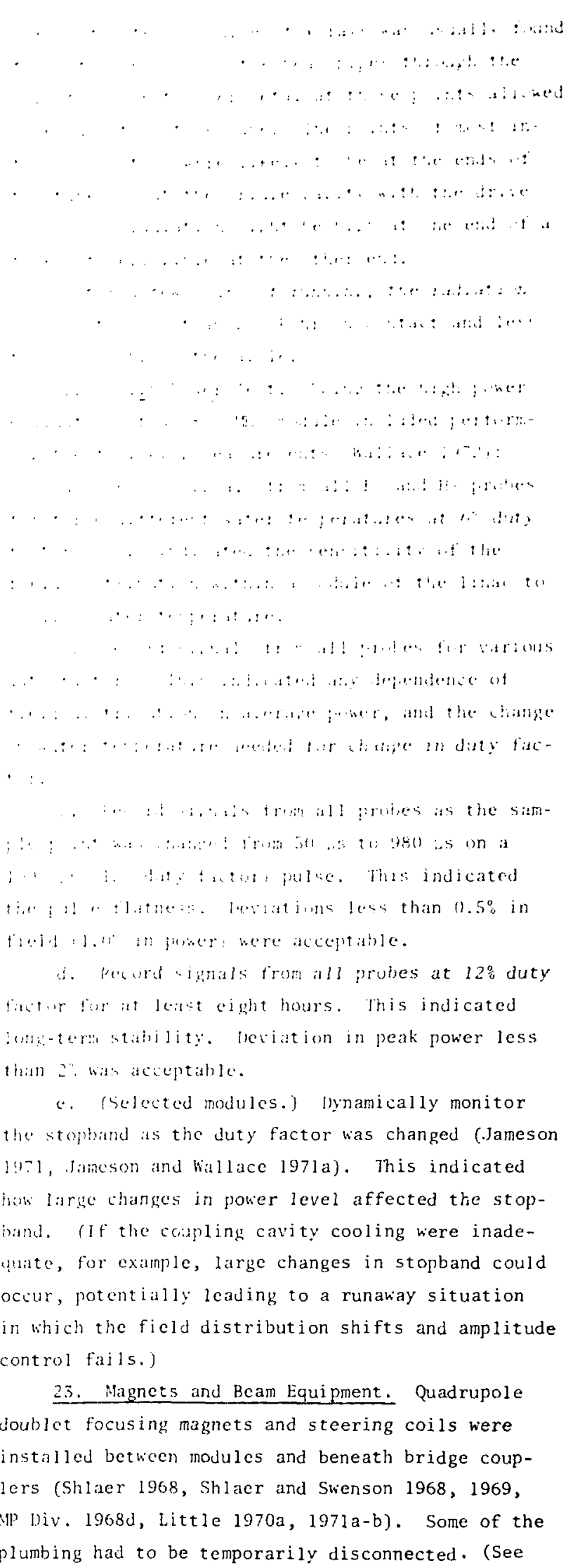




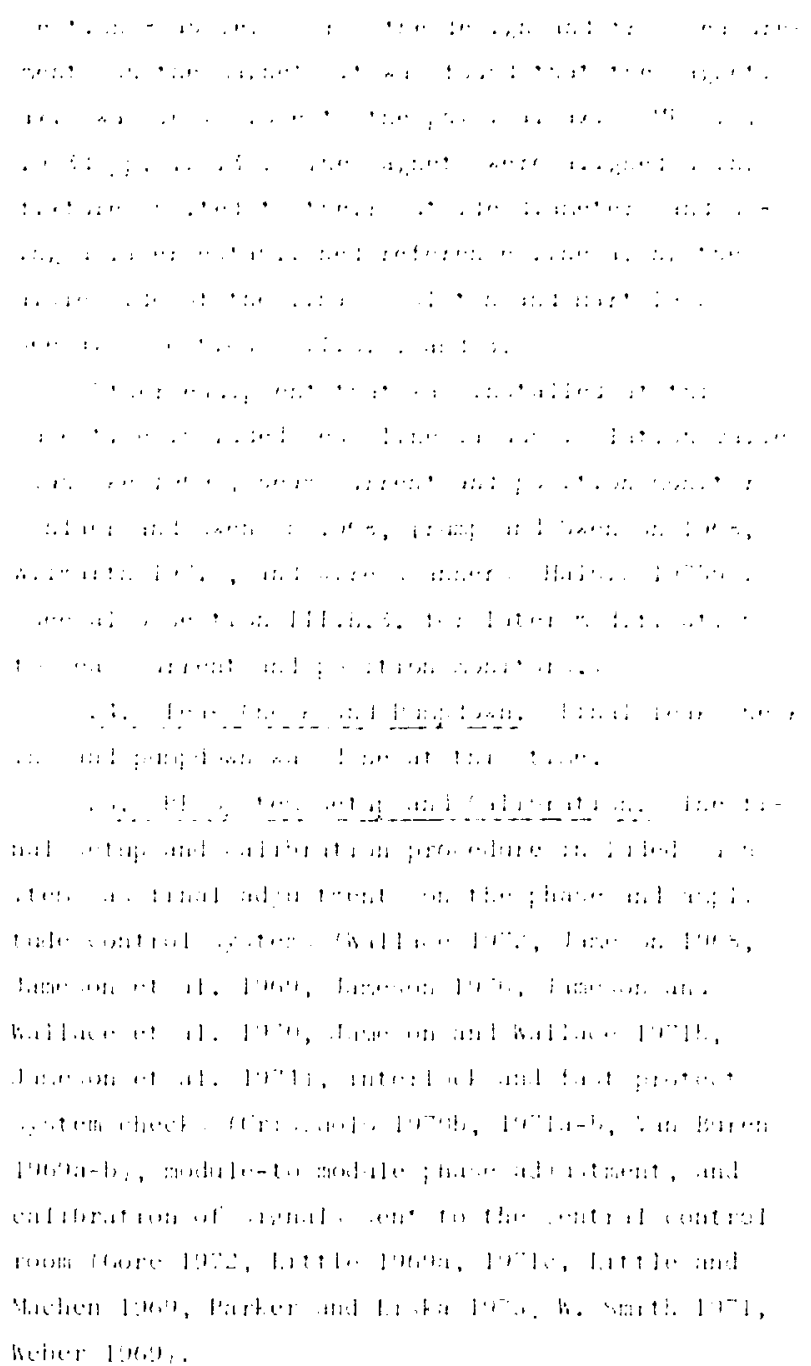

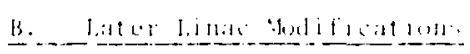

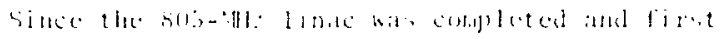

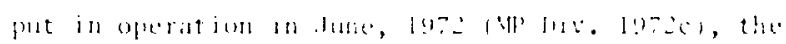
following! modificat ons hitue heon mate.

1. Bridge coupler length correction. In proparation for the high-intensity tests of laxpl: in $197+$ the "della t" procedure for set $\mathrm{i}$ me modete phatses and amplitules fCrandall and swenson laga, Crandall et al. 1972, Jameson and swerison 1972, crandall 1974a, 1976) was re-examined, and the lengths of the tanks and the spacings between tanks within modules vere remeasured to $\$ 0.13 \mathrm{~mm}$ or better accuracy (Crandal] 1974b, MP Div. 1974d p.5). It was found that due to systematic accumulation of errors in tank segment lengths (each of which was within tolerance) and due to longitudinal deformations made when tuning by septum-bending, the lengths of the tanks and the spacing between tanks in certain

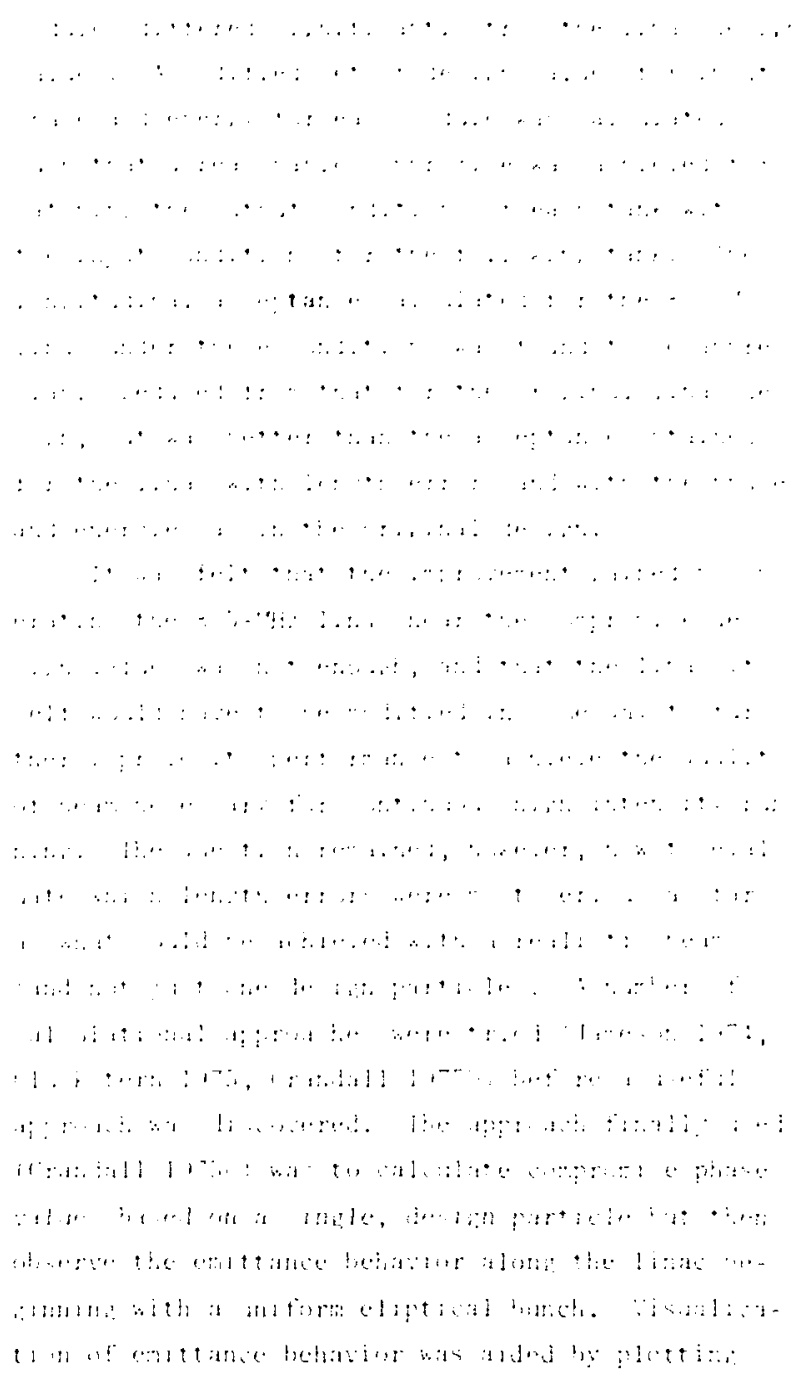

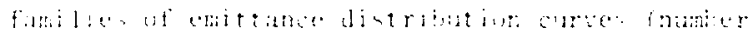

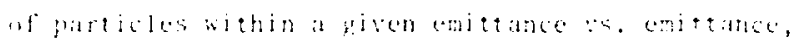

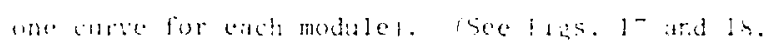
This approach ind atod that correcting the lenth crove in the kndule ja bridge coupler ats most inportant, and that changing nine uther heluge conplors would make only it $s$ light improvement.

veanwhile, waious approiches for correcting spacings or otherwise compensating for length errors were being explored. Some increase in acceptance could he obtained by raising the amplitudes fand appropriately changing the phases), but the linac was already being run five percent above design and it was felt any other increase should be held in reserve (Jameson 1974 ). Changing relative amplitude levels from tank to tank within a module was found to fill out the acceptance fish in some regions but to leave peculiar holes in other regions 

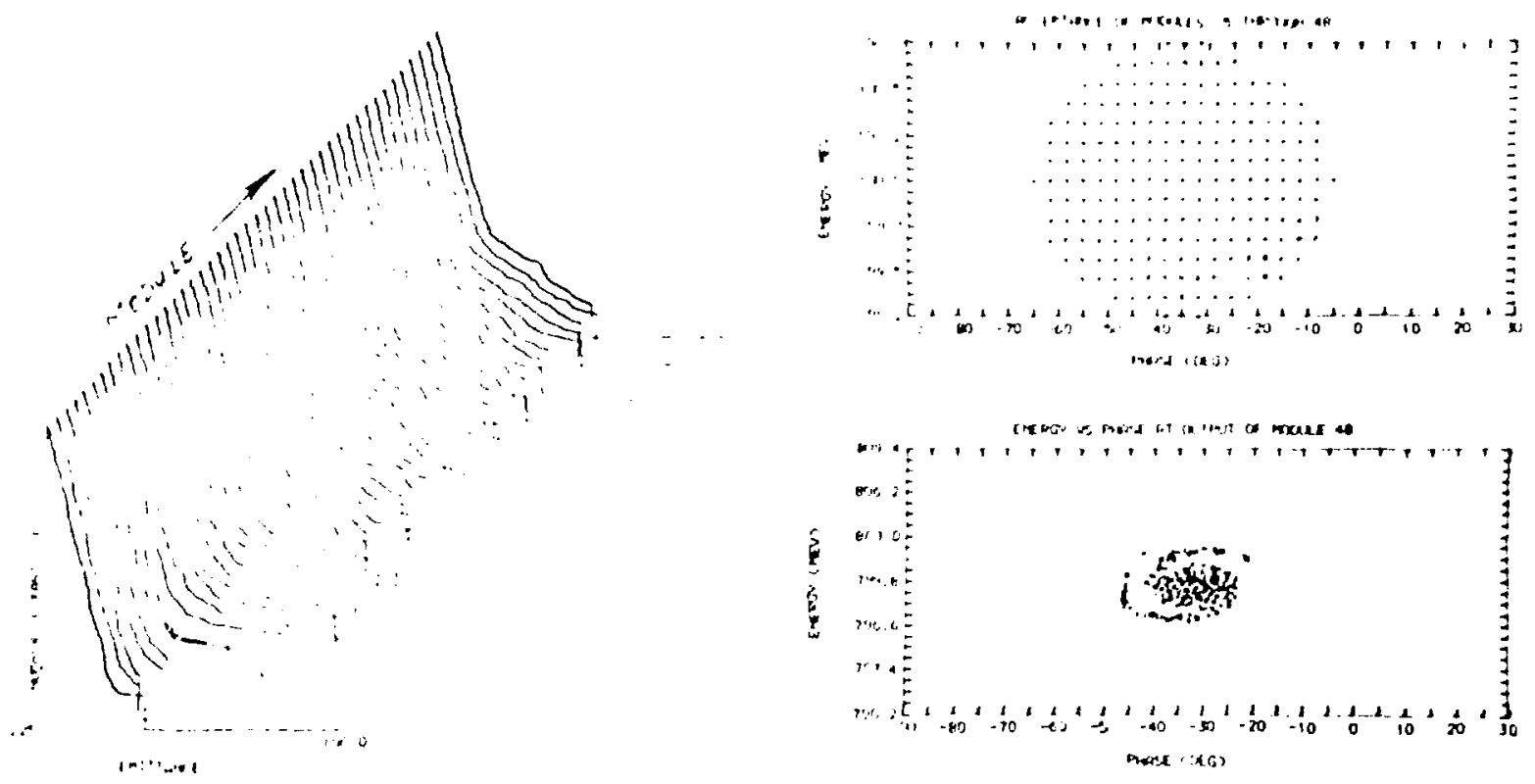

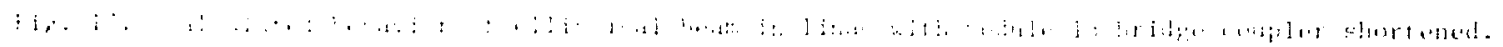
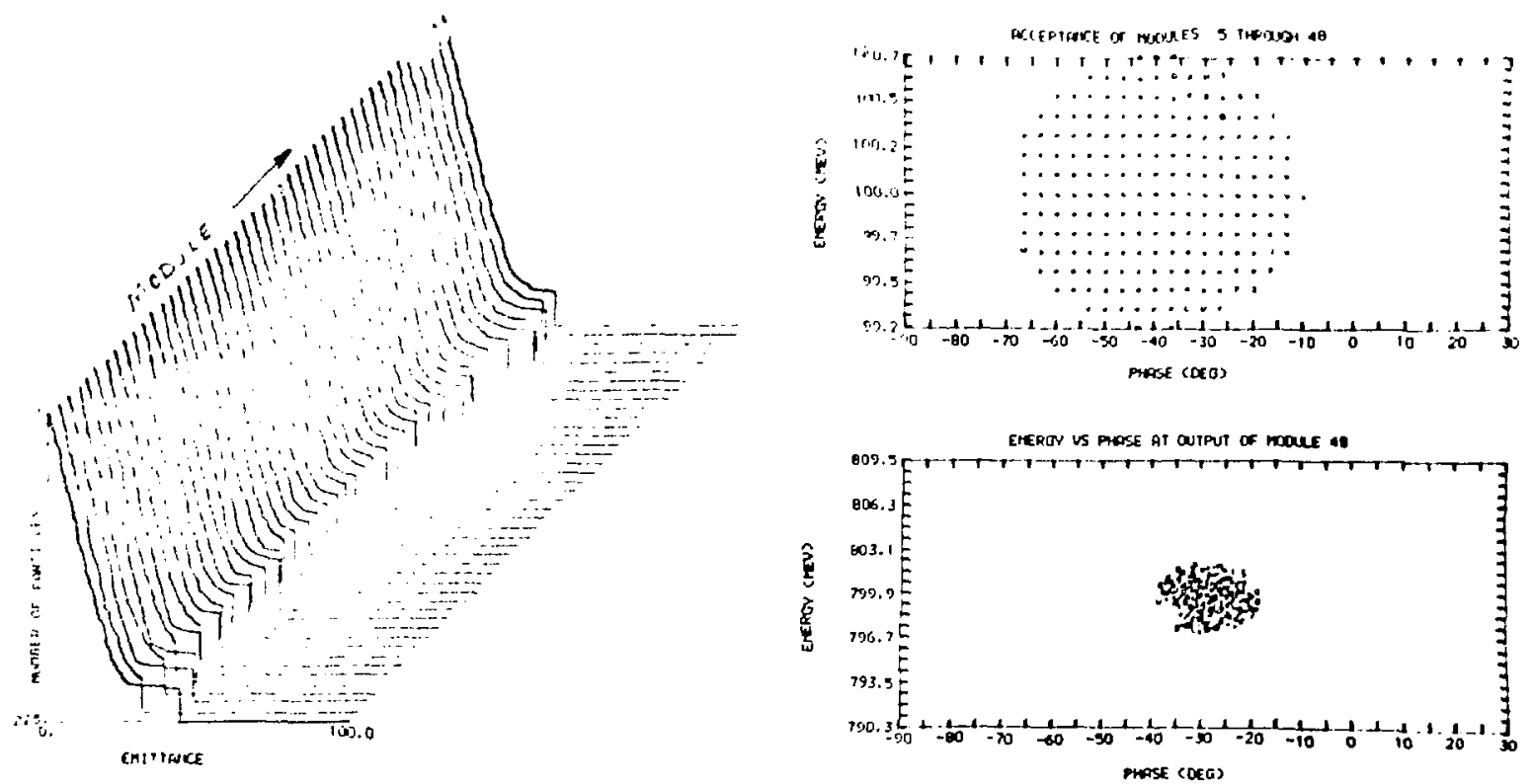

Eig. 18. Calculated behavior of elliptical beam in linac with all bridge couplers modified. 


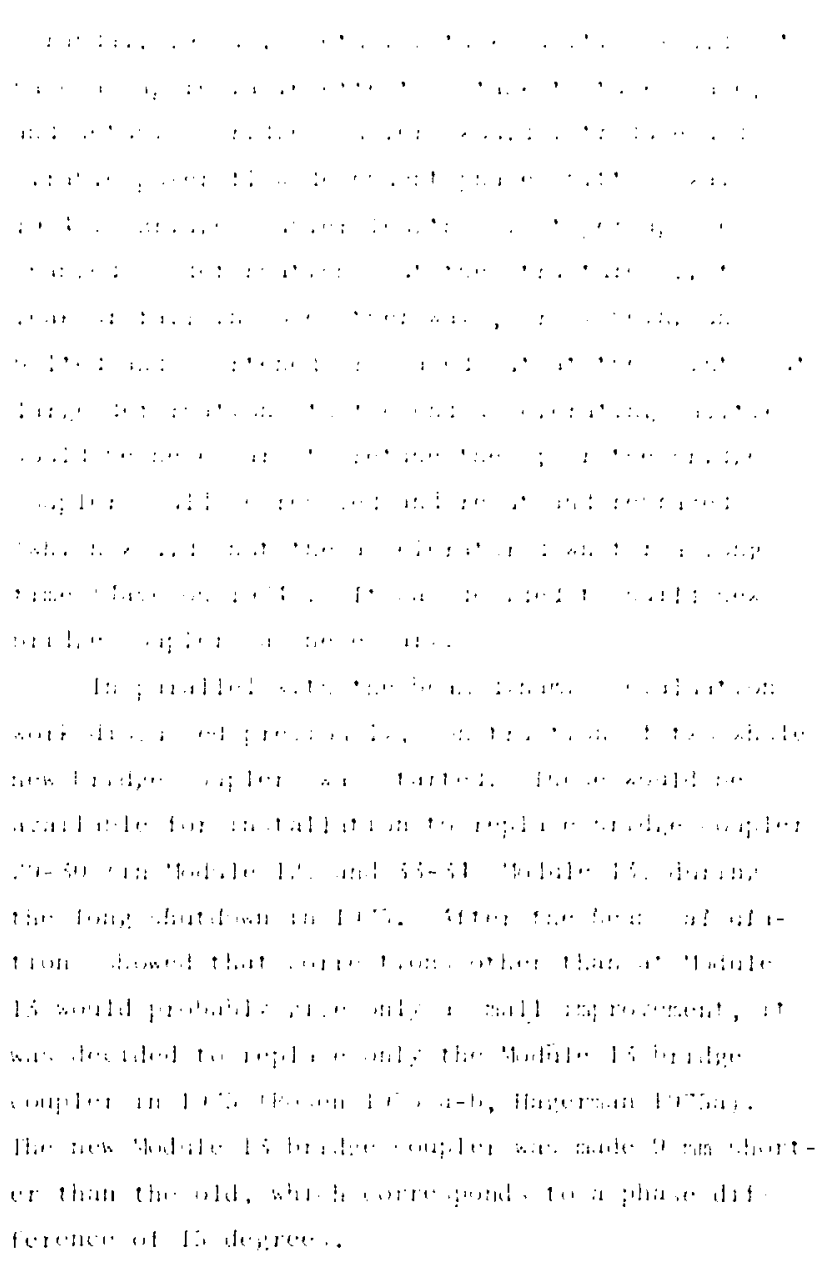

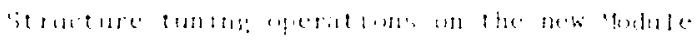

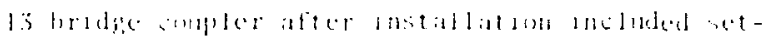

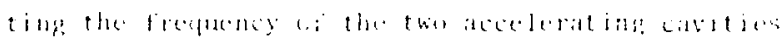

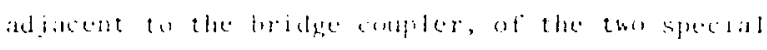

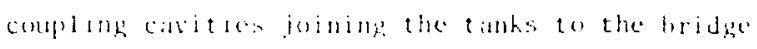
canity, and of the bradge cavity itselt. Bridut

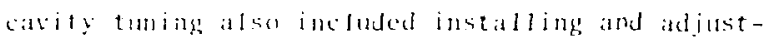
ing posts such as to minimize power-fluk phase shifts and onlatging the input iris to achicue the desired coupling. (Appropriate stops from the uriginal tuning procedures, sections Il.c. and 1$)$, were folloned.) Hextra bridge coupler posts and end tuners fabricated daring the original construction period were usol after boing claned and machined as meesssary. It was not necessary to change the number of bridge-cavity posts, but the new bridge cavity used $5.08 \mathrm{~cm}-\mathrm{diam}$ posts in place of the $2.54-\mathrm{cm}-\mathrm{dian}$ posts used in the old bridge cavity. A jig used in enlarging irises during the original construction was found and refurbished to aid in enlarging the new bridge coupler iris.

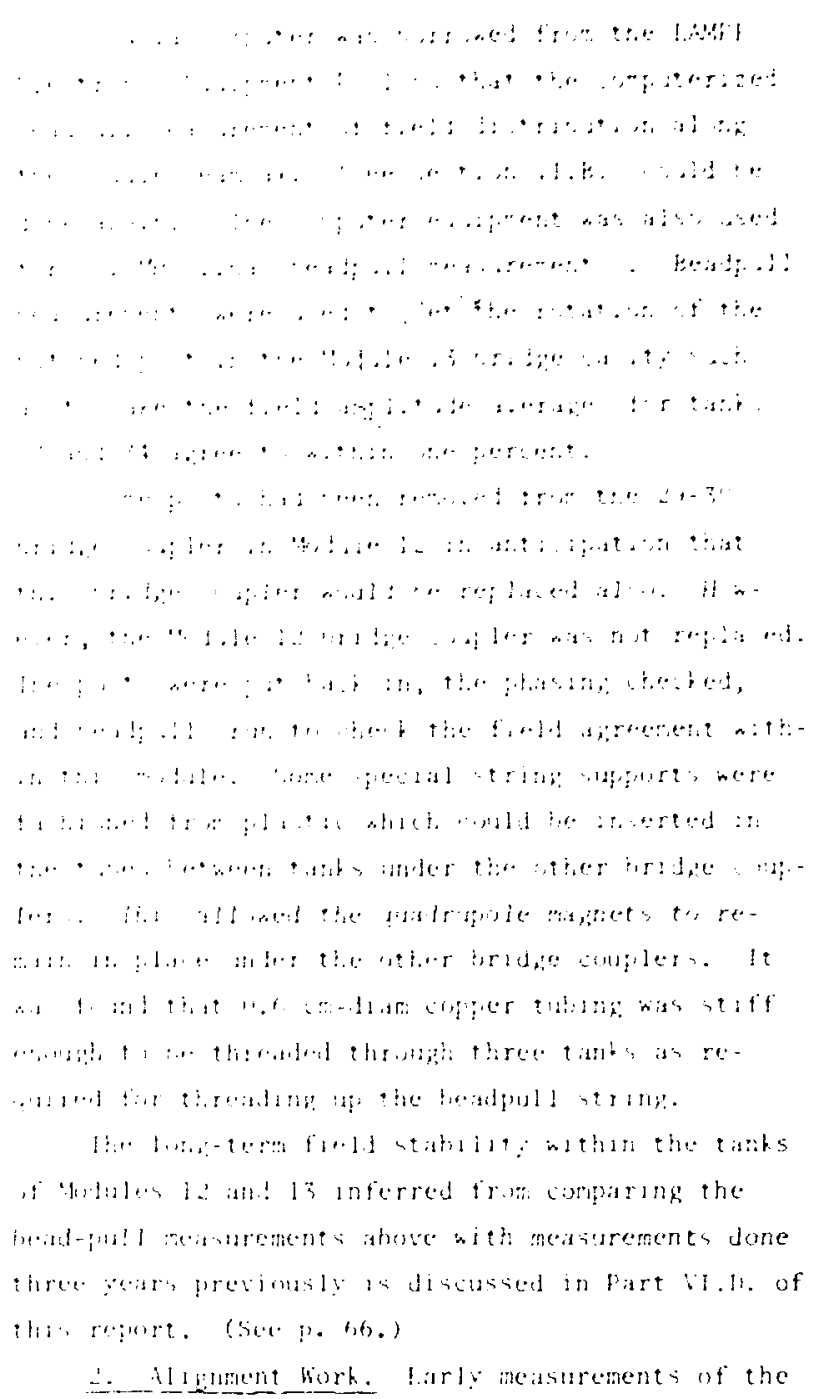

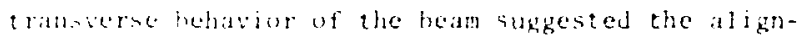
ment bit lanets in the first part of the $805-012$ lana at ght be improved, and a program of aljgnnent

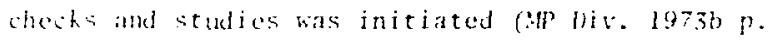
13, Jamesua lg73a-c, liska and lialbig 1973, Liska $\left.19733_{13-1}, 1971 ;-e\right)$. It was found that use of an optical level for determining vertical position combined with a taut wire for determining horizontal position hould permit alignment to the accuracy initial1! envisioned but not obtained with the laser technique (.4P iniv. 1973d pp. 12-13). The 805-141z accelerator bas then aligned using the new techniqucs. The alignment obtained was within $\pm 0.18 \mathrm{~mm}$ using the accurately machined casings of the quadrupole doublets as the reference, or within $\pm 1.02 \mathrm{~mm}$ using the tank ends as the reference (MP Div. 1974b pp. 12-13). A LAMPF coordinate and monument system was established (Swenson and Liska 1974a-b, Harrison 
$\therefore \quad: \because, \quad, \quad, \cdots, \cdots, \quad \because \cdots, \ldots, \ldots, \ldots$

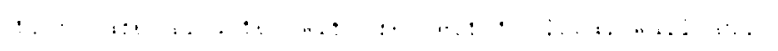

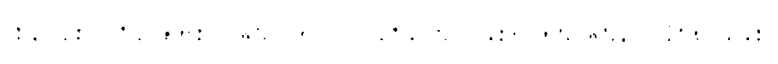
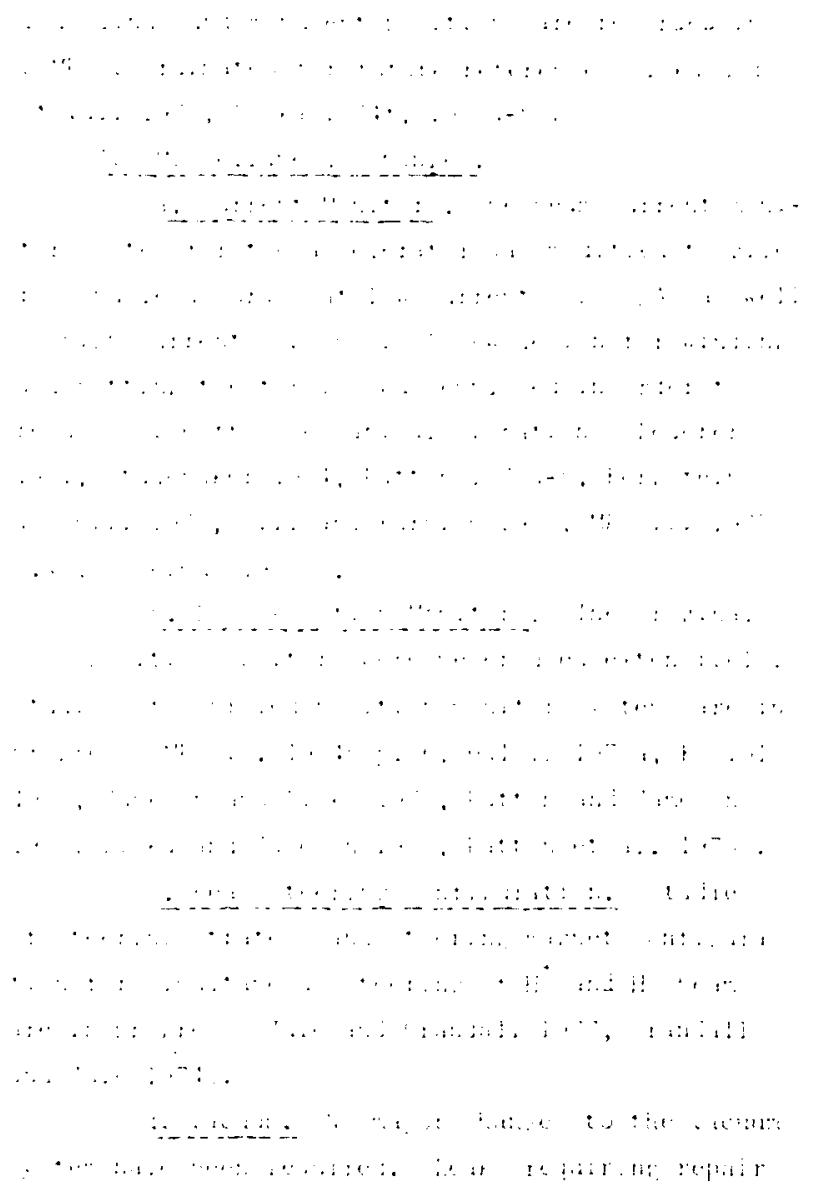

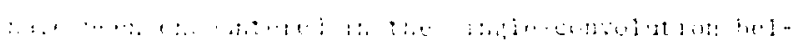

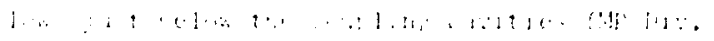

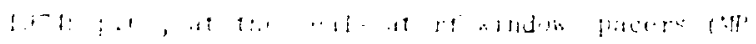

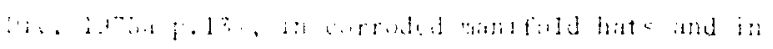

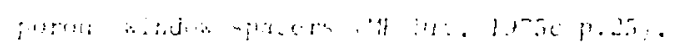

i.. $\quad$ m.

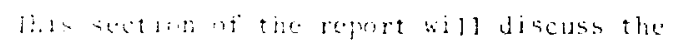

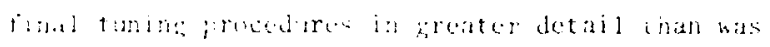

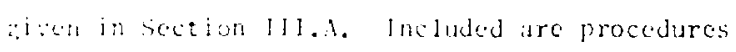
for acolerating ar lowpling cavit: tuning in the tannel, bridge coupler tuning, and ficld distribution moasurcment and flattoning (Swain ct al. 19-2, Potex and knapp 19.2J. The organization of this section parallos the steps given in the actual proceciure instructions used by the tuners (Sharp 1072). The final tuning took place arter all the sections of a module vere mounted in place on the rails and after the plumbing for the water cooling system was complete.

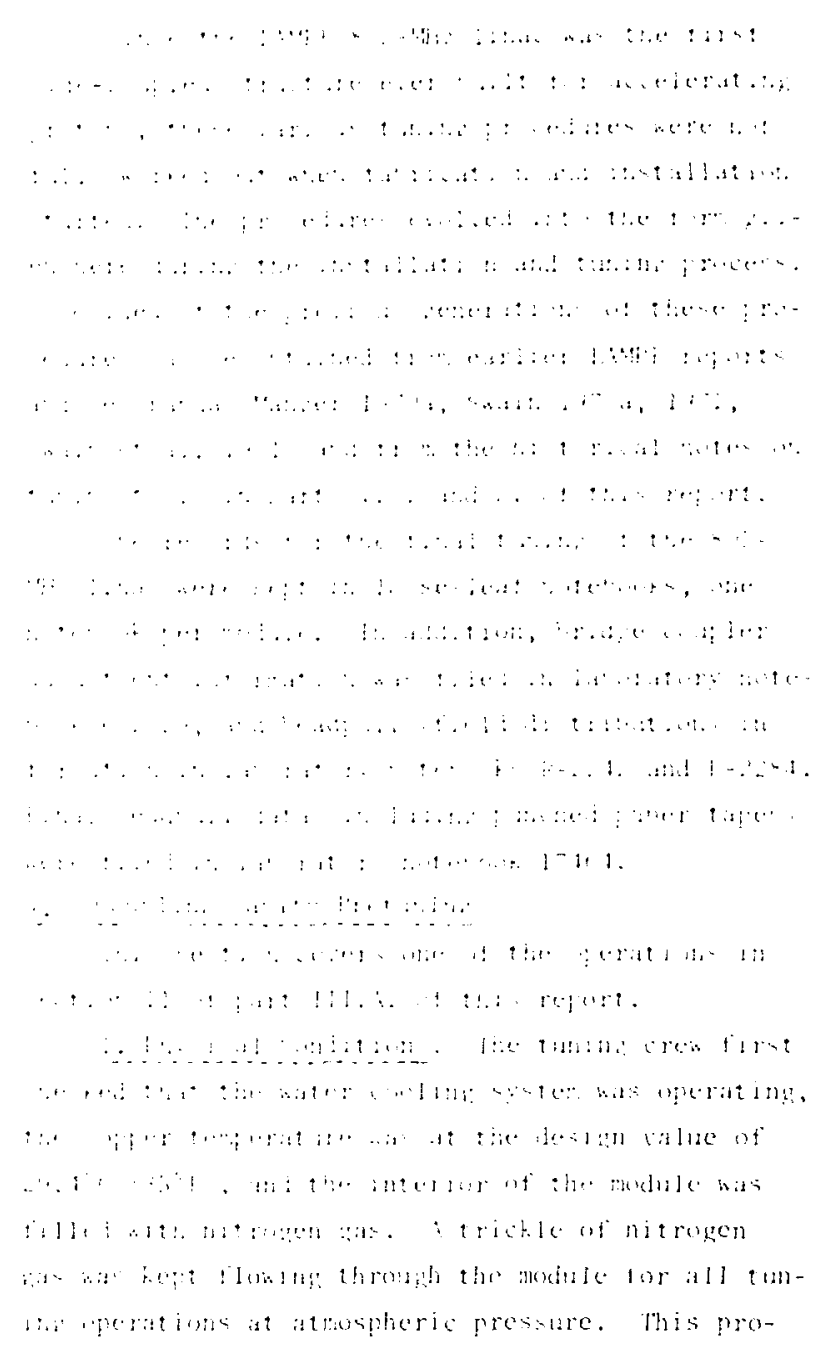

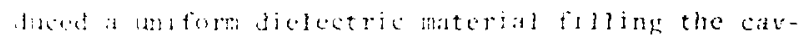
at as and areiented axidation of the copper of the linas. Whon this was not done, mrying dielectric propertion of air with variable humidity resulted in a resosant frepuency that varied 20 or $30 \mathrm{kllz}$. lebber stoppers inere used in the coupling cavity pump out holes to retain the nitrogen gas.

The $-2-m o d e$ rrequeney wanted for the 1 inac structures at $29.1^{\circ} \mathrm{C}\left(85^{\circ} \mathrm{l}\right)$ kith nitrogen gas was 804. $5.5 .1 \mathrm{MH}$. This corresponded to a $\pi / 2$-mode freyuency of sis. 000 yll at $29.1^{\circ} \mathrm{C}$ under vacuum.

2. Set irequency. AI coupling cavities in a module (with the exception of the coupling cavities that were part of the bridge coupler assemblies) were set to a preliminary frequency determined by extrapolation. (Sec Section l.b. of this report.) A special coupling cavity probe (see Section V.C.1.) was used to both short out the neighboring accelerating cavities and to introduce loops for injecting 


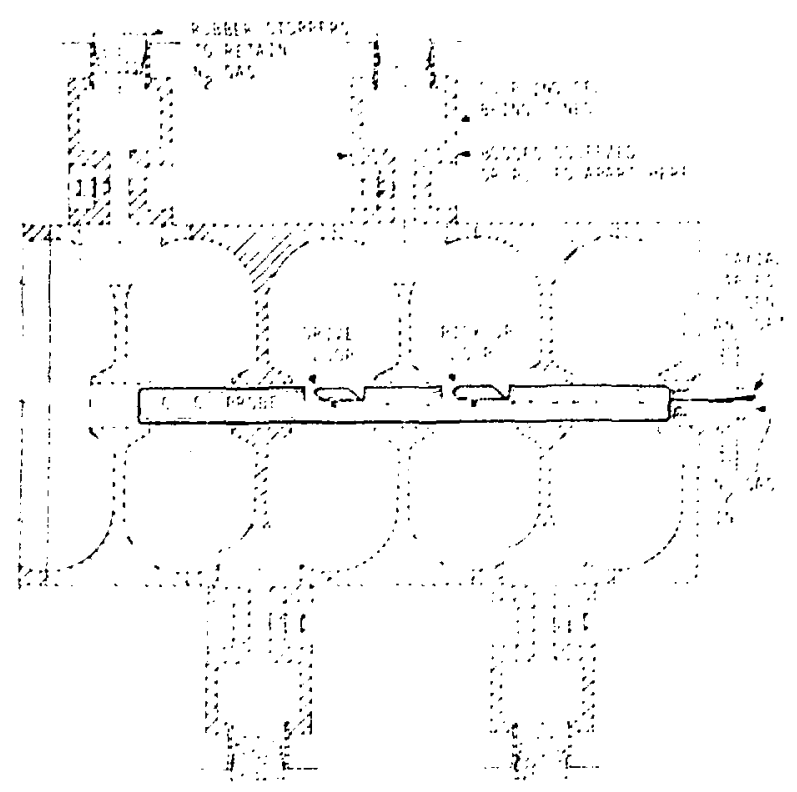

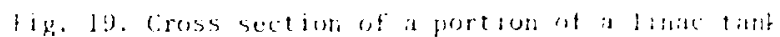

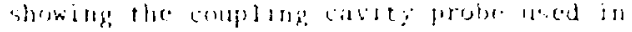

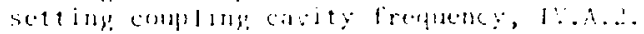

and picking up a swept-frequency siphal. Tise forehe was inserted along the bean hole, rotaled to orient the loops to point toward the cavity being tunced, and moved long: tudinally to obtain maximu signal.

(See lig. 19. forther detajla on Prequency meisureinents are given in section V.A. of this report.)

If the resonant frequency of the comping cavity was high, it was lowered by using a lead mallet to tap on the flat sides of the carity, thus brinting its reentrint bosses closer together. If the resonant frequency was low, it was rasised by tapping: on a phenolic wedge inserted between the reent rint bosses through the pumpout hole, thus moving the bosses farther apart.

In : veral instances, coupling cavities were retuned after the vacium manifolds and caps had been welded on the nozzles at the pumpout holes. In the case of cavities to be lowered in frequency, this was done as above. In the case of cavities to be raised in frequency, one tapped on the rounded sides of the coupling cavity to make a small adjustment (perhaps $50 \mathrm{kHz}$ ) or used a spacial wrench to make a large adjustment, as in Fig. 20. The bottom of the boss was restrained by its proximity to the segment body; pulling on the wrench moved the top of the boss slightly outward, Caution was necessary in using this wrench. In one instance, over-zealous use
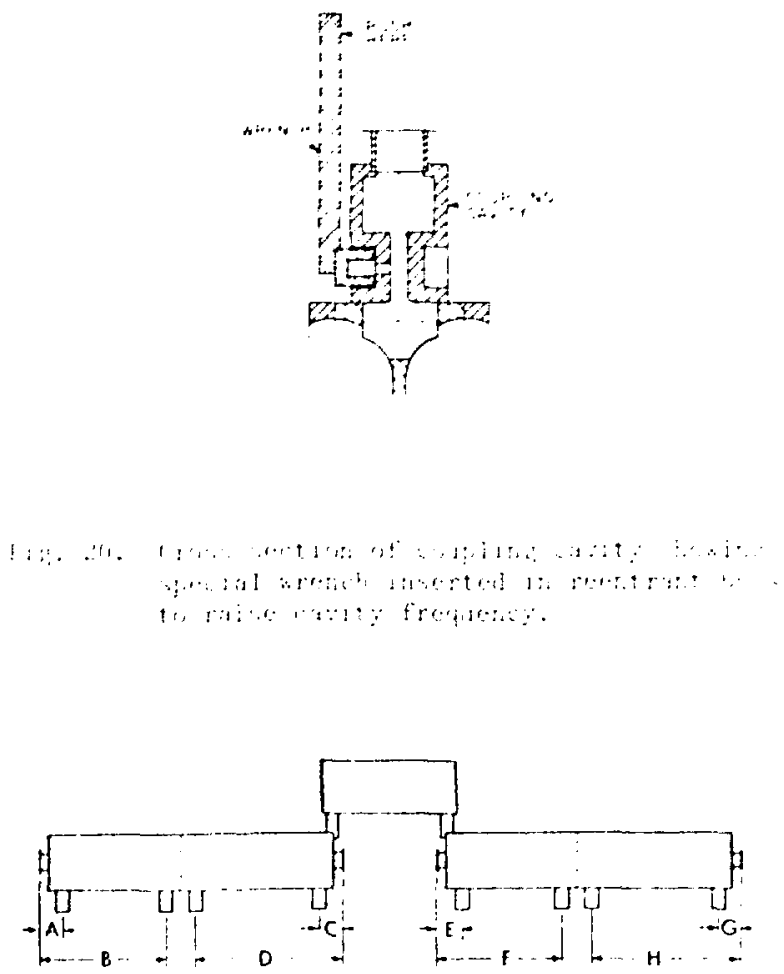

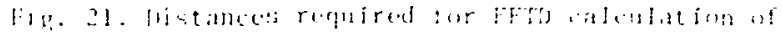
toul wr probe positans, M.p. stepl.

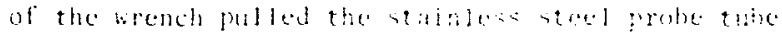

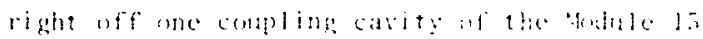

hridge coppler assemple.

B. Acelorating datity loming

This section covers one of the operations briefly described previously in section 11 of part III.A. of this report, Accelerating cavitics bere sonctimes called main cells for brevity.

1. Determine nistances. The longitudinal distances from the middle braze joint on the first and last lower coupling cality in cach tank half to the face of the flange at the end of the tank were determined (lig. 21). $A$ computer program, form for Tuning llata (FFFD), was then run using this dat? to gencrute a Main Cell Data Sheet (sce Fig. 22) with appropriate distance information for each accelerating cavity for the tuning tools to be used in step 6 below. Since the tool positions for nose stretching were different from those for septum bending, there were versions of FFTD appropriate 


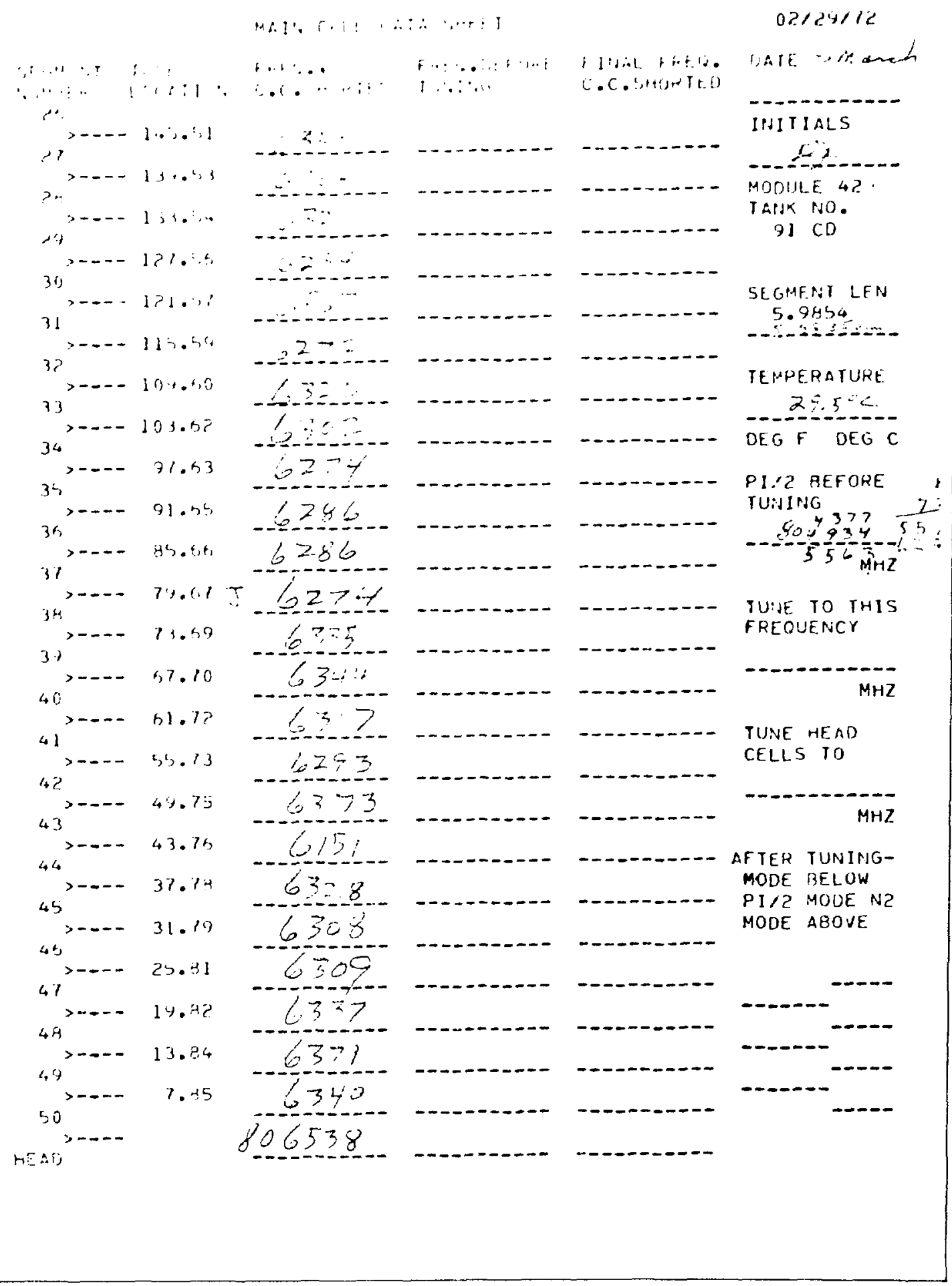

Fig. 22. Example of Main Cell Data Sheet used to give probe or tool positions to the tuners and to record $f$ inal accelerating cavity frequency tuning data, steps $1-4$ of IV.B. This sheet covers the downstream half of Tank 91 in Module 42. Such sheets were filed in module notebooks. 


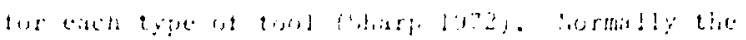

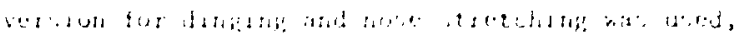

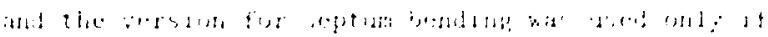

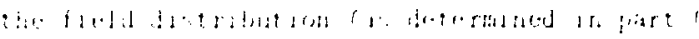

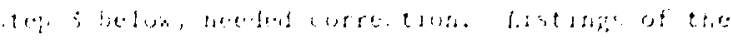

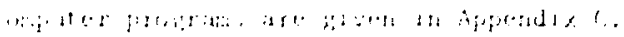

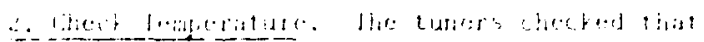

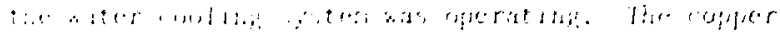

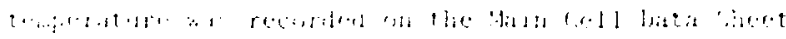

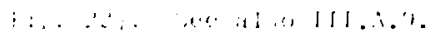

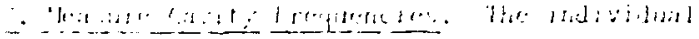

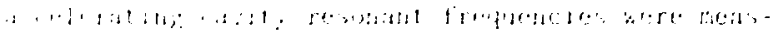

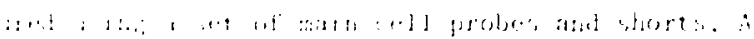

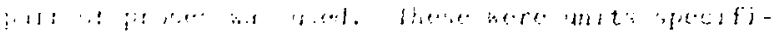

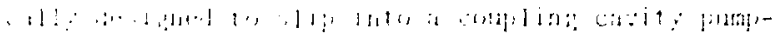

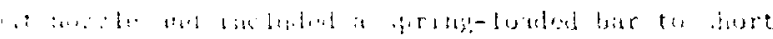

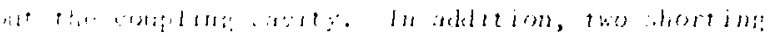

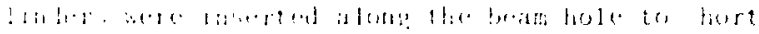

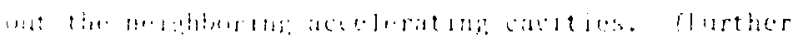

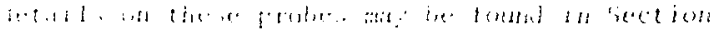
. 1 . . , wh trenduth

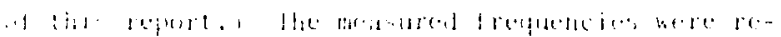

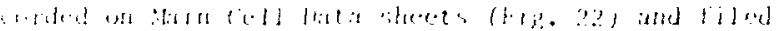

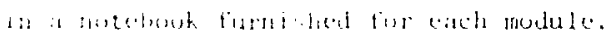

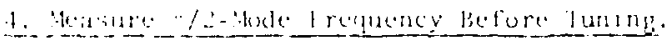

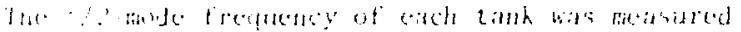

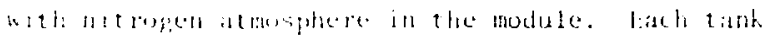
was loulated from the rest of the module by the inserten of shortimg pitas in holes provided for this

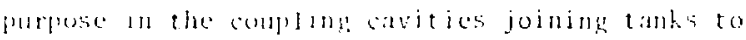
bridge compley cant ien. The results nere rocolded

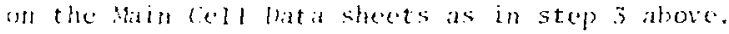

5. Calculate frequencies. The desired individllal accoloritills cotuty frequencies for each tank were calculated using a combination of empirical and theoretical results. Both the individual cavity frequencies bofore tuning (step is) and the tank " $/ 2$-mode frequency bofore tuning (step d) bere used in the calculation. (Further details are given in Section V.B.? of this report.) listher a llewlettlackard $9100-1$ programabie calculator or a version of progrim IFIT was used to do the calculation. If the programable calculator was used, the printouts were taped to Checklist 1: Main Cell Tuning (Fig. 23) and filed in the appoopriate module notebook. If a version of IFTO was used, new Main Cell Data sheets were generated, showing the desired individual cavity frequencies, the amount of frequency

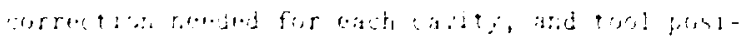

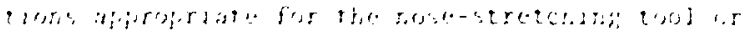

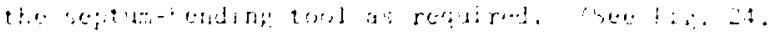

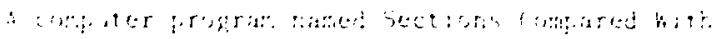

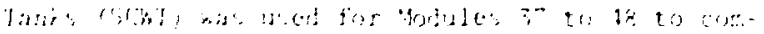

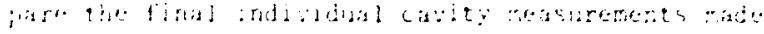

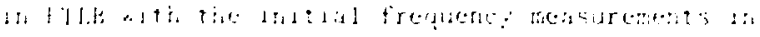

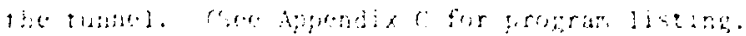

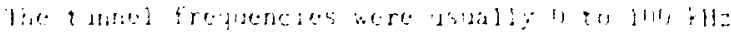

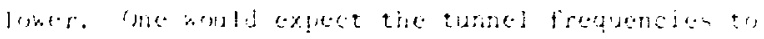

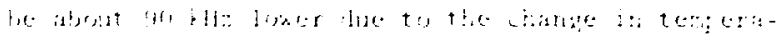

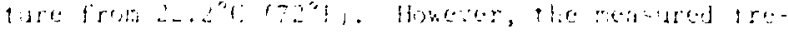

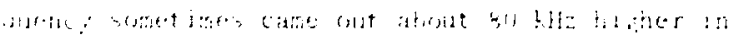

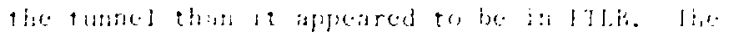

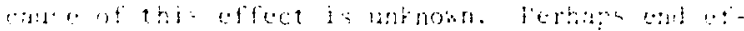

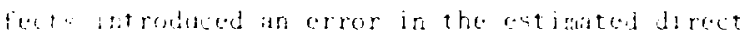

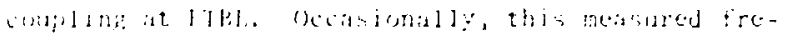

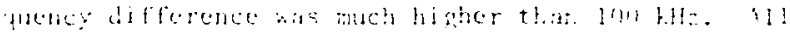

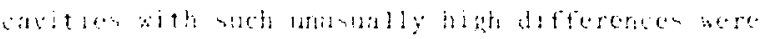

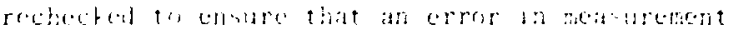

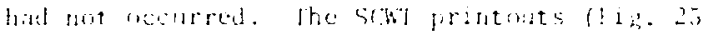

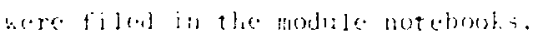

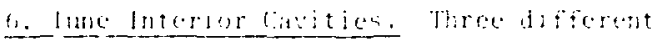

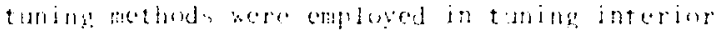

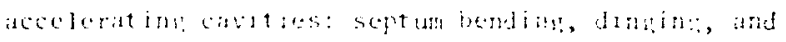
noue stretchint. Septua bending was used tor the injtial tuming for Holules 5 through zf. Infertunatcly, this rethod was fomd to affect th fiold distribution, and fas abindonced for initial tuning. flarts af lodules 1.3 throme 26 were later retuned to correct their field distributions. Sodules z: through is wers initially tuned by dinging and nose stretching. Combinations of all three nethods were used to flatten the field distributions wen necessary. Further information on these matters is given in [I.C..3. of this report. Tab]e $\mathrm{T}$ in Appendix B ists the tuning technique used for cach linac tank.

a. Septum Bending. In this method, a tool was inscrted in the beam hole and a threaded portion expanded to grip the drift tube hole joining a pair of accelerating cavities, as in Fig. 26. A hammer arrangement at the exterior end of the tool was then used to deform the whole septum between cavities, moving the nose regions longitudinally. This lowered the frequency of the cavity on one side of the septum and raised the frequency of the cavity on the other side. By starting the tuning near the 


\begin{tabular}{|c|c|c|}
\hline vate $8 \mathrm{Man} 7^{2}$ & CHECOLIST: TLNE CELLL & Module: :42 \\
\hline Initials 20 & & Tänik $\neq 91$ \\
\hline
\end{tabular}

$\therefore \quad \therefore$

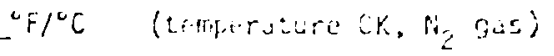

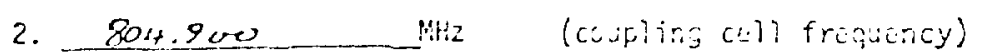

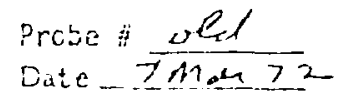

E. 1 . 99 dine (riwin ceil data sheats)

2.

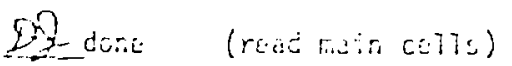

3. 804.934 (n/2-noce fict of tank, $H_{2}$, before turing)

4. $[$.

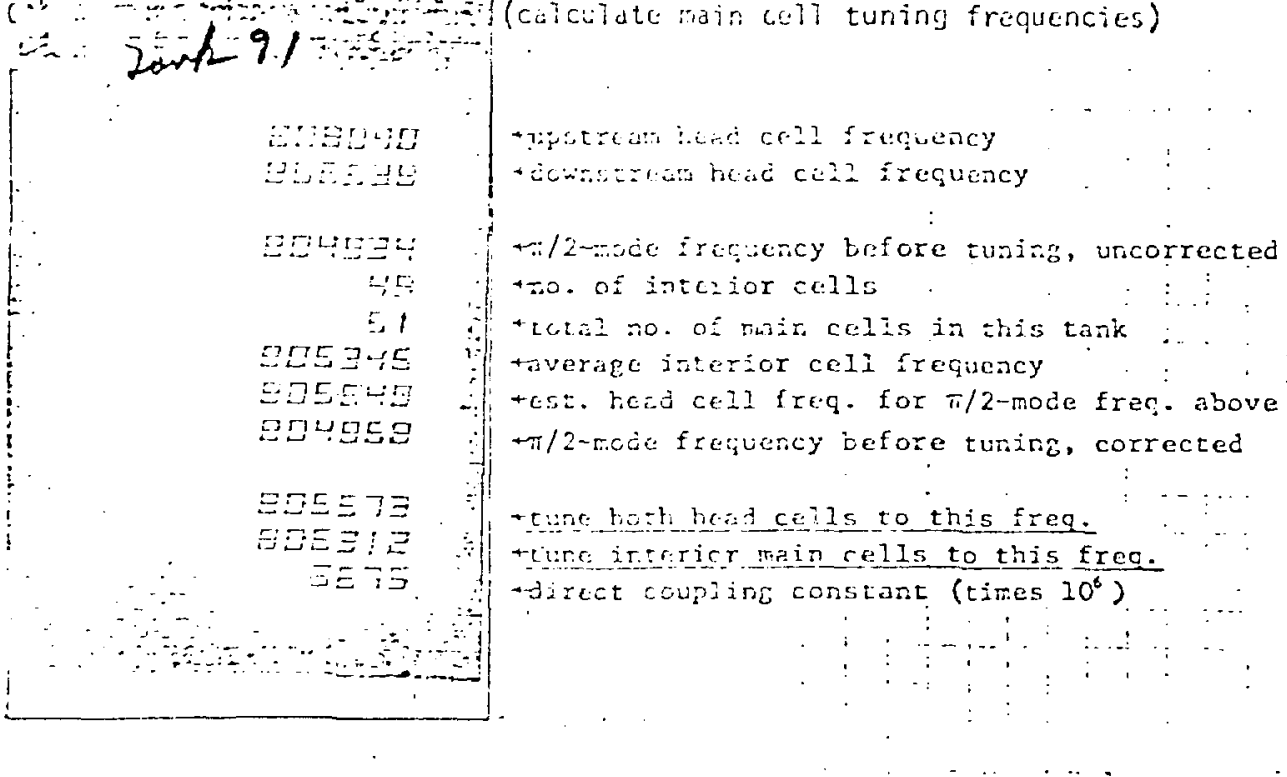

Fig. 23. Example of CHECKLIST 1: MAIN CELI TUNING data sheet, with results of accelerating cavity frequency calculation. (Filed in module notebooks.) 


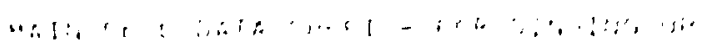

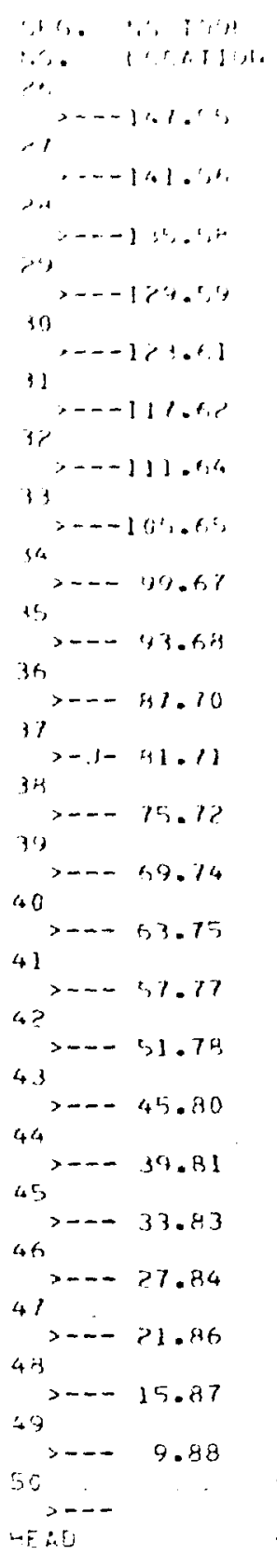

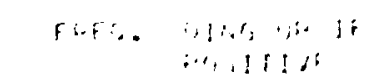

द. 345

6304

6312

6248

6558

6266

6308

6278

6266

6232

6278

6265

6337

6333

6310

6331

6373

$6 / 53$

6322

6304

6310

6333

$63 \geq 0$

6344
1) 10018

$0.113-16-7-$

C.319.

$63 / 0$

$13 / 2$

6312

6313

$63 / 8$ SFGHENT LE:

6312

6304

6311

6312

633

6312

$\leq 310$

6310

IUIALC

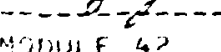

Th.T.K PIIT.

i) $\mathrm{CO}$

\subsection{4}

TE SPERATURE

UEG $F$ DEG $C$

fi/a gefOHe

TUAJING BAHZ

804.934

$804.834 \mathrm{FPN}$

TUNE TO THIS

FRFOUENCY

806.312

6312

6310

6322

6314

6311

$63 / 2$ aFIER TUNING-

MODE BELOW

$63 / 2$ PI/2 MODE N2

TUIAE HEAD

CELLS TO

805.573

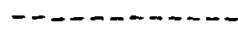

$K K=0.047836$

$K D=-0.003675$

2310

MODE ABOVE

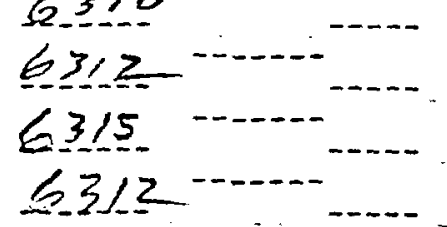

$6536-\quad 5523$

$J=K \cdot E \cdot-O \cdot R \cdot \ldots$ JOINT FL.

Fig. 24. Example of new Main Cell Data sicct used in steps 5-8 of IV.B. The amount of frequency correction needed for each cavity is listed in the column under "Ding Up if Positive." 


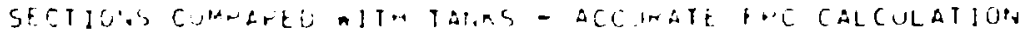

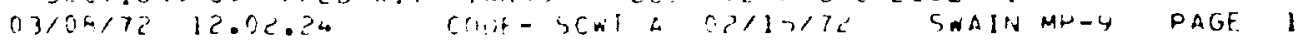

\begin{tabular}{|c|c|c|c|c|c|c|c|c|c|}
\hline \multirow{3}{*}{ DATE } & \multicolumn{7}{|c|}{ Indr } & \multirow{3}{*}{$\begin{array}{l}\text { IUSPE TO } \\
\text { IUNNEL }\end{array}$} & \multirow{3}{*}{$\begin{array}{l}\text { ERH } \\
\text { DIF }\end{array}$} \\
\hline & $\iota$ & $1 . \forall T$ & Extron & tiof $\ldots$ & f miti. & fint ... & $t=2$ Gin & & \\
\hline & $\therefore$ & $f I_{L}:$. & it in & ILU & lim in $r^{2}$ & 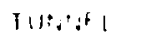 & IIINNEL. & & \\
\hline-- & -- & $\ldots \ldots$ & $-\ldots$ & $\ldots \ldots$ & $\ldots-\cdots$ & 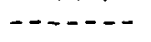 & $\ldots .$. & $\ldots-\cdots$ & -- \\
\hline $1>1$ & 1 & -05.011 & 1.0118 & nog.tini- & 1.210 & شù. . טצy & ס ל. & 005.574 & 1.507 \\
\hline $12 ? 1$ & 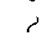 & $-0 \cdot \ldots+16$ & -.020 & gues. 3xis & .166 & Wuateras & $-.02 \%$ & HUB.319 & \\
\hline 1601 & $j$ & $\operatorname{sos} \theta i c$ & -.015 & 400.345 & .011 .3 & Hus. $11 t$ & .001 & 606.313 & \\
\hline $1 イ 1$ & 4 & $\operatorname{son} 0.40$ & -.04 & $M(15.34: 3$ & .078 & ron.s1 & .000 & 806.313 & \\
\hline $1>>1$ & 5 & $40 \ldots+.4 ?$ & -.025 & כ50.180. & $.0-4$ & $n(t) .301$ & -.017 & 600.313 & .013 \\
\hline 1281 & + & $-\sin .+10$ & .310 & 400.120 & .016 & $\mathrm{HOH} \cdot \mathrm{D}_{4} 4$ & .331 & Hot. 313 & .021 \\
\hline ?? 1 & 7 & 403.410 & $-.0>0$ & n00.39: & .000 & nün.\$11 & -.00 .3 & HOS. 313 & .017 \\
\hline $1 \geqslant 1$ & 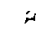 & $-0 \cdot \ldots 10$ & -.075 & 430.345 & $\left..4 r^{\circ}\right)$ & -30.3130 & -.013 & nor. 313 & - \\
\hline १?! & $\sqrt{4}$ & $-(1+, \ldots+10$ & $-.04+10$ & 906.370 & . gam & $=09.7 \mathrm{Mr}$ & $-.0<H$ & $n 00.313$ & .017 \\
\hline $1>1$ & 10 & $20 \cdots+10$ & -.041 & 104.370 & $.00 \%$ & 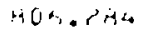 & $-.0<y$ & .06 .313 & .011 \\
\hline $1>21$ & 11 & $40+\ldots 1^{\circ}$ & $-.0 \cdot 0$ & Mus. Basu & .03 .4 & $f+0 \cdot 1, \sin a^{3}$ & $.0 r^{\prime}$ & muto.311 & .059 \\
\hline & $1 \div$ & $\ldots \cdot q^{\prime} \cdot$ & 1 & 0.000 & $:$ & HON.MP & .213 & $m 06.311$ & \\
\hline 1ン1 & 14 & $-c ; \ldots, \cdots !$ & $-0,13+$ & $m 05.30 .1$ & $0 n / 6$ & nor. 040 & $-.0<3$ & 404.313 & 17 \\
\hline $1<1$ & 14 & $+1, \cdots, \ldots$, & $.1 \mathrm{~h}$ & $-1,+, 0,7$ & $-n 1: 4$ & :-ur.jo? &.$r i t$ & rut. 31$\}$ & Sמי \\
\hline $130 !$ & 14 & $-60 .+1$, & - Ex \{1 & $m(y+2) 3+2$ & 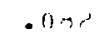 & Hoc..tris & -.030 & $\pi 00.313$ & 0 \\
\hline 1271 & 10. & $50 \cdot 1.3+4$ & $-01,3,4$ & auh getis & .016 & $46+\ldots, \cdots$ & $-.0<\%$ & 805.313 & .011 \\
\hline 1?? & 11 & $+0 \% 36$. & -.63 .4 & 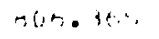 &.$(j \cdot, m$ & nu. . s r y & -.0104 & 906.313 & .031 \\
\hline ist & $1+$ & Hun. $3 \because$. & -.011 & Mus. Ins! & .01 & rop. 361 & -.0 & 400.313 & .014 \\
\hline 1277 & $1 \%$ & $00+.364$ & -.0 & $0,0 h .3 F_{1}^{2}$ & .005 & 400.300 & -.0 & 400.313 & .022 \\
\hline $1>>1$ & iी & $\operatorname{mon} . \mathrm{Mr}$ & $-n$ & $06.36{ }^{2}$ & .031 & POn. & & HOt.313 & .36 \\
\hline 1ンை & 71 & $40, \ldots .36$, & -.63 .4 & rito. 36$)^{2}$ & .004 & $40, \ldots 11$ & -.1 & Ho 4.313 & \\
\hline $1+7$ & $\therefore$ & $\therefore 00.3+1$ & .1 & $\operatorname{Hos} \cdot 362$ & .1150 & $M O 1, .513$ & ? & HOP. 313 & \\
\hline はくン & $? 1$ & $+1, \ldots 1$ & .051 & 304.430 & $.00^{7}$ & $\therefore 04.423$ & & 806.313 & .060 \\
\hline けンン & . & mon.s's, & -.034 & noti. 305 & .07 & toh. 11. & 0 & 406.313 & .035 \\
\hline & 25 & 6.04 .437 & 1 & 0.000 & 1 & 200.051 & & 806.313 & I \\
\hline रे & ;. & $40 \% .4 \%$ & -.041 & mus. 3rs & .104 & 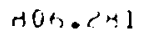 & -.037 & 006.313 & .015 \\
\hline 1207 & 27 & $-31 . .436$ & $-.04 i$ & 205.145 & $.0<1$ & 800.350 & & 0.313 & \\
\hline $1>01$ & $2 r$ & $-0, .43 \pi$ & -.041 & mon.3ks & .017 & GOH. $30 \mathrm{H}$ & -.005 & mon. 313 & .042 \\
\hline $1 \partial ? ?$ & 24 & (29.43) & $.0 \% 3$ & mos. 455 & .150 & GOt, . ST: & 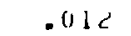 & $80 t .313$ & -.011 \\
\hline 1277 & 30 & $40 \times 1.430$ & -.041 & Hub. 3kh & .131 & 800.254 & -.054 & 800.313 & -.012 \\
\hline $1 ?>1$ & 31 & in $(5) .43 c^{\prime}$ & .26 H & 405.100 & .133 & einn. Sถ 7 & & 800.313 & -.014 \\
\hline $17 ? 7$ & 37 & 400.437 & -.041 & mon. 385 & .113 & RŨt.27? & -.0 & 806.313 & .006 \\
\hline 1227 & 33 & $506.43 ?$ & -.047 & xus.3As & .065 & 906.320 & .007 & 406.313 & .054 \\
\hline 1227 & 34 & 904.432 & -.047 & 406.385 & .043 & $806.30 ?$ & -.0 & 5.313 & .036 \\
\hline 227 & 35 & $503.432^{\prime}$ & -.0 & 305.385 & .111 & Bu & -.0 & 5.313 & .008 \\
\hline 77 & $3+$ & $4 . .4$ & -.0 & $.3 A 0$ & .094 & $R C$ & - . & .313 & .025 \\
\hline 77 & 3 & 15.432 & -.047 & 06.385 & .099 & $-25 B$ & -.0 & .313 & .020 \\
\hline & $3 r$ & 6.434 & J & 0.000 & 1 & .274 & -.0 & .313 & \\
\hline 21 & 34 & 15.434 & -.044 & 406.395 & .060 & 80 & .0 & .313 & \\
\hline $2 i$ & (1) & 0.439 & -.0 & .400 & .05 & 4 & & 3 & 71 \\
\hline 21 & 41 & 0.434 & -.0 & .397 & $.0 \Delta 0$ & 80 & & 3 & 47 \\
\hline $2 ? 1$ & 42 & 406.439 & -.043 & 906.396 & .103 & BO & .0 & 313 & 24 \\
\hline 37 & 43 & 802.439 & .045 & 906.485 & .112 & 8 & & 3 & 15 \\
\hline 37 & 44 & 400.439 & -.174 & 406.265 & .114 & .151 & -.1 & .313 & .013 \\
\hline 2? I & 45 & 805.439 & -.043 & $806.39 \mathrm{H}$ & .068 & 3 & .015 & 806.313 & .059 \\
\hline 221 & $4 h$ & 203.439 & -.044 & ל4 & .087 & 806.3 & -.0 & 806.313 & .040 \\
\hline 221 & 47 & 805.434 & -.054 & sun. 3rs & .07 & .3 & -.0 & 806.313 & \\
\hline & 48 & $80 t .437$ & $-.03 y$ & $\pi 00.400$ & .063 & 6.337 & .024 & 806.313 & \\
\hline & 49 & 805.434 & -.019 & 805.420 & .049 & 806.371 & .058 & 806.313 & .078 \\
\hline 1 & 50 & 860.434 & -.044 & 306.390 & .050 & 806.340 & .027 & 806.313 & .077 \\
\hline & - & 5.410 & & 0. & & $80 h .538$ & .964 & 74 & \\
\hline
\end{tabular}

Fig. 25. Example of printout from SCWT code for comparing accelerating cavity frequencies measured in ETLB with frequencies measured in the beam tunnel. See step 5 . 


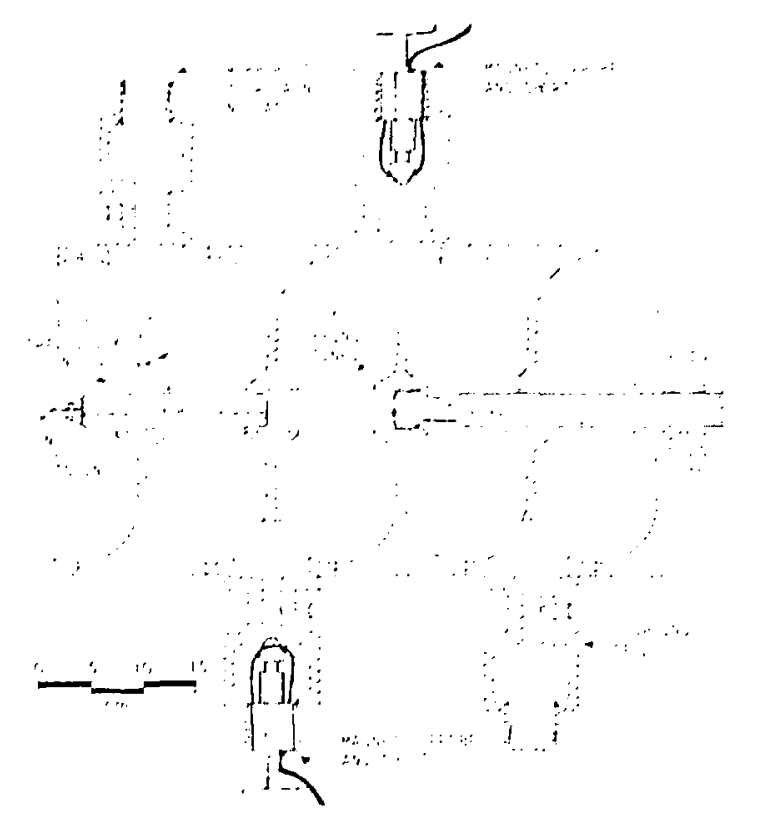

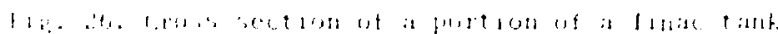

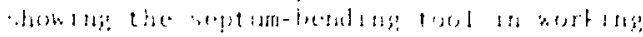

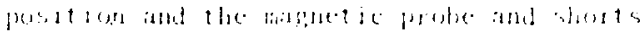
wacd in IV.R.6.it.

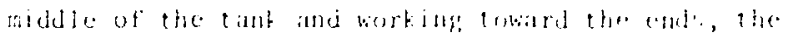

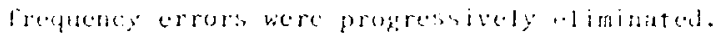

If regitons of a tant were esther all high an frequency or all low in frequency before tumang, quite large errors conld accumblate in the septumbending process by the time the end of the regum was reached. The camblat ine frequence error hearas very large in certain two-tank modulen, and it loccame obvious that pulling or pushing suh larpe crrors to the end of the tant produced significant changes in the field distribution. Sometimes tike distribution fell very low or hooked ap rery high at the ends (see lig. 62, p.63). Therefore it was decided to abandon septum bending as the primar: method for initial tuning.

further information on septam-bending tools may be found in section r.J.l.

b. Dinging. Accelerating cavities which were low in frequency were rajsed by making indentations in the cavity 'all along the diameter. It was found that a blunted cold chisel tip would fit between the cooling water passages which covered most of the outer diameter. A single sharp blow or the special chisel with a mallet would change the frequency 10 to $20 \mathrm{kll}$. Repeated blows had a reduced effect due to work-hardening of the copper.

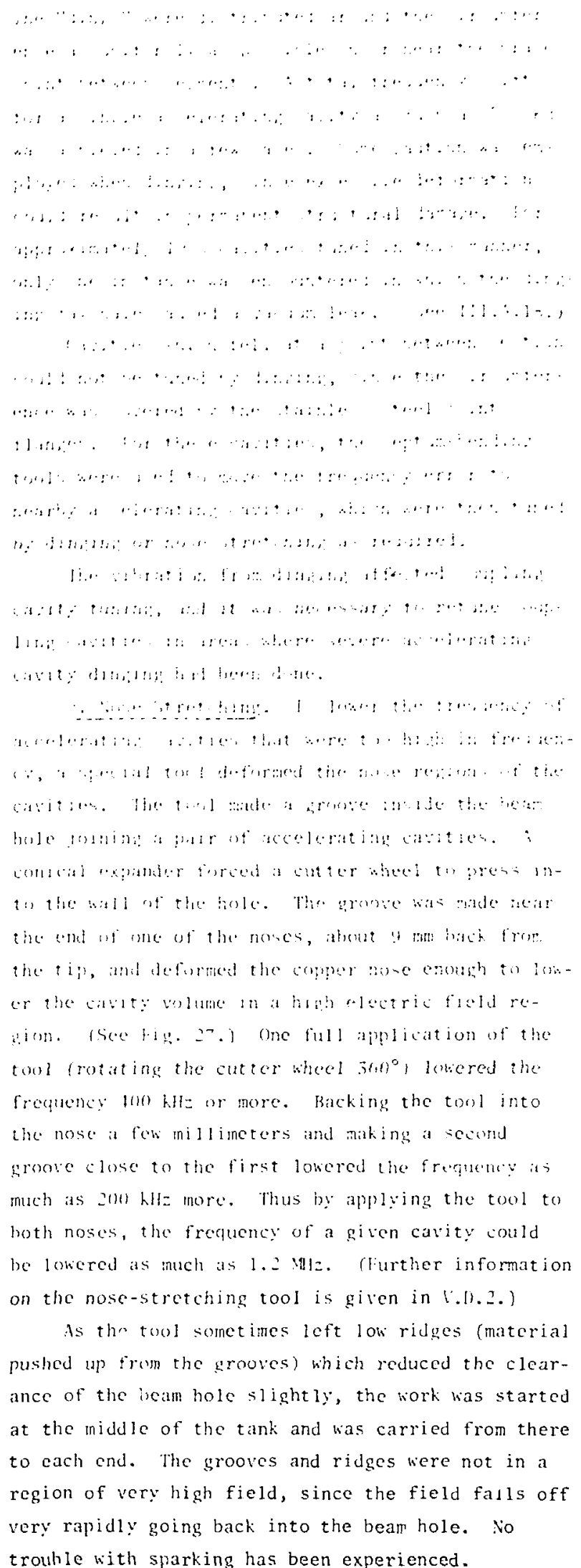




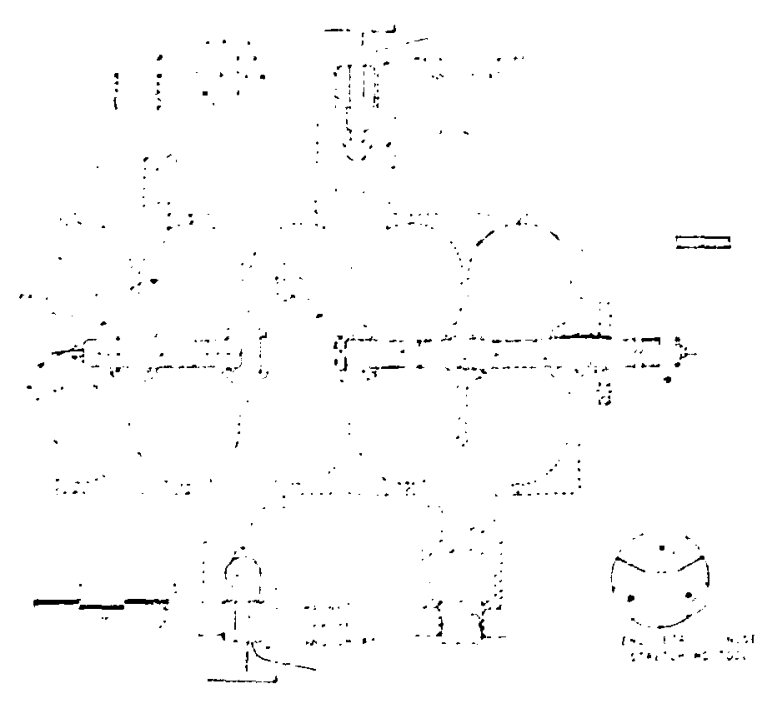

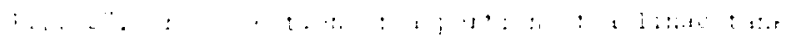

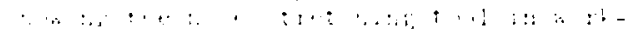

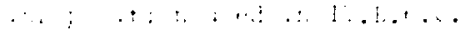

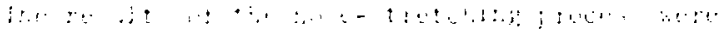

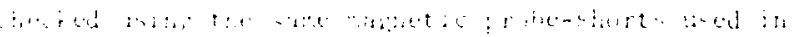

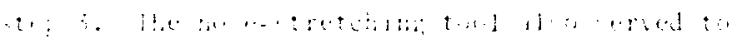

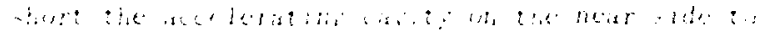

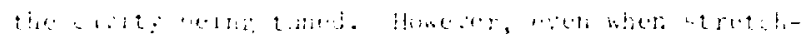

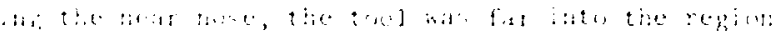

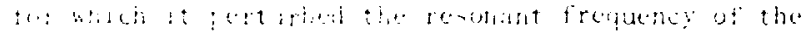

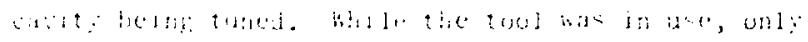

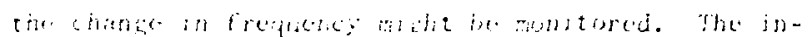

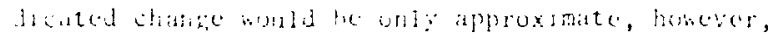

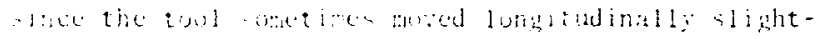

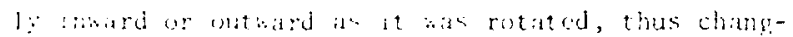
ing the amount at jertarbed the frequeney. To matic the find check of the cartity frequency, it was necesary to lousen and bithdras the tool somentat.

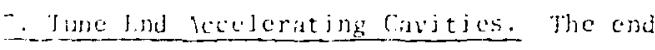
accoicrating cantics lacad calities) of cach tank vere usually tuncd using the septum bending method. Heide savities at the end of the module gno joint ring) and slightly low in frequenc: (a rare occurrence) were brought up by dinging. In either case, these were tuned to the frequency predicted for end iarities.

Un alternate scheme which produced similar (but not identical) results wis to tune the head cavities to give minimum field in the first coupling cavity.

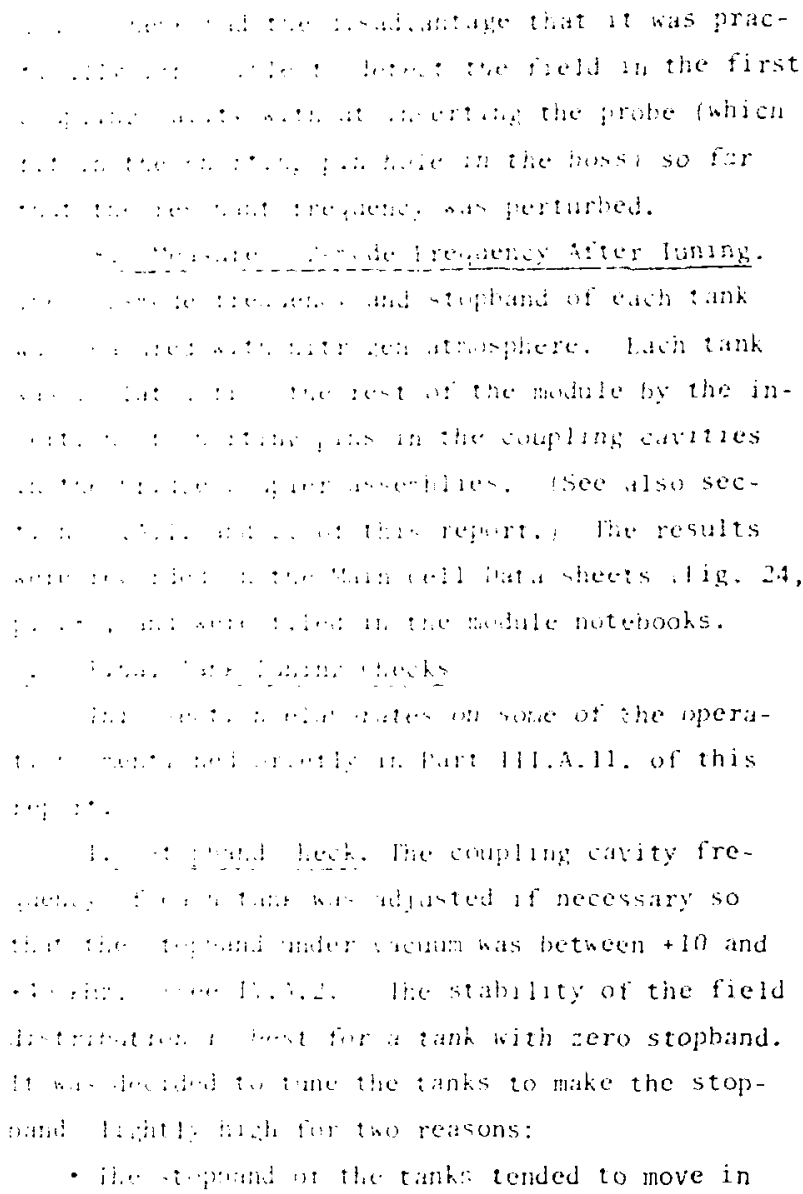
lige nentide diretion wer a period of time. Ap-

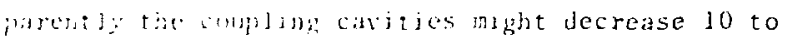
311 hiz ave! lake first wonth or two after tuning. there is no cudenee as yet that this downward trond continues after the first few months, however.)

- fheoretical and experimental results indicated that the cratsicnt hehatior of the field distribution was better if the stopband was positive rather than negative. (liurther information on this point is giron in VI.A.l. and Append ix G of this report.)

i portable racuum roughing pump was used for this and the following vacuum measurements. A rubber hose betweon the pump and a flange which could be clamped to a coupling cavity pump-out nozzle prorided a comrenient method for connecting the pump to a modtle whose racuum manifold had not been installed.

The following steps bere f,llowed when starting a vacuum roughing pump for a module with a vacuum manifold:

(1) Start fore pump and hold pump flange against tank flange. The flanges will hold together without 


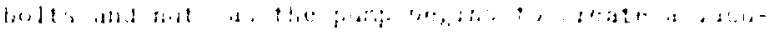
i.'.

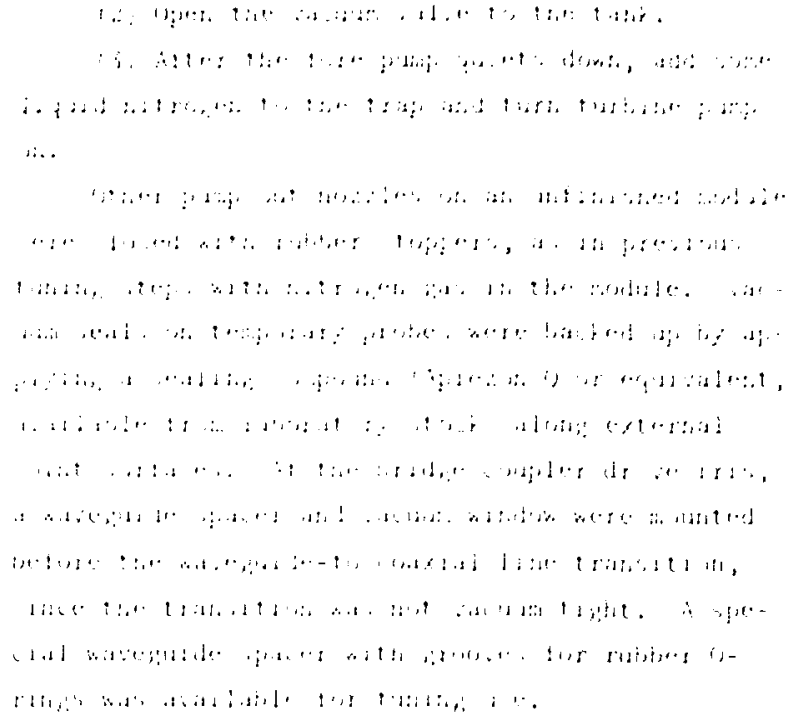

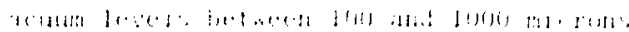

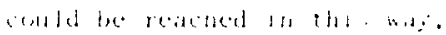

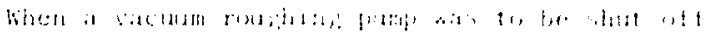

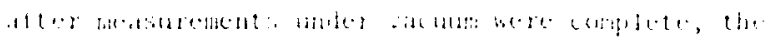

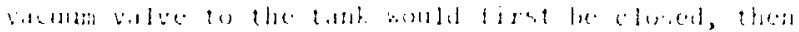

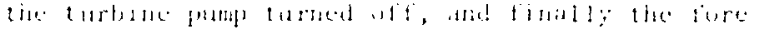

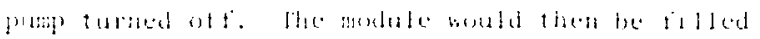

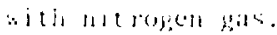

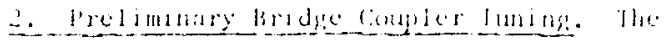

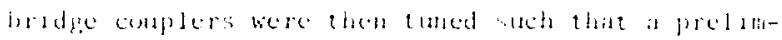

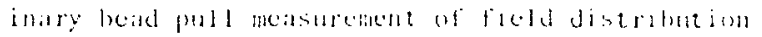

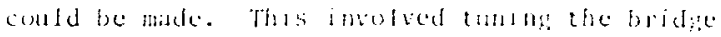
coupler to the correct frepuency and ald justant the posts such that die phase shitt atcoss the bridge coupler was independent of the direction of net energy flow through the bridge compler. Steps? through 7 and 11 through 1.1 of sebtion h below were followed to do this.

3. Freliminary Bondpuld ind Ficld Plattoning. The ficld distribution within each tank has sheoked using a beadpull measurement. In this type of moatsurement, a small perturbing object is carried along! a string stretched along the beam axis, and the amount of clectric field present at cach point is doduced from the resulting variation in the $\pi / 2-m o d e$ frequency of the module. Ihta processing and display were handled by a minicomputer. Further details on this type of measurement are given in section $l i$ of this report.

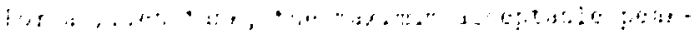

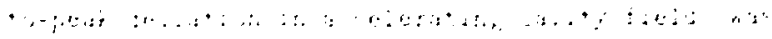

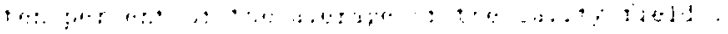

:

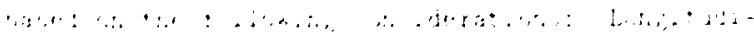

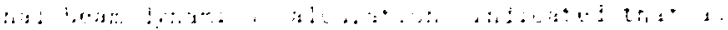

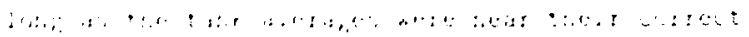

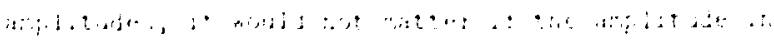

.

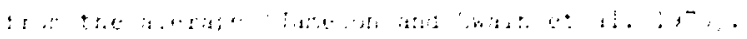

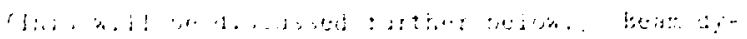

: :

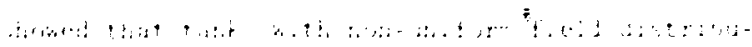

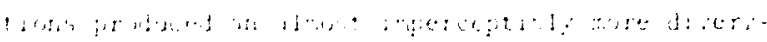

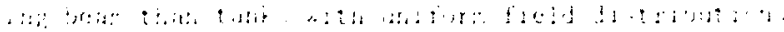

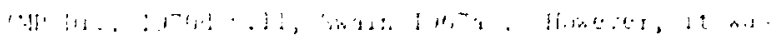

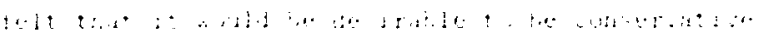

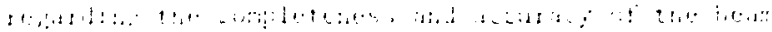

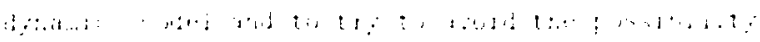

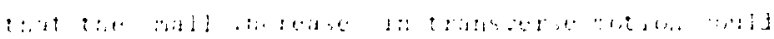

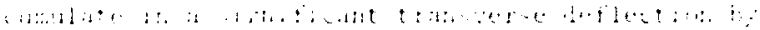

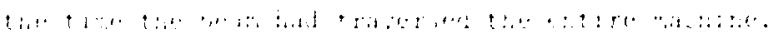

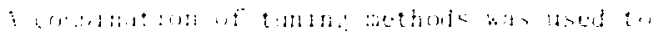

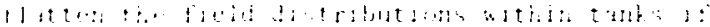

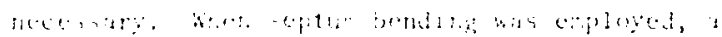

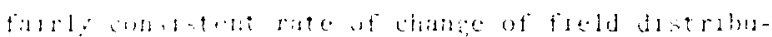

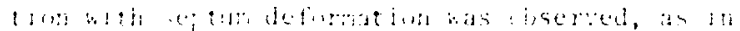

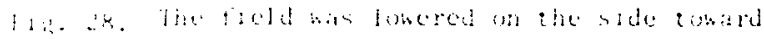

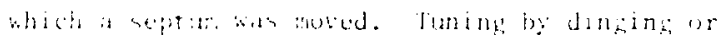

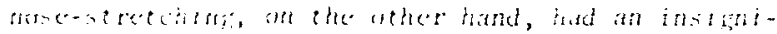

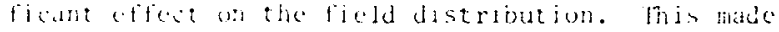
possib] the fullowimb flat tening procodure:

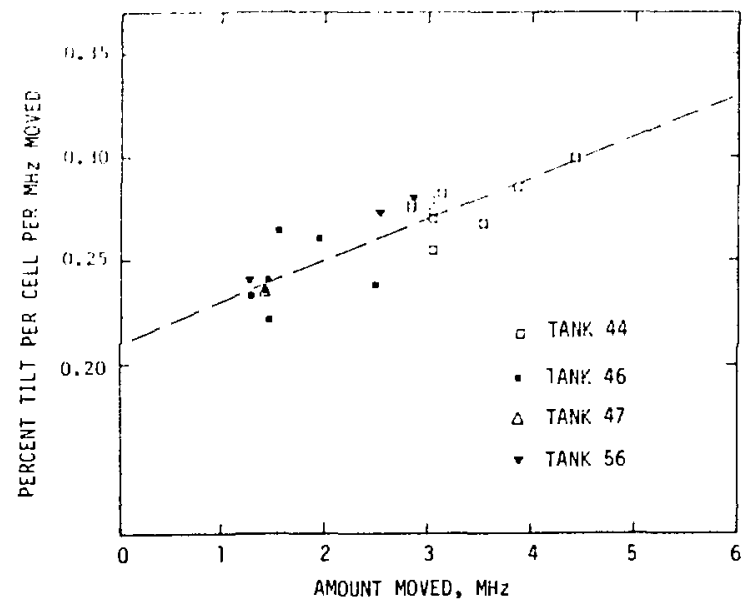

Fig. 28. Measured field distribution tilt rates for tilt caused by tuning accelerating cavities by septum bending. 


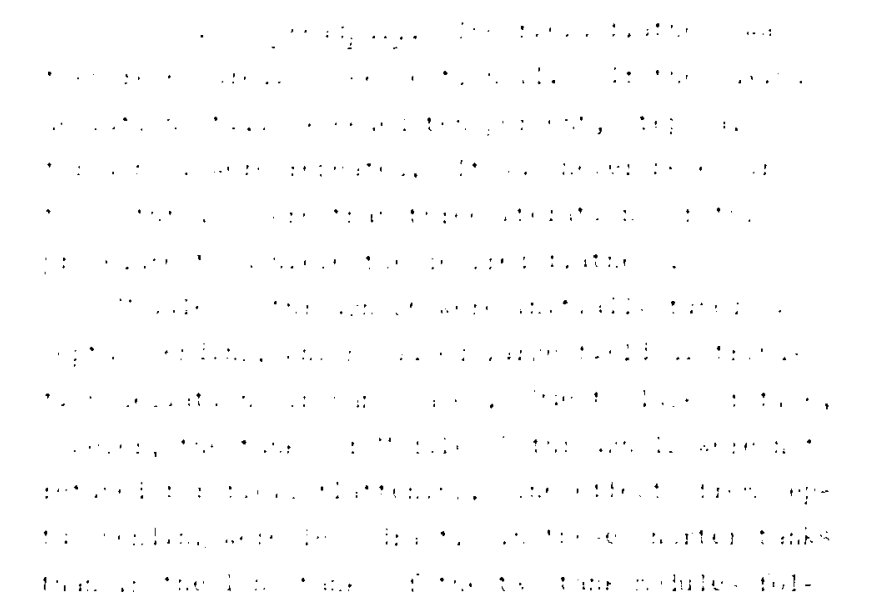

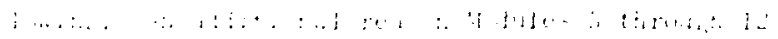

a

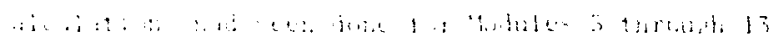

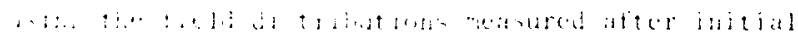

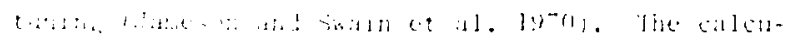

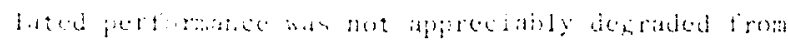

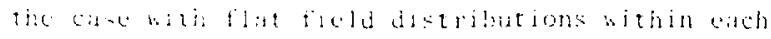

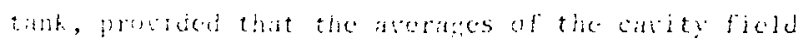

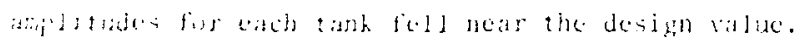
In the artat linat, the arerages were adjusted to

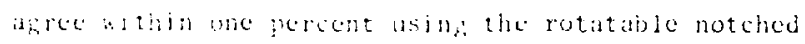

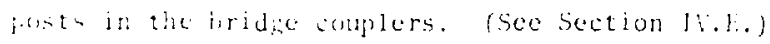

laiks in todales 13 through 26 were retuned or partly retumed when nesessury according to tho above ilattening procedure in order to bring the maximum feah-to-peak amplitude deriation down to approximately ten percent or less for all these modules. The retuning tended to bring severely deformed septums back ncar their original positions.

Only two tanks (Tanks $; 1$ and 9.4) in the remainder of the 1 inac, lodules 27 through 48 , required

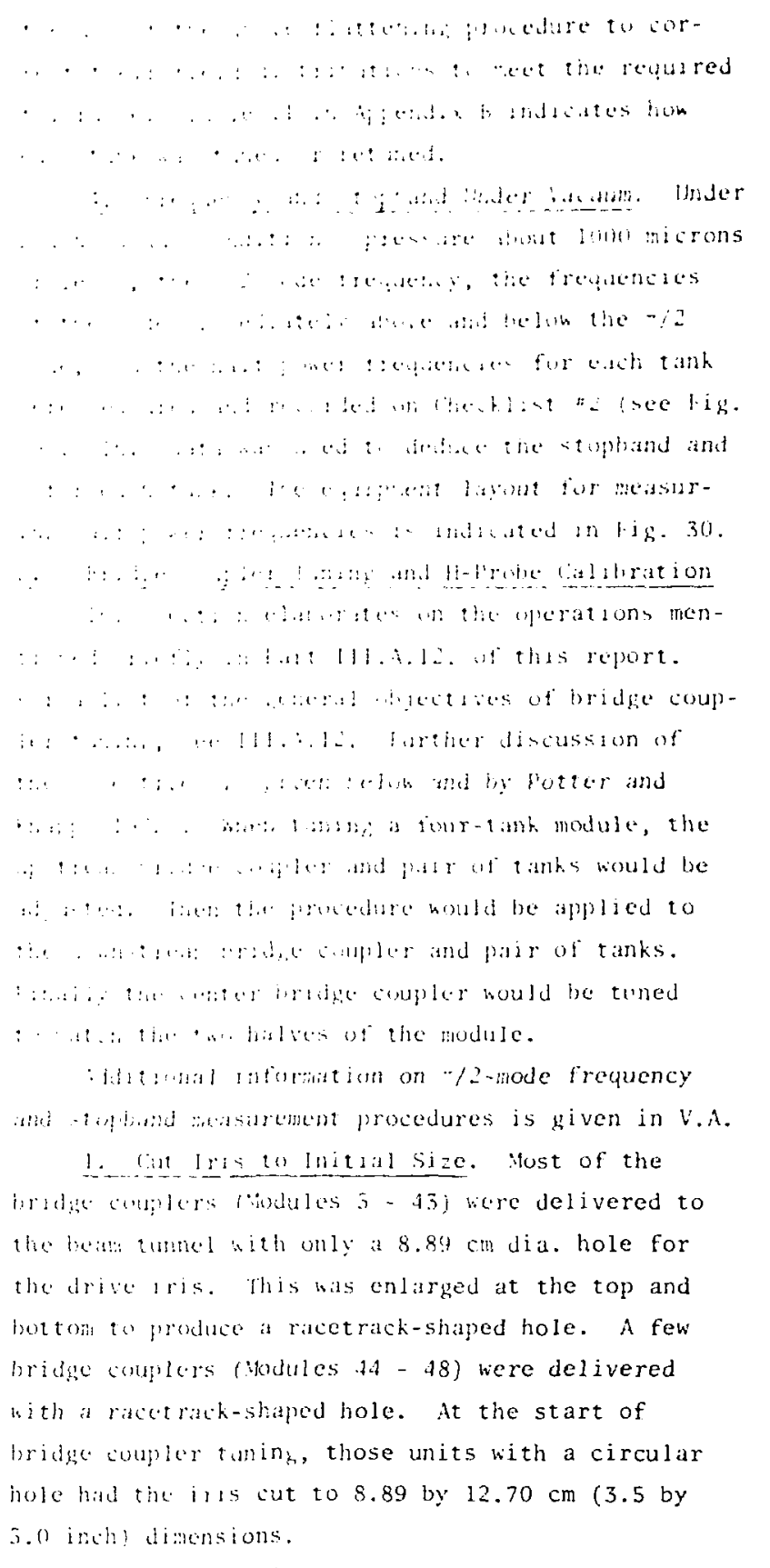

․ Intal11 Adjustable Posts. Completed bridge coipler carities have three kinds of posts: end tuners, fixed post tuners, and center post tuners. (Sec lig. 15 on p. 14 and Fig. 31.) The fixed and the conter post tuners are water cooled, but the end tuners are not. The end tuners are fixed posts mounted at the flat end faces of the bridge coupler cavit: and penetrate along the center line of the cavity. Their lengths were chosen such as to set the bridge cavity $T \mathrm{H}_{010}$ mode frequency properly, as will be discussed in Steps 11 and 18 below. At the 


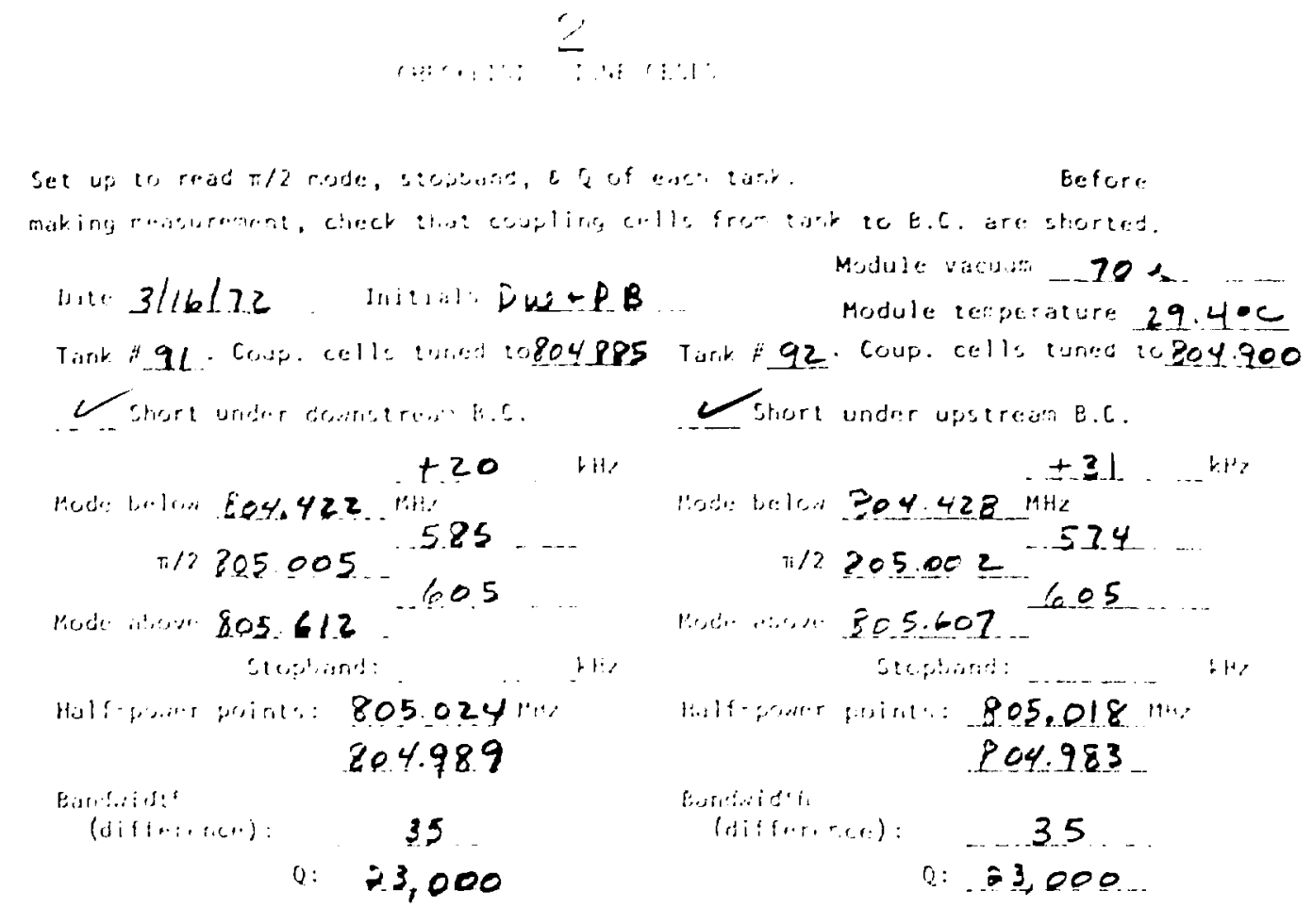

\begin{tabular}{|c|c|c|c|c|c|}
\hline$\underset{(B A N D W}{\left(H_{2}\right)}$ & 0 & $\begin{array}{l}\text { BAHOW. } \\
\text { (KHe) }\end{array}$ & $\begin{array}{c}0 \\
\ldots \ldots\end{array}$ & BANDIW. & $Q$ \\
\hline 50 & 16100 & 40 & 20100 & 30 & 26800 \\
\hline 49 & 36,400 & 34 & 30000 & 29 & 27800 \\
\hline $4 \mathrm{~B}$ & 16400 & 39 & 21200 & 28 & 28300 \\
\hline 47 & 17100 & 37 & 21800 & 27 & 29800 \\
\hline 46 & 17500 & 36 & 22400 & 26 & 31000 \\
\hline 45 & 17900 & 35 & 23000 & 25 & 32200 \\
\hline 44 & $1 \times 300$ & 34 & 23700 & 24 & 33500 \\
\hline 43 & 18700 & 33 & 24400 & 23 & 35000 \\
\hline 42 & 19200 & 32 & 25200 & 22 & 36600 \\
\hline 41 & 19600 & 31 & 26000 & 21 & 38300 \\
\hline
\end{tabular}

Half-power point $=(t=0.71 \mathrm{Vat}$ rejonance $)=3 \mathrm{~dB}$ down

$Q=($ res. freq. $) /($ bandwidth $)=805,000 /(b . w$. in kHz)

$8 / 17 / 71$ CES

Fig. 29. Example of CHECKLIST 2: FINAL CELL TUNING data sheet used in Step 4 of Part IV.C. (Filed in module notebooks.) 


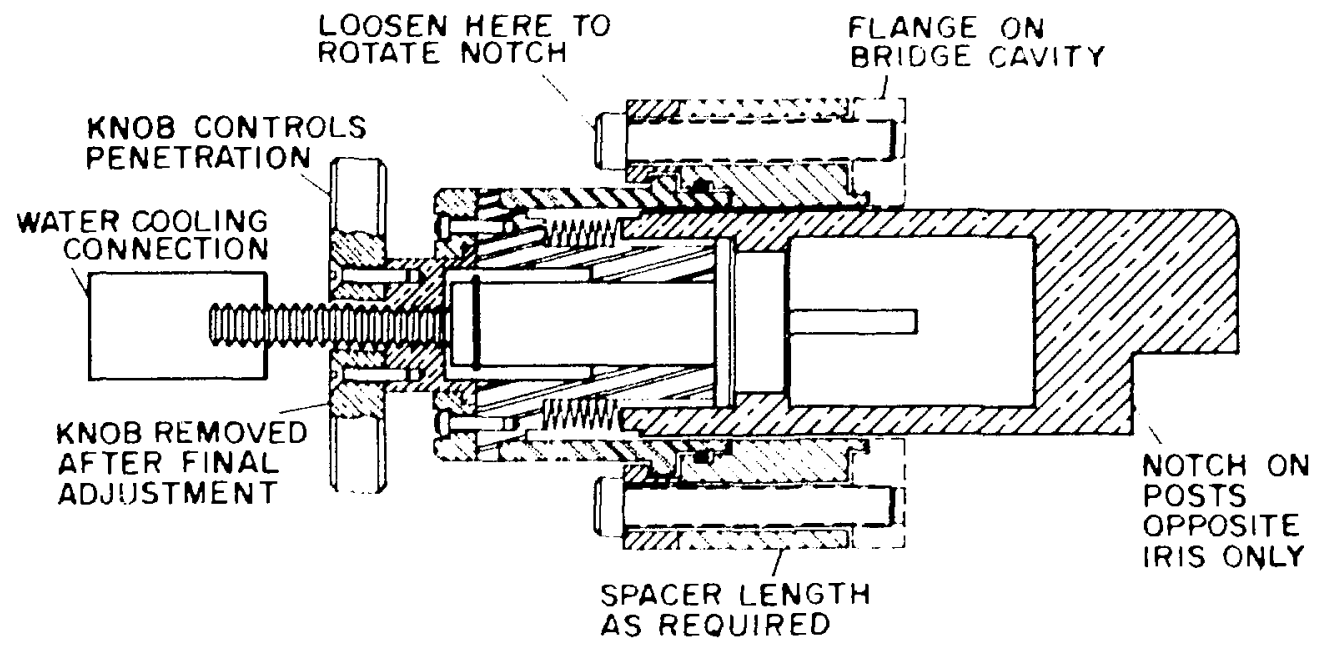

$11,1, \quad 3.1,1$,

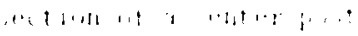

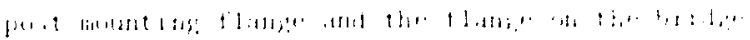

cranter.

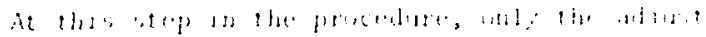

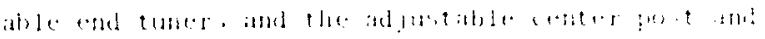

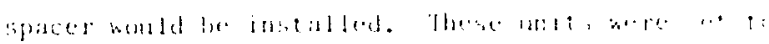

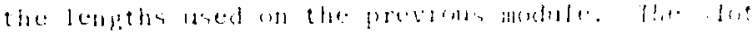

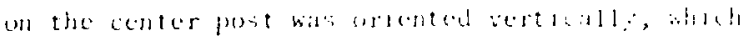

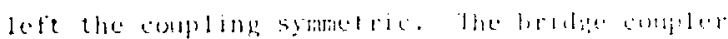

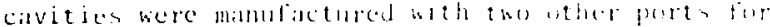
ad justable post aners alome the tront wall. These

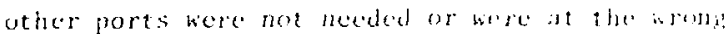
positions for phase compensat lon on the hatpl singsulz linac, and were seabed off with soppor blanks (as in lig. .31$)$.

\section{Ndjust conter loust fortetration. Hha:e} compensation is achieved when the phase between parts of a linac structure is independent of the amount of bean loading. In the case of a single tank operated in the $\pi / 2$ mode, phase compensat ion occurs when the other modes are symetric about the $\pi / 2$ mode, that is to say, when the stopband is closed. In the case of a bridge coupler cavity, the other nearby modes are not symmetric ubout the desired $\mathrm{TM}_{010}$ mode, but the modes can be shifted such that the modes below compensate for the modes

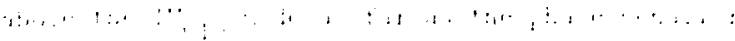

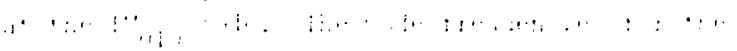

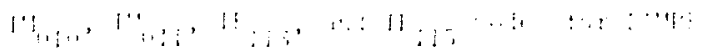

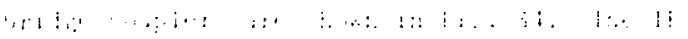

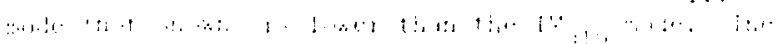

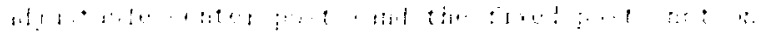

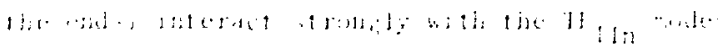

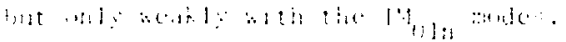

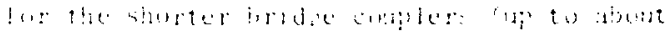

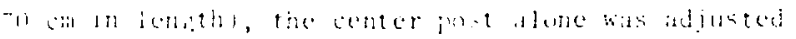

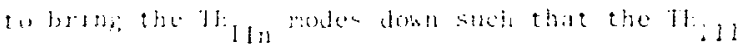

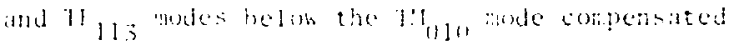
brought lown unt il it resumanty souplod the halles

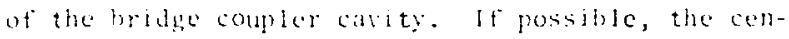
ter post penctration was set to obtain less than one degree change in the phase shift across the bridge coupler as the drive was switched from one cind of the iodule to the other. isec lis. 5.5 for moasurement equipment layout. I If this could be done, one then shippea down to step ll of this procedure.

If the bridge coupler being tuned was longer than about $\rightarrow$ (l) $\mathrm{cm}$, one found that either no setting 


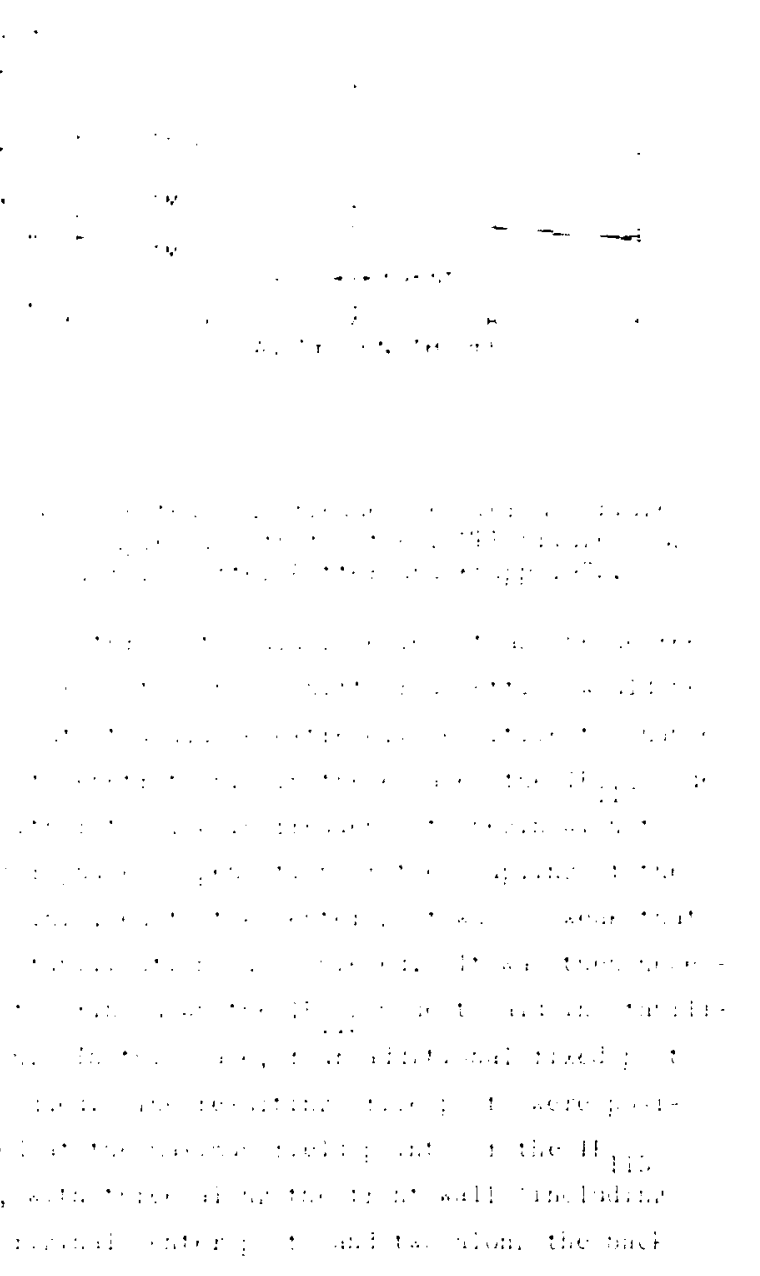

$\therefore \therefore$.

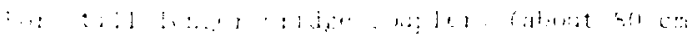

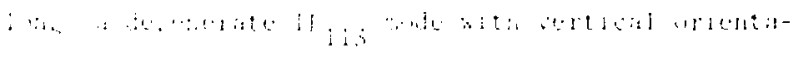

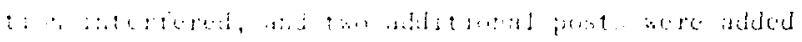

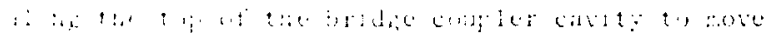

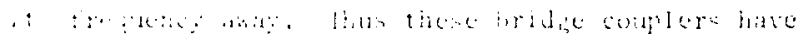

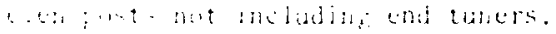

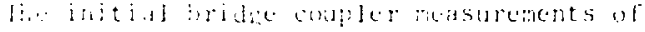

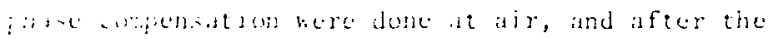
apruxingte jost confighration required was deter-

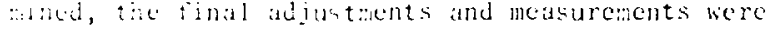

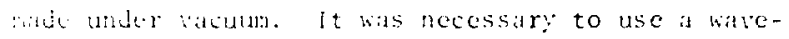
atid specer and hindow between the iris and the coawal-jine-to-baveguicie transit ion to prevent the ination from aceturbing the ficlds and resomant frequencies in the bridge coupler and to pernit

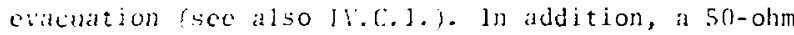
terminition was connected to the transition for
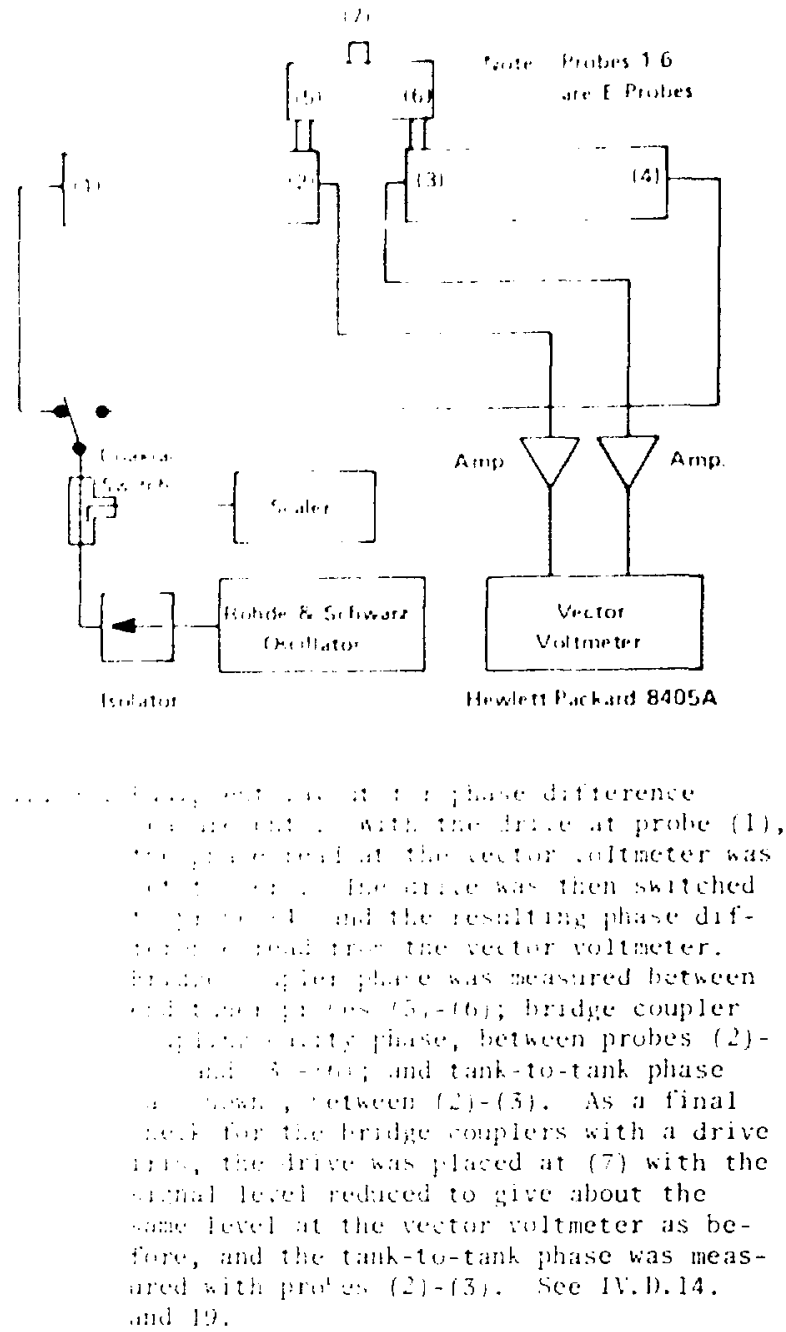

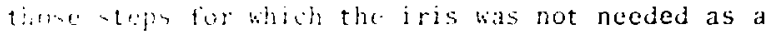
jrive print.

inc to the larions trial configurations and icoritiog processes involved in bridge coupler tunint, it wis found better to not use a standard data fheet for the measurenents until Step 20 below was roached. Irolininary bridge coupler measurement data bee recorded in a laboratory notebook, usually Sotebook 14-2229. Some of the early measurement lat al were recorded in the module notebooks.

4. [rill For Additional posts If Required. lloles were drilled for four or six additional fixed posts if required. Before the drilling was started, the slots dom into the coupling cavities in the bridge coupler assembly would be plugged so that chips would not fall down into the end cavities of the tanks. A fixture that clamped to the bridge coupler wias used to support a portable electric Jrill in position while drilling. While the 


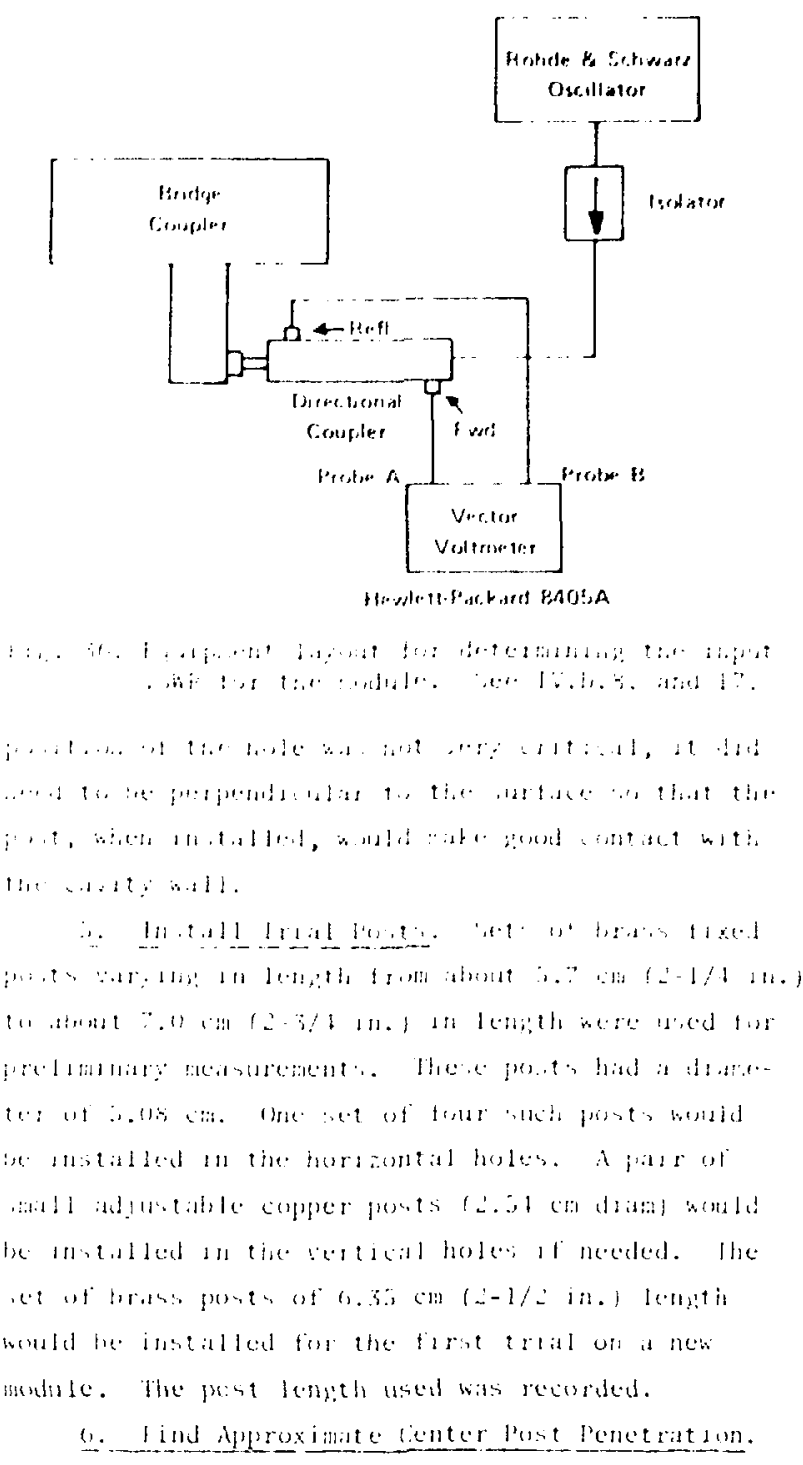

The penctration of an unatiched center post was adjusted by hand and the adjustahle end tuners were moved 1 of or out uneil the $1 / 2$-mode frequency of the bridge coupler plus linat units on either side was close to the average of the $" / 2$-mode frequencies a the individual units, and unt il the noarest modes of the combined structure were approximately symet rical about the $/ 2$-mode. The required center post spacer length was then recorded.

\section{Install center Post. The center post was} installed with a spacer of length determined in Step 6. The center post and the adjustable end tuners were then set unde: vacuum such that the $\pi / 2$-mode frequency of the bridge coupler plus linac units on cither side was within $\pm 1 \mathrm{kHz}$ of the average of the $\pi / 2-$ mode frequencies of the individual units, and

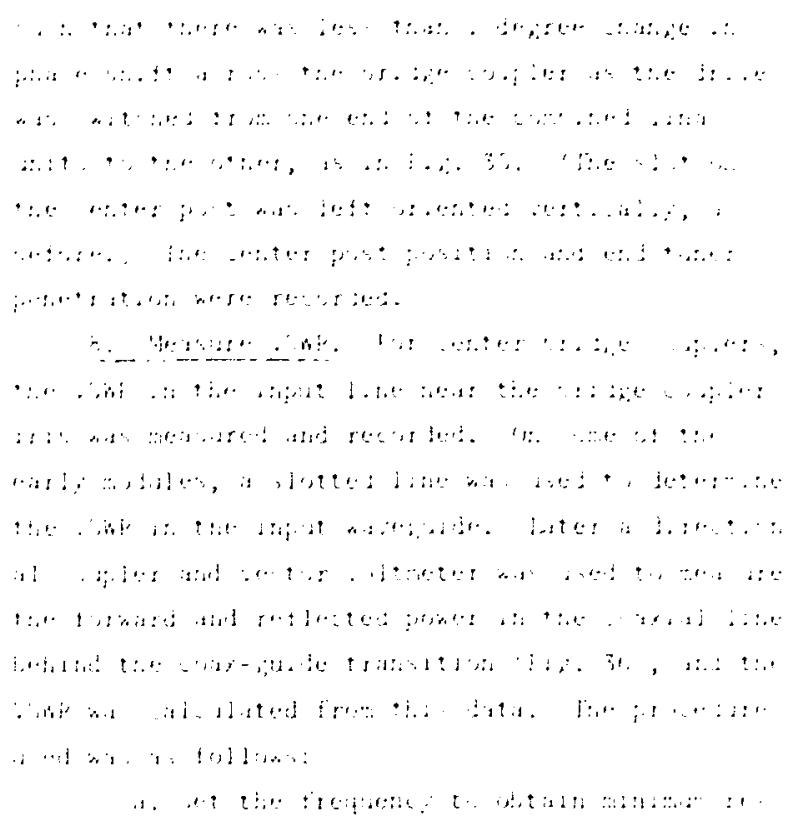

Whether the irst was anercoupled or was undercoupled could be detcrinded by making use of the fact that the impodance jocus for the iris and andwe did encirsle the center of a smith chare plot if the iris was overcoupled, but did not if it was malercoupled, for frequencies near the -12 mode. The question was resolved without actually drawing surh a graph, as follows: Probe a of the vector voltineter was connected to the forward output of the coupler and probe $B$ to the reflected output. The phase meter was set to zero using the largest scale ( $₫ 180$ degrees). The frequency was then varied from resonance to a point for which a maximum in reflected amplitude was reached. If the phase moved in one direction but then returned to near zero as this frequency variation was being made, the iris was undercoupled. If the phase did not recurn to zero (but generally kept moving in whatever direction it started), the iris was overcoupled. 


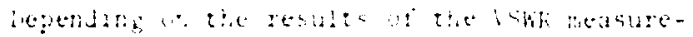

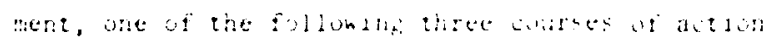
nere tahen:

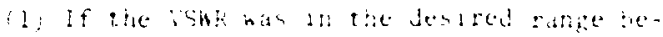

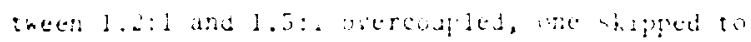
52011.

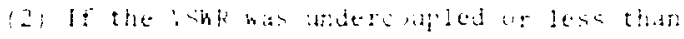

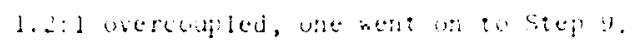

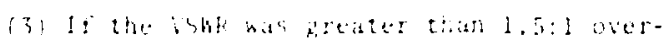

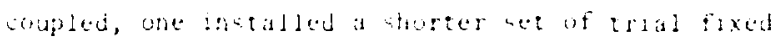

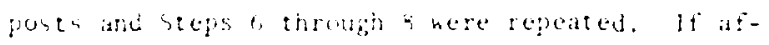

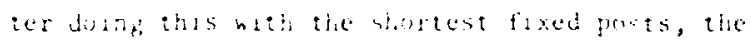

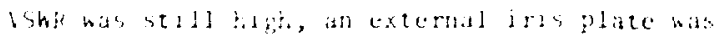
machated and cat by trat to the proper size. The

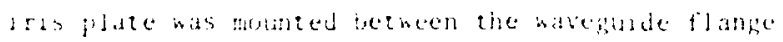

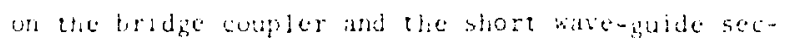
thon leadelis to elic ri indow.

bencrally the procedure went grablally enough

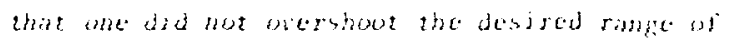
Shik. It nas unly on bradge couplers that were changed from one post to tile posts for the like) ateer the iris had already peon colarged that casts

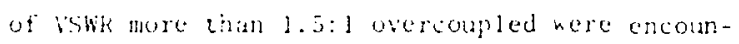
tered.

9. Inlarge Iris. A siecial fixture bolted to the waveguide flange on the center bridge couplers was used to hold a heary-dyty power drill in position for milling the iris to a larger sizc. As in Sten 4, precautions were taken to prevent chips from ertering the linac sections below.

If there was room to enlarge the iris longitudinally, the racetrack was made longer and the length recorded. Steps os through 8 were then repeated using the same trial set of fixed posts.

If the iris was already cut to maximum size, with the racetrack extending all the way to the stainless stecl waveruide $f l a n g e$ at top and botton, a longer set of trial fixed posts was installed and Steps 6 through 8 repeated. In a few cases. even the longest posts did not bring the VSWR to 1.2 overcoupled. In this event, the iris was cut to approximate a rectangular siape by using a smal1er radius to enlarge the four portions of the opening corresponding to corners.

10. Install Permanent Fixed Posts. Four fixed copper posts were cut to the length of the successful trial posts and were installed in the bridge coupler. (The water cooling passage in

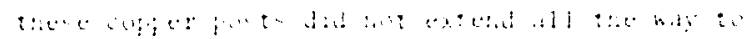

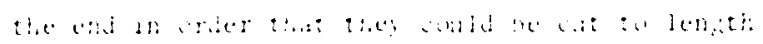

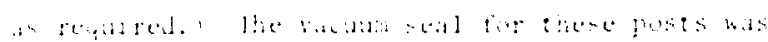

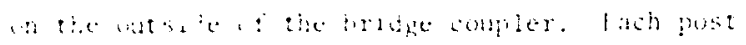

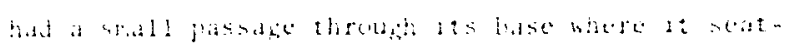

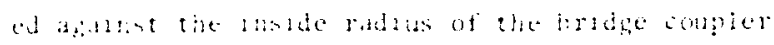

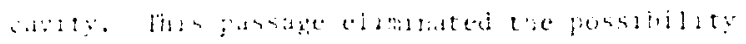

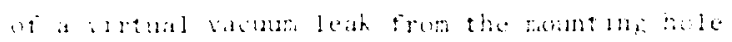

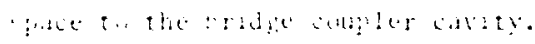

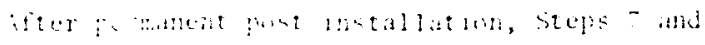

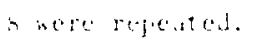

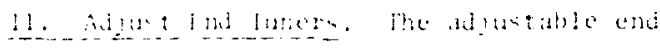

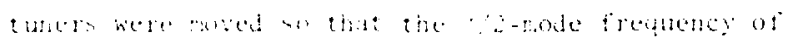

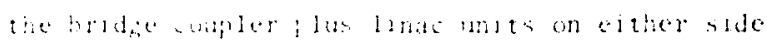

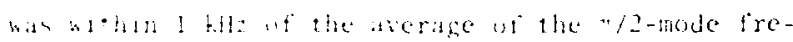

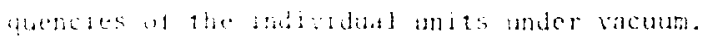

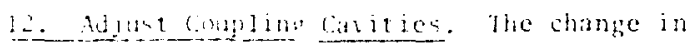

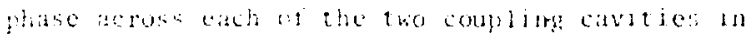

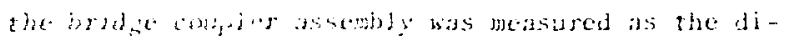
rection of dial was changed. a vector voltmeter and 1 probers thatit inta the adiustable end tunes of the ardace ceapler abore and $\mathrm{d}$ probes insered along the bean nole and the tistet accelerating cavity beIow acro used. isectig. 35.$)$

If the phase change was greater than 2 or 3 deprees, the frequency of the coupling carity was adjusted. To lower the frequency, the flat sides of the coupling callity were tapped or squeezed together. To raise the frequency, the side of the carity towards the middle of the bridge coupler was pulled out, thus moving its reentrant bosses farther apart. Two machine nuts brazed to the outside wall of the cavity together with a special wrench that spanned the side of the cavity were used to do this, as in $\mathrm{Fig}$. 37. If a large uphard correction in frequency has required, a hydraulic cylinger was inserted in the bridge coupler through the iris and placed between the coupling cavity bosses. The cy1 inder was then expanded to force the bosses farther apart.

13. Adjust Phase With End-End Drive. The change in phase between tanks was measured as the drive point was switched from one end of the linac unit to the other. Electric probes were inserted along the beam pipe centerline to pick up signals from each of the end accelerating cavities underneath the bridge coupler to do this, as in Fig. 35 . The penetration of the center post in the bridge 

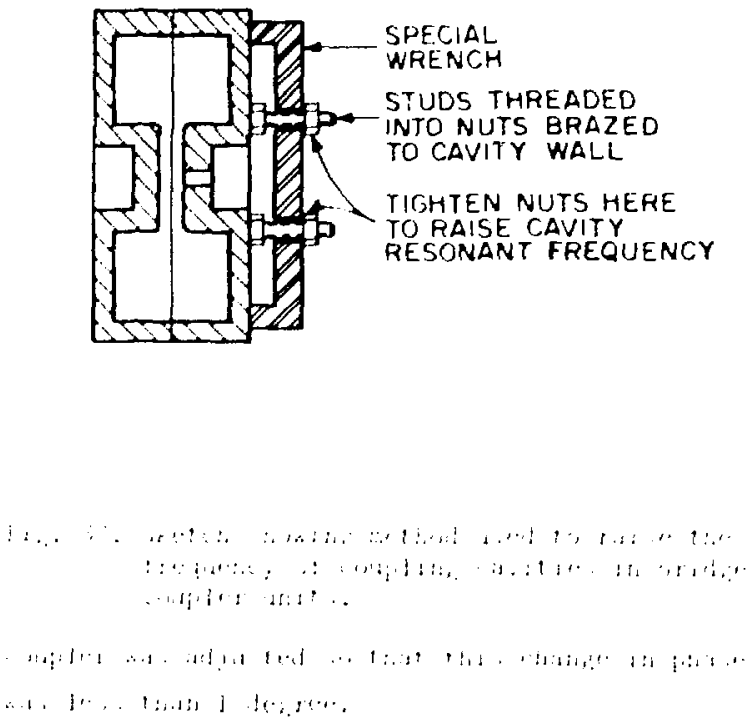

11. (1, t t +

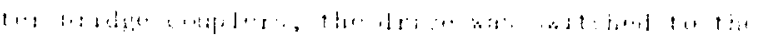

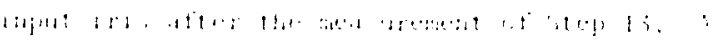

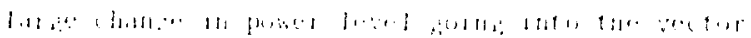

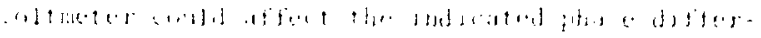

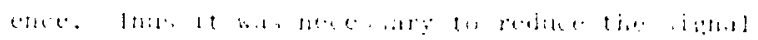

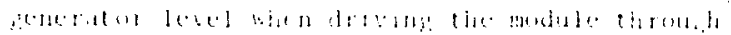

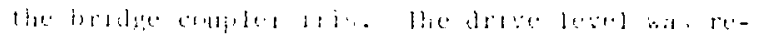

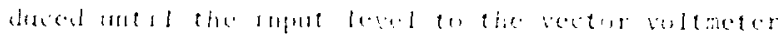

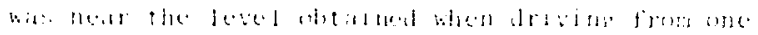

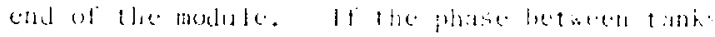

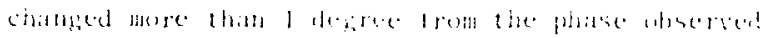

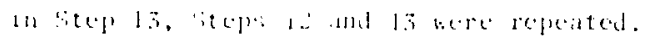

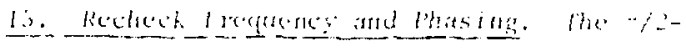
mole freguency was recheched [sec step ll) and the phasimg with ond-end amb conter drive wis recheched (sec steps 1.3 and 1.1 ) at this point and realjustod it nocosiats.

16. Measure Stopband. The modale stupinatol was moasured with the drive at one end of the module and the pichup point at the other end.

\section{Check iswik.}

a. No lixed losts lised. If no lixed posts tore used in the bridge coupler carity, the lsiti was measured (see IV.D.8. and Fig. 36) and the iris was enlarged (as in Step 9) until the VSWR was between $1.2: 1$ and $1.5: 1$ overcoupled. Steps 15 and 16 were repeated after each cut.

b. Fixed Posts Used. If fixed posts were used in the bridge coupler cavity, the iris had pre-

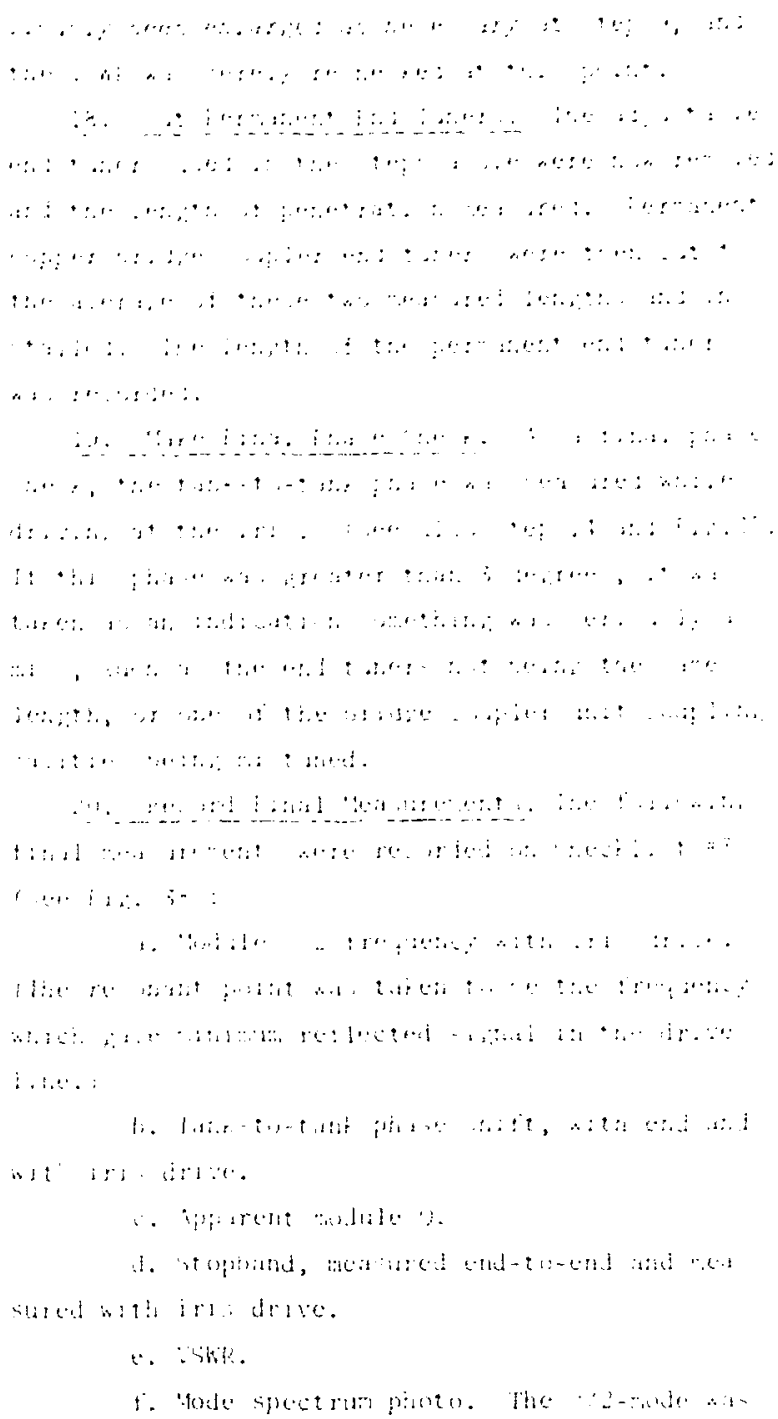

positened on the center cross marks it leat a a modes on either side were shown. flbotos and atse? intormat ion maty ustall ly be found in laboritory ne: book k-223es if not given on tis Chechlist $=\vec{s}$ sheot.

If the mode spectrum wis not symetrical about the "/2 mode for sereral modes, it might indicate the hridge coupler did not have the right number or lingth of fixed posts. (A spectrum with mods. pairing often could be observed before the coupling ciuities below the bridge coupler were tuned - Step 12. There should not be mode pairing at Step 20.)

21. Set H-Probes. The monitor loops (11-probes) were part of the tanks, rather than of the bridge couplers, but are included here since they were set at this point in the tuning sequense.

The monitor loops were adjusted to deliver a nominal 10 watts of peak power when the tanks were 


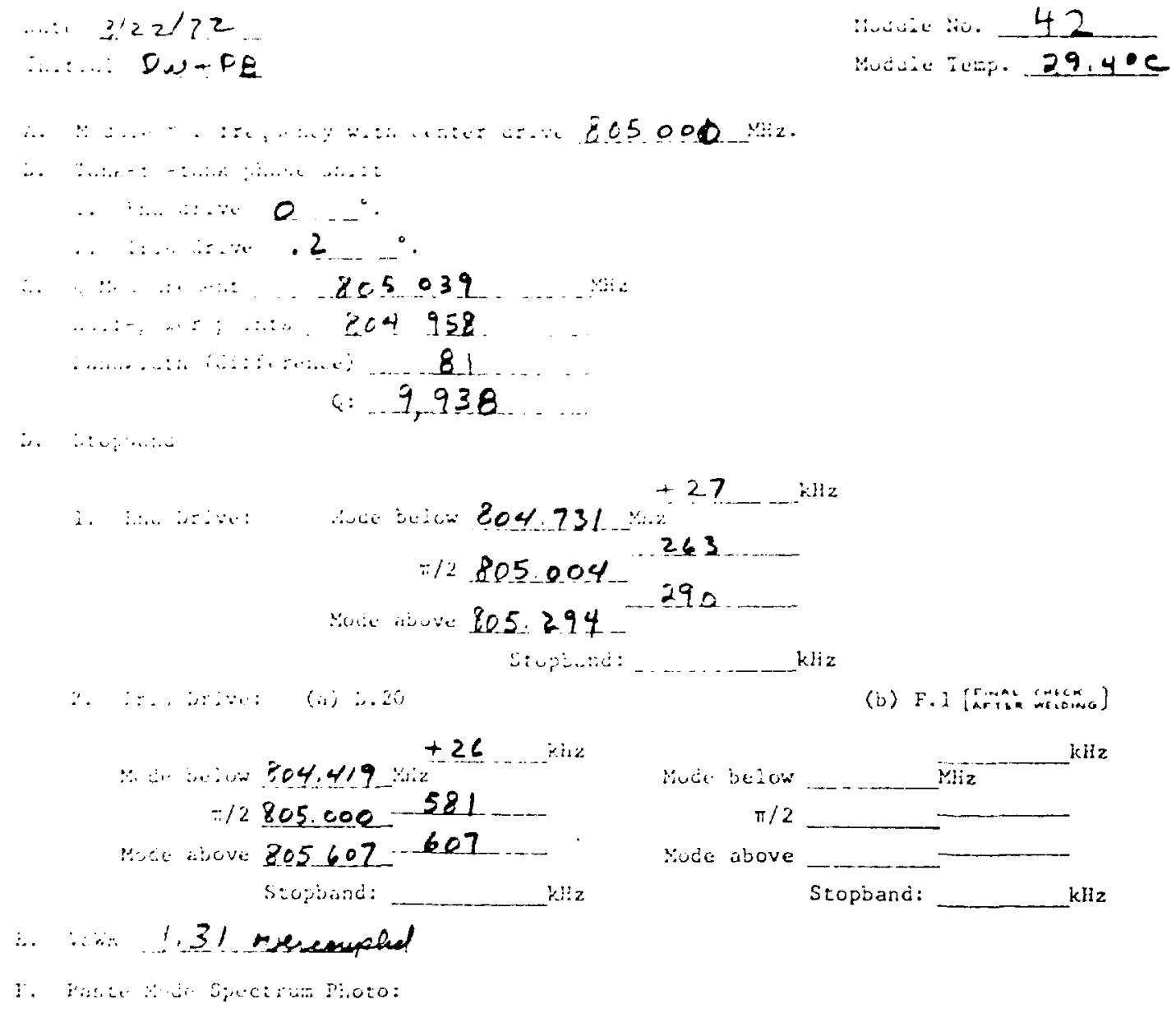

Fig. 38. Example of CHECKLIST 3: FINAL MODULE MEASUREMENTS datasheet used in IV.D.20. and IV.F. These sheets were filed in the module notebooks. 


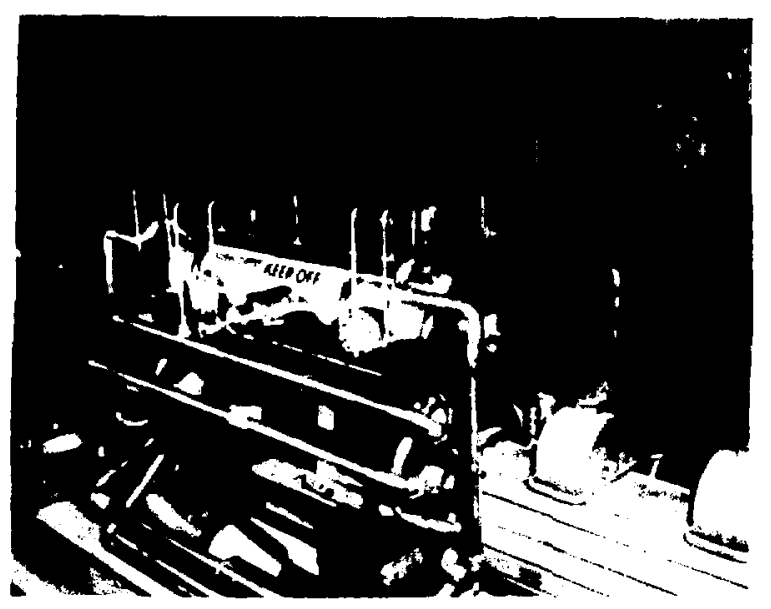

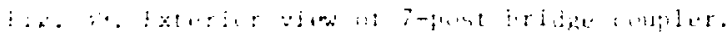

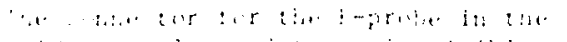

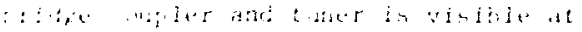

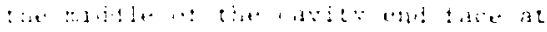

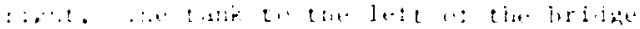

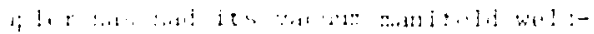

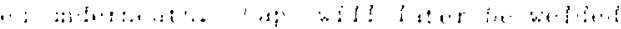

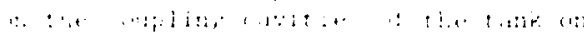

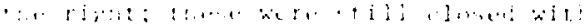

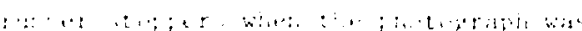
$\therefore+1,:$

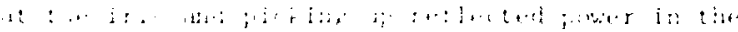

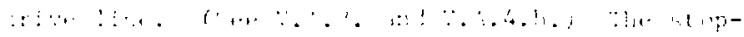

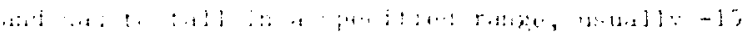

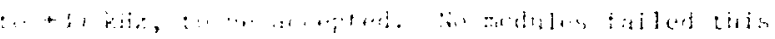

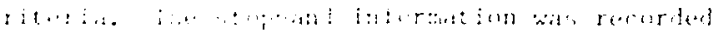

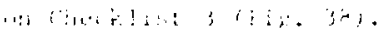

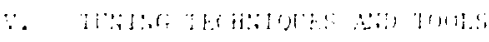

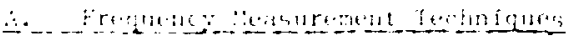

1. Exsonant Froguney. The standard method in mestetin single cavit: or cavity chain mode : reilereles wate an follows: Wwo electric or magati prober iare positinned so as to be lighty

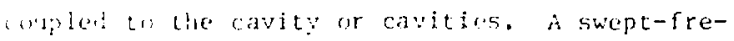
fruacy sinal was introduced with one probe. The rupporsis wit picked up by the other probe and display ! b vertical deflection on an oscilloscope ithose irstizontal deflection was synchronized with lie irequency sweep. (See Figs. 41 through 43 for (xamples of equipment set-ups.) The resonant modes appeared as inverted peaks in the horizontal trace (Fig. 44). A marker signal was added to this trace to permit accurate determination of the frequencies of the resonant modes thus displayed. Part of the signal from a stable signal generator was fed to a mixer-detector, along with the swept-fre-

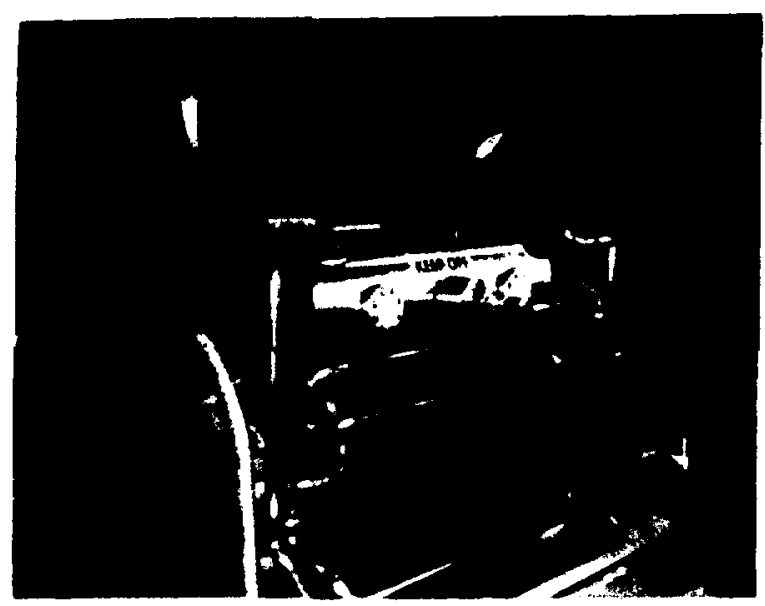

Hip. $\therefore$ H. Heterior vin of completed l-post bridge

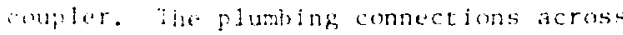

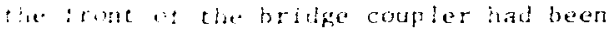

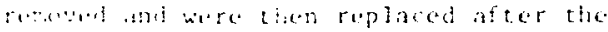

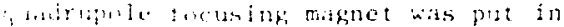

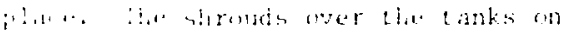

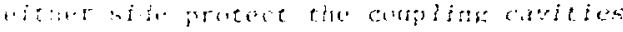

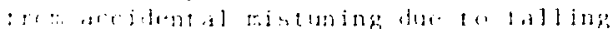

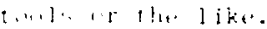

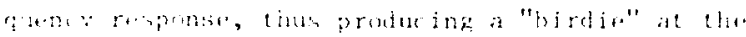

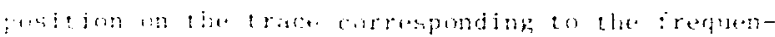

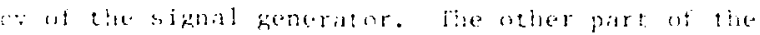
ijgal from the simal generatur was sulut to a soiler, where the cycles ri a suitably hetorodined sig nal were combed to parje a readout consisent to ferter than $1 \mathrm{kHz}$. When the marker was superimposed on the tip or one of the response peaks, the frequency (usualiy in kliz difference from 800 :9iz) was read of the scaler. The positions of the probes might then be adjusted slightly to check that the probes themselves were not perturbing the cavity frequency.

\section{Pi/2 Mode Identification. It was often} necessary to Jetermine which of a whole family of modes on the swept-frequency display was the $\pi / 2$ mode. A convenient way to do this was to introduce a perturbation (e.g., a shorting pin only partly inserted) in the coupling cavity at one end of the chain, and watch how this moved the modes in frequency. Since the $7 / 2$ mode had nearly no field in the end coupling cavity, but all other modes had some field in this cavity, such a perturbation shifted all other modes, leaving the $T / 2$ mode almost unaffected. Thus the mode that appeared not to move was the $\pi / 2$ mode. 


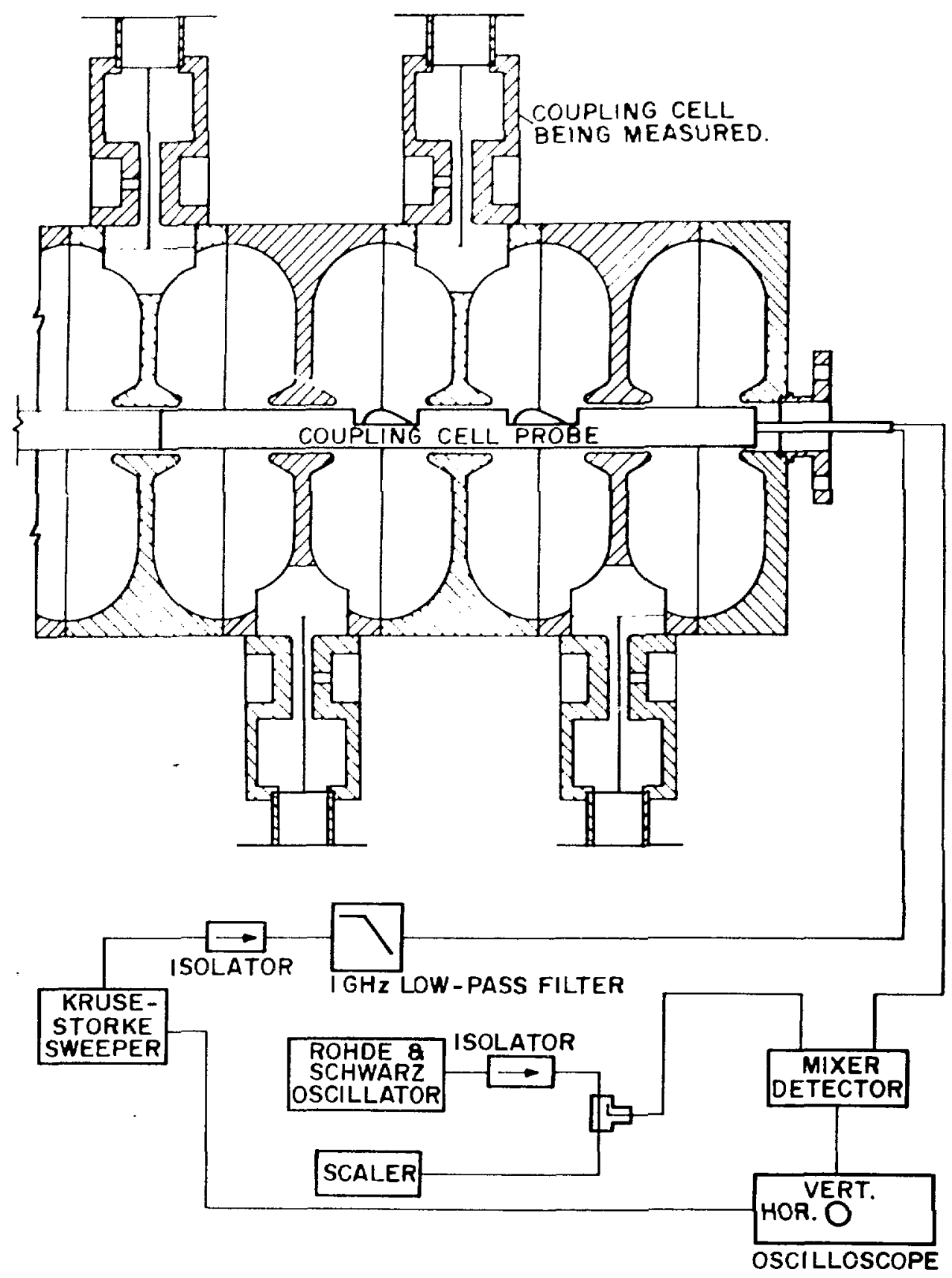

Fig. 41. Equipment set-up for coupling cavity frequency measurement. 


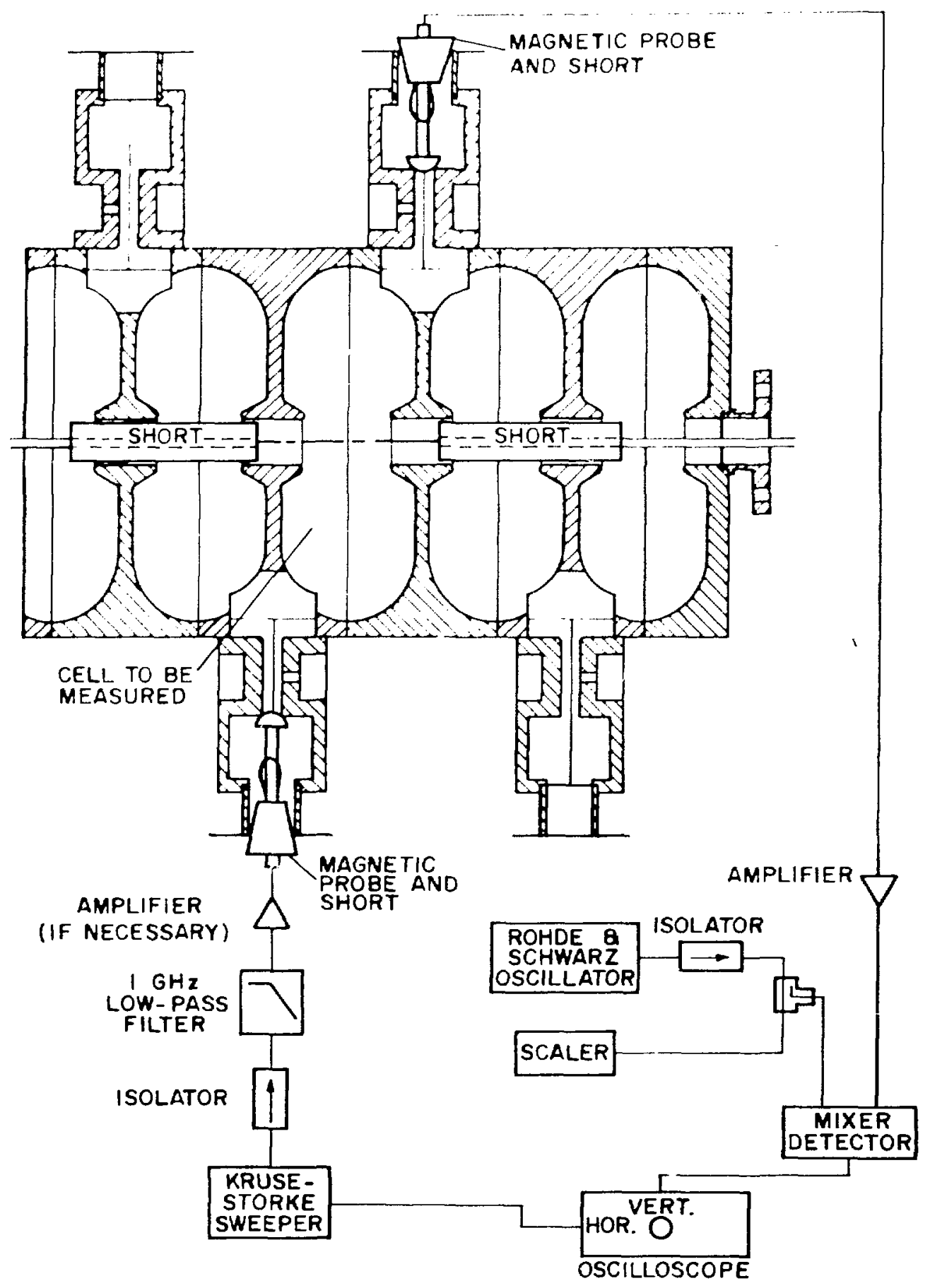

Fig. 42. Equipment set-up for accelerating cavity (main cel1) frequency measurenent. 


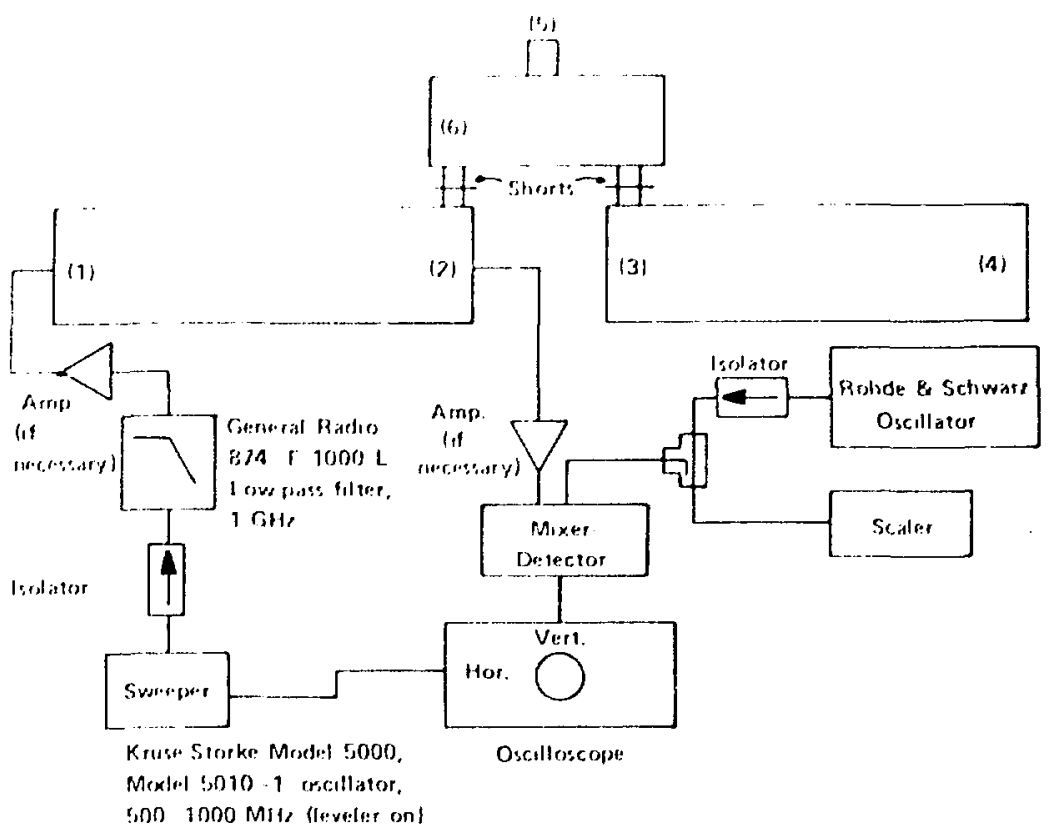

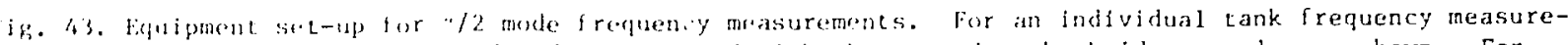
ment, probes (1)-(2) or (3)-(4) were used with shorts under the bridge coupler as shown. For module "/2-tecte freguency measturements, a special spacer with grooves for rubber o-rings and a wiveguide-to-cosplal transition were altached at the fris (5), and the shorts in the coupling cavities benoath the bridge coupler were removed. With the drive at ( 3 ), one put the pickup at (6). If drivjng at (1) and picking up ac (4), a 50 ohm terminatinn was used at (5).

3. Stophand. The term stophand, as used in the aning process, was defined as the difference in mede spacing on either side of the t/2-mode frequen$: y$. If $f_{a}, f_{b}$, and $f_{:} / 2$ designated the frequencios if the mode above, the mode below, and the $" / 2$ mode, espectively, the stopband $s$ was determined by

$$
s=\left(f_{a}-f_{T / 2}\right)-\left(f_{\pi / 2}-f_{b}\right) .
$$

his is an accurate determination of the stopband, caning the separation between passbands, when the idths of the passbands on either side are large compared with the stopband jetween them, as was the ase for the LMPPF 8D5-MHz accelerator structures.

The equipment set-up for stopband measurements as as shown in Fig. 43. For tank stopband measureients the probes $(1)-(2)$ or $(3)-(4)$ were used with horts in the bridge coupler coupling cavities as hown. For module end-to-end stopband determinaions, the shorts were removed and probes (1)-(4) rere used, with the iris (5) properly terminated. 'or the determination of module stopband through the
Iris, the shoris were removed and the drive was placed at (5) and the pickup at (2) or (3). (Formerly the pickup was placed at (6), but iris-end cuner probe: interactions sometimes perturbed the results. See V.A.4.b. below.)

\section{Possible Pitfalls in Frequency Measure-} ments.

a. Poor Contact by Shorting Pin. In measuring the resonant frequency of a linac cavity or tank, the neighboring cavities or parts of a module are isolated by means of shorting bars or pins. Usually there was no trouble experienced in using the coupling cavity probe - if it was long enough, the isolation was satisfactory. However, when one was using the accelerating cavity probes or using shorting pins to isolate a single tank of a module, one had to check that the shorting bars or pins made good contact, or the resonant modes of other parts of the structure would perturb the frequency of the desired cavity or section. One way the tuners used to detect that a short was not making good contact was to notice if the swept-frequency response on the oscilloscope was broader 


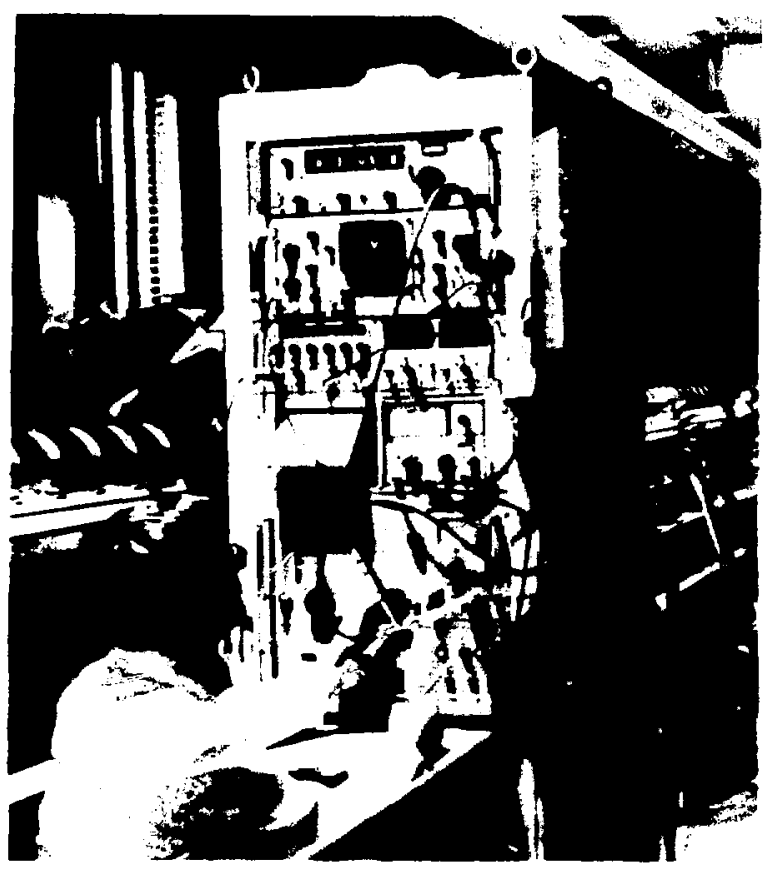

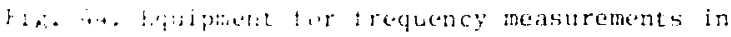

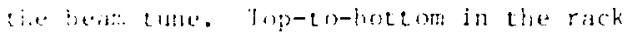

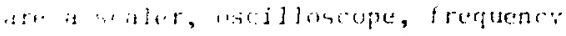

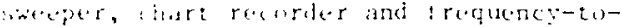
altase woverter, and signal generator. ine conjling raytios on the tank at loft hale suretine pins held in place with large rutier bende, which wis tine shorting metiend lacel before the combines probe and

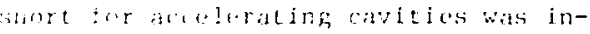
$\because \cdot 1,21 \cdot 1\}$

than usual or the tank ') lower, since a poor short ustatily lowereid the of of the resonance in question. b.-. Iris Is is idge Coupler End Tuner probe Interaction. There is an indication that a siznal non-resomant ly coupled from the iris to the E-probe in the end tuner of a bridge coupler can perturb the results of stopband or module Q measurements made using the E-probe. Stopbands as measured using this probe may differ up to $10 \mathrm{kHz}$ from stopbands measured using an E-probe in one of the end accelerating cavities.

One may envision the iris to be counled to the E-prote by means of some spurious 1 ow- $Q$ mode in the bridge ca: ity, perhaps a $\mathrm{TE}_{113}$ vertical mode near the module $\pi / 2$ mode. The spurious mode has very little energy other than in the bridge coupler, and thus distorts the swept-frequency response observed in the bridge coupler as compared with that observed elsewhere.

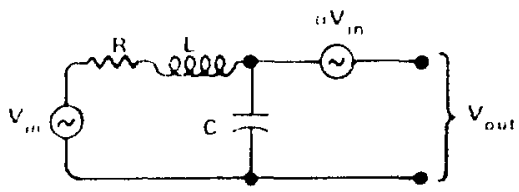

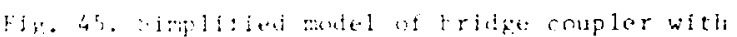

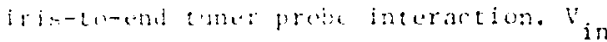
reprenento the irin drive and yout the end

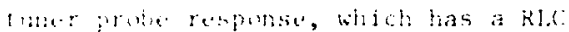
ar ies atonance lus a term proportional t" the trio. The torm th represents lae 1.20 .2 at some spurions mode in the

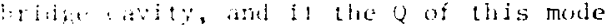
in mol lower tiant the normal resonant

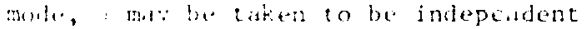

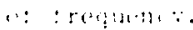

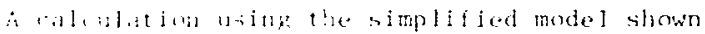

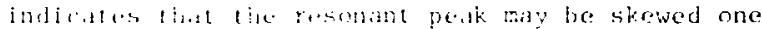
way or the uher, or in the symetrical case, may

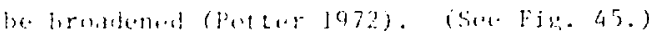

oficturtion of any or all of the three peaks used in a sopband masurement would perturb the result of the meisurement. Symmetrical or unsymFiet $r i c a l$ broadening of the response peak makes the moasured ? lower than when such distortion is not present.

c. Apparatus Too Close to 1ris. Special equipment, such as a waveguide-to-coaxial transition, should not be mounted directly upon the llange at the drive iris, since the resonant frequency of the bridge coupler cavity may be perturbed. A special waveguide spacer with grooves for rubber $0-r i n g s$ and a window assembly were generally used between the iris and the transition. This permitted measurements under nitrogen or under rough vacuum as desired. If the iris was not being used as a drive point, a $50 \mathrm{ohm}$ termination was connected to the coaxial end of the waveguide-tocoaxial transition.

d. Humidity Effects. Variations in humidity in air-filled cavities may result in changes in resonant frequency of as much as $30 \mathrm{kHz}$. For this reason, a trickle of nitrogen gas was kept flowing through the 805-MHz linac modules for all final tuning operations at atmospheric pressure. (See also IV.A.1.) 
E-

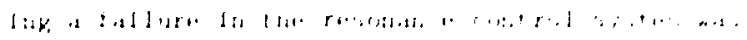

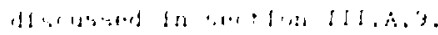

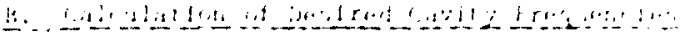

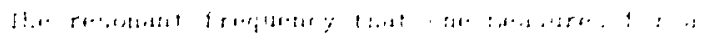

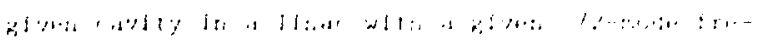

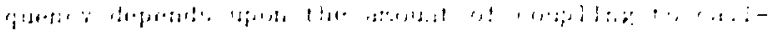

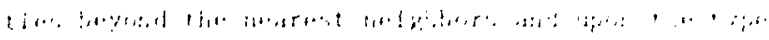

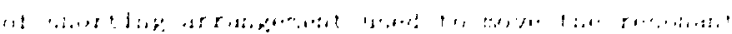

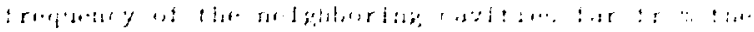

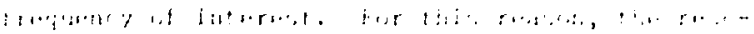

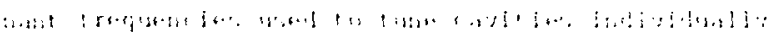

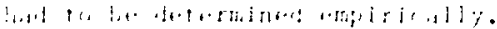

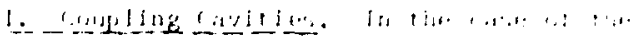

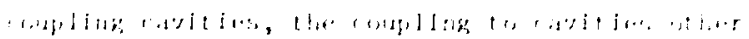

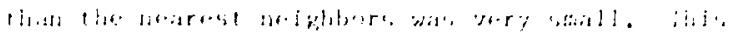

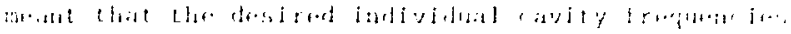

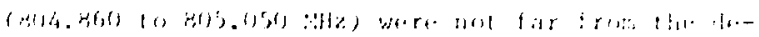

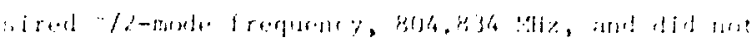

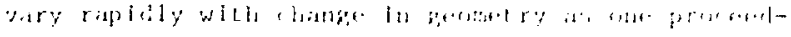

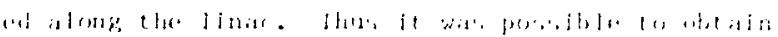

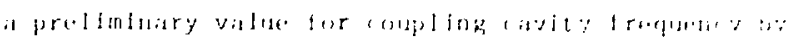

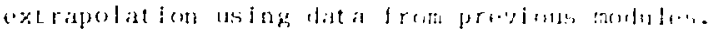

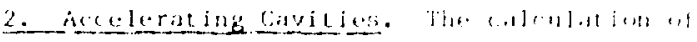

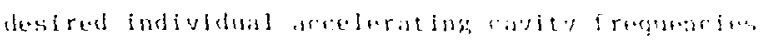
was based on selected reseldth from the theery al

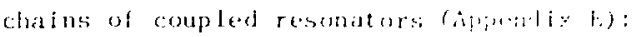

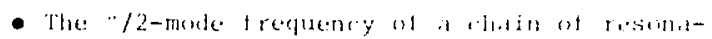

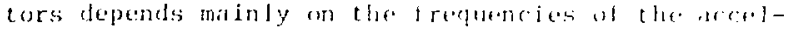
erating resomalors, since the coupling resonateras contain very little entrgy in this mode.

- To obtain a stable field diteributin, tib interior accelerat.jng resonators shomld all be taned co a single frequency, $f_{j}$, but the end acculerating resonators should be tuned to a diflerent fremaency, $f_{e}$ These frequencies are related to the $: / 2$-mode Irequency, $f_{\| / 2}$, and the amount of coupling directly between accelerating resonators (second nearect neighbor coupling), $k^{\prime}$, by

$$
\left(f_{i} / f_{\text {T: } / 2}\right)^{2}=1-k^{\prime}
$$

and $\left(f_{e} / f_{\pi / 2}\right)^{2}=1-0.5 k^{\prime}$.

- For a chain of resonators in which any one accelerating resonator contains as much energy as any other, the effect of a frequency error in any one accelerating resonator on the $\pi / 2$-mode Erequency

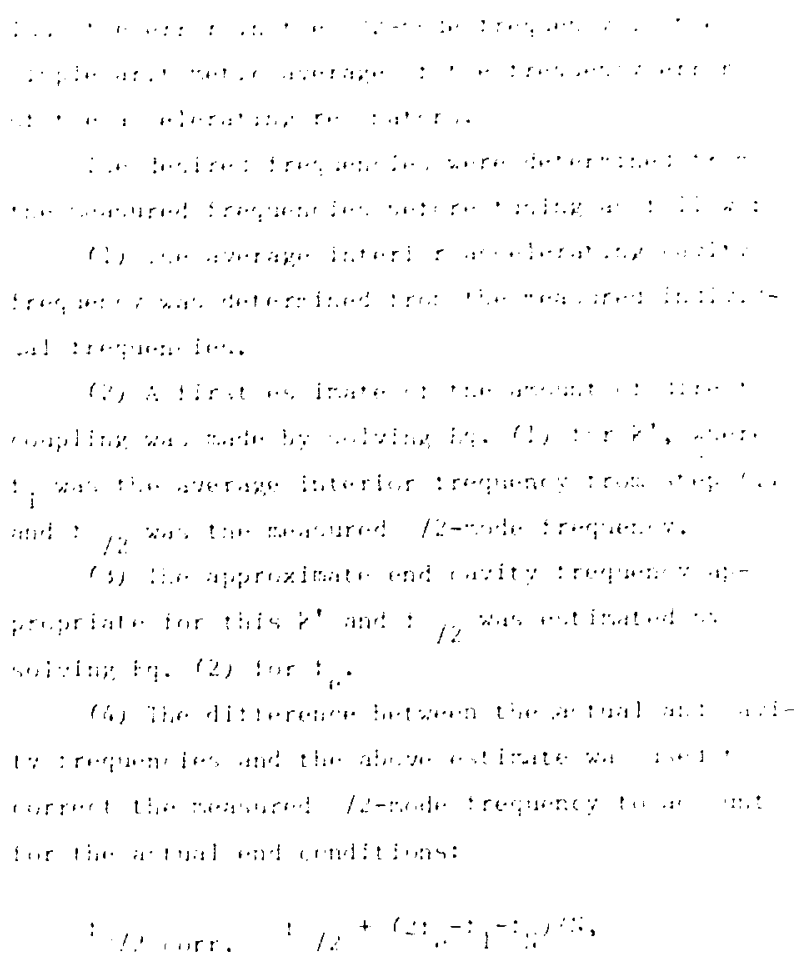

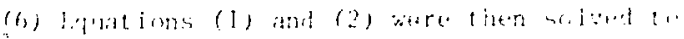

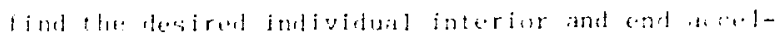

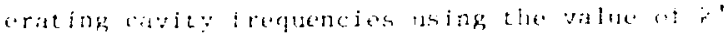

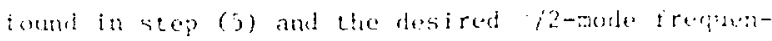
(')

The ahove calculation was implomented in prattice by the use of a Hewlett-packard 9100-i programable calculator. The algoritlm was coded ama saved on magnetic program cards. Jater, the alinrithm was incorporated in a prosman for gencerating forms for tuning data (program FFli)).

For nitrogen atmosphere and $22.2{ }^{\circ} \mathrm{C}\left(72^{\circ} \mathrm{F}\right)$, Fil. Tuning Laboracory conditions, the desired $f_{. / 2}=804.930$ " $1 \mathrm{Iz}$; for witrogen atmosphere and $29.4^{\circ} \mathrm{C}\left(85^{\circ} \mathrm{F}\right)$, tumel tuning conditions, the desired $r_{: / 2}=804.834: \mathrm{miz}$. These correspond to $r_{r / 2}=805.000 \mathrm{Mz}$ at $29.4^{\circ} \mathrm{C}$ under vacuum conditions. One manetic program card was set up for the calculations for FTI, and another card and the FFTD 


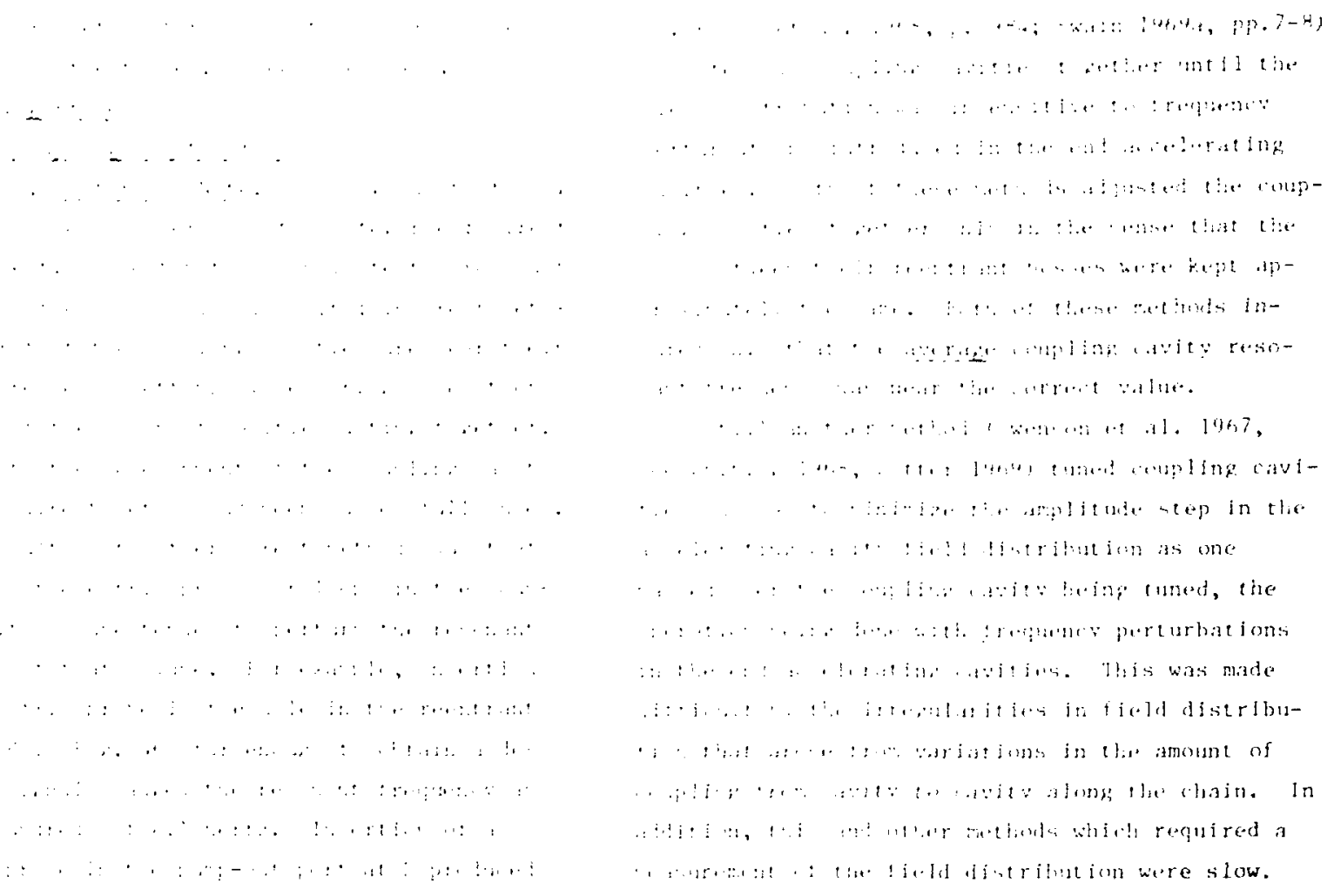

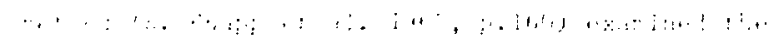

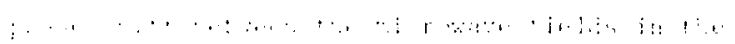

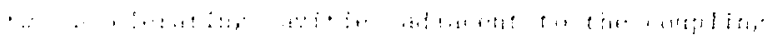

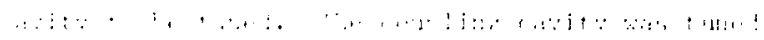

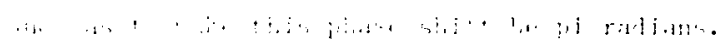

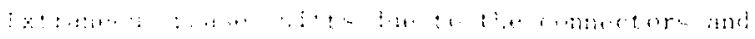

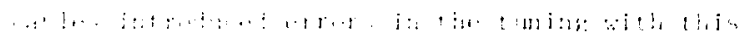

, , : $:, \ldots i$

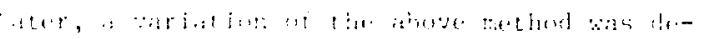

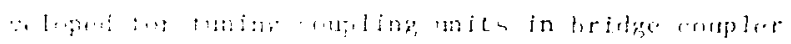

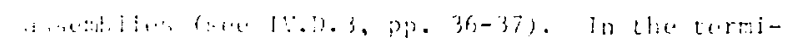

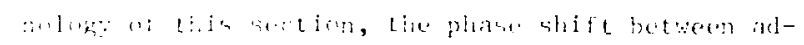
farent aneleratting resonaleres was monitored as the

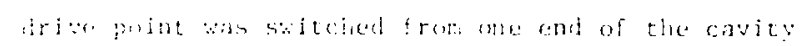

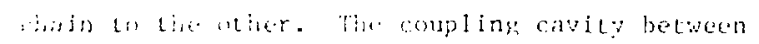
whe then adjused such tatat this plase shift did not chane as the direction of nel power flow was i.anged.

Wtace indirert methods exaraned the stopband or the ri field distribution of tike whole chain of cavities. one ard: method (B. Kapp 1966 ) adjusted all coupling cavitios together until the stopi) and was closed as determined from the spectrum of resonant modes of the cavity chain. Another method 


\section{(a) i fi. $\quad$ i.}

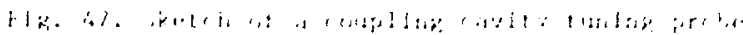

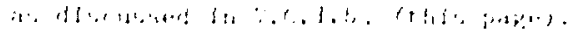

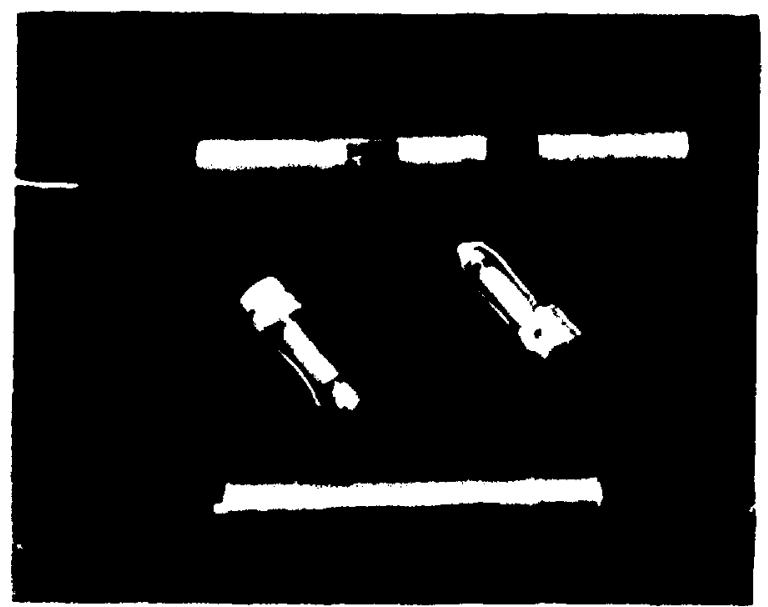

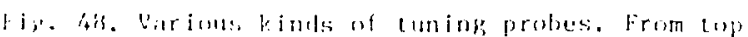

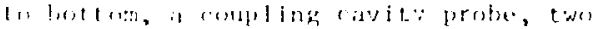

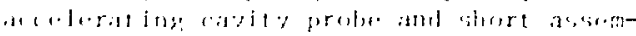

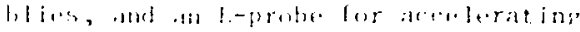

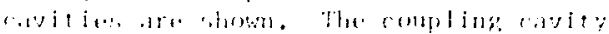
probe and the loprobe are imbrerted alomp

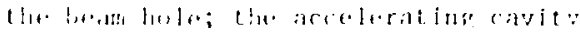

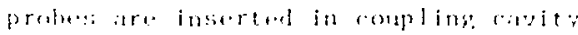
prort:s.

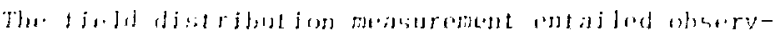

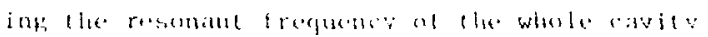

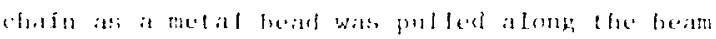
line an a tinf st rink, at t ime-consuming procelure.

All of these indirect metheses (with the possible (rxeption of the closent-sitopband method) sulfered frot: the fact that jn normal operation of any "/2-mode structure, the coupling cavjties have very little energy in them, and therefore any measurement on the structure as a whola was relatively insensitive to the resonant frequency of any particular coupling cavity. The motivation for finding a workable direct method was that the tuning could then be done quickly and accurately, with the individual coupling cavity resonant frequencies, as welI as their average, set to the desired value. A probe suitable for implementing the direct method was developed (Swain and Manger et al. 1970) in February and March, 1970 (which was after Module 5 was fabricated).

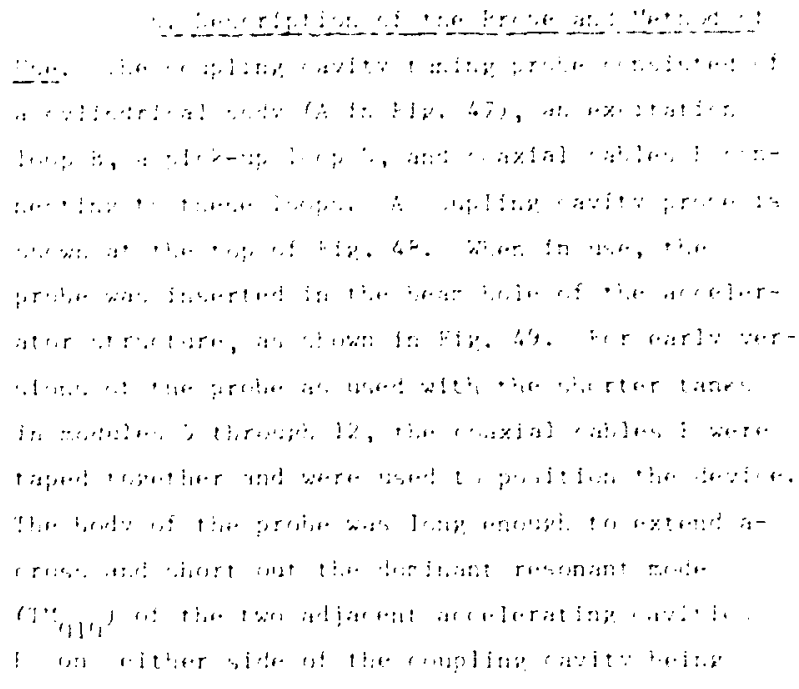

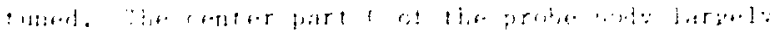

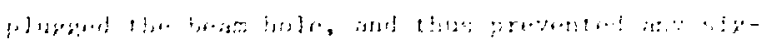

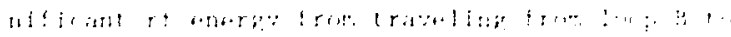

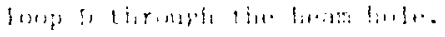

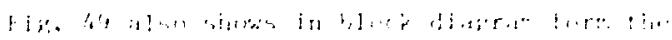

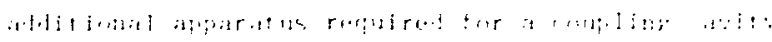

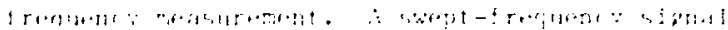

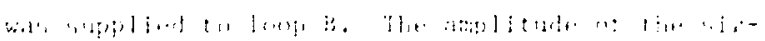

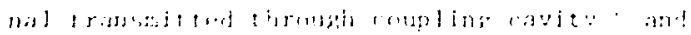

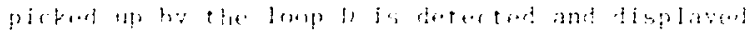

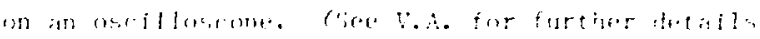

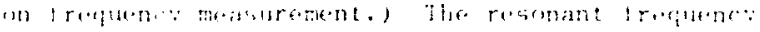

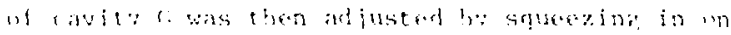
peinte a or pustions the reentrant bosises rarther upart with a weige inserted thrombl the port at 1 .

Short ing fins mighe be inserted at I to short out the cimpling cavities on the opposite side uf the structure from the coupling cavity being etsneds. It was later found that it was not necessary to short out the coupling cavities nn the opposite side, since the probe had a strongly directional characteristic. However, the apparent frequency of a coupling cavity read without shorts on the opposite side was slightly different from the reading with shorts. For example, the coupling cavities on Module 6 when measured without shorts appeared to be about $30 \mathrm{kHz}$ lower than when measured with shorts.

For the low-energy end of the 805-9. $\mathrm{Hz}$ linac, misorientation of the probe in the Iongitudinal direction until the detected signal fell to half its maximum value resulted in a frequency error of $25 \mathrm{kHz}$. Misorientation of the probe rotationally 


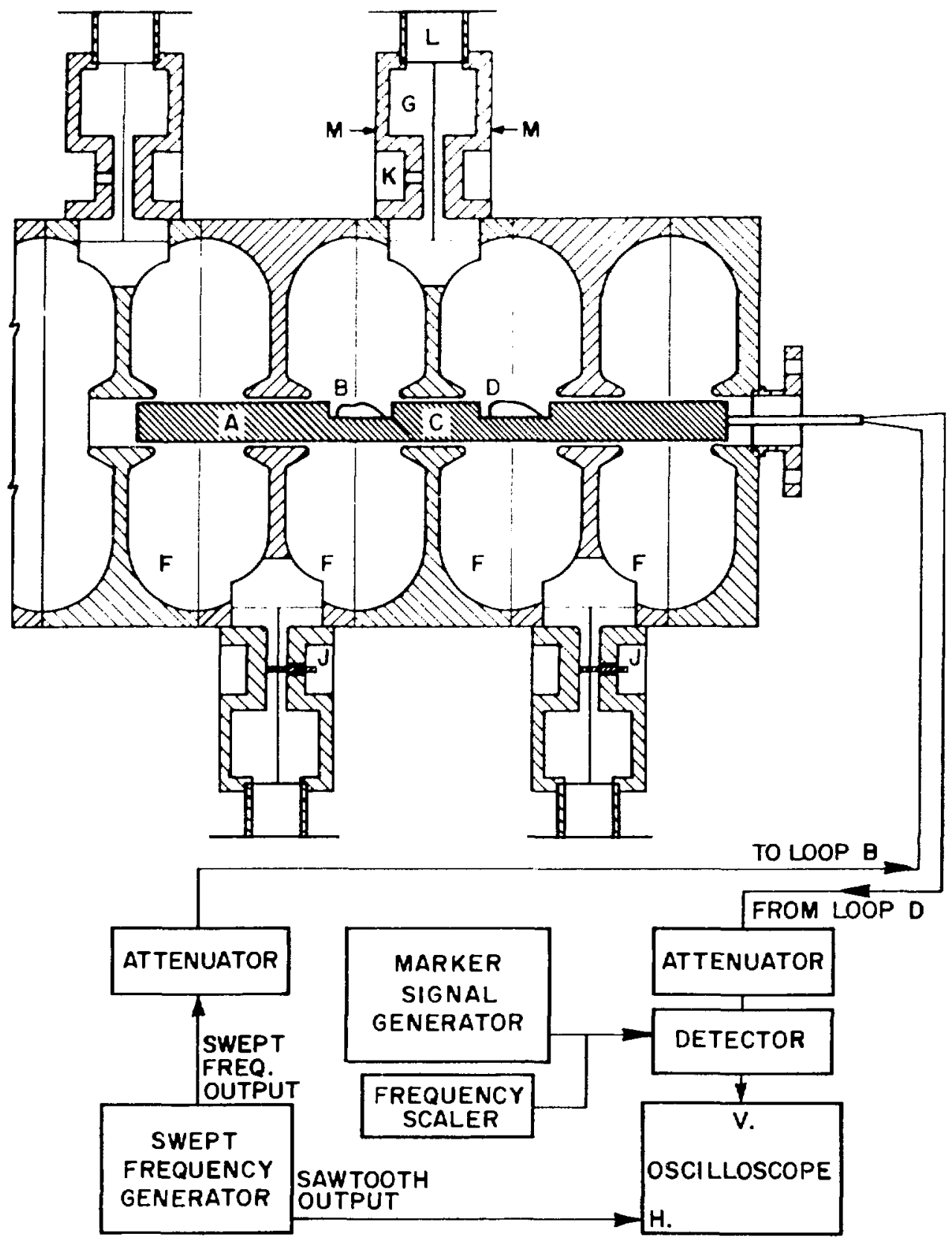

Fig. 49. Coupling cavity probe and other equipment needed to adjust the frecuency of a coupling, cavity (f). 


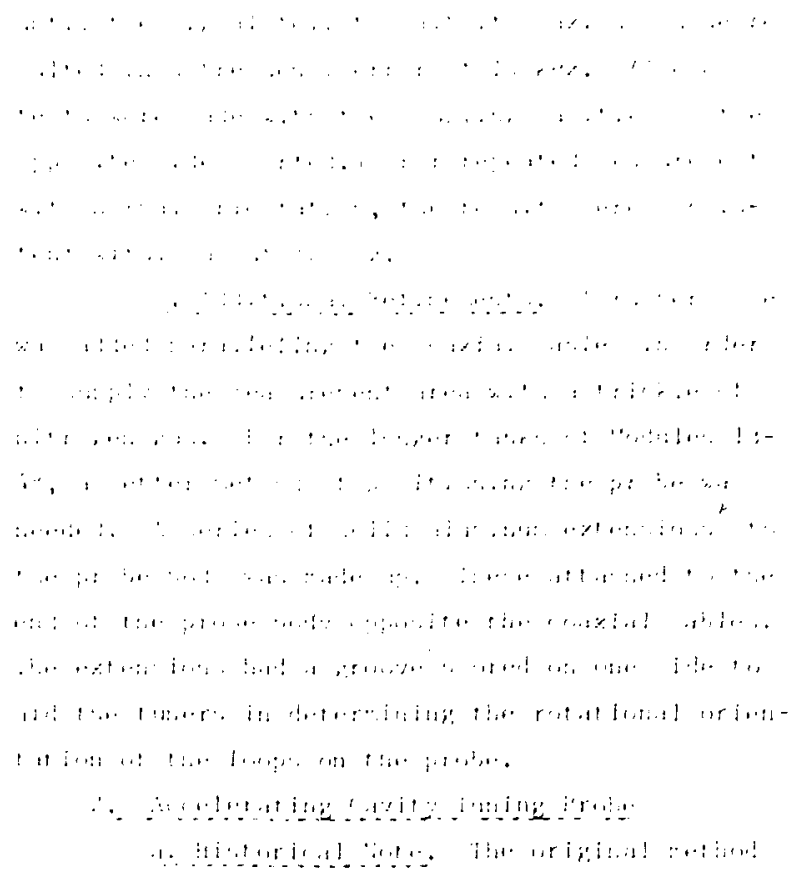

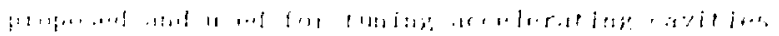

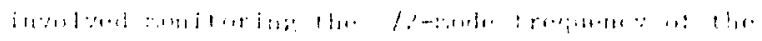

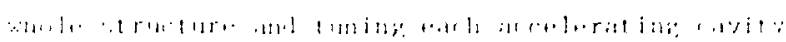

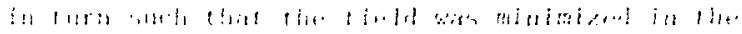

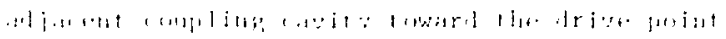

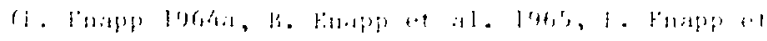

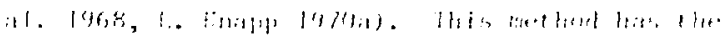

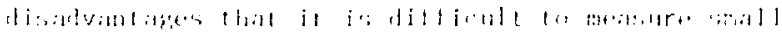

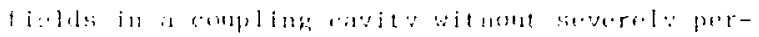

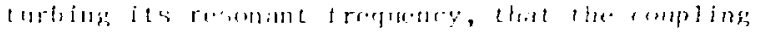

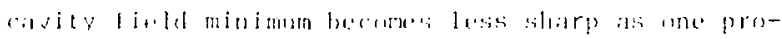

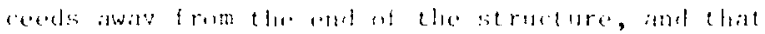

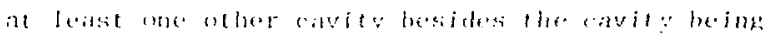
tumed must be anjusted an reble step in the laning provess in ureler to maintain the "/2-mode frequency al Lllo desired value.

A second methol of tuning acereleriteng cavitics was developod and tested on the lilectron Pro-

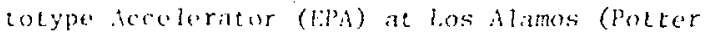
1969). In the socomd melhod, electrical shorts are inserted in the accelerating cavities adjacent to the accelorating civity heing tuned and also in the coupling cavitias adjacent to the cavity being tuned. (Various coupling cavity shorts were tried. One of the best schemes was a simple I-shaped copper pin, rounded at the ends, and held in place by a rubber band cut from an automobile tire inner "Suggested by Oliver Rivera. † Suggested by Dennis West.

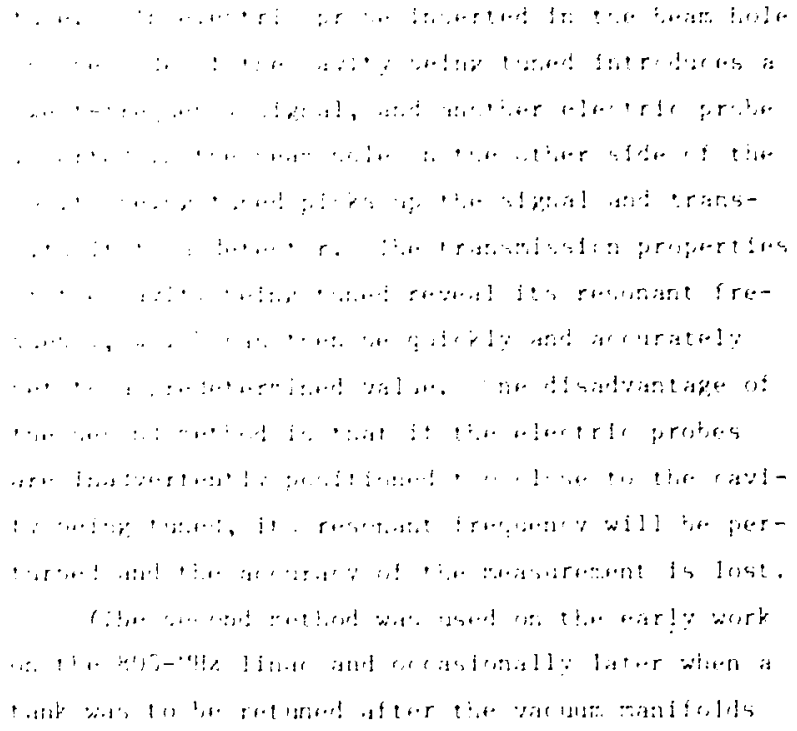
inf: the proximity of the dominant resonant frequency of these cavities to inlerfere with the accelerating cavity measurement.

Tests on necember 2, 1970, indicated that devices of this tupe may be used to set accelerating cavity rrequencies with a repeatability of better than $410 \mathrm{kllz}$ at $807 \mathrm{Mtiz}$. (Further experience showed that frequency measurements were repeatable within $3 \mathrm{kHz}$.

The tlind tuning method was used for the initral tuning of Module 14 and modules thereafter. The built-in shorts for the coupling cavities 

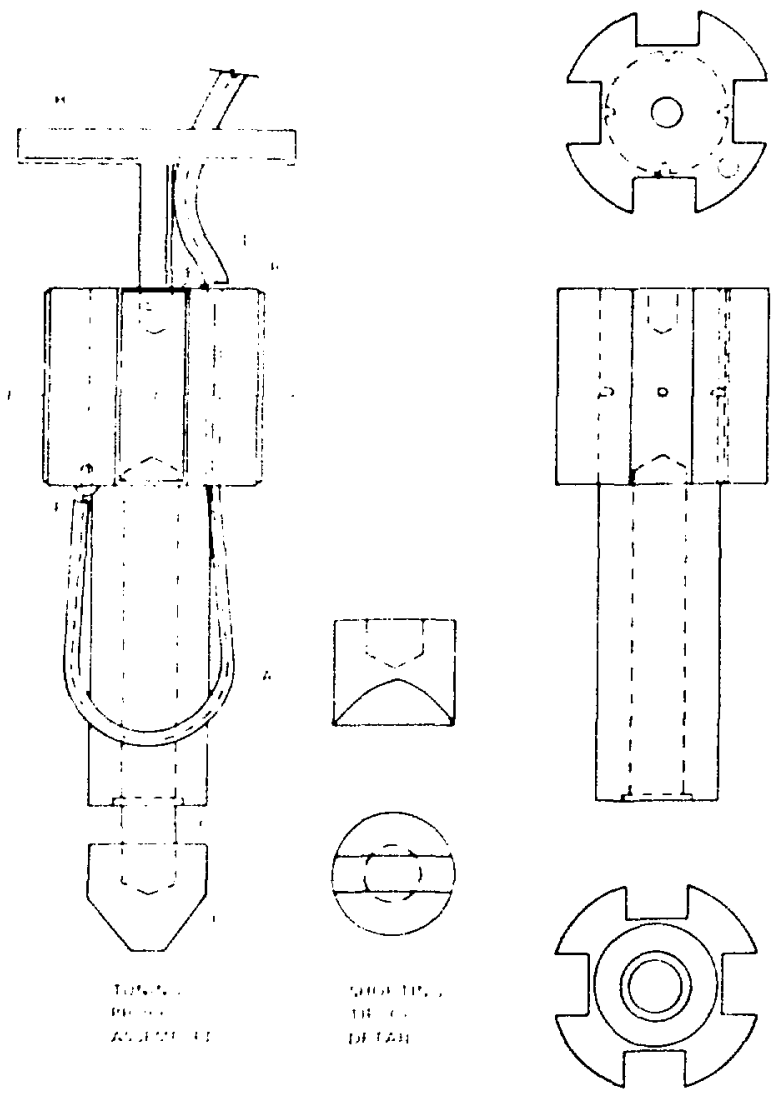

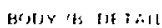

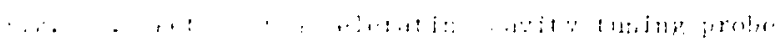

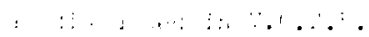

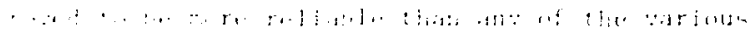

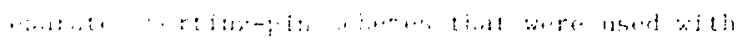

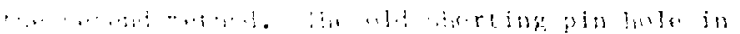

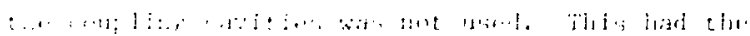

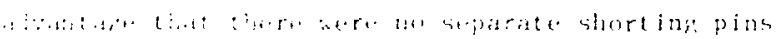

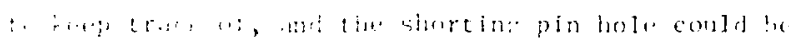

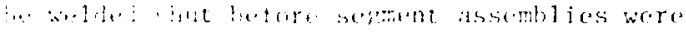

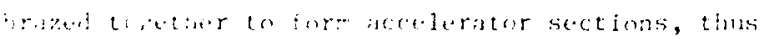

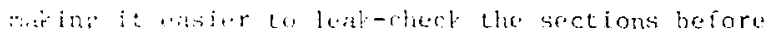
and ater instillation. In addition, the position-

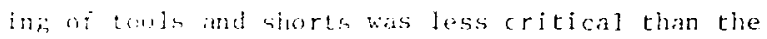

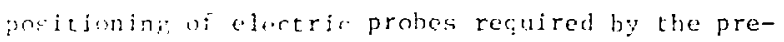
yidus nethod.

B. buscrotion of libe Probe. liach accelcrating cavity tining probe consisted of a manetic picklp (or exciter) loop, as slown at $A$ in Fig. 50 , an assemily $C$ whicis elrectrically short circuited the dominant resonant mode (TY10) of a coupling cavity, and an assembly $B$ which holds the above loop and shorting assemtly in proper alignment when in use.

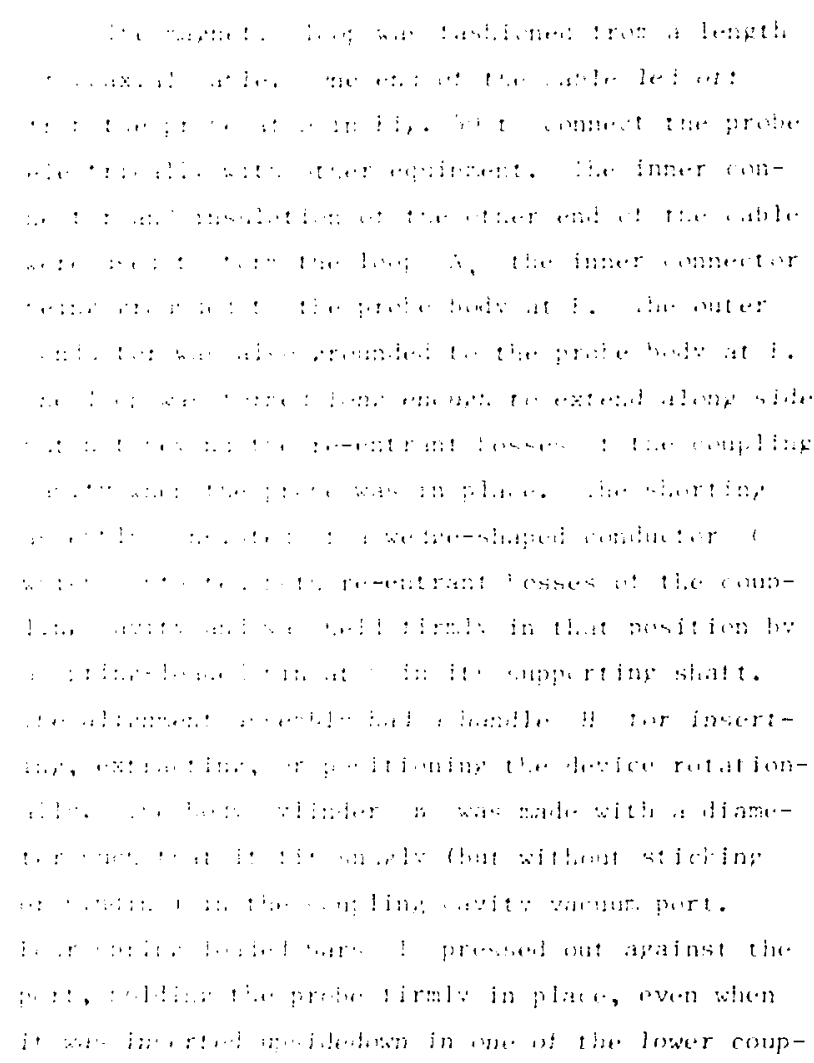

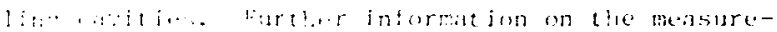

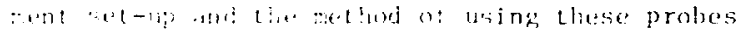

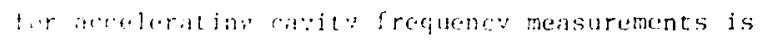

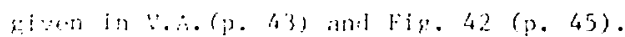

11. Tum 1136016

1. Sopturt Bending Tor:. The septum bending uon ? as designed" for use in the construction of the Flectron Prototype Accelerator. The tool was also used for the early tuning work on the IAMPF 805-iflz accelerator. After the dinging and nosestretching tools were developed, the septum bending tool was used for cavities which had joint flanges (which prevented use of the dinging too]) and for field flattening within a tank. (See also IV.B.6.a, p. 26.)

The tool was arranged so that the tuners could grip the beam hole wails between accelerating cavitjes and move the whole septum longitudinally such as to lower the resonant frequency of the accelerating cavity on one side of the septum and raise the Erequency of the cavity on the other side (see Fig. 26, p. 30). The tool consisted of an expandable

\footnotetext{
The septum bending tool was designed by W. J. Van Dyke.
} 


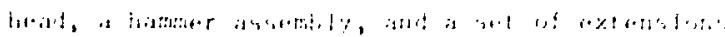

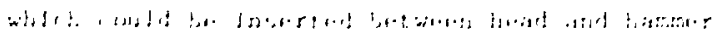

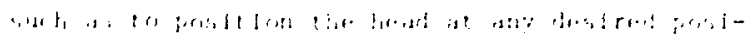

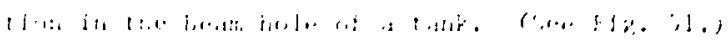
:

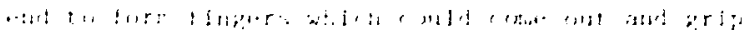

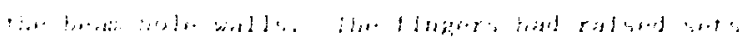

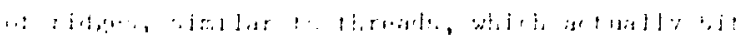

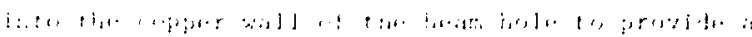

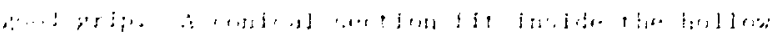

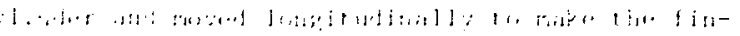

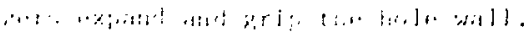

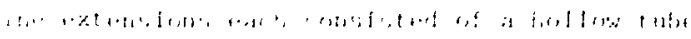

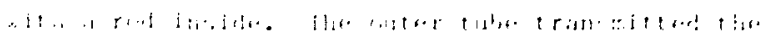

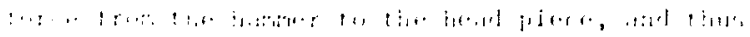

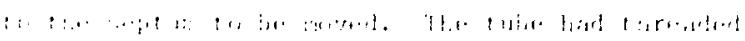

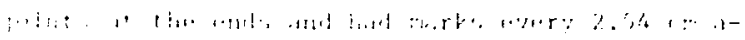

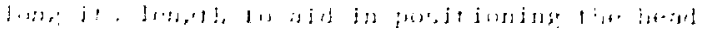

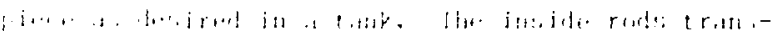

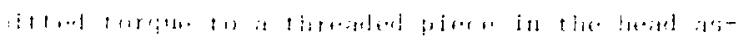

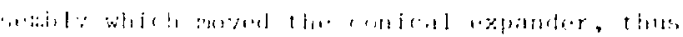

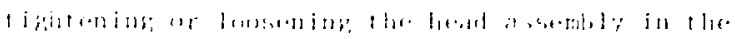

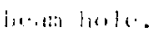

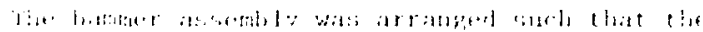

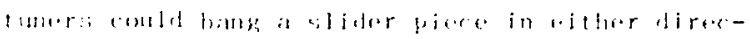

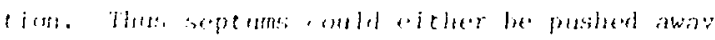
from ar pulled tout towards the cond of the tant from

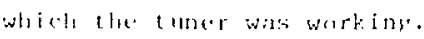

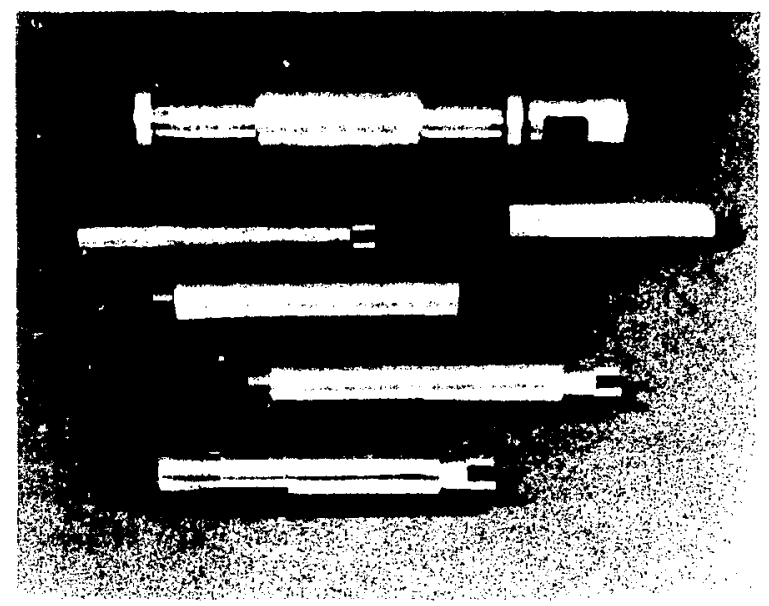

Fig. 51. Septum-bending tool parts. From top to bottom, a latmmer assembly, an extension interior piece and a handle for tightening the tool, an extension exterior piece, a set of extension pieces, and the expandable head assembly are shown.

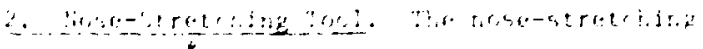

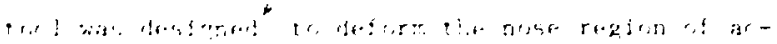

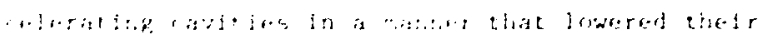

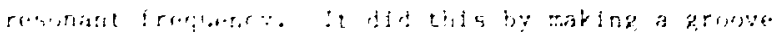

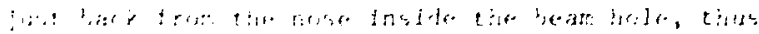

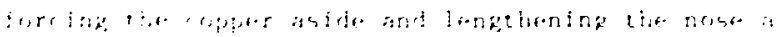

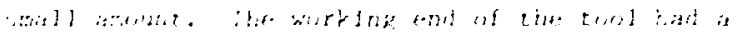

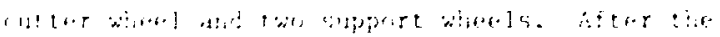

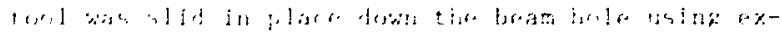

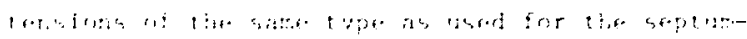

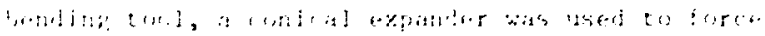
[

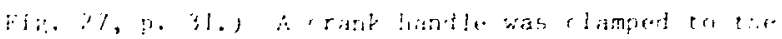

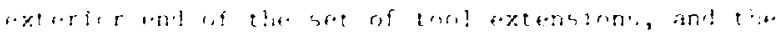

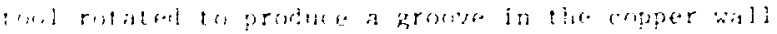

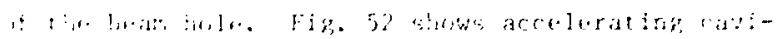

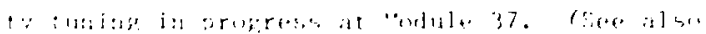
$\because \because \ldots$, , : , p. , , ,

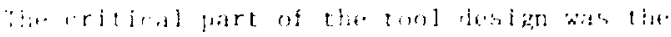

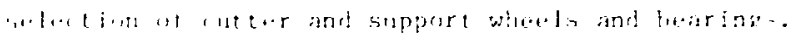

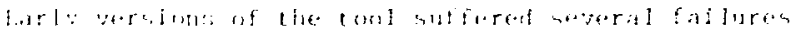

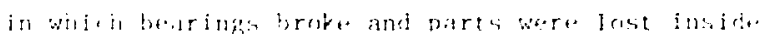

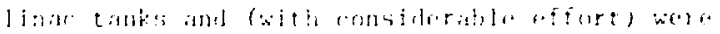

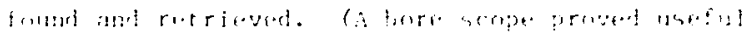

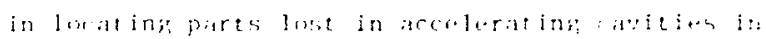
mill-tint.)

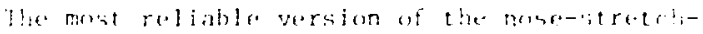

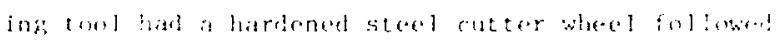
by a hardened and ridged steol follower whed and blen a llat follewer whecl. The cuterer and first rollower usod no sporial bearing; the second follower was a ball-bearing assembly. The stresses on these whecls were very high when the tool was in use. Uriginally two hall-bearing wheels plis the cuttur wheel were used. Replicement of the first fall-hearing wheel by the solid ridged follower wheel had two beneficial effects. It rediced the tendency of the cutter to move in an unwanted helical path instead of the desired circular path when one was enlarging the original groove. It also crushed any ridges or burrs left in the copper by the cutter wheel, thus leaving a smooth surface relieved of stress for the ball bearing to roll on. The reliable design retained the second ba11-bearing wheel, since the flexibility of the bearing

\footnotetext{
*he nose-stretching tool was designed by D. Liska and R. Kandarian.
} 


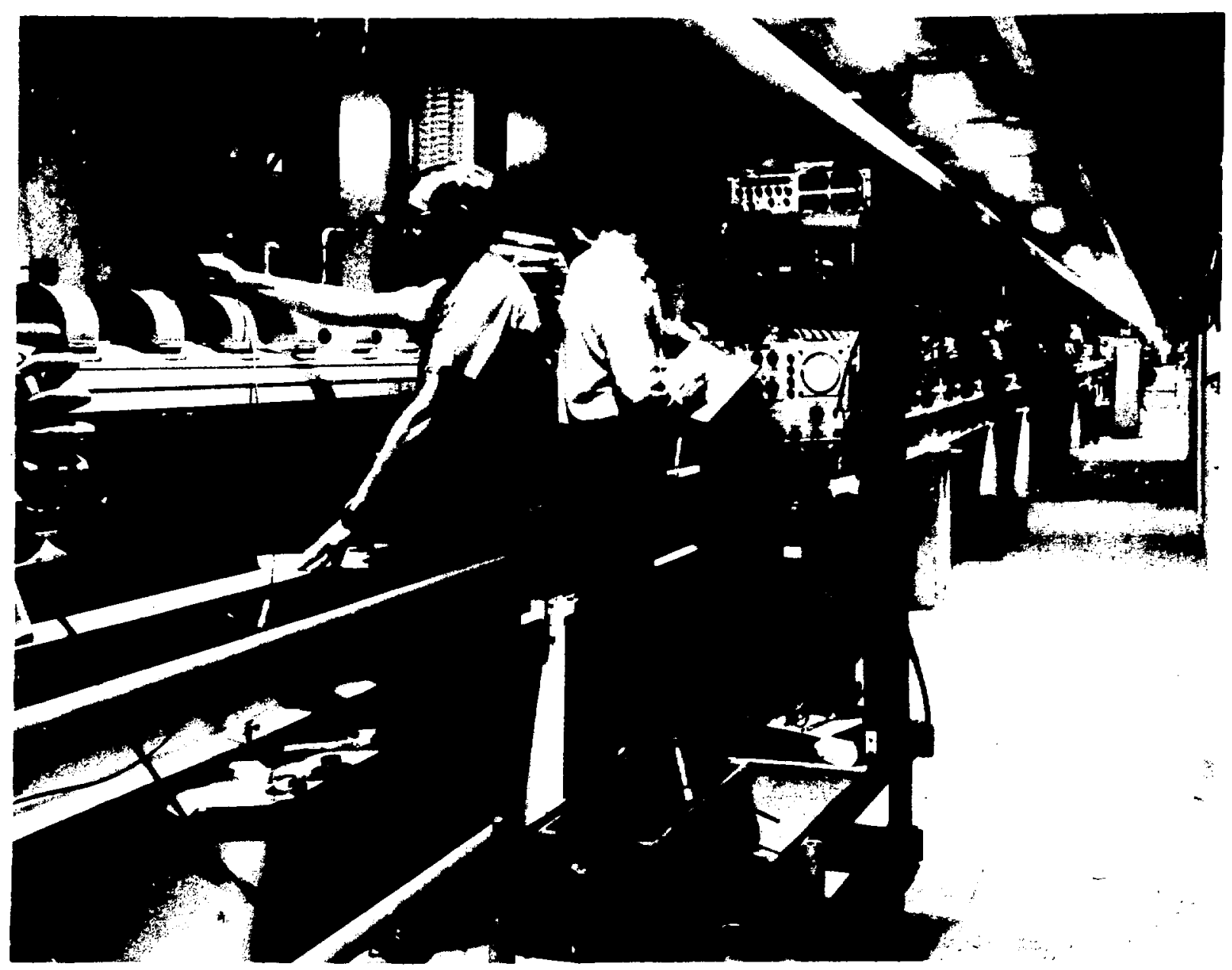

Pig. 52, Accelerating cavity final tuning in progress at Module 37. The tuning gear was mounted on an elevated platform which could be rolled along the accelerator beam tunnel as needed. The box in the hollom foregrouml was used to store extensions and parts of the nose-stretcising and septum-bending tonls when not in use.

prothese better tracking than would have been possible with a solid wheel in this position.

The need for the strongest possithle ball bearinf hecame evident when soveral bearings obtained from laboratory stock failed. The ball type bearing was nectisiar $;$ because it was short. i longer needic or roller bearing would have produced more of a perturbation in the cavity resonant frequency when the tool was in place. The best ball bearings available were purchased. (The cost was about nine times that for the similar stock bearing.) These were knowl as miniature precision bearings (:PB's) and were available from Delco, New leparture, and other manufacturers. The bearings used were size lassification SR4RHH, and were rated at a radial load of 290 newtons at 42 radians/second (vs. 200 newtons for the cheaper bearings). The added strength was duc to better heat treatment of the steels and greater precision in the rolling parts. Viven so, the rated load given was below the requirements of this application. Loads of about 800 newtons (at very low speed, fortunately) were probably encountered in practice.

What made these bearings trustworthy for use on the nose-scretching tool was the excellent ball retainers used. These retainers held the balls in place even when the outer race cracked (which happened once before the ridged solid follower wheel was installed). The cheaper bearings used inadequate retainers which immediately released the balls when the outer race cracked. 


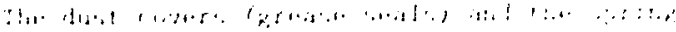

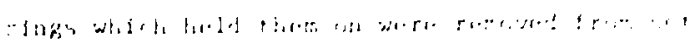

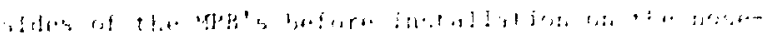

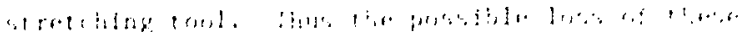

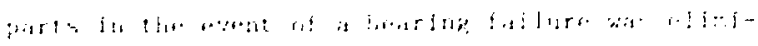

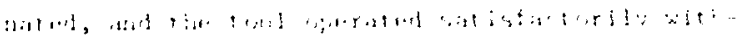
,il 1 i., $\cdot$ in.

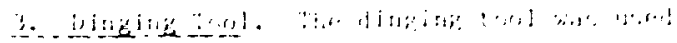

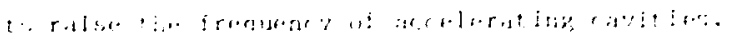

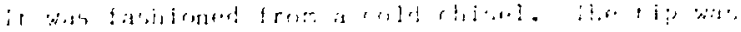

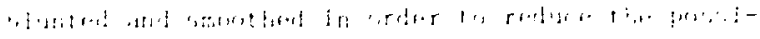

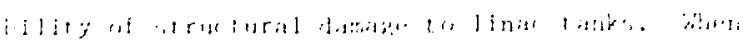

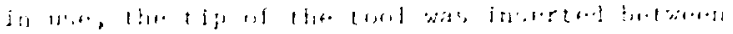

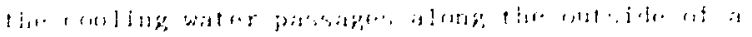

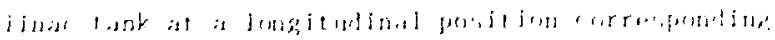

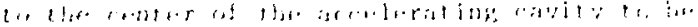

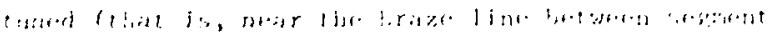

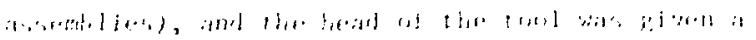

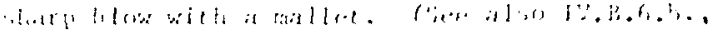
i. 31,1

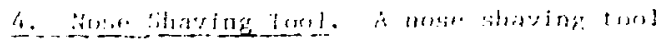

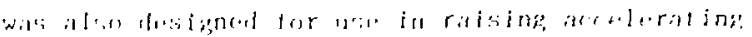

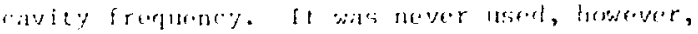

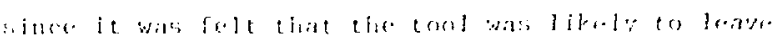

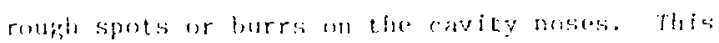
would be moletej rable since the region of the ravit: near the nose tip has a bigh fir lal istadient, and lance sparking or sputtoring misht areur.

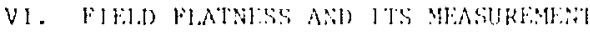

A. Overvitu.

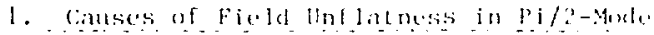
linac structures. We ligst discuss the need for field flatnoss moasurements. Ficld unflatuess in a $/ 2-\operatorname{mode} 1 \mathrm{inar}$ strueture my arise in four ways. Only the first two of the four allow diagnosis and treatment using low-power field distribution measurements. The four ways are:

(1) Variations in coupling between resonators cause variations in amplitude along the structure.

The cavity-to-cavity couplings show nog 1 ifible power or frequency dependence in the 805-947 linac. hence a pattern of field variations caused by coupling variations can be considered to be frozen in. Care must be taken in construction to minimize such coupling variations. The tuning and flattening procedure discussed in section IV.C.3. was de-

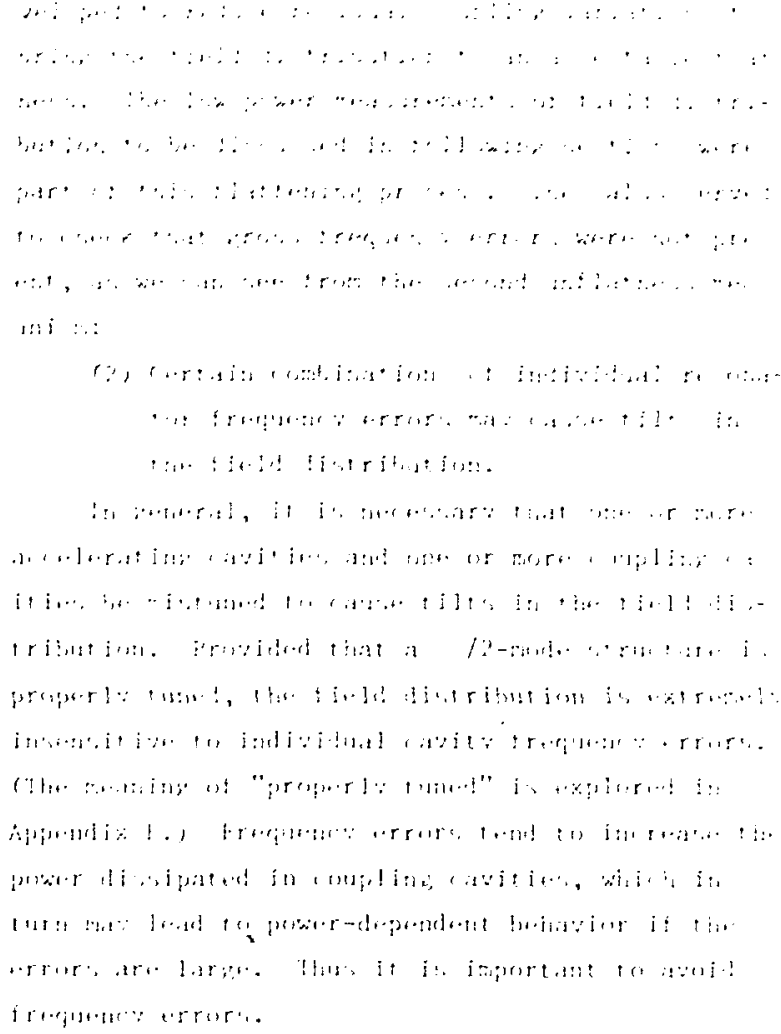

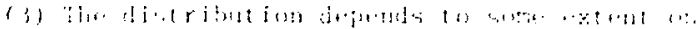

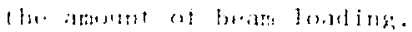

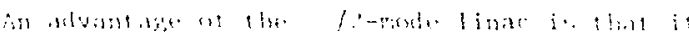

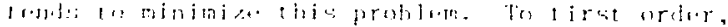

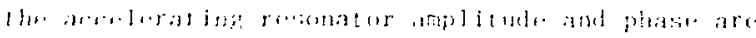

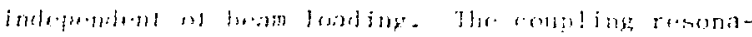

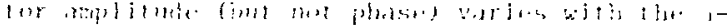

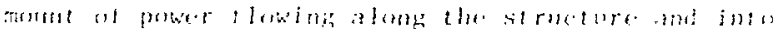

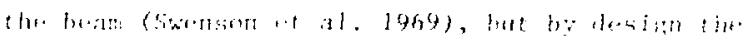

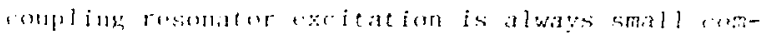
pared with the anelerate ing resomator araitation. Agitin, the strueture must be property tment. (sife Appendiz F.) only when the struelure is made tyLremely long or Lhe bean landing is make cetremel: heavy miglit esmplications arise in this regard. In il lomg structurc, beam loading causcs an amplitade droop; and beam loading combined with improper stopband may calse a shift in phase. (See Appendix F for estimates of beam loading effects.)

(4) Interaction of an improper stophand with an mflat field distribution may produce field distribution variations dependent on average power dissipation in a moduic.

If the field distribution of a module is not flat, which may be the result of mechanism (1) 


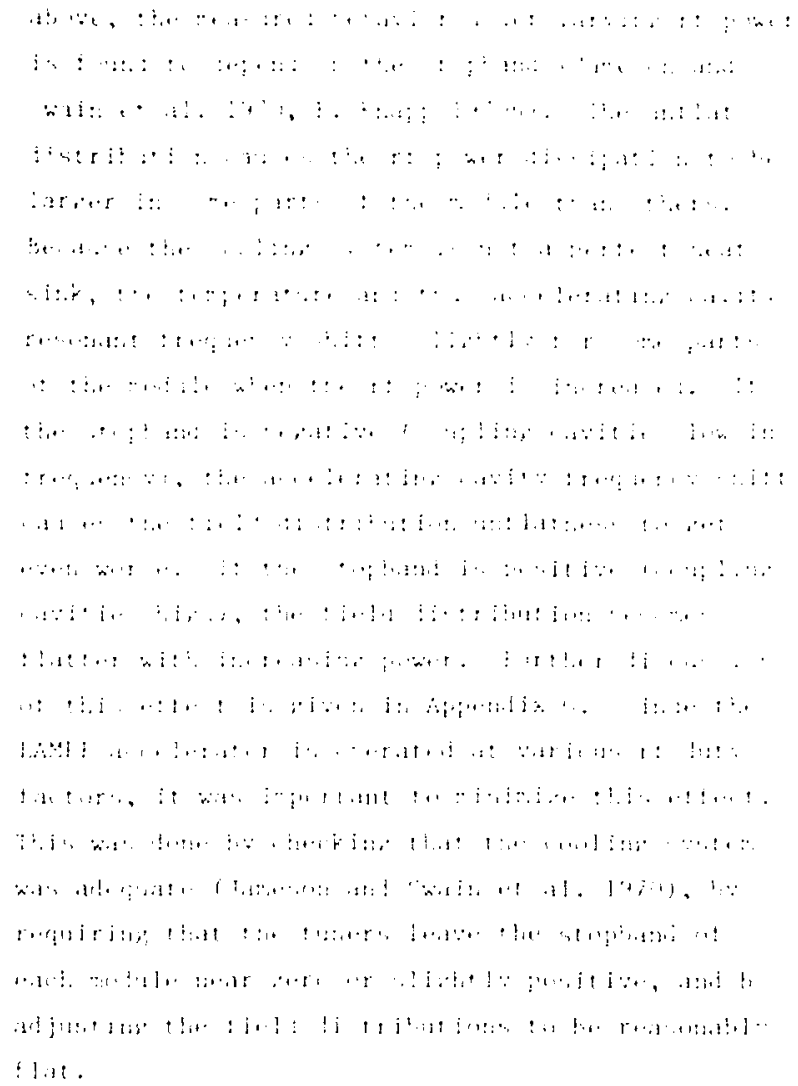

Yore recently a few measurements were made of the beam loading effect (mechanism (3) aboye). A peak beam current of about $9 \mathrm{mi}$ produced an amplitude droop of one per cont and plate rianores uf less than one jegree (Swain and Jameson 1976, Swain 1976), which are consistent with the estimate of beam loading effect developed in Appendix $F$. These measurements used the existing pjckup loops (one

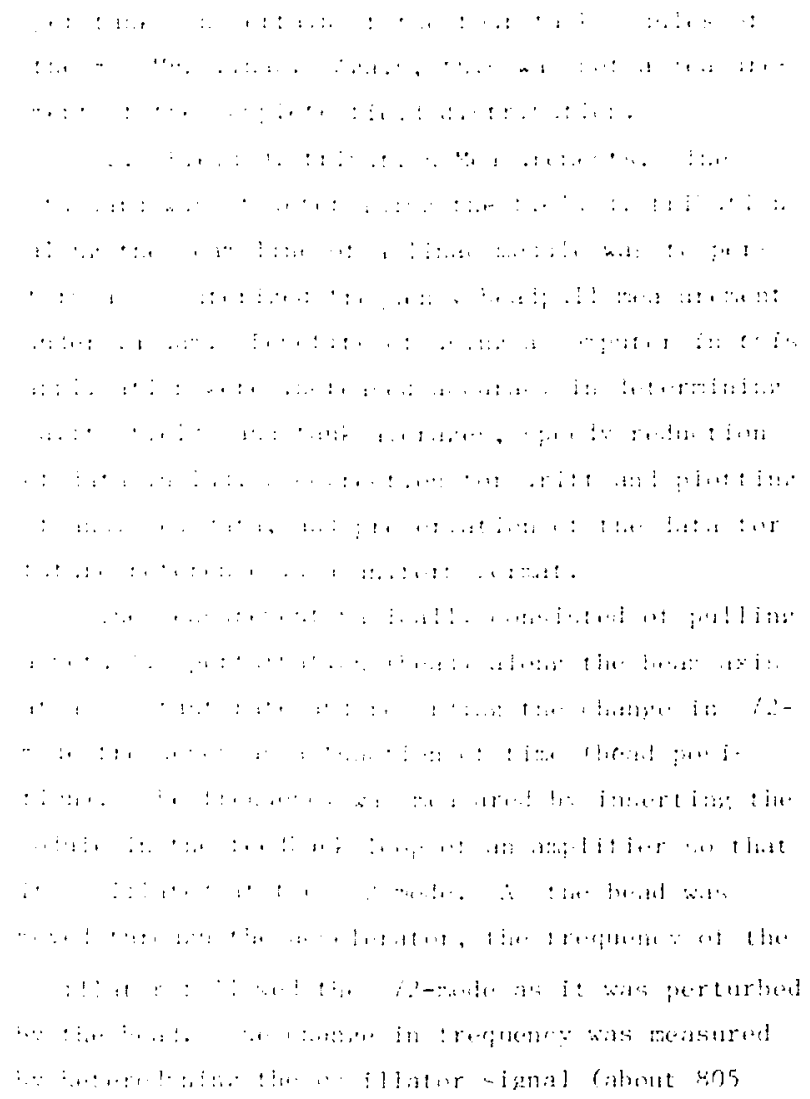

The computer protram converted the incoming periak lata to freguency data, and recorded the initial frequency with the bead out of the tank. As che bead moved through the module, the resulting irequency was compred with the in tial baso-lino frecuenc" to doternine the change in frequency. since the head passed through a region of zero field insicle the dritt tubes between accelerating cavities, thr basc line could be uplated to provide a correction for drift of the unperturbed -/2-mode frequency with temperature fluctuations. Two separate measures of the cavity field were recorded, one being the field at cavity center and the other being the integral of the ficld as the bead passed through the cavity. Displays of these measures on a storage scope enabled the tuners to assess flatness within each tank and to adjust bridge coupler posts so as 


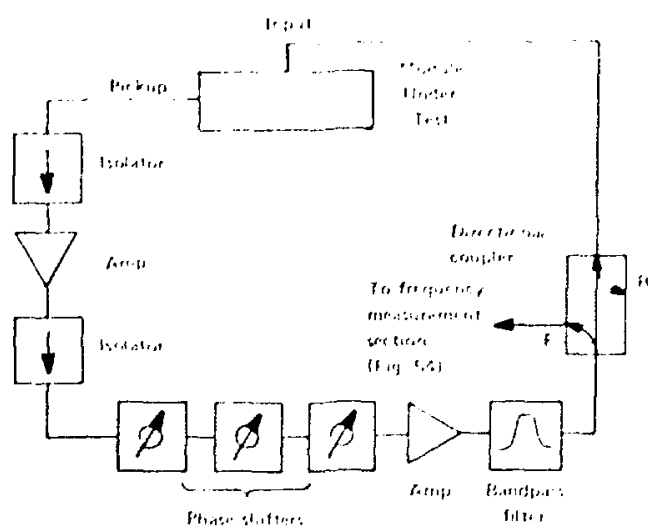

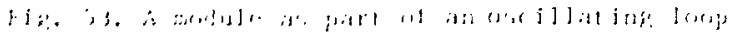

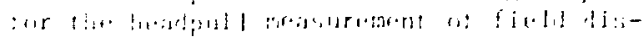
fritilition.

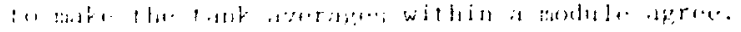

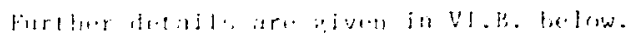

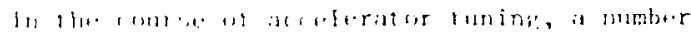

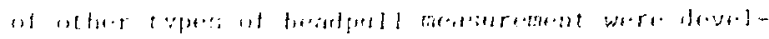

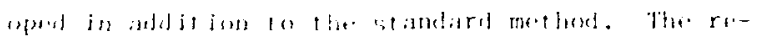

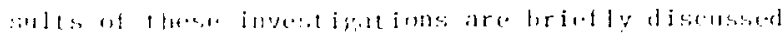

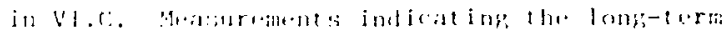

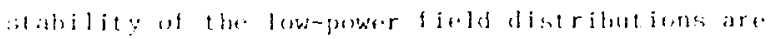

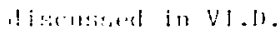

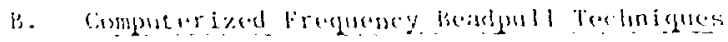

1. Elortrical consideratens. The head poll meisurement is hased on the fact that the ineroduction ut a tmall metallic or dialectric objert in a rivity perturbs the resomant frequence of the ravjLy (Harvey 1963). The amount of frequency perturbation is proportional to the volume of the small objert and to the square of the rield intensity at the point occupied by the small object before the object was introduced. Introduction of a metallic abject in a region of electric ficld lowers the Crequency; introduction of such an object in a region of masnetic field raises the frequency. In the case of a linac module, the whole module is considered to be the cavity. The field along or near the beam axis is primarily electric. A small metal bead was carried along a string stretched along the beam axis, and the electric field intensity squared at each point was found from the resulting variation in the $7 / 2$-mode frequency of the module. The bead size was chosen such that the frequency of the module dropped about $2 \mathrm{kHz}$ when

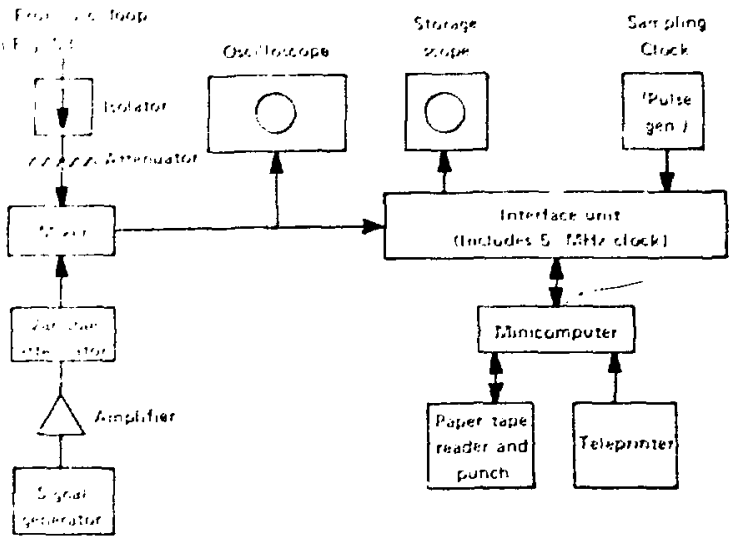

Fi\%. Sk. computerizod frequercy measurement equipment set-up for beadpull measurements.

the beral with in the center of an acceleratiog cayit $\because$.

The resonant frequency of the module was de-

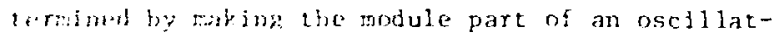
ing, loop, as shown in ip. 53. Plase shifters and abonlpass filter were provided to facilitate makins the locp resonate at the $-/ 2$ mode and not at mu af the many other possib]e modes of oscillation at th. linac tadule. The phase shifters were set such als to give a minimum at the rilected signal utput of the djrectional coupler. Two solid-state amplifiers (20 dB each) provided sufficient gain to make the 100 oscillate. Isolators reduced the intluence on resonant frequency of the equipment external to the linac module.

The frequency of the oscillating loop was monitored by comparing the signal with that from a stable signal generator, as shown in Fig. 54. The difference frequency coming out of the mixer was adjusted (by varying the signal generator frequency) to be about $10 \mathrm{kHz}$, with the signal generator frequency on the low side. Thus the input signal to the interface unit had a base line at around $10 \mathrm{kHz}$ and dipped to about $8 \mathrm{kHz}$ each time the bead traversed an accelerating cavity. The frequency of this signal was sampled 60 times per second in the following manner. The interface unit contained circuitry for counting cycles of a 5-MHz clock for 8 periods of the input signal. Upon recelpt of a pulse from the sampling clock, the interface unit 


\section{$\therefore \therefore$}

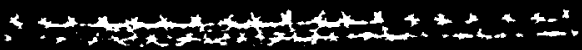

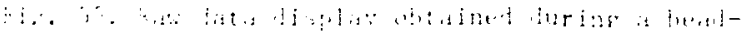

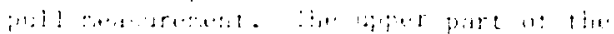

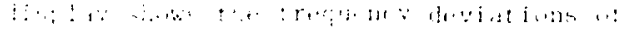

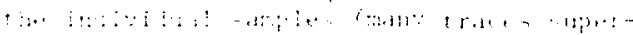

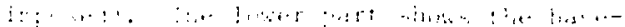

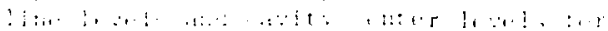

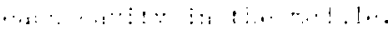

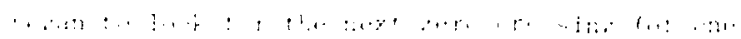

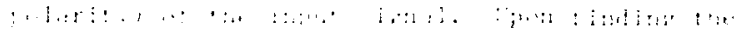

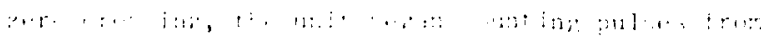

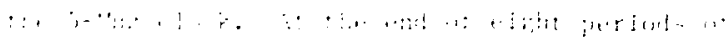

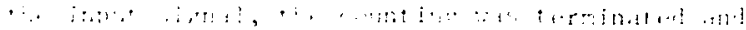

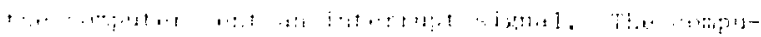

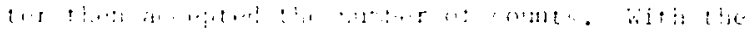

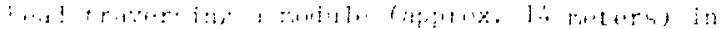

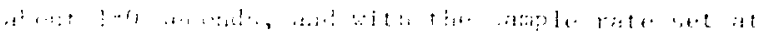

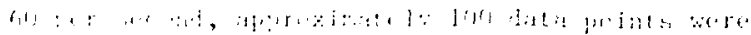

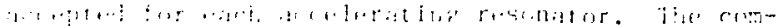

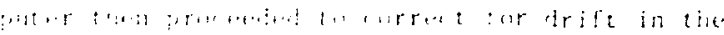

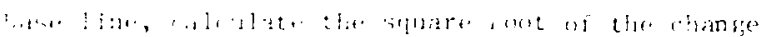

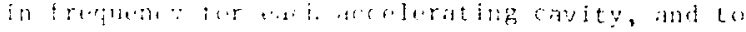

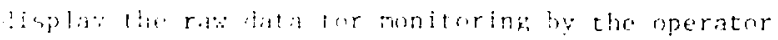

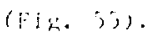

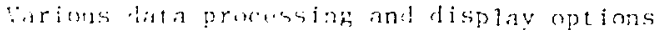

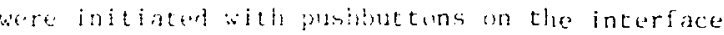
unit or comrands via the teletype. Data were recurdou and labeled by mens of puacled paper tape,

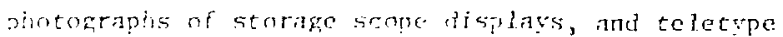
priatouts. Further detajls of the mechanical arrangelients are given in Section 2 and of the computer algorithms and data displays in Section 3 below. Information on teletype comands and on equipment used and electrical connections is given in hppendix $H$.

2. Mechanical Corsiderations. The initial method for making a beadpull measurement with the

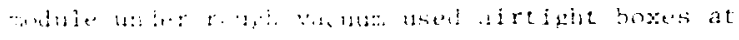

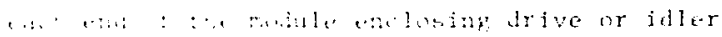

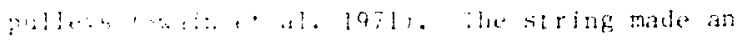

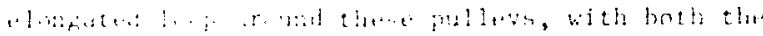

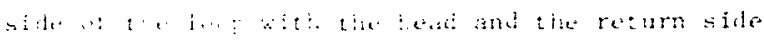

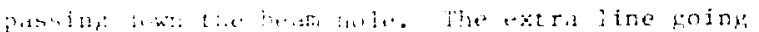

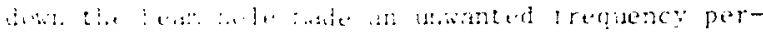

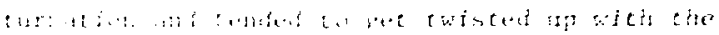

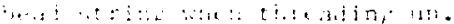

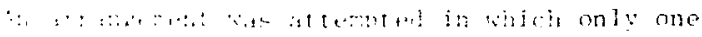

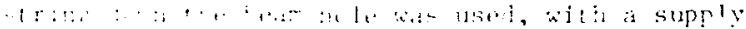

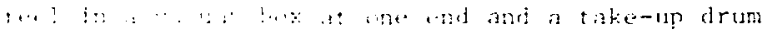

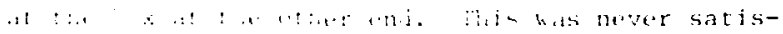

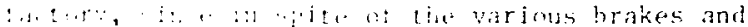

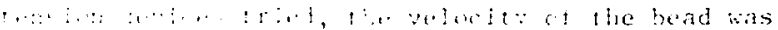
$\therefore+1: \cdot \cdot \cdots$

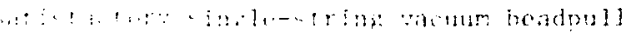

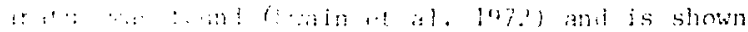

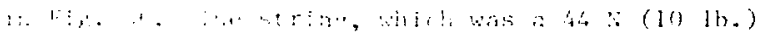

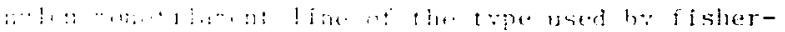

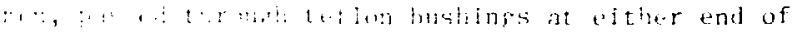

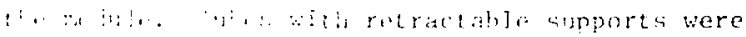

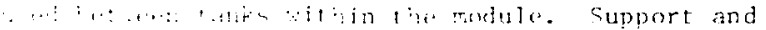

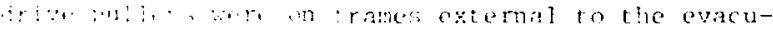
r.ei sreas, and ames ure held in place on the

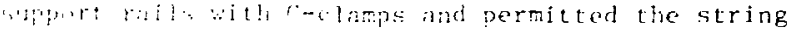

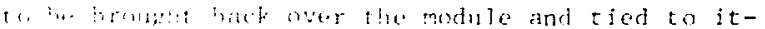

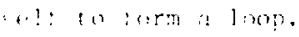

Une ent pieces each consisted of an aluminum 1 lange, a siort plastir tube, and a pair of aluminut parts holdins ile ter fon bushing. The flange plecr boted th the and flange of the module. The plastic cube perinitced one to see when the bt... had reached the tarl of the module. The tefion bushing was ensily romoved by unscrewing one of the two remaining aluminua parts.

The tuhes for use between tanks were also plastic, so that it calld be seen if the string was in correct position on its support. Aluminum flanges at each eni of these tubes allowed some longitudinai movement of the tube to accommodate the variable inter-tank spacings. Extensions were available to accommodate the larger inter tank spacings.

The follcwing procedure was used to thread up the bead pul1 apparatus:

(1) Clamp left and right drive bracket to the support rails with C-clamps. 


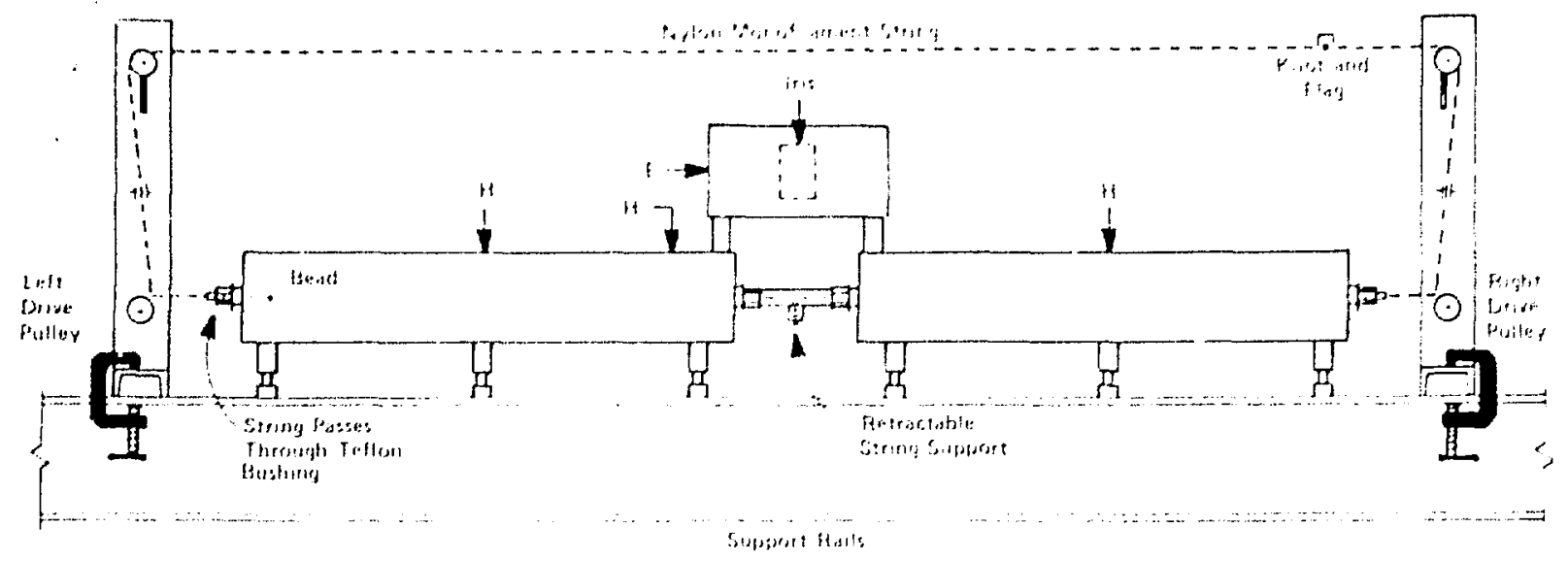

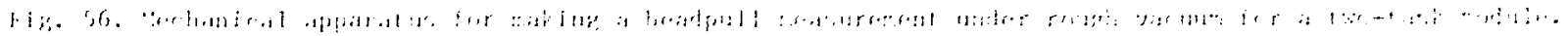

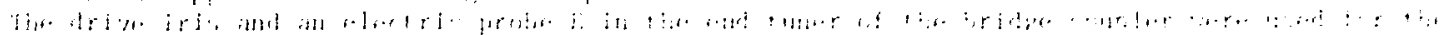

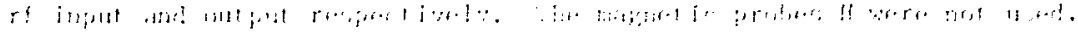

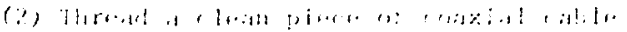

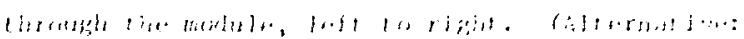

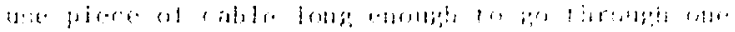

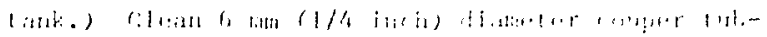

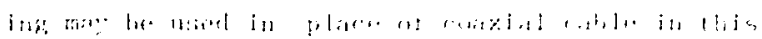

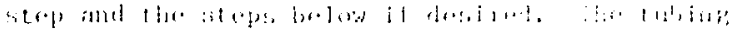

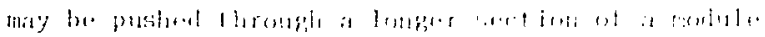
than rable withent janmina.

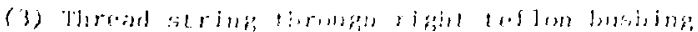

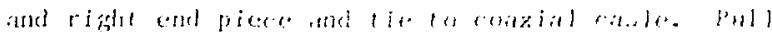
string into right tak. boll right emel piene to and flange: and insort and clanap tof lon bushing.

(4) Pull string to bap betwern tanks. fiut of from conxial cable. Tic nut an end of string and drop through center tube with strings support retracted. (bo this with extention boltent to denter tube, if extension necoled, lemes nut and ristie end of string to coixial cable. Pall atel inta next tank. Bolt one end of center tube $i$ in place. (If this is four-tank module, repeat this step for remaining tanks.)

$\rightarrow$ string out of left end of module. Cut off from coaxial cable. Take a vard-long, piece of string and thread it from the outside end through the left end picce (with teflon bushing removed) and tie it to the end of the main string. With this, pull the end of the main string through the left end piece and cut off yard-long string and knot. Thread end of main string through teflon bushirs and clamp bushing in place.

(6) Pull string around pulleys and back over module to starting place, as shown in Fig. 56. Al-

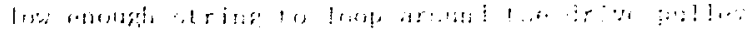

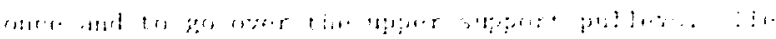

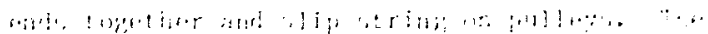

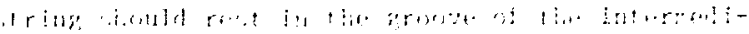

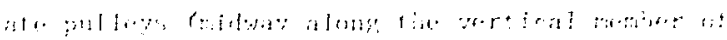

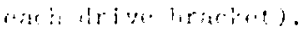

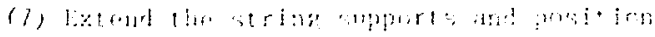

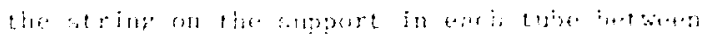

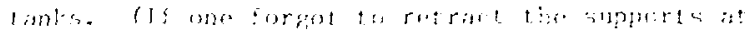

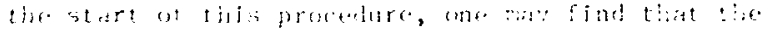

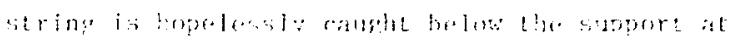

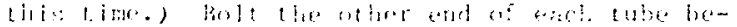

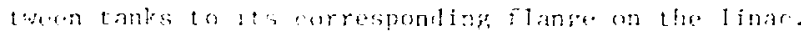

(4) Position the bnot just a tar let af the upper right support pullew, and mut marker flag oyer the knot. Bake off left teflon busting and forth beacl (f rom aluminum foil, about b rm lnng) arounel the string between the teflon bushing and the lert

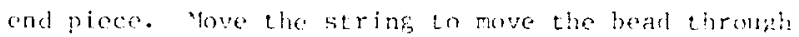
the hole in the left and piece. De-clamp the terlon hushing to the left end piece.

abump down for rough varuum; 13 Pa (1000) microns) or less can usually be obtained.

vacuum levels in the neighborhood of 4 Pit (300 microns) were avojded, since some kind of rrplina interaction appeared there. Porlaps this wa: because natural ionization occurs around $3 \mathrm{pa}$ (20) microns). The oscillation would tat to lock 10 a certain frequency, as seen in Fig. 57. The iniividual cavity raw data waveforms were distorted from something like that in Fig. 58 to something like that in Fig. 59. When one went to vacuum 

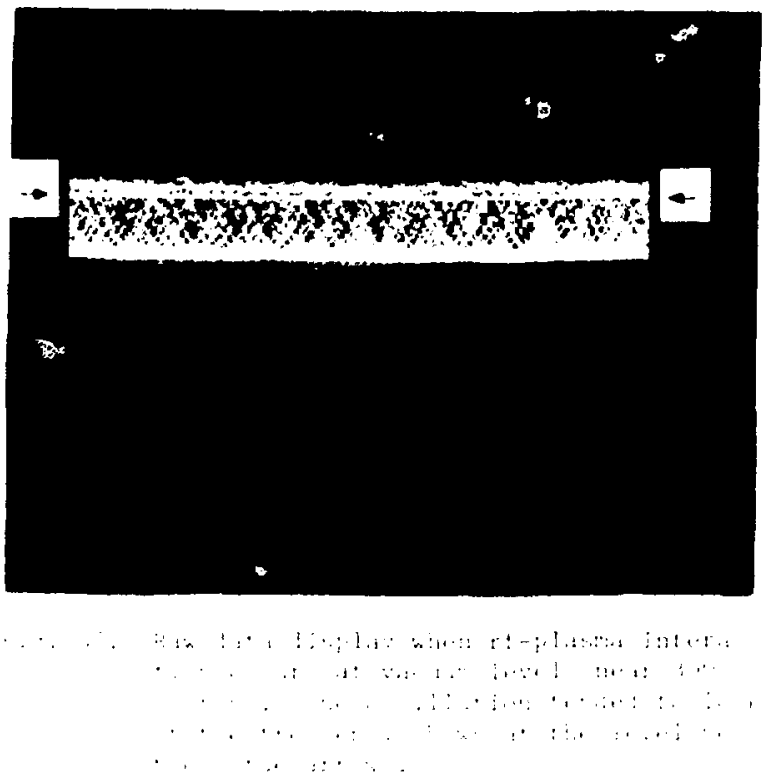

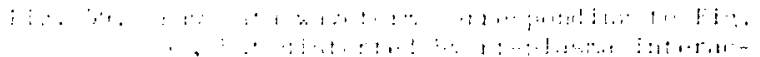

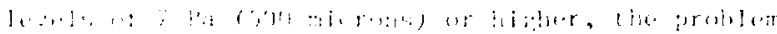
$\therefore \cdot 1: 1 \quad+1 \times 1:$

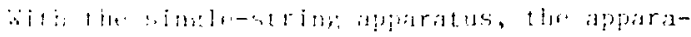

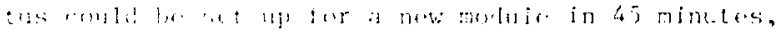

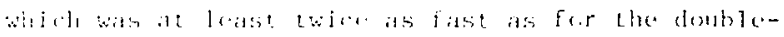
string apearalus formerly $1140 \mathrm{~d}$.

1. Sul ware and operat jog rongiderations. Varions oplons for diala acpusition or display were selected by the operater by pusting one of the buctons on che incerface unit or by typing a paje of characters on the teletype. (Seo Appendix H.) $\therefore$ logging aption queried the operator regarding the conditions of the measurement. (A sample log is shown in Fig. 60.) The steps in the data acqui-
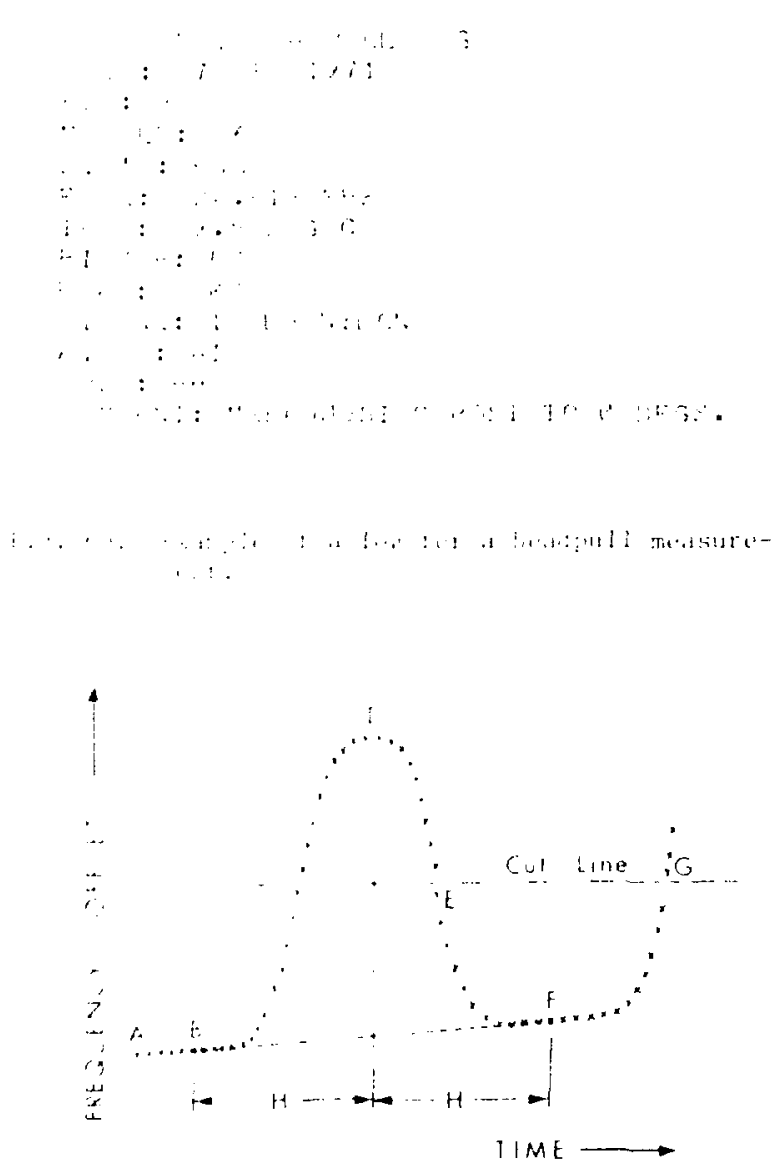

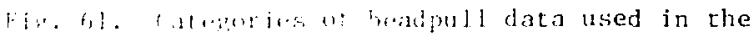
shlame for baseline correction and

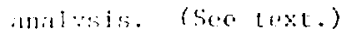

Litiun process discussed below took place after the nperator lad male lis log entries, had started the le.ild arive molur, and had pushed the "GO" interrupt hut ton on the interface unit.

The interface unit counted clock pulses for wigllt poriods of the input signal. When the minicomputer rocived an interrupt from the interface unit indicaling the count was ready to be read in, the following steps were initiated. The computer accopted the count. The count was the: converted 10 aycles por second, and the offset of this frequency from a referenco frequency was computed, and the result was stored in one of two raw data areas in the core memory, as discussed in the following paragraph. The reference frequency was simply the first frequency received after the computer was 


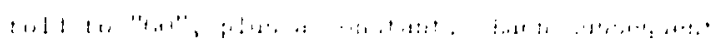

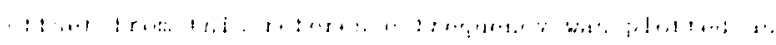

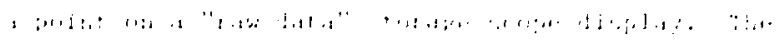

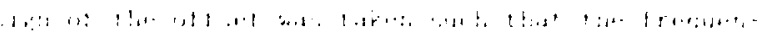

!

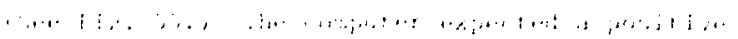

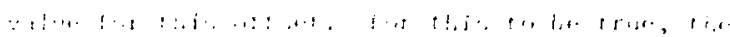

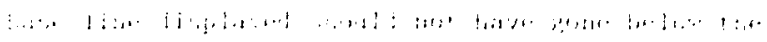

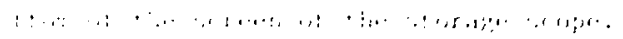

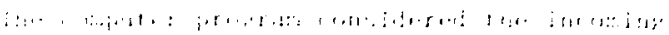

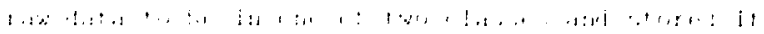

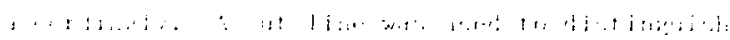

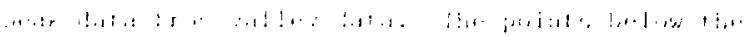

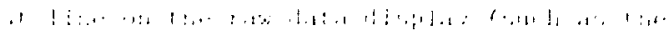

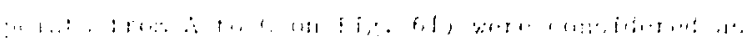

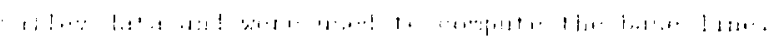

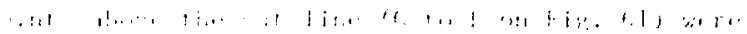

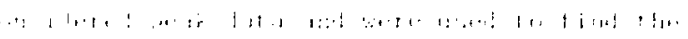

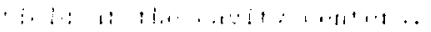

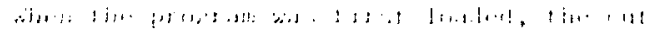

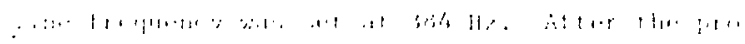

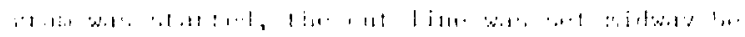

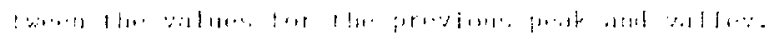

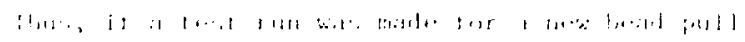

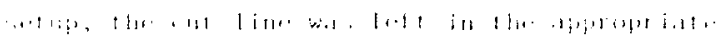

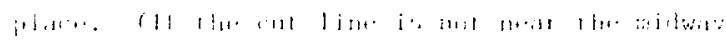

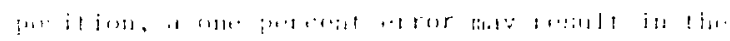

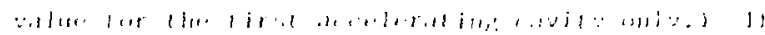

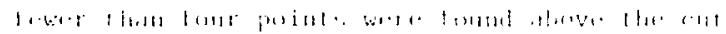

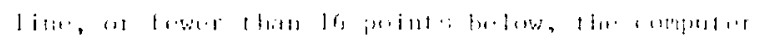

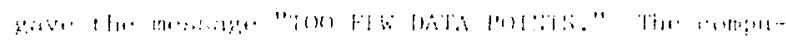

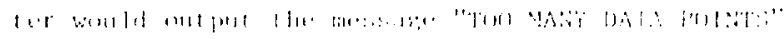

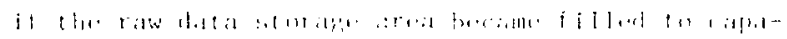
i i $\because$.

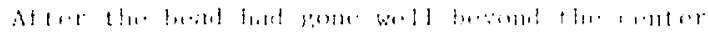

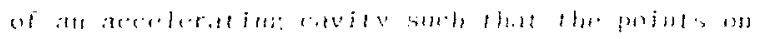

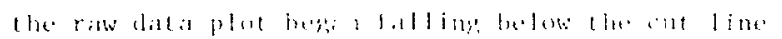

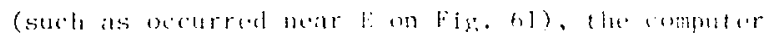
was programed to do the following:

(1) Imerpolate te find the times of the antlinc crossingis (at (: and li) for the corront poik.

(2) Find the time midway between the timesi determined in step (1). Jhis is taken to be the time (at D) for which the boal was at the center of the cavity.

(3) Avernge the four data points whose times were the closest to the cime determined in step (2). This is saved as the pak position.

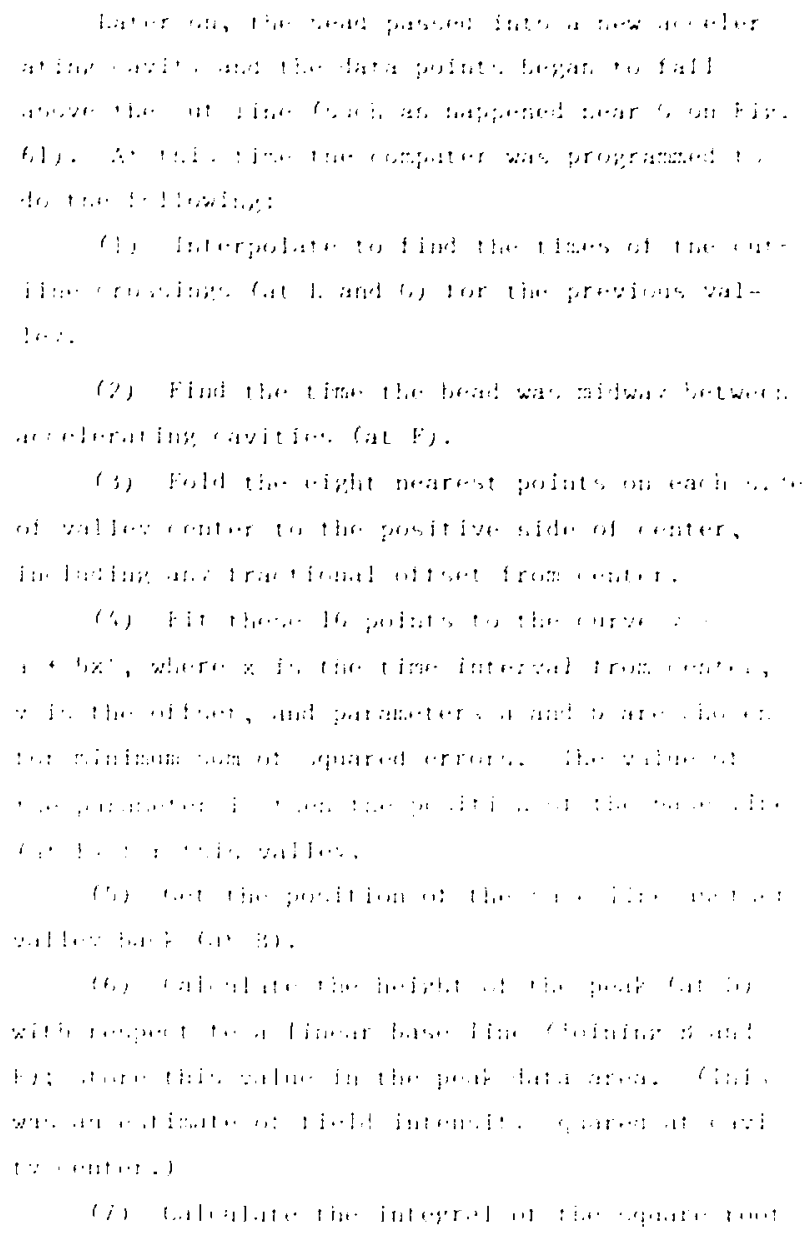

The computer sensed that the bead had left a lank wien it fount no cut-1 ine crossings [or an interval $2 \mathrm{H}$ seconds long. To find the last baseline position for the last accelerating cavity of a trnk, the computor averaged eight points near a time $H$ seconds later than the time of the last peak. After the bead left each tank, the tank average was calculated for the peak data and the cavity average 


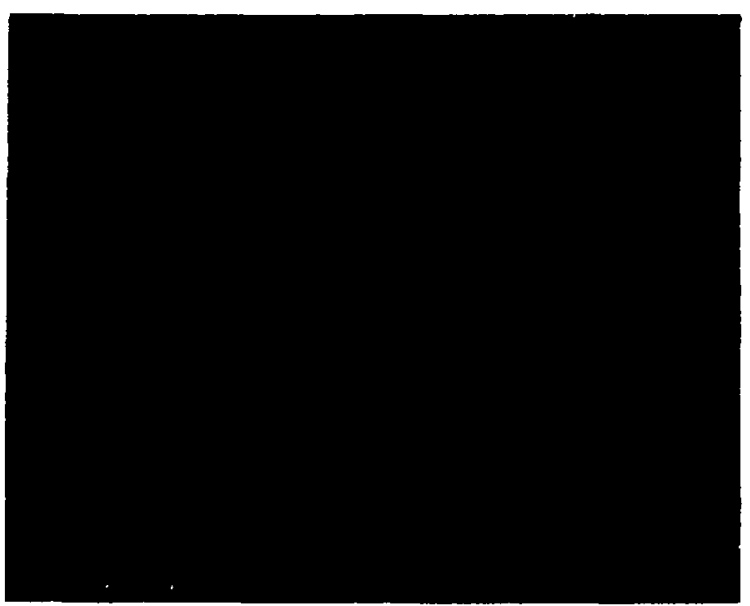

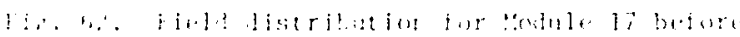

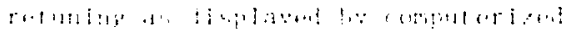

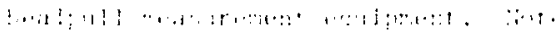

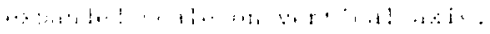

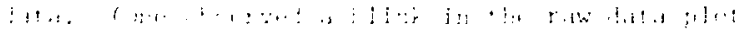

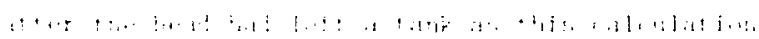

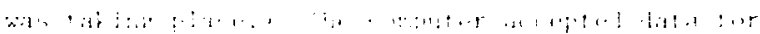

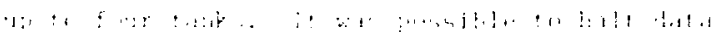

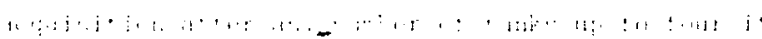

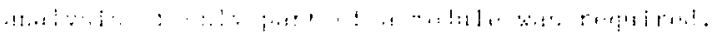

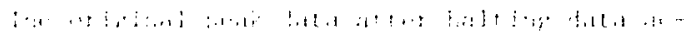

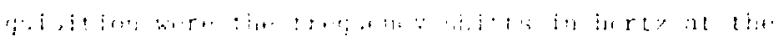

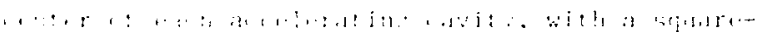

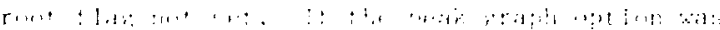

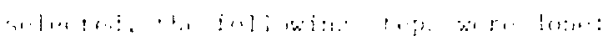

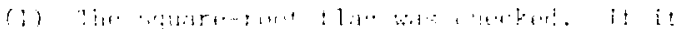

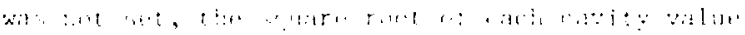

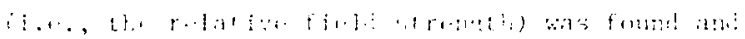

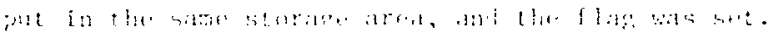

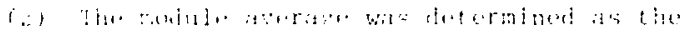
averitgo of tial tank averiates.

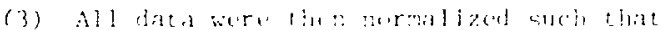

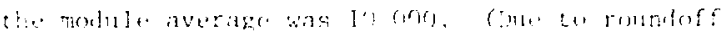

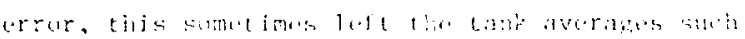

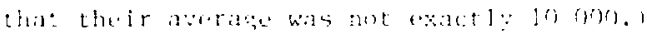

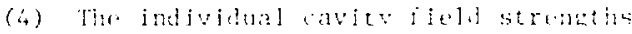
and the tant averages nore ploted on the varalet

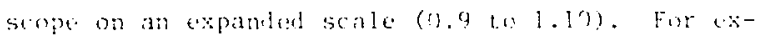
anples, see fists. he and fis.)

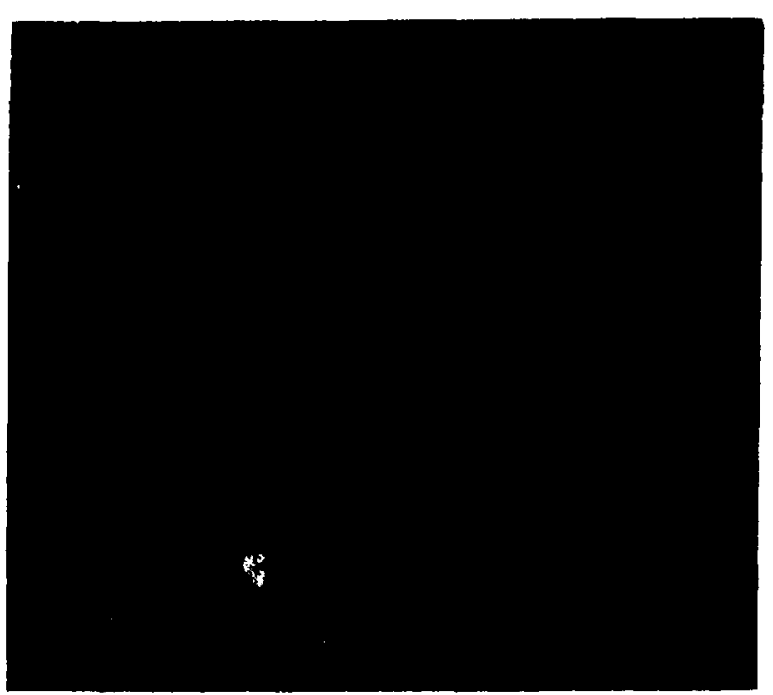

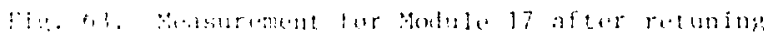

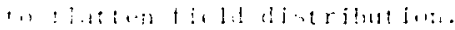

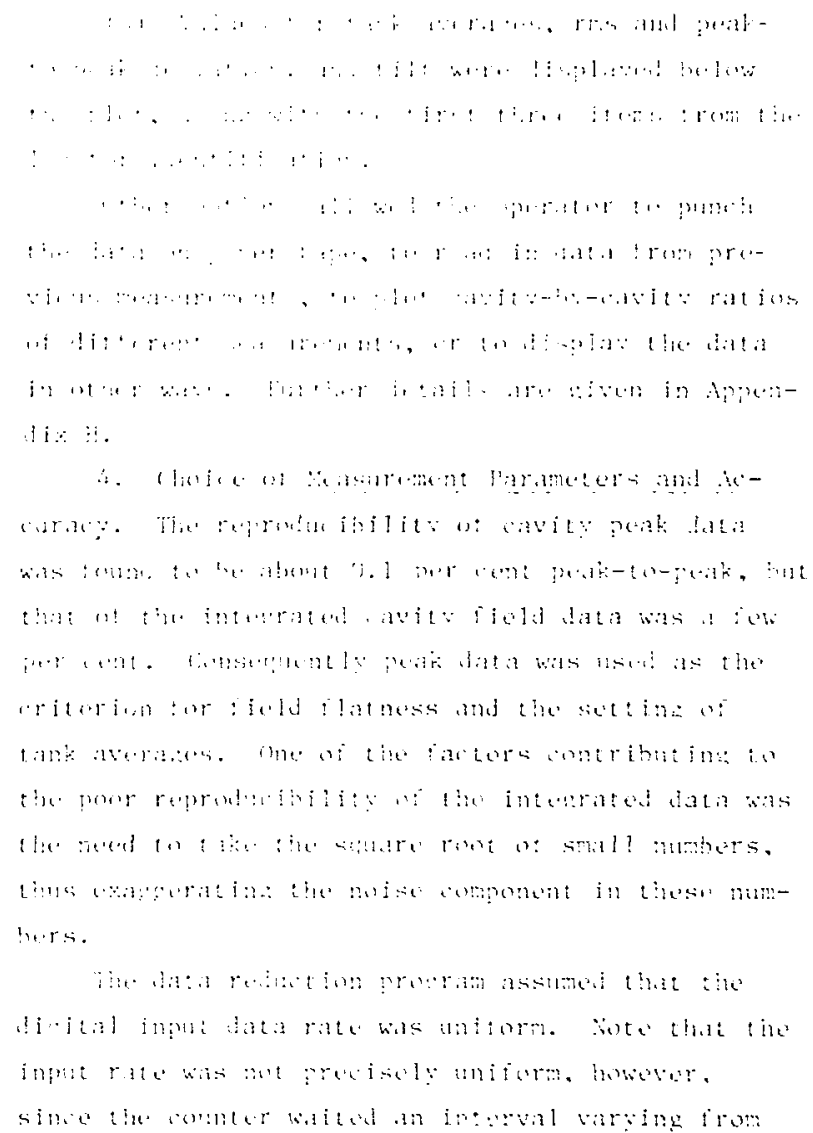



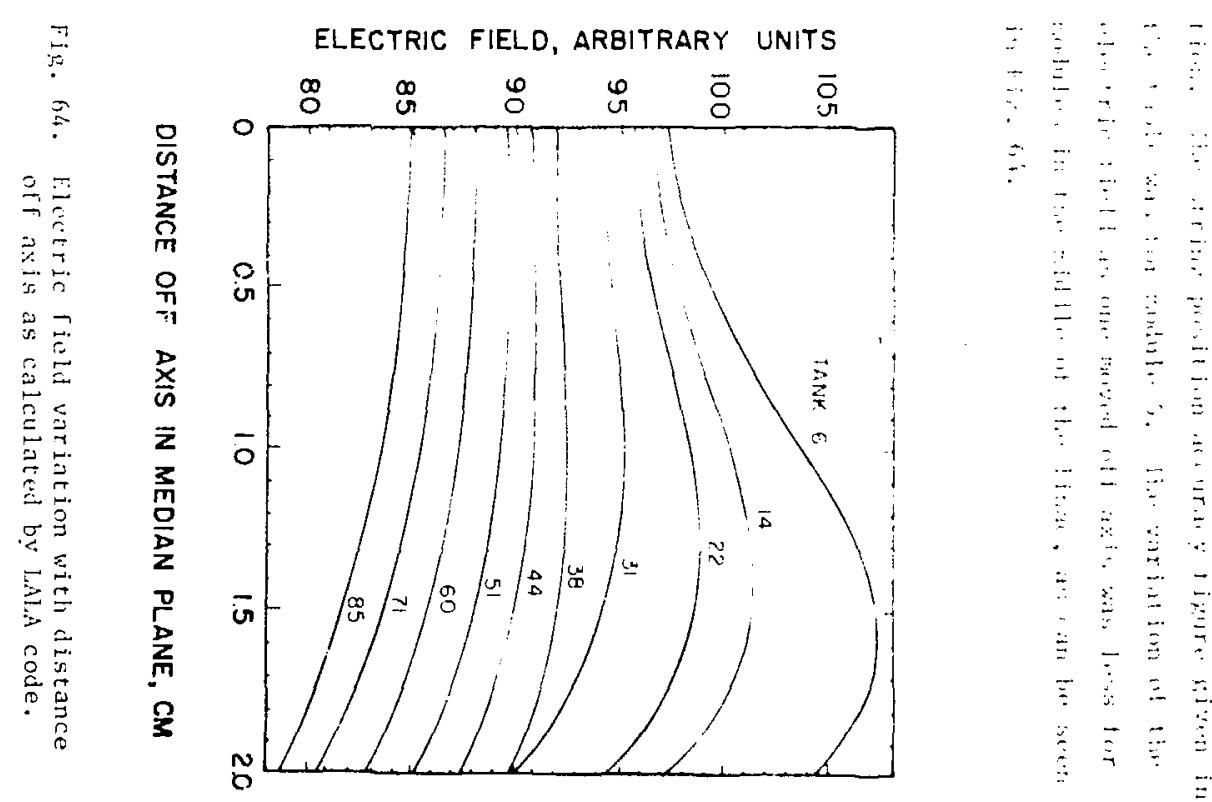


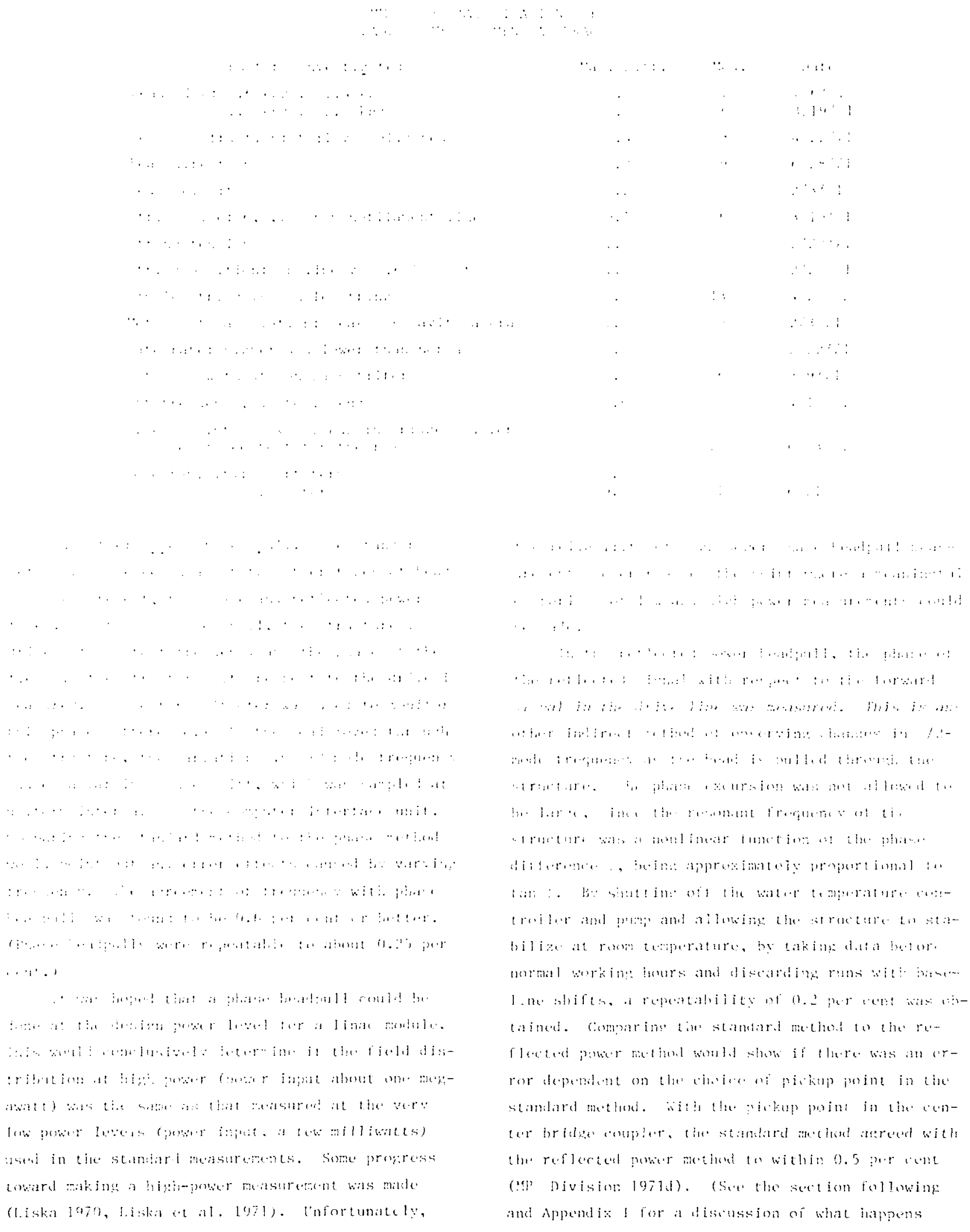




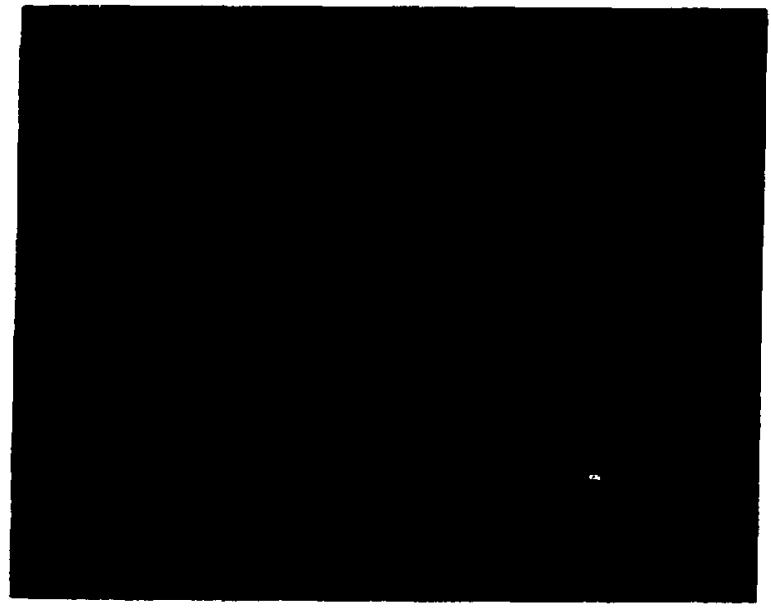

Fif. 65. Ratio of beadpul1 measurements for Module 1. With the pickup at different points.

when the pickup point is alscwhere for frequency beadpulls.)

These varlous resulis indicate that the standard beadpul] method was indeed accurate enrugh to set the tank averages within a module to better than the $\$ 2$ per cent accuracy recuired for proper beam dynamics and easy linac initial turn an.

3. Effect of Beadpull Pickup Point. It has been experimentally determined that the pickup point for a phase or frequency beadpull affects the measured field distribution. This error occurs as a linear tilt between the drive and pickup points in the module and is independent of the bead size, As J. M. Potter has noted (MP Division 197ld), the ercor results not from an actual change in the field distribution but from a phase shift introduced by the presence of the bead. If part of the structure traversed by the bead is included in the oscillating loop, this phase shift causes an error.

An estimate of the error based on the coupled resonator model with only nearest neighbor couplings is

$$
e_{\max }=4 N n_{d p} /\left(k^{2} Q_{a} Q_{c}\right)
$$

where $\mathbf{N}$ is the total number of accelerating cavities in the structure, $\mathrm{n}_{\mathrm{dp}}$ is the number of accelerating cavities the pickup point is removed from the drive point, $k$ is the nearest-neighbor coupling, and $Q_{a}$ and $Q_{c}$ are the $Q^{\prime} s$ of the accelerating and coupling cavities. (See Appendix I.) The value of

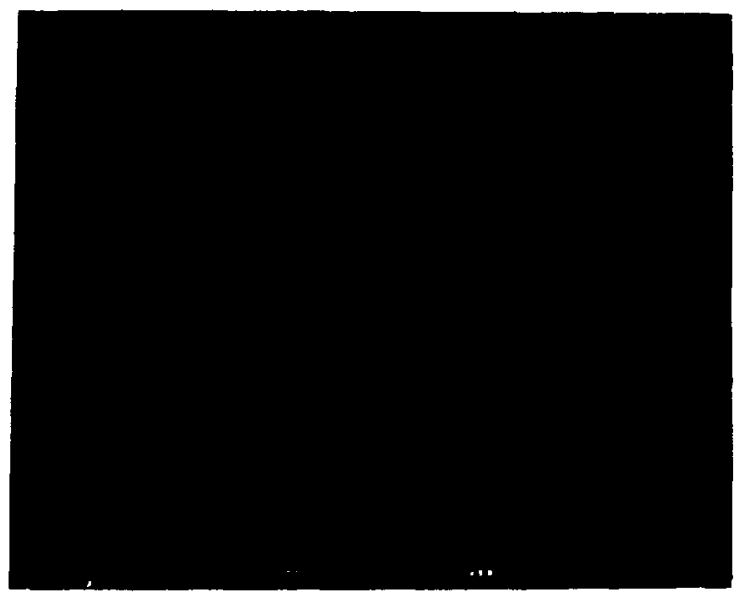

pig. 66. Field distrjbution in Jodule 12 as measured in 1975, three years after initial installation.

$k$ may be found from inble B-III in Append $1 \times$ B for the IASPF structure, or may be estimated from mode spacing as in Appendix I. This croor was avojeded for the mensurements on the 805-4ll\% linas by both driving and picking eip the signal at the conter bricge coupler cavities.

pigure 55 shows the ratio of a beadpuld with the pickup point midway along the fourth tank to a beadpull with the pickup at the bridge coupler (meisured on Module 11, July 23, 1971, ruris 1 and 8). Substituting $\mathrm{N}=128, \mathrm{n}_{\mathrm{d}}=48, \mathrm{O}_{\mathrm{a}}=20000$, $Q_{c}=8000$, and $k=.046$ in I.q. (3), one finds e max - $7 \%$, in reasonable agreement with the measured difference of $8 \%$.

\section{Observed long-Term Stability of Field isistri-} butions.

In connection with certain bridge coupler length correction work described in section III.B.I. of this report, measurements of $805-\mathrm{MHz}$ linac tank Field distributions were made for ilodules 12 and 13 approximately three years after the initial tuning was completed. Comparison of the 1975 measurements with the 1972 measurements shows no detectable change in the field distribution within tanks as measured at low power. Fig. 66 shows the field distribution within Module 12 in 1975; only the upstream bridge coupler had been adjusted since 1972 . Fig. 67 shows the ratio of the 1975 measurement to 


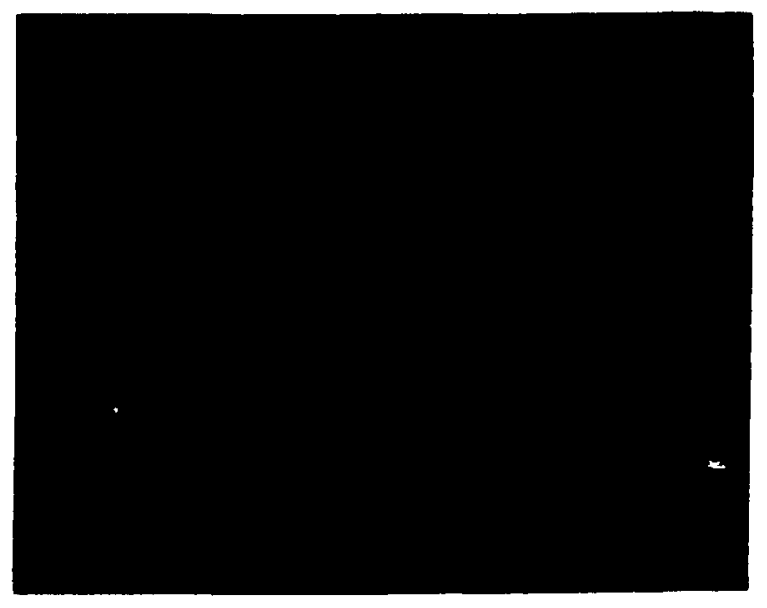

Fig. 67. Ratios of beaspull measurement on Hodule 12 done in 1975 to measurement done in 1972.

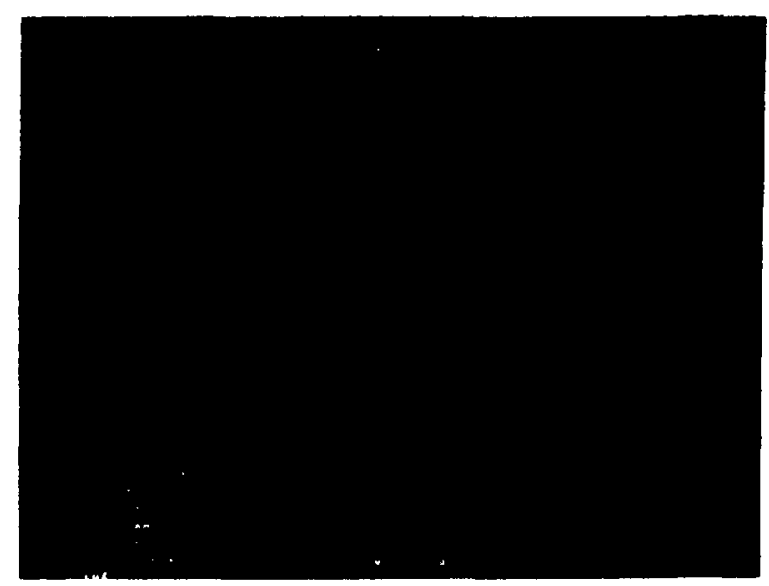

Fig. 69. Ratic of 1975 to 1972 measurements for Module 13.

the 1972 measurement. Figures 68 and 69 show similar results for Module 13, whose bridge coupler was replaced in 1975 . The r.m.s. scatter in the ratio of 1975 to 1972 measurements in Figs. 67 and 69 is about one-fourth of one per cent. This is about the same as the scatter in the ratio of different runs made in 1975, as shown in Fig. 70.

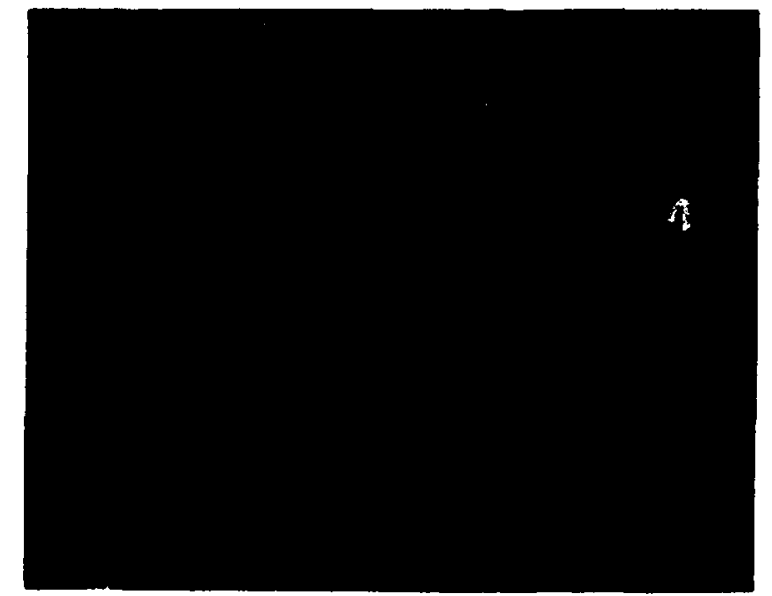

Fig. 68. Field distribution in Module 13 as measured in 1975.

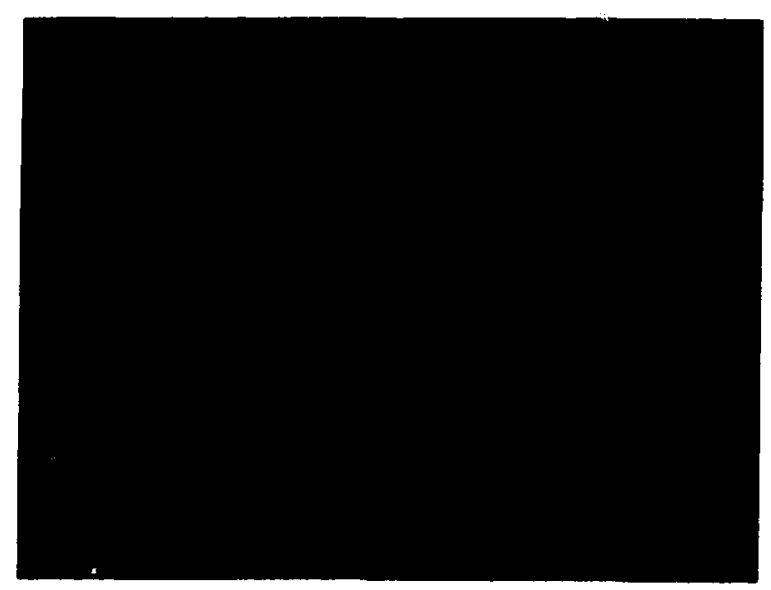

Fig. 70. Ratio of two beadpu11 measurements of Module 13 made in 1975.

The fact that the low-power field distributions remain stable over long time periods indicates that the cavity-to-cavity couplings and cavity frequencies of the $805-\mathrm{MHz}$ side-coupled linac structures remain reasonably stable over long time periods. 


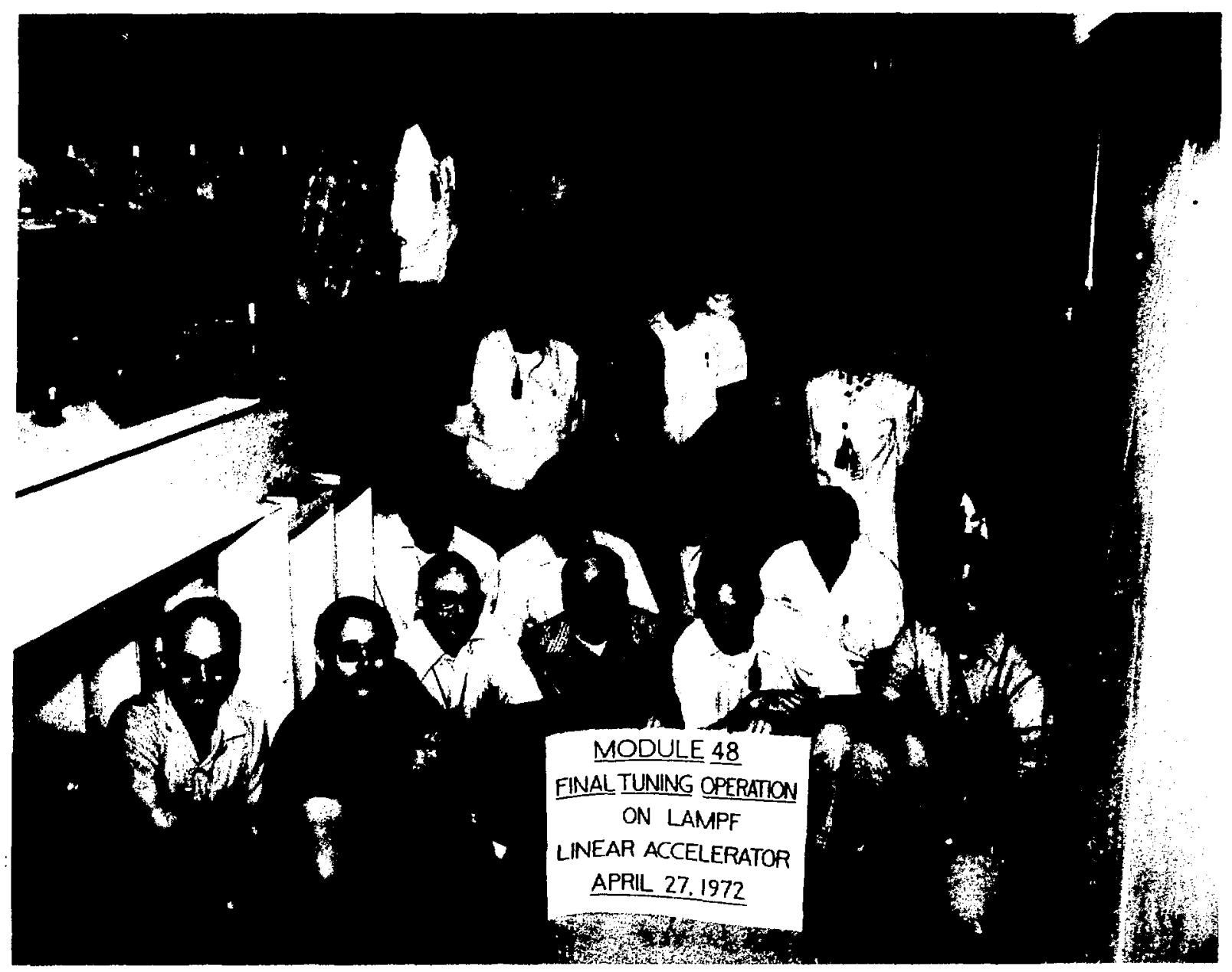

Fig. 71. It's done! Persons involved with structure tuning and some of their contributions: (Front row) Bob Carly - probe calibration, Oliver Rivera - tuning and tool improvements, Dave Jones - tuning, Cecil Stark - tuning, Paul Beauchamp - tuning, Bob Romero - tuning, (2nd row) Don Liska - beadpull equipment design and supervision, Jim Potter - bridge coupler stabilization - beadpull improvements, John Zastrow - beadpul1 cquipment, Charlie Manger - prebraze and section tuning and supervision, George Swain - procedure design and supervision, (on I-beam) Don Holcom - rf testing, Bob Patton - rf testing, Mike Dugan - rf testing, Dennis West - tuning and tool improvements, (back rows) Jerry Wallace - rf test design, Buck Hayes - machining, Bob Harrison - iuning and beadpul1 data processing, Jess Lee - machining supervision, Ed Knapp - structure design and modifications, Joe Van Dyke - tuning tool design, Bob Jameson - coordination and scheduling and $r f$ system design, Rene Mills - data col ction, Bob Kandarian - tuning tool design, and Seth Rislove cooling system installation supervision.

\section{ACKNOWLEDGMENTS}

The successful completion of the project to fabricate and precisely tune 10000 cavities and to check the performance of the 44 modules of the LAMPF $805-\mathrm{MHz}$ linac depended on the conscientious and persevering efforts of a great many people. Some of the persons particularly involved in the structure tuning process are shown in Fig. 71. The author is especially indebted to E. Knapp and James Potter for developing the theory, to R. Jameson and $J$. Sharp for refining and documenting procedures, to E. R. Martin for beadpu11 computer software, and to C. Manger, O. Rivera, and D. West for developing procedures and hardware for various measurements.

C. Manger supervised the pre-braze tuning. D. Liska assisted in final tuning supervision. 


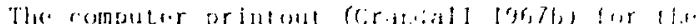

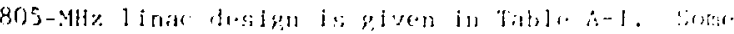

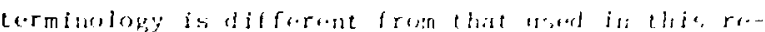

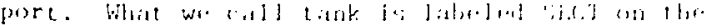

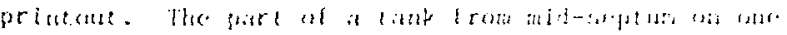

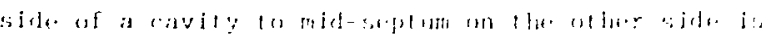

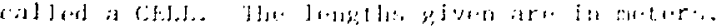

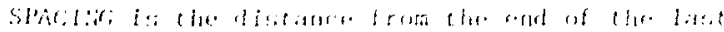

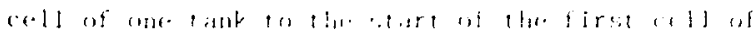

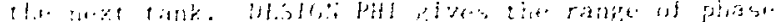

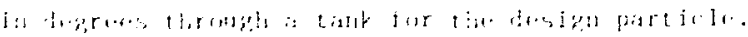

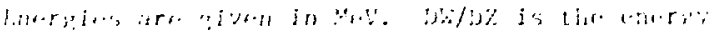

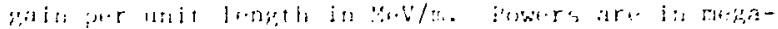

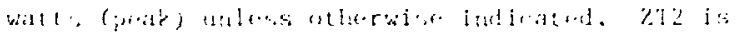

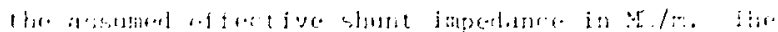

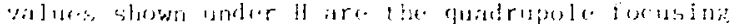

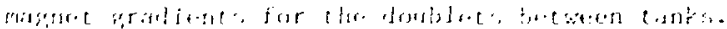

:ABH. $a-1$

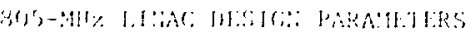

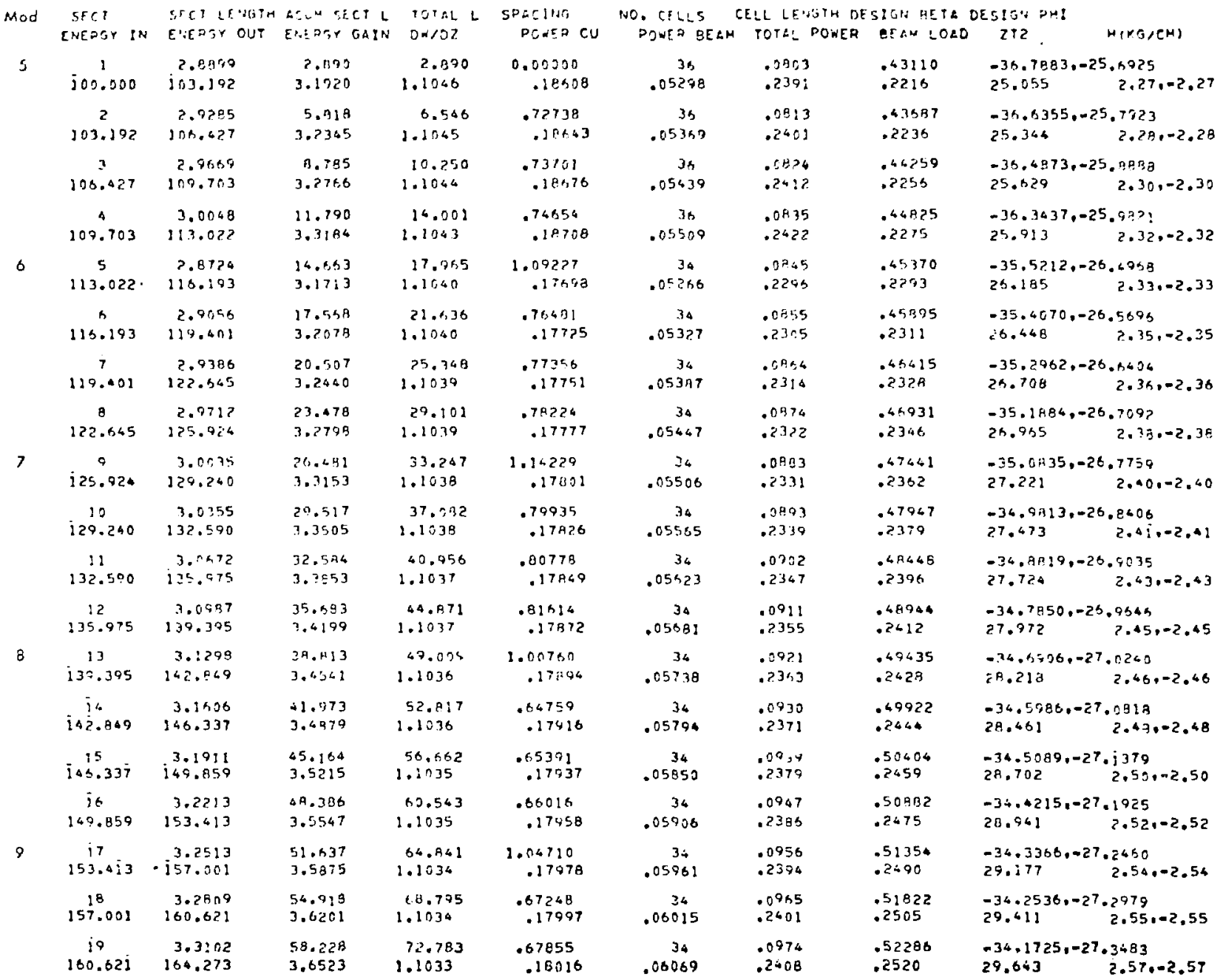




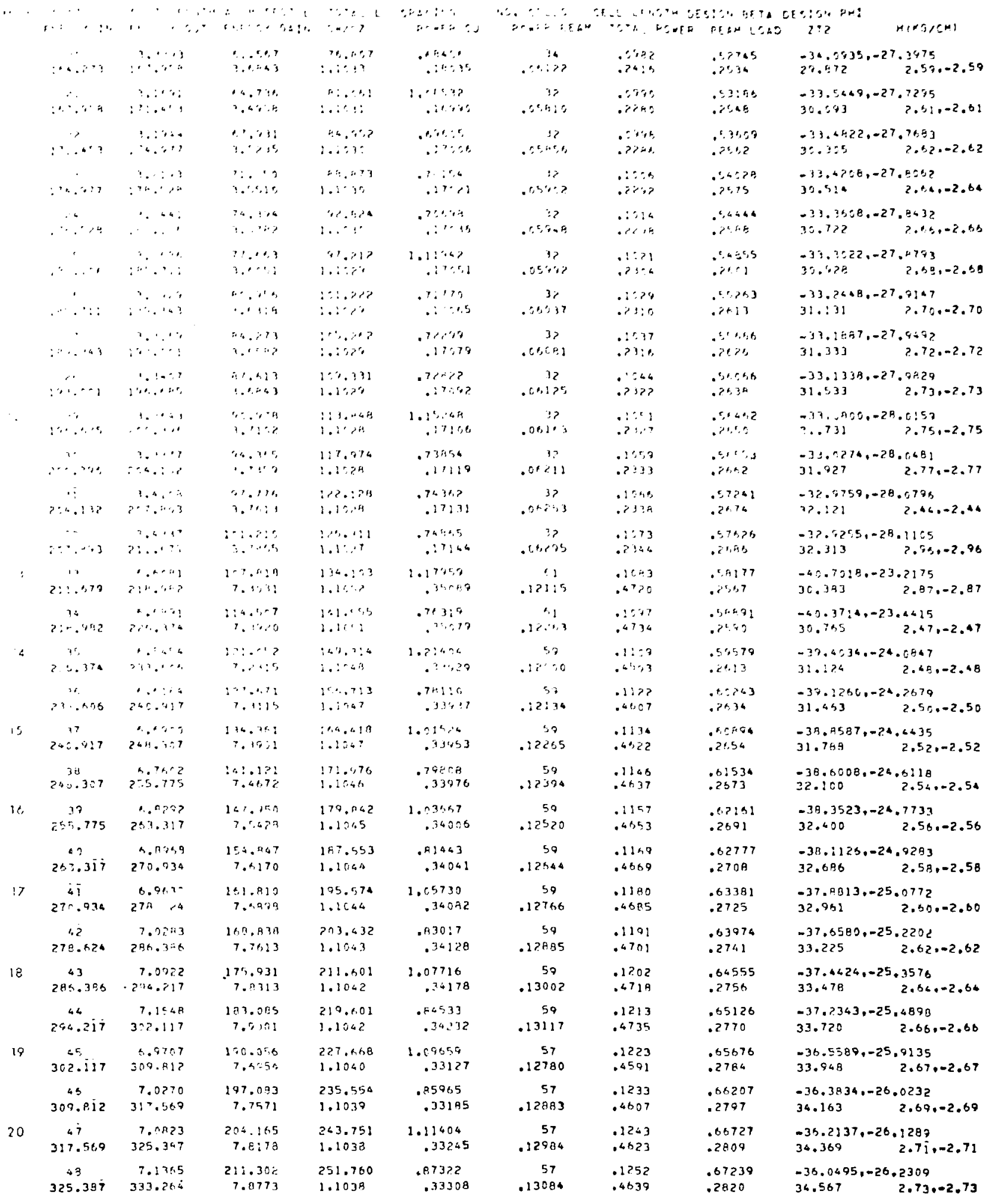




\begin{tabular}{|c|c|c|c|c|c|c|c|c|c|}
\hline$\because \quad$ : & $E+1=-, \quad: 4$ & $\begin{array}{l}\cdots,: \cdots \\
\cdots, \cdots\end{array}$ & 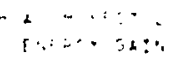 & $+\cdots$ & 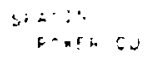 & $\because: x_{0}=0$ & 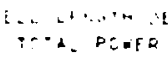 & 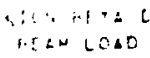 & 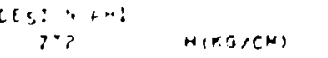 \\
\hline \multirow[t]{2}{*}{. } & $3+\ldots$ & \begin{aligned}$\ddots & \vdots \\
$\hdashline & -\end{aligned} & $\because \cdots \cdots$ & $\because \because{ }^{4}:$ & $\therefore: \cdots$ & $\begin{array}{c}2+4 \\
\therefore 2 \times 1\end{array}$ & $\therefore \therefore$ & $\begin{array}{l}\because+1< \\
\therefore+1\end{array}$ & 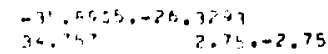 \\
\hline & $\therefore+c:=$ & $\therefore \cdot$ & $\therefore \therefore$ & 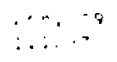 & $\begin{array}{ll}\ldots \\
\cdots\end{array}$ & $\therefore 7$ & $\therefore \because$ & $\begin{array}{l}* a+1 \\
\because \cdots 2\end{array}$ & $\begin{array}{l}-\because 4,70,-20.4,43 \\
34 x+5 \quad 6,7,-2.77\end{array}$ \\
\hline \multirow[t]{8}{*}{$\cdots$} & $\approx$ & $\because \ldots$ & r... & 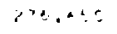 & 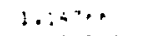 & $\therefore ?$ & $\therefore \therefore:$ & An: & $-15.4+75 .-20.5: 0=$ \\
\hline & $i 6 . .73$ & $y+\ldots+z$ & $\ldots, \cdots$ & $: \ldots:: 4$ & $.3: 1:$ & $.23,1$ & $-4 \cdot i \cdot 5$ & $.6 \cdot 2$ & $2.79 .-2.79$ \\
\hline & - & J... & $\ldots$ & $=\ldots \ldots$ &.+2 & $\leq$ & $\ldots$ & $.+5: 20$ & $-4,4030,-20, \ldots+44$ \\
\hline & $\therefore \because$ & $\cdot \cdot \cdot$ & $\therefore \ldots$ & $\therefore, \cdots$ & $. \because+2$ & $.2: 4+3$ & $\ldots+$ & . ' & $P . E:-2 . E 1$ \\
\hline & $\cdot$ & $* \ldots:$ & $\ldots \cdots$ & $\therefore \cdot: 2$ & $\therefore \ldots \ldots$ & $\therefore$ & $\therefore a^{3}$ & $\therefore \cdots, 0$ & $-\because, \cdots 3,-20,1+6=$ \\
\hline & $\because \cdot . ?$ & $\because, \cdot$ & $\cdots \cdots$ & $\therefore: \quad \therefore$ & $\therefore+b$ & . : :־4 & 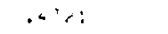 &.$\Delta \cdot$ & $2.43,-2.63$ \\
\hline & + & ,... & $\because \quad \ldots \cdots$ & $\because \ldots$ & $\cdots \cdots$ & $\cdots$ & $\therefore \cdots$ & $.71:: 2$ & $-\therefore \ldots, s,-2 t, \cdots t r$ \\
\hline & $\cdots \cdot \cdots$ & $\because \ldots \cdots$ & r. . . : : & $\therefore: \therefore *$ & $\cdot \cdots$ & $.21+4$ & .4 & .'...? & $7.05 .-7.5: 5$ \\
\hline \multirow[t]{4}{*}{$\cdot \cdot$} & & $\because \quad 1$ & $\therefore . .4:$ & $\cdots, \ldots$ & $\therefore .: \therefore$ & 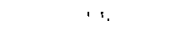 &.$: \because 4$ &.$\cdots ?$ & $-16,+71, \ldots-27, \ldots 77$ \\
\hline & $\because \quad \cdots$ & $\cdot \cdot \cdot$ & $\cdots$ & $\therefore::: 3$ & $\because \because: \because$ & 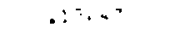 & $\ldots$ & $\cdots \cdots$ & $2.35 .-2.67$ \\
\hline & + & $\cdot \cdot$ & $A^{\prime}, \cdots$ & $\because: . \cdot:$ & $\ldots+\infty$ & $\because$ & $\therefore \therefore$ & 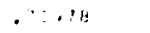 & $-4 .,+x=, 27,: 342$ \\
\hline & $\cdot \cdot \cdot \cdot \cdot$ & $\therefore \cdot \cdot$ & $\cdot \because:$ & $\therefore \therefore, 3$ & $\therefore+c$ &.$:: \therefore 7$ & $\cdots \cdot$ & in it & 2.58 .02 .87 \\
\hline \multirow[t]{4}{*}{. } & $\cdots$ & $\because \because: \leftarrow$ & 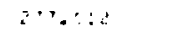 & $x \cdot t \cdot 1 \times 2$ & $2 .: 5 \cdot 4$ & $\therefore 3$ &.$: 1,1$ & $.7: 2^{2}$ & $-34.054 .0 .-27.2039$ \\
\hline & $2, \cdots$ & $4+\cdots$ & $\because \ldots \cdots$ & $\therefore .1 \div 13$ & $.32>0.3$ & $.136: 5$ & $.4: 7$ & .250 .04 & $7.9:--2.9 !$ \\
\hline & $\cdot$ & $\because$. &.$\quad \therefore \ldots$ & $\cdots,: 6_{2}$ & $\ldots+?$ & $x$ & $\therefore \cdots$ & $.: 1: 5$ & $=36.3404 .-27.7 \times 8:$ \\
\hline & 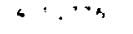 & $4: \quad \ldots$ & s. : : : r & $\therefore:: 17$ & $.3, \ldots$ & .13442 & $.6 \cdot 77$ & $\ldots+:$ & $2.93 .-2.93$ \\
\hline \multirow[t]{4}{*}{. } & $\div:$ & 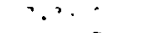 & $\because \because \cdots:$ & $3-2.746$ & $i . z^{*}+i$ & $\because$ & 114 & $.7+2=7$ & $-36, .2448,-27,722 i$ \\
\hline & $4: \operatorname{is}=$ & 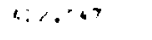 & 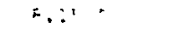 & $\therefore: 232$ & $\cdot 2 \cdot 11$ & $.235 ; 7$ & .4767 & $\therefore+1 A$ & $2.94 .-2.78$ \\
\hline & $\cdot$ & ?.r. & $\therefore \ldots: \cdots$ & $\because r . r 3$ & $.9+:$ & $\because 2$ & $\therefore \cdots$ & $.2+2$ & $-34.0432 .-27.7831$ \\
\hline & $4 \cdot .4$ & $4 \pi \cdot=$ & $2 . .4$ & $\therefore: \quad \cdot$ & $\cdots, \cdots n$ & $.1 \div: 2$ & $.4 \cdot 2$ & $.7+44$ & $30.91 \quad 2.99,-2.98$ \\
\hline \multirow[t]{4}{*}{ - i } & $\cdot:$ & $\because 4$ & $\cdot \cdot ?$ & $\because \cdots \cdot 0$ & $\therefore .2, \cdots$ & 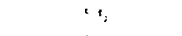 & . : pre & $.7,50$ & -34.0646 .027 .4523 \\
\hline & 6.14 & $4: 4,4: \therefore$ & $1 . .4 \cdot 4$ & $\therefore: \cdots$ & $.1 .+2$ & $. \therefore 17: 5$ &.+1.7 & $.2 \cdot 30$ & $3.0 \%,-3.00$ \\
\hline & $1=$ & $\because: \leftrightarrow$ & $.7: \ldots$ & $\because 764$ & $1+: 4 ?$ & $\therefore$ & $\therefore \cdots$ & .12721 & $-33.5 .4 P A .-27.505 \mathrm{~A}$ \\
\hline & $4 . .44^{\circ}$ & $6+1+-\infty$ & $\therefore \ldots$ & $\ldots+?$ & $\because \because: a$ & $.1 .: 78$ & $.41 .: 2$ & 0.95 & $35.5 .3 \quad 3.0 .0 .0 .00$ \\
\hline \multirow[t]{4}{*}{. : } & 17 & $\because \cdots$ & 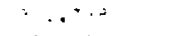 & $\because \cdot x>7$ & $1.2 \cdot r \cdot \beta$ & $\because 8$ & $\therefore ;, y$ & $.7: 746$ & $-33.5557,-27.54 .53$ \\
\hline & $\cdots+\ln 4$ & $4: .:$ & 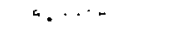 & $\therefore::=$ & $.3 \cdot \because 4$ & $.23 \div 46$ & .218 .4 & $.2+4 ?$ & $30.145 \quad 3.00 .-3.00$ \\
\hline & 16 & $\because \cdots$ & 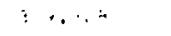 & $7+4.6 \cdot A$ & $.+\cdots:-r_{i}$ & 5,5 & $\therefore$ : & $.741: 3$ & $-73.7053,-27.4533$ \\
\hline & $6 \times \quad .:$ & 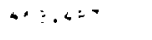 & $\therefore \ldots r$ & $: \ldots$ &.$\because 2.2$ & $.234: 5$ & $.412 !$ & .2949 & $3.62 .-3.00$ \\
\hline \multirow[t]{4}{*}{$\ldots$} & 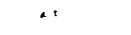 & 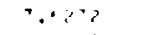 & 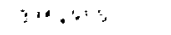 & 25.949 & $1.74 \times 21$ & $1: 5$ & .1357 & .74474 & $-33.5775,-27,6717$ \\
\hline & $4 . .27$ & $4: \ldots$ & 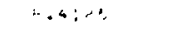 & $1 .: \div$ & .7 .77 & $.23 r_{1} 33$ & .6735 & $.2 \times 53$ & $3.00 .-3.00$ \\
\hline & $\cdots$ & $\because \cdots$ & $\therefore 4 . .2$ & $2: ? \cdot 18$ & $. x+2::$ & 55 & $.231,3$ & .74327 & $-33.5923 .-27.722 \mathrm{k}$ \\
\hline & $4: .27 .7$ & $a: \cdot 1$ & $\therefore$. s i & $1.21>0$ & $.74: 60$ & .24050 & .4750 & .7558 & $3.30 .-3.00$ \\
\hline \multirow[t]{4}{*}{$\because$} & .7 & $7.4: \cdots$ & $3: 2 \cdot r \div 7$ & $41: .724$ & 1.25723 & 53 & $.7 a r$ & $.7 \div 171$ & $-33.2515 .-27.0263$ \\
\hline & $A F .+2$ & $a$ and $1+3$ &.$+:{ }^{2} 12$ & 1.1079 & $.323: 4$ & .13601 & .4500 & .2763 & $37.050 \quad 3.00 .-3.00$ \\
\hline & $x=$ & $\because 4::$ & $3=7 . \div 4$ & $4: 0,0,7$ & .79147 & 53 & 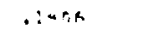 & .75501 & $-33.1793 .-27.0589$ \\
\hline & $4 \div 913$ & $470^{5}=$ & $x+2: 4$ & $\therefore: 57 ?$ & $.34,75$ & $.12 \times 0$ & $.45=4$ & $.2 r, B_{3}$ & $3.00,-3.00$ \\
\hline \multirow[t]{4}{*}{$\cdot$} & $\therefore$ & $\therefore$ с & $3 *+2$ & $4>7.2: 8$ & $2,8+x: ?$ & 53 & .1412 & $.75,5.25$ & $-33 .: 090 .-28.0105$ \\
\hline & $4=x \cdot 0^{-x}=$ & $\leq \cdots \cdots 2$ & $\because g=x$ & $2.1: 27$ & $.324<4$ & $.137: 9$ & .4517 & .2477 & $37.306 \quad 3.00 .-3.00$ \\
\hline & ${ }^{7 r}$ & 7.5160 & 374,465 & $435, F=0$ & .70713 & 53 & .1419 & .74144 & $-33.0407 .-28.0519$ \\
\hline & $5 \cdots \cdot 527$ & 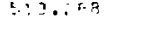 & $5.2+2$ & 2.10 .77 & $.7 \lambda 2$ & .13777 & $.4 x=0$ & .2976 & $37.279 \quad 3.03 .-3.00$ \\
\hline \multirow{4}{*}{$\therefore$} & $\because$ & 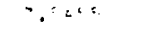 & $3=7 \cdot-2$ & 446.064 & 1.275 .5 & 5 & 11436 & .76457 & $-32.9741 .-28.0904$ \\
\hline & $\because: \because,:=0$ & $5 ?: .-9$ & $=.: i: \infty$ & 2.1027 & .77554 & .13433 & .0643 & .2530 & $37.349 \quad 3.000-3.00$ \\
\hline & -2 & $7,5 \div 8$ & $3: 2,1: 2$ & 452,553 & .71333 & 53 & .1429 & .76765 & $-32,9093,-28, i 2 \mathrm{E} 8$ \\
\hline & $52 \bar{i} \cdot * 0$ & $575.50,3$ & ค. $35: 7$ & 1.10 .37 & - $37,64,6$ & .13689 & $.465 B$ & .2983 & $37.616 \quad 3.05 .03 .00$ \\
\hline \multirow[t]{4}{*}{$\therefore:$} & 3 & 7.5 .5 & $3 \div 7.213$ & $45: .552$ & $1.00 .26,2$ & 53 & .14 .25 & .77358 & $-32.8462,-28,160 j$ \\
\hline & $52+.53$ & 574.769 & $9.3 \cdots$ & 2.2026 & .35738 & .13944 & $.4 t+6$ & .2457 & $37.681 \quad 3.00 .03 .00$ \\
\hline & $\because$ & $7.0 \div 1$ & 42.543 & $4.97 .9: 6$ & .71547 & 53 & .1441 & .77365 & $-32.7667 .-28.2024$ \\
\hline & $52=.3+9$ & 568.759 & 5.4136 & 1.1026 & $.328: 1$ & .13958 & .4621 & .2490 & $37.543 \quad 3.00 .-3.00$ \\
\hline \multirow[t]{4}{*}{$; 4$} & 75 & $7.5+40$ & 412.512 & 478.590 & 1.02038 & 53 & $.3 \div 46$ & .77658 & $-32.7249 .-28.2377$ \\
\hline & $54 m .768$ & 555.218 & 8.6503 & 1.1026 & $.32 R B 3$ & .16051 & .4653 & .2994 & $37.602 \quad 3.00 .-3.00$ \\
\hline & 76 & 7.5524 & $420.2=5$ & 467.007 & .72641 & $S_{3}$ & .1651 & .77945 & $-32.6666 .-28.2722$ \\
\hline & $555.2: 8$ & 563.699 & 8.4814 & 1.2026 & .32455 & .14103 & .4706 & .2997 & $3.00,-3,00$ \\
\hline
\end{tabular}




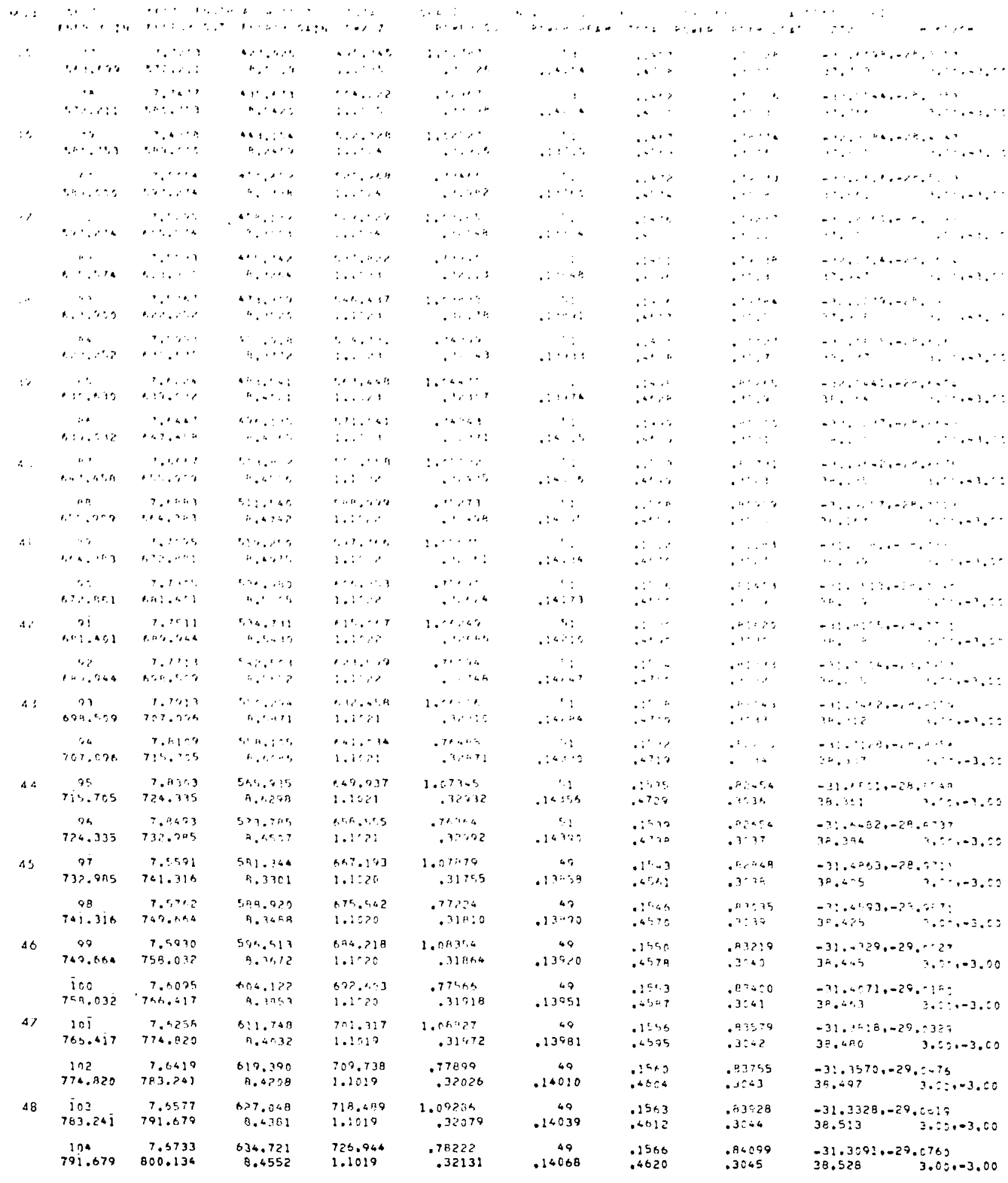




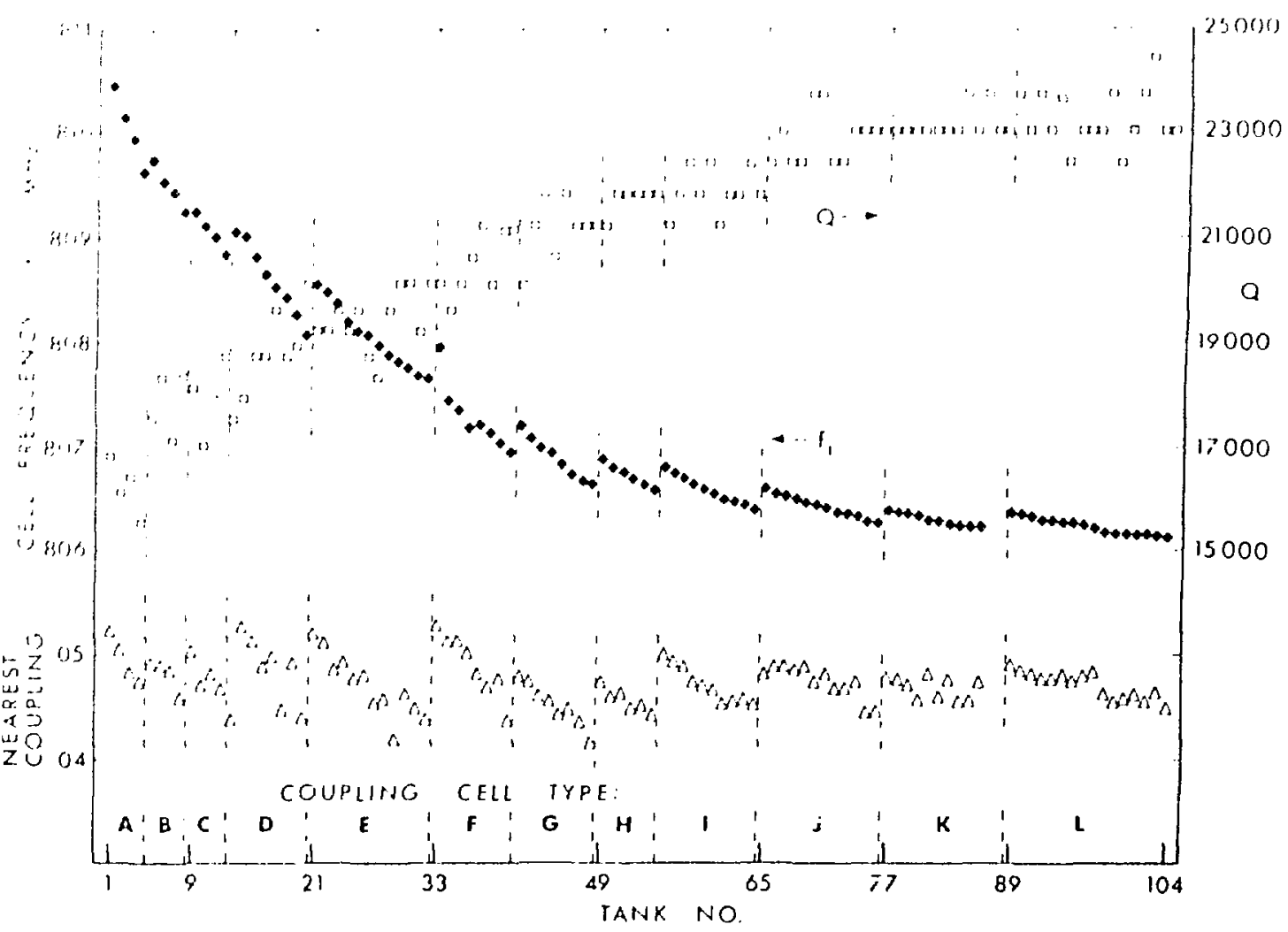

FiE. B-1. St lested parancters versus tank number for the 805-9Hz linac. 


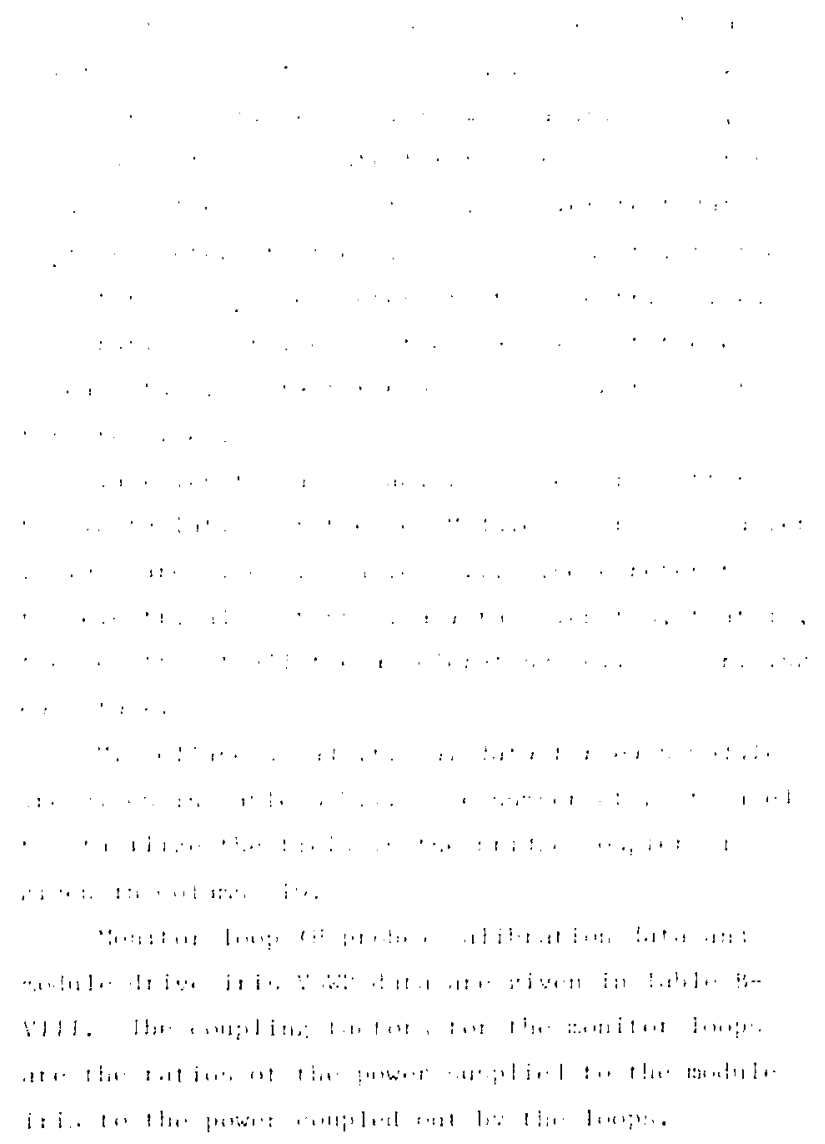

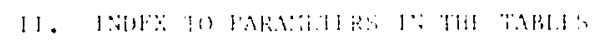
P.lramenter i.131, 1,1,itin

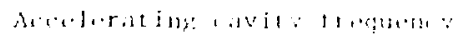

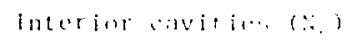

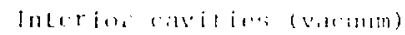

End cavitien, $\quad \therefore)$

Aceveration ravitits, no./tank

Aceess to beam tumncl

Encrancess to cumel

Gates along tunnel
VII 205

V1!

207

190

$111 \quad 110$

189

111 213

H1 212

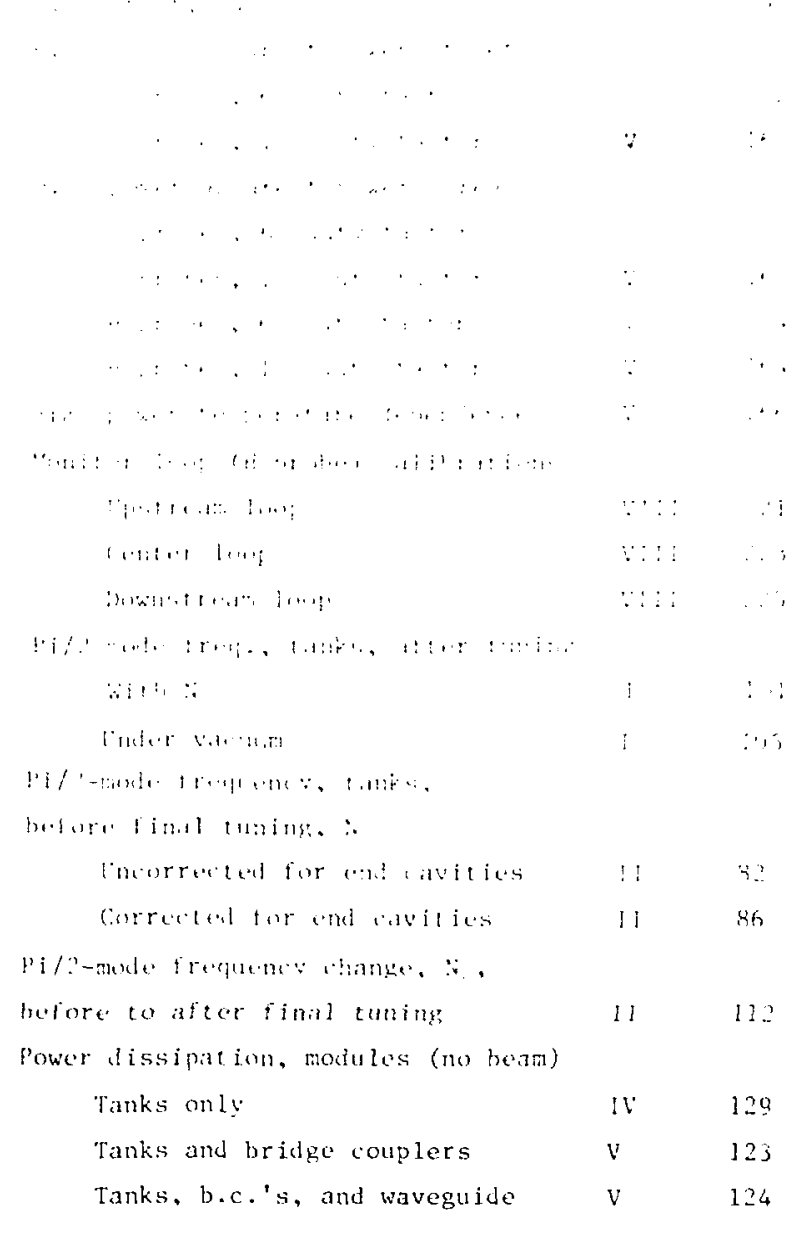

Beam hole diameter 


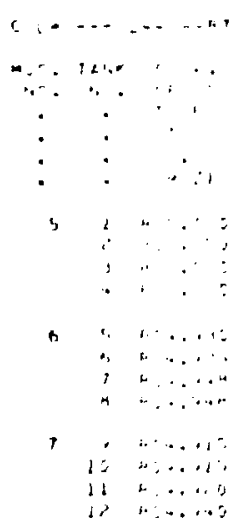

a $130 . \ldots \ldots$ i. a... id and

4

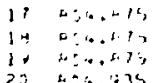

10

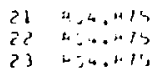
23 स: $24 .+13$

11

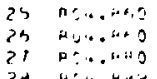

12

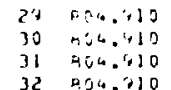

13330960123

$14 \quad 35$ now. 3505

$\begin{array}{ll}35 & 014.135 \\ 36 & 00.335\end{array}$

1537004.420

35 BC4.tho
639 BO..830 $40 \quad 104.920$

1741804.715

42004.410

$843 \quad 804.475$

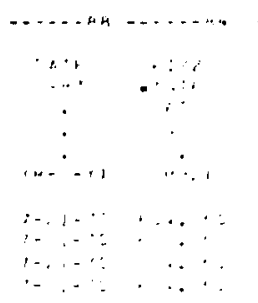

$\because \ldots 10, \ldots$. a : - , . . .

1. $\quad-\cdots \quad \ldots \quad \ldots$

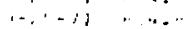

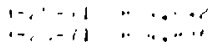
n- ..-11 ,.. . and r......

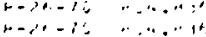

$\cdots+16 \quad n ; \ldots, d x$

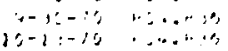
$3-3-31, \ldots .$.

$15-1-i 0 \quad \cdots \cdots+c$

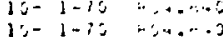
$\begin{array}{ll}10-1-i 0 & -3.0 .0\end{array}$

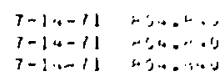

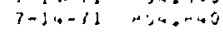

$1-1 !-11 \quad-3+.+\cdots$

$1-13-11$ in $4 ., \ldots+0$

$1-13-11+5+1+100$

$1-13-11+5, \ldots 40$

$4-17-12 \quad+00.6400$ $4-?, 2=1 ? \quad 4: 4,1: 40$ $4=3-12$ matalis $4-5-12$ Mi4.54

1-20-7! Mi4.940 $\begin{array}{ll}3-7-12 & 304.060 \\ 3-6-72 & 804.040\end{array}$ $2-15-72 \quad 504.1340$

5- $6-71 \quad 50 \% .8100$

$2-2 b-72 \quad 904 . \cdots+0$

$5-7-71$ e0., 010

$5-7-11$ a $64 ., 1 i 10$

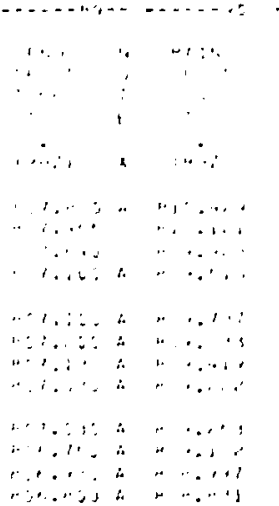

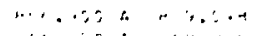

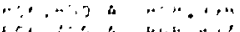
and

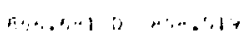

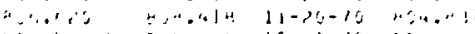

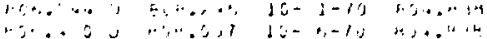

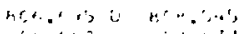

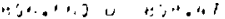

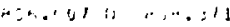

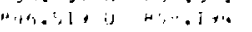

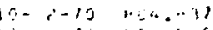

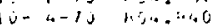

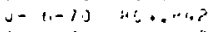

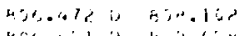

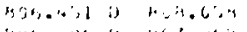

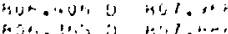

$11-i-10 \quad 41,2, \ldots+14$ $11-3-10+34.2+2$

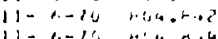

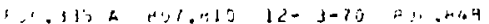

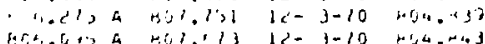

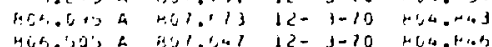

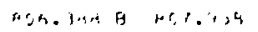

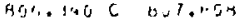

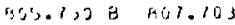

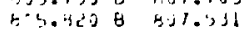

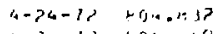
$4-64-13 \quad 434.69$ 4 - $4-11$ HOG

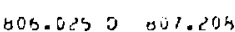
$\begin{array}{ll}\text { anb.442 } & 1107.313 \\ 106.047 & 00 \% .214\end{array}$ 605.452 \& 607.135

$1-.0-11 \quad 004.1152$ $7-14-75$ 80.4. $3-2-72$ P.5 4.846 $: 2-7<\quad 164.6106$

a) 30.015

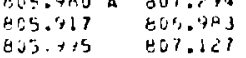
$5-7-71+004.424$ $13-24-72 \quad 004.340$

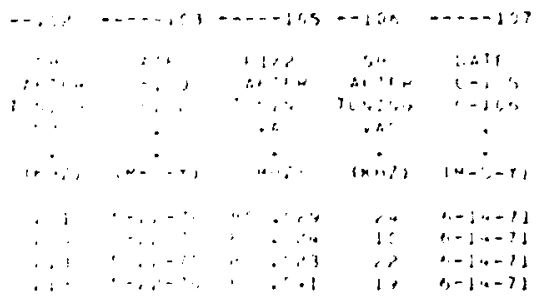

$\therefore \quad 1 . \ldots 1, \ldots, \ldots 17 \quad 1-31$

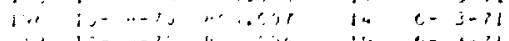

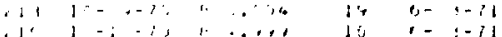

$1,1-\ldots-11 \quad \ldots,+1 \% \quad-10 \quad 4-21,-11$

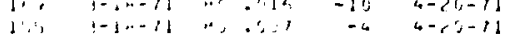

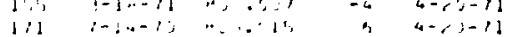
in i-1.10 w.

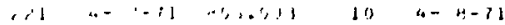

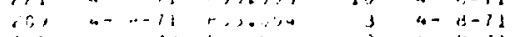

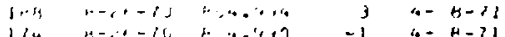

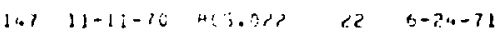

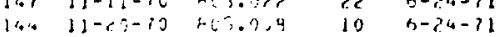
$11 . \quad 1 j-11-19$ ris.

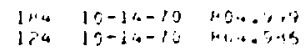
$\begin{array}{lll}134 & 12-14-16 & 11.40 .45 \\ 1,1 & 10-14-10 & 505.025\end{array}$

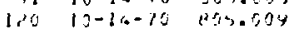

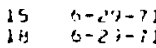

$\begin{array}{ll}22 & 4-26-71 \\ 19 & 6-23-71\end{array}$

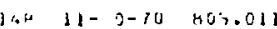

1.65 $11-0-10$ Howitis

$25 \quad 7-6-71$

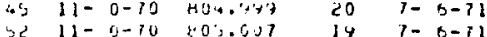
$113 \quad 11-0-70 \quad 003.01$

$7-6-71$
$7-b-71$

int $12-1,-10$ p5:.01A

$137 \quad 12-15=10 \quad 803.000$

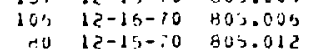

$31 \quad 3-11+-7$

$2 \quad 7-14-7$

$\begin{array}{rl}2 & 7-14-71 \\ 24 & 7-14-71\end{array}$

$4-24-12 \quad 405.001$

117 40-25-72 605.014

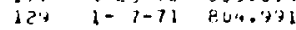

li3y 4-14-16 804.t45

$414-25-72$

21 $4-2 r^{2}-7$

$394-21-72$

16.) 1-20-71 40.

69 3-7-72 $104.9 \mathrm{Mz}$

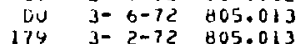

$26 \quad 4-4-12$

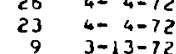

$154 \quad 5-3-11 \quad 805.011$

$\begin{array}{lll}158 & 5-3-71 & 805.011 \\ 116 & 3-2-72 & 805.010\end{array}$

$\begin{array}{rll}127 & 5-11-11 & 804.473 \\ 10 & 5-11-71 & 824.944\end{array}$ 


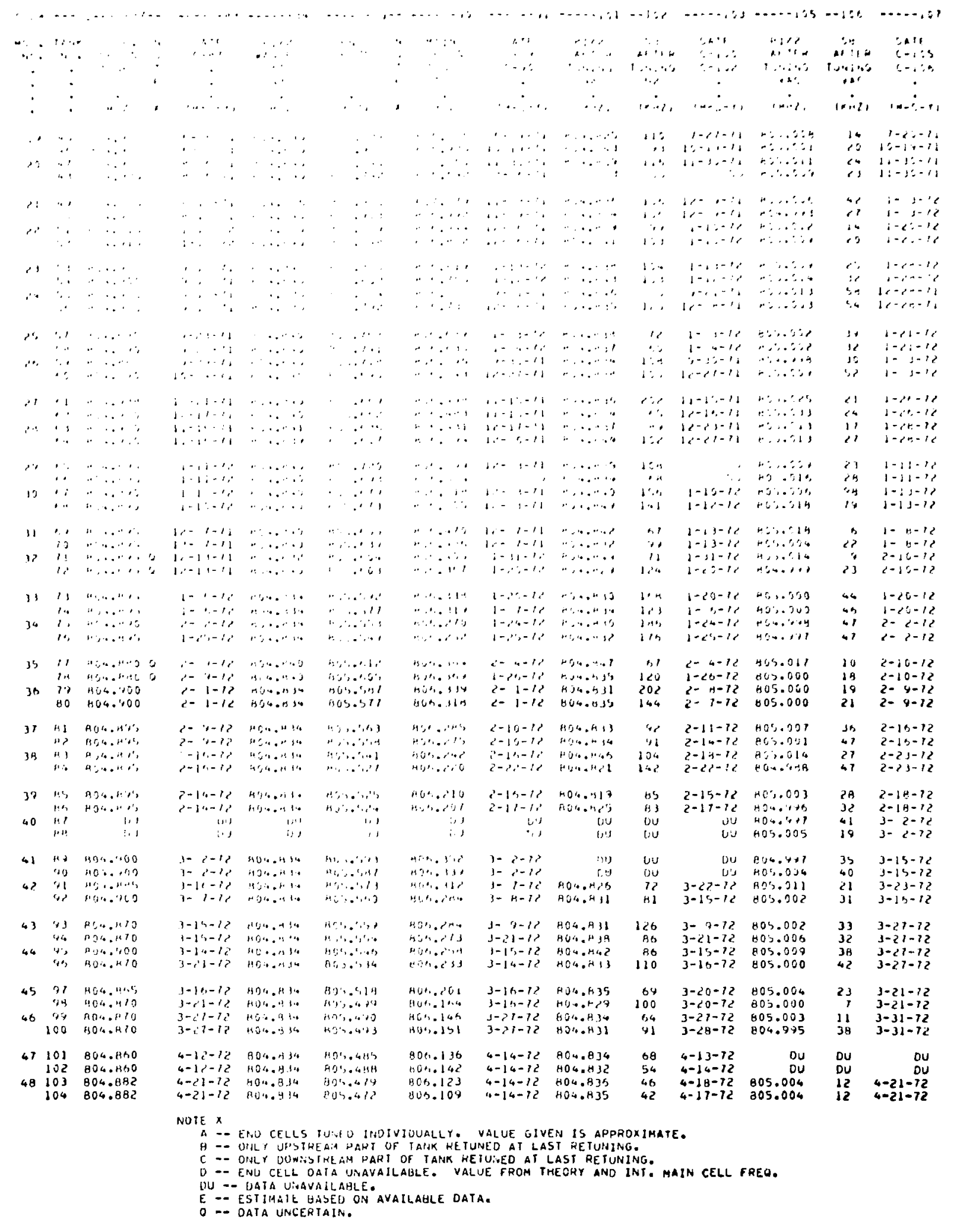




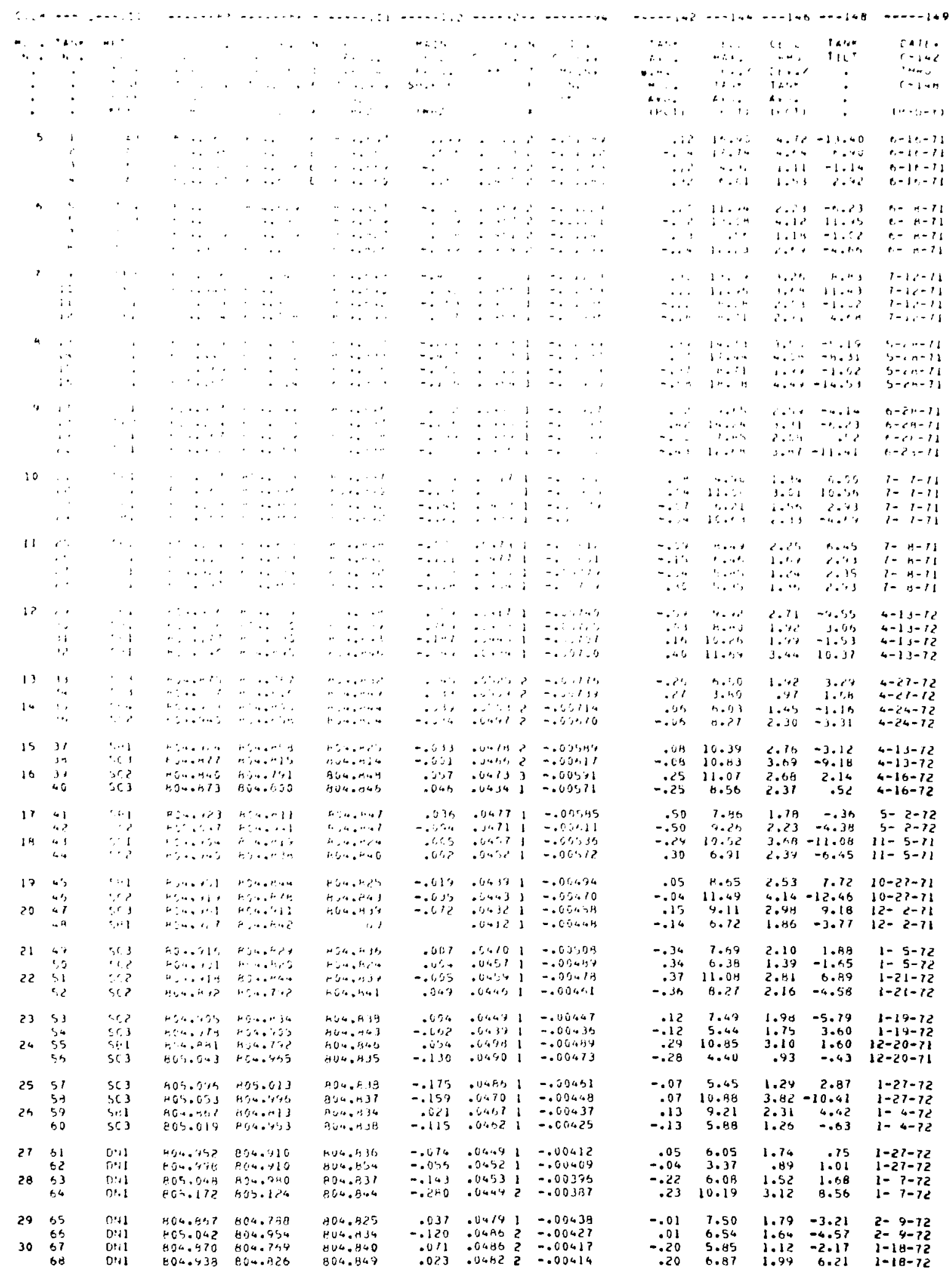




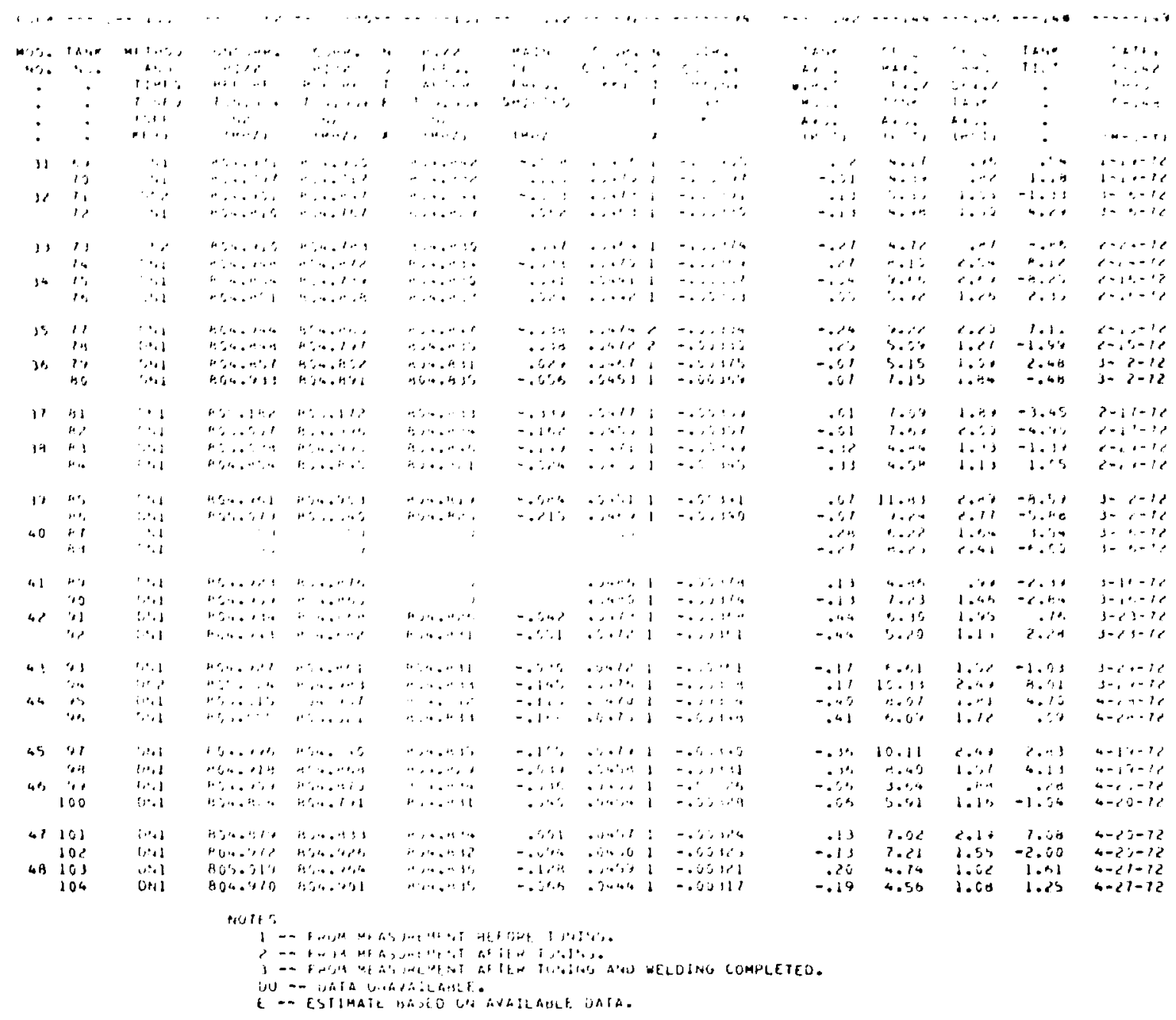

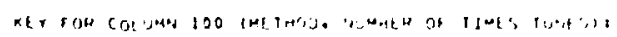

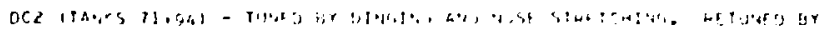

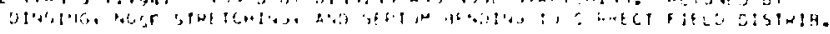

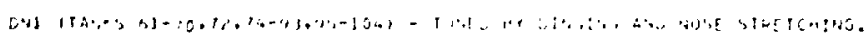

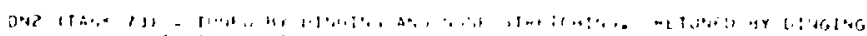
40,

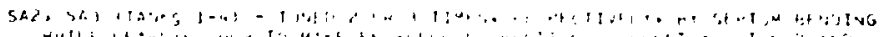

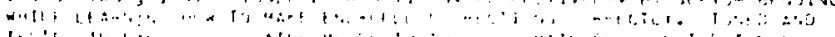

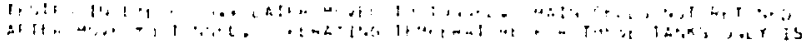

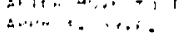

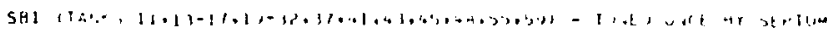
if ... 1 in.

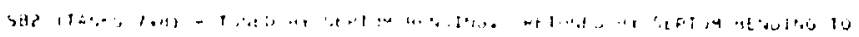

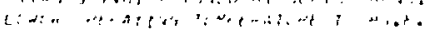

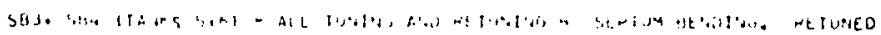

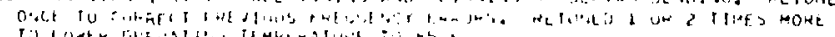

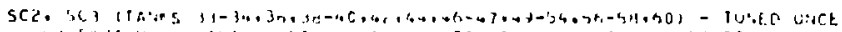
of 5terua of

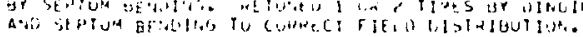

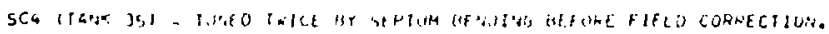

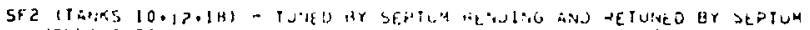

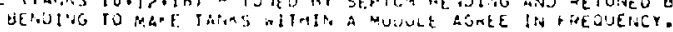

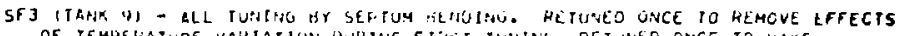

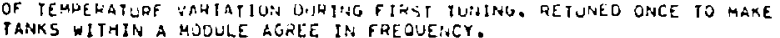




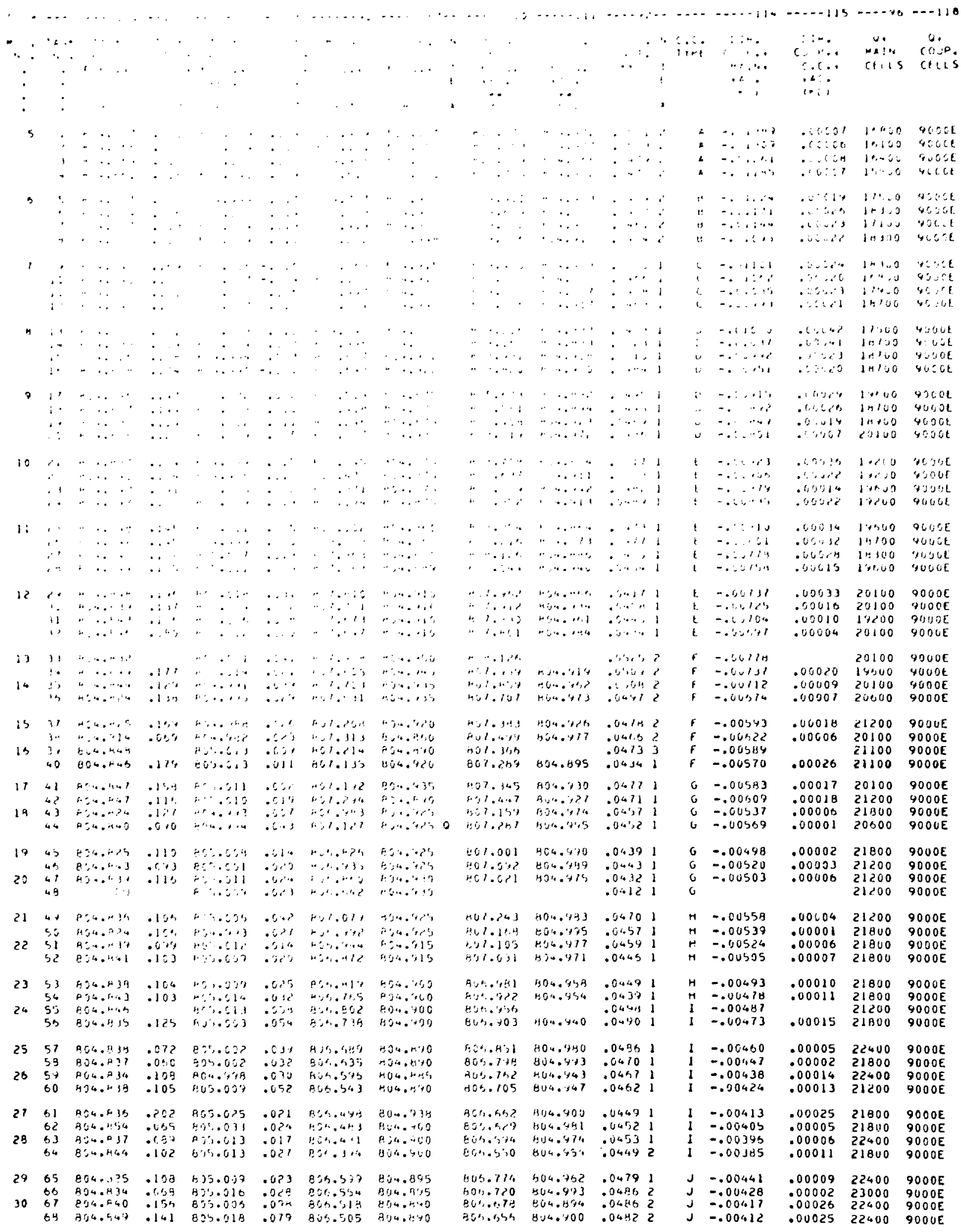




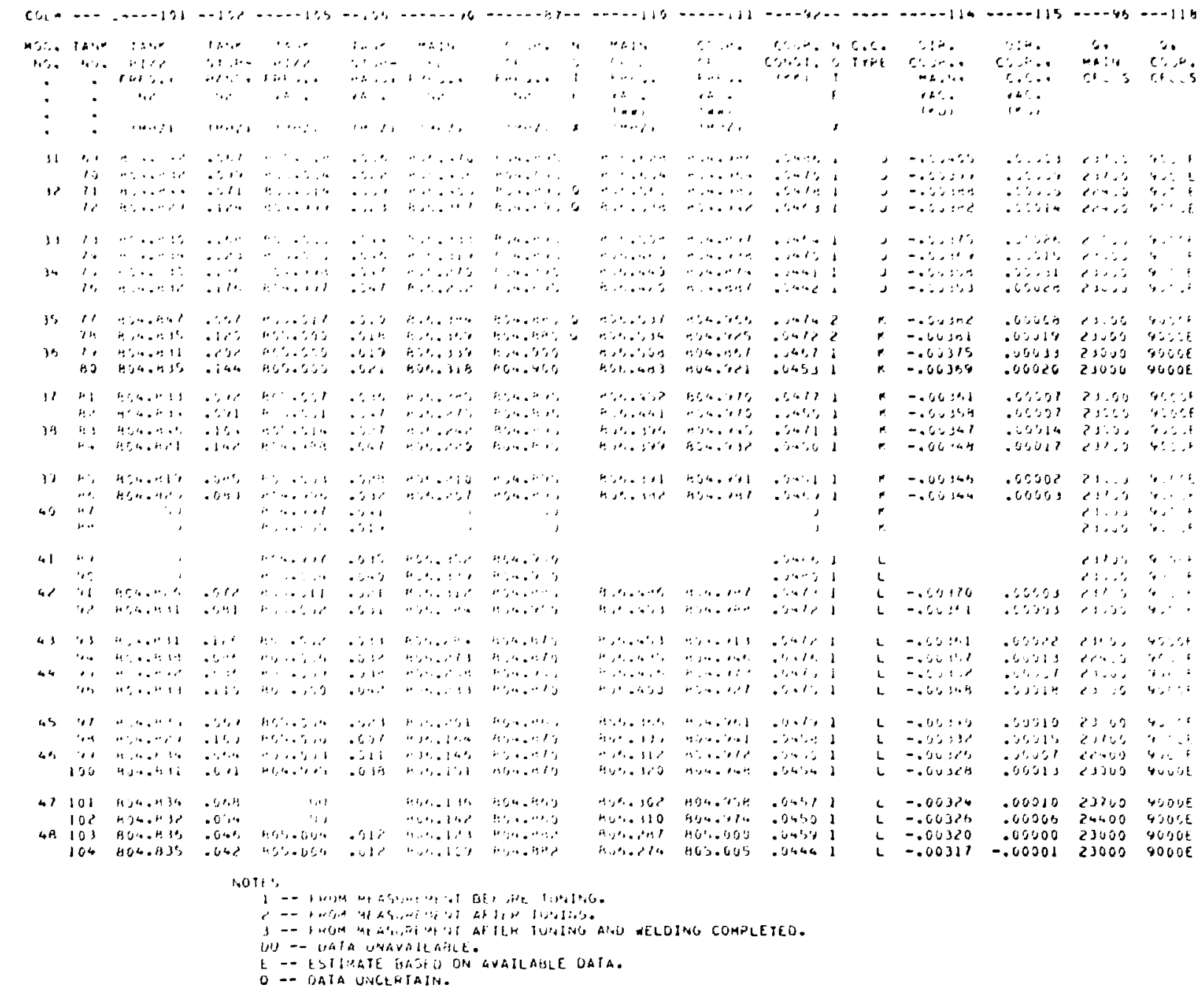




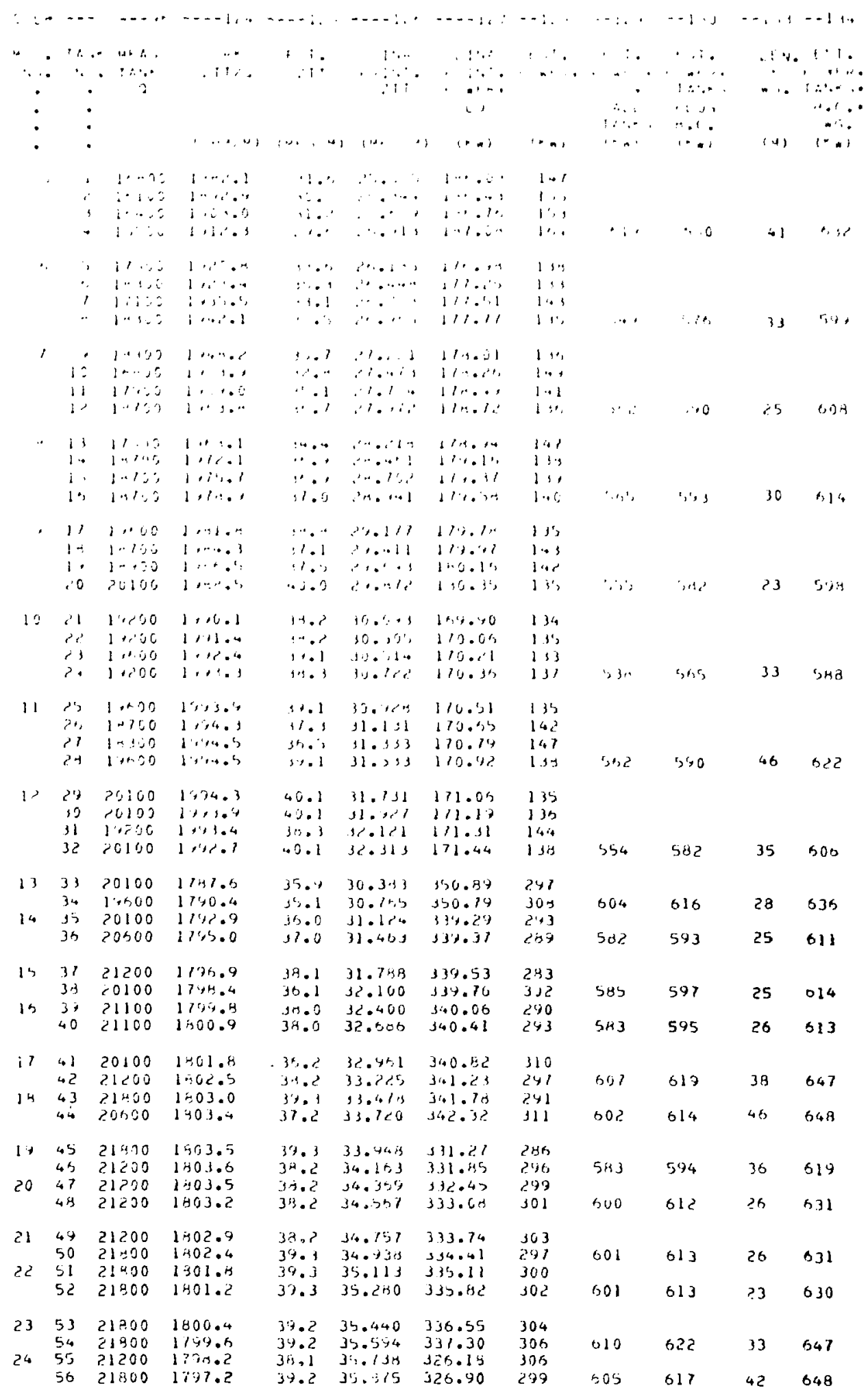




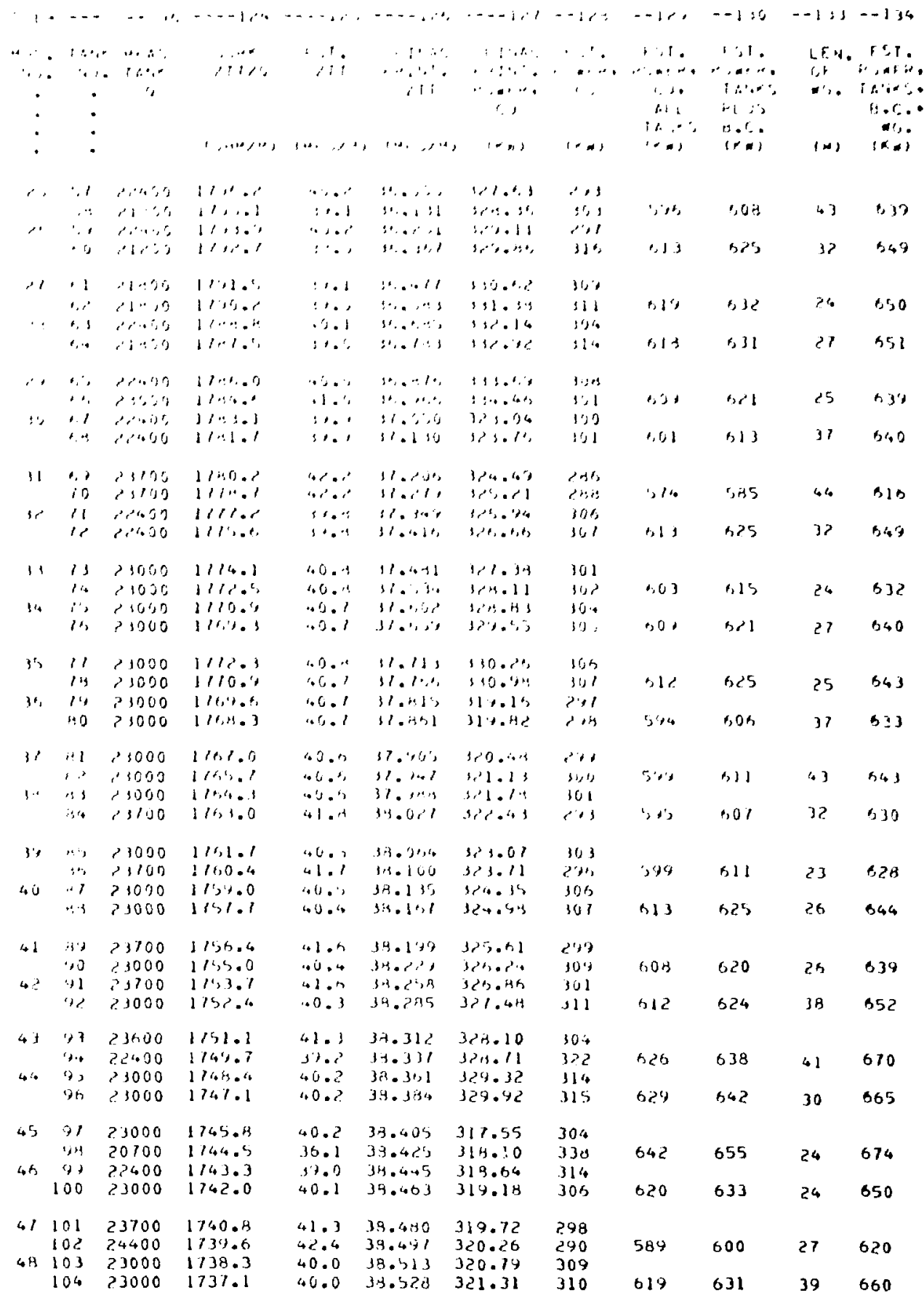




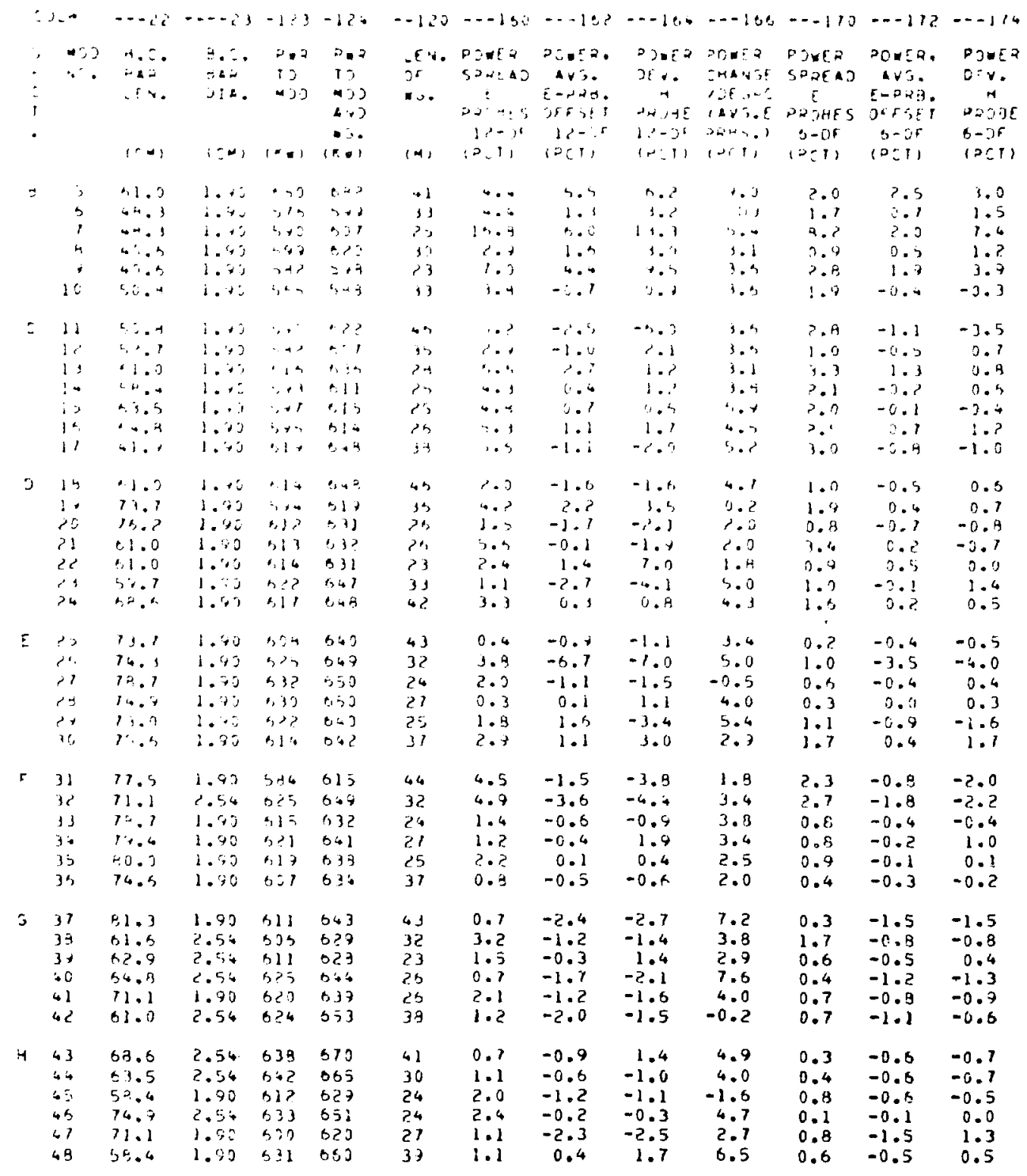


TABLE B-V]

TANK LENGIHS AND SPACINGS

\begin{tabular}{|c|c|c|c|c|c|c|c|c|c|c|}
\hline COL* & $-\infty-\infty$ & $---=$ & ----177 & ----178 & ----177 & ----178 & ----177 & $---\infty 170$ & ----177 & ---0178 \\
\hline $\begin{array}{l}\text { MOD } \\
\text { NO. }\end{array}$ & $\begin{array}{l}\text { FIRST } \\
\text { TANK } \\
\text { OF } \\
\text { MOO. }\end{array}$ & $\begin{array}{l}\text { LAST } \\
\text { TANK } \\
\text { OF } \\
\text { MOO. }\end{array}$ & $\begin{array}{l}\text { TANK I } \\
\text { LENGTH } \\
\text { (CM) }\end{array}$ & $\begin{array}{l}\text { SPACE } \\
\text { TO NEXT } \\
\text { PAPK } \\
\text { (CM) }\end{array}$ & $\begin{array}{l}\text { TANK } 2 \\
\text { LENG TH } \\
\text { (CM) }\end{array}$ & $\begin{array}{l}\text { SPACE } \\
\text { TO NEXT } \\
\text { TANK } \\
\text { (CM) }\end{array}$ & $\begin{array}{l}\text { PANK } 3 \\
\text { LENGTH } \\
\text { (CM) }\end{array}$ & $\begin{array}{l}\text { SPACE } \\
\text { TO NEKT } \\
\text { TANK } \\
\text { (C:4) }\end{array}$ & $\begin{array}{l}\text { TANK } \\
\text { LENGTH } \\
\text { (CH) }\end{array}$ & $\begin{array}{l}\text { SPACE } \\
\text { PO NEXT } \\
\text { TAPK } \\
\text { (CM) }\end{array}$ \\
\hline $\begin{array}{r}5 \\
6 \\
7 \\
8 \\
9 \\
10\end{array}$ & $\begin{array}{l}1 \\
5 \\
9 \\
13 \\
17 \\
21\end{array}$ & $\begin{array}{r}4 \\
8 \\
12 \\
16 \\
20 \\
24\end{array}$ & $\begin{array}{l}289.560 \\
291.515 \\
300.022 \\
312.842 \\
325.062 \\
317.030\end{array}$ & $\begin{array}{l}71.953 \\
75.383 \\
90.033 \\
65.141 \\
67.330 \\
69.680\end{array}$ & $\begin{array}{l}293.599 \\
290.782 \\
303.723 \\
315.567 \\
327.571 \\
319.344\end{array}$ & $\begin{array}{l}73.439 \\
77.236 \\
80.813 \\
65.639 \\
57.859 \\
70.411\end{array}$ & $\begin{array}{l}295.779 \\
293.969 \\
306.771 \\
318.922 \\
33 ! .236 \\
321.638\end{array}$ & $\begin{array}{l}14.585 \\
78.395 \\
61.669 \\
66.210 \\
68.428 \\
10.813\end{array}$ & $\begin{array}{l}300.794 \\
296.774 \\
310.086 \\
321.013 \\
334.049 \\
324.107\end{array}$ & $\begin{array}{l}108.493 \\
114.275 \\
100.353 \\
105.195 \\
107.910 \\
112.240\end{array}$ \\
\hline $\begin{array}{l}11 \\
12 \\
13 \\
14 \\
15 \\
16 \\
17\end{array}$ & $\begin{array}{l}25 \\
29 \\
33 \\
35 \\
37 \\
39 \\
41\end{array}$ & $\begin{array}{l}28 \\
32 \\
34 \\
36 \\
38 \\
40 \\
42\end{array}$ & $\begin{array}{l}326.728 \\
336.446 \\
661.514 \\
654.926 \\
669.556 \\
683.842 \\
696.824\end{array}$ & $\begin{array}{l}71.857 \\
73.721 \\
75.440 \\
78.113 \\
79.624 \\
81.432 \\
83.071\end{array}$ & $\begin{array}{l}329.113 \\
338.338 \\
509.511 \\
661.954 \\
677.034 \\
590.182 \\
703.341\end{array}$ & $\begin{array}{r}72.3+7 \\
74.648 \\
120.345 \\
100.338 \\
101.933 \\
104.673 \\
106.695\end{array}$ & $\begin{array}{l}331.727 \\
340.779\end{array}$ & $\begin{array}{l}12.898 \\
15.024\end{array}$ & $\begin{array}{l}333.764 \\
343.339\end{array}$ & $\begin{array}{l}115.336 \\
117.043\end{array}$ \\
\hline $\begin{array}{l}18 \\
19 \\
20 \\
21 \\
22 \\
23 \\
24\end{array}$ & $\begin{array}{l}43 \\
45 \\
47 \\
49 \\
51 \\
53 \\
55\end{array}$ & $\begin{array}{l}44 \\
46 \\
48 \\
50 \\
52 \\
54 \\
56\end{array}$ & $\begin{array}{l}709.564 \\
697.522 \\
709.042 \\
719.653 \\
730.075 \\
739.654 \\
722.681\end{array}$ & $\begin{array}{l}84.567 \\
85.997 \\
87.348 \\
88.707 \\
64.287 \\
65.039 \\
65.913\end{array}$ & $\begin{array}{l}715.769 \\
703.473 \\
714.108 \\
725.025 \\
734.888 \\
744.502 \\
726.745\end{array}$ & $\begin{array}{l}108.585 \\
109.639 \\
111.798 \\
112.997 \\
115.555 \\
117.295 \\
119.291\end{array}$ & & & & \\
\hline $\begin{array}{l}25 \\
25 \\
27 \\
23 \\
29 \\
30\end{array}$ & $\begin{array}{l}57 \\
59 \\
61 \\
63 \\
65 \\
67\end{array}$ & $\begin{array}{l}58 \\
60 \\
62 \\
64 \\
66 \\
62\end{array}$ & $\begin{array}{l}731.241 \\
739.861 \\
747.751 \\
755.500 \\
762.876 \\
741.540\end{array}$ & $\begin{array}{l}66.739 \\
67.452 \\
64.151 \\
54.859 \\
69.576 \\
70.134\end{array}$ & $\begin{array}{l}735.546 \\
743.684 \\
751.591 \\
759.054 \\
765.425 \\
744.987\end{array}$ & $\begin{array}{l}119.799 \\
121.303 \\
122.718 \\
124.107 \\
125.710 \\
126.655\end{array}$ & & & & \\
\hline $\begin{array}{l}31 \\
22 \\
33 \\
34 \\
35 \\
36\end{array}$ & $\begin{array}{l}69 \\
71 \\
73 \\
75 \\
77 \\
79\end{array}$ & $\begin{array}{l}70 \\
72 \\
74 \\
76 \\
78 \\
80\end{array}$ & $\begin{array}{l}70.0 .551 \\
754.647 \\
760.557 \\
766.031 \\
772.323 \\
763.452\end{array}$ & $\begin{array}{l}70.709 \\
71.265 \\
71.971 \\
72.423 \\
72.979 \\
73.515\end{array}$ & $\begin{array}{l}751.416 \\
757.123 \\
763.773 \\
769.500 \\
775.018 \\
750.806\end{array}$ & $\begin{array}{r}127.673 \\
99.761 \\
100.246 \\
101.112 \\
101.595 \\
102.403\end{array}$ & & & & \\
\hline $\begin{array}{l}37 \\
38 \\
39 \\
40 \\
41 \\
42\end{array}$ & $\begin{array}{l}81 \\
83 \\
85 \\
87 \\
89 \\
91\end{array}$ & $\begin{array}{l}82 \\
84 \\
86 \\
88 \\
90 \\
92\end{array}$ & $\begin{array}{l}753.303 \\
757.939 \\
762.366 \\
766.884 \\
771.180 \\
775.277\end{array}$ & $\begin{array}{l}73.927 \\
74.345 \\
74.833 \\
75.331 \\
75.662 \\
76.109\end{array}$ & $\begin{array}{l}755.729 \\
760.316 \\
764.579 \\
769.262 \\
773.387 \\
777.143\end{array}$ & $\begin{array}{l}102.944 \\
103.853 \\
104.343 \\
104.775 \\
105.857 \\
106.009\end{array}$ & & & & \\
\hline $\begin{array}{l}43 \\
44 \\
45 \\
46 \\
47 \\
48\end{array}$ & $\begin{array}{r}93 \\
95 \\
97 \\
99 \\
101 \\
103\end{array}$ & $\begin{array}{r}94 \\
96 \\
98 \\
100 \\
102 \\
104\end{array}$ & $\begin{array}{l}779.440 \\
793.069 \\
756.171 \\
759.409 \\
762.521 \\
765.863\end{array}$ & $\begin{array}{l}76.551 \\
75.939 \\
77.231 \\
77.549 \\
73.113 \\
78.235\end{array}$ & $\begin{array}{l}781.152 \\
784.868 \\
757.751 \\
751.073 \\
763.935 \\
757.151\end{array}$ & $\begin{array}{r}107.081 \\
107.526 \\
108.102 \\
108.555 \\
109.123\end{array}$ & & & & \\
\hline
\end{tabular}


TABL.E B-VII

ACCESS, COMRNICATIONS, AND MISCELIANEOUS DATA

\begin{tabular}{|c|c|c|c|c|c|c|c|c|c|c|c|c|}
\hline $\begin{array}{l}5 \\
\varepsilon \\
C \\
1 \\
0 \\
A\end{array}$ & $\begin{array}{l}c \\
0 \\
b \\
0 \\
R\end{array}$ & $\begin{array}{l}\text { MOJ } \\
\text { No. }\end{array}$ & $\begin{array}{l}\text { FIAST } \\
\text { TANK } \\
\text { OF } \\
\text { rOD. }\end{array}$ & $\begin{array}{l}\text { LAST } \\
\text { TANK } \\
\text { OF } \\
\text { MOO. }\end{array}$ & $\begin{array}{l}\text { ACCESS- } \\
\text { LARGE } \\
\text { MAZE } \\
\text { OR } \\
\text { SMAMAZE } \\
\text { DELEV. }\end{array}$ & $\begin{array}{l}\text { WALL } \\
\text { OR } \\
\text { GATE }\end{array}$ & $\begin{array}{ll}1 & P \\
N & H \\
T & O \\
E & N \\
R & E\end{array}$ & $\begin{array}{ll}T & P \\
E & H \\
L & 0 \\
\varepsilon & N \\
& E\end{array}$ & $\begin{array}{l}P \\
2 \\
5 \\
T \\
S\end{array}$ & $\begin{array}{l}\text { C.C. } \\
\text { TYPE }\end{array}$ & $\begin{array}{l}\text { BEAM } \\
\text { HOLE } \\
\text { DIA. } \\
\text { (CK) }\end{array}$ & $\begin{array}{l}\text { ACC. } \\
\text { CELLS } \\
\text { PER } \\
\text { TANK }\end{array}$ \\
\hline 8 & GREEN & $\begin{array}{r}5 \\
6 \\
7 \\
8 \\
9 \\
10\end{array}$ & $\begin{array}{r}1 \\
5 \\
9 \\
13 \\
17 \\
21\end{array}$ & $\begin{array}{r}4 \\
8 \\
12 \\
16 \\
20 \\
24\end{array}$ & 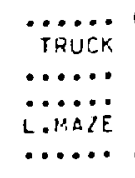 & 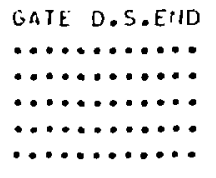 & $\begin{array}{l}\text { YES } \\
\text { YES } \\
\text { YES } \\
\text { YES } \\
\text { YES } \\
\text { YES }\end{array}$ & $\begin{array}{l}\ddot{009} \\
\ddot{3619} \\
\dot{56 i 9}\end{array}$ & $\begin{array}{l}1 \\
1 \\
5 \\
1 \\
1 \\
1\end{array}$ & $\begin{array}{l}A \\
B \\
C \\
D \\
D \\
E\end{array}$ & $\begin{array}{l}3.175 \\
3.175 \\
3.175 \\
3.175 \\
3.175 \\
3.175\end{array}$ & $\begin{array}{l}36 \\
34 \\
34 \\
34 \\
34 \\
32\end{array}$ \\
\hline C & BLUE & $\begin{array}{l}11 \\
12 \\
13 \\
14 \\
15 \\
16 \\
17\end{array}$ & $\begin{array}{l}25 \\
29 \\
33 \\
35 \\
37 \\
39 \\
91\end{array}$ & $\begin{array}{l}28 \\
32 \\
34 \\
36 \\
39 \\
40 \\
42\end{array}$ & $\begin{array}{l}\ldots \ldots \\
\ldots \ldots \\
\ldots \ldots \\
\ldots \ldots \\
\ddot{E} E \bar{E} \\
\ldots \ldots \\
\ldots \ldots\end{array}$ & 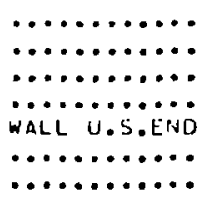 & $\begin{array}{l}\text { YES } \\
\text {-ME } \\
\text { YES } \\
\text { YES } \\
\text { YES } \\
\text { YES } \\
\text { YES }\end{array}$ & $\begin{array}{l}\ldots \ldots \\
\ldots \ldots \\
5019 \\
\ldots \ldots \\
5620\end{array}$ & $\begin{array}{l}1 \\
1 \\
5 \\
5 \\
7 \\
5 \\
5\end{array}$ & $\begin{array}{l}E \\
E \\
F \\
F \\
F \\
F \\
G\end{array}$ & $\begin{array}{l}3.175 \\
3.175 \\
3.810 \\
3.810 \\
3.810 \\
3.810 \\
3.810\end{array}$ & $\begin{array}{l}32 \\
32 \\
61 \\
59 \\
59 \\
59 \\
59\end{array}$ \\
\hline 0 & VIOLET & $\begin{array}{l}18 \\
19 \\
20 \\
21 \\
22 \\
23 \\
24\end{array}$ & $\begin{array}{l}43 \\
45 \\
47 \\
49 \\
51 \\
53 \\
55\end{array}$ & $\begin{array}{l}44 \\
46 \\
40 \\
50 \\
52 \\
54 \\
56\end{array}$ & 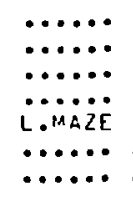 & $\begin{array}{l}\ldots \ldots \ldots \ldots \\
\ldots \ldots \\
\ldots \ldots \\
\ldots \ldots \\
\cdots \cdots\end{array}$ & $\begin{array}{l}\text { NO } \\
\text { YES } \\
\text { YES } \\
\text { YES } \\
\text { YES } \\
\text { YES } \\
\text { YES }\end{array}$ & $\begin{array}{l}\ldots \ldots \\
\ldots \ldots \\
5656 \\
\ldots \ldots \\
5656\end{array}$ & $\begin{array}{l}5 \\
5 \\
5 \\
5 \\
1 \\
1 \\
1\end{array}$ & $\begin{array}{l}G \\
G \\
G \\
H \\
H \\
H \\
I\end{array}$ & $\begin{array}{l}3.810 \\
3.810 \\
3.810 \\
3.810 \\
3.810 \\
3.810 \\
3.810\end{array}$ & $\begin{array}{l}59 \\
57 \\
57 \\
57 \\
57 \\
57 \\
55\end{array}$ \\
\hline$\varepsilon$ & REO & $\begin{array}{l}25 \\
26 \\
27 \\
28 \\
29 \\
30\end{array}$ & $\begin{array}{l}57 \\
53 \\
61 \\
63 \\
65 \\
67\end{array}$ & $\begin{array}{l}58 \\
60 \\
62 \\
64 \\
66 \\
68\end{array}$ & 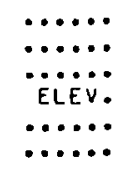 & 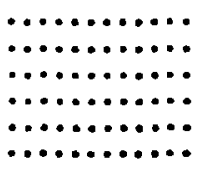 & $\begin{array}{l}\text { YES } \\
\text { YES } \\
\text { YES } \\
\text { YES } \\
\text { YES } \\
\text { YES }\end{array}$ & 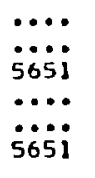 & $\begin{array}{l}1 \\
1 \\
1 \\
1 \\
1 \\
1\end{array}$ & $\begin{array}{l}1 \\
1 \\
I \\
I \\
J \\
J\end{array}$ & $\begin{array}{l}3.810 \\
3.810 \\
3.810 \\
3.810 \\
3.810 \\
3.810\end{array}$ & $\begin{array}{l}55 \\
55 \\
55 \\
55 \\
55 \\
53\end{array}$ \\
\hline $\mathbf{F}$ & ORANGE & $\begin{array}{l}31 \\
32 \\
33 \\
34 \\
35 \\
36\end{array}$ & $\begin{array}{l}69 \\
71 \\
73 \\
75 \\
77 \\
79\end{array}$ & $\begin{array}{l}70 \\
72 \\
74 \\
76 \\
78 \\
80\end{array}$ & 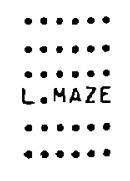 & $\because \ldots \ldots \ldots \ldots$ & $\begin{array}{l}\text { YES } \\
\text { YES } \\
\text { YES } \\
\text { YES } \\
\text { YES } \\
\text { YES }\end{array}$ & $\begin{array}{l}\ldots \ldots \\
\cdots \ldots \\
695 i \\
6951 \\
\ldots \ldots\end{array}$ & $\begin{array}{l}1 \\
1 \\
1 \\
5 \\
5 \\
5\end{array}$ & $\begin{array}{l}J \\
J \\
J \\
J \\
K \\
K\end{array}$ & $\begin{array}{l}3.810 \\
3.810 \\
3.810 \\
3.810 \\
3.810 \\
3.810\end{array}$ & $\begin{array}{l}53 \\
53 \\
53 \\
53 \\
53 \\
51\end{array}$ \\
\hline$G$ & PEACH & $\begin{array}{l}37 \\
38 \\
39 \\
40 \\
41 \\
42\end{array}$ & $\begin{array}{l}81 \\
63 \\
85 \\
87 \\
89 \\
91\end{array}$ & $\begin{array}{l}82 \\
84 \\
86 \\
88 \\
90 \\
92\end{array}$ & $\begin{array}{l}\cdots \ldots \ldots \\
\because \ldots \ldots \\
\ddot{M A Z E} \\
\cdots \ldots \ldots \\
\cdots \ldots\end{array}$ & $\begin{array}{l}\ldots \ldots \ldots \ldots \\
\ldots \ldots \ldots \ldots \\
\ldots \ldots \ldots \ldots \ldots \\
\text { GATE O.S.END }\end{array}$ & $\begin{array}{l}\text { YES } \\
\text { YES } \\
\text { NO } \\
\text { YES } \\
\text { YES } \\
\text { YES }\end{array}$ & $\begin{array}{l}\ldots \ldots \\
\ldots \ldots \\
4670 \\
4670 \\
\ldots \ldots\end{array}$ & $\begin{array}{l}5 \\
5 \\
5 \\
5 \\
5 \\
5\end{array}$ & $\begin{array}{l}K \\
K \\
K \\
K \\
L \\
L\end{array}$ & $\begin{array}{l}3.810 \\
3.810 \\
3.810 \\
3.810 \\
3.810 \\
3.810\end{array}$ & $\begin{array}{l}51 \\
51 \\
51 \\
51 \\
51 \\
51\end{array}$ \\
\hline H & YELLOH & $\begin{array}{l}43 \\
44 \\
45 \\
46 \\
47 \\
48\end{array}$ & $\begin{array}{r}93 \\
95 \\
97 \\
99 \\
101 \\
103\end{array}$ & $\begin{array}{l}96 \\
96 \\
98 \\
100 \\
102 \\
104\end{array}$ & 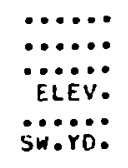 & 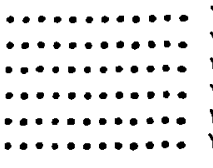 & $\begin{array}{l}\text { YES } \\
\text { YES } \\
\text { YES } \\
\text { YES } \\
\text { YES } \\
\text { YES }\end{array}$ & $\begin{array}{l}\ldots \ldots \\
\cdots \cdots \\
4853 \\
4853 \\
\cdots \cdots\end{array}$ & $\begin{array}{l}5 \\
7 \\
7 \\
7 \\
7 \\
7\end{array}$ & $\begin{array}{l}L \\
L \\
L \\
L \\
L\end{array}$ & $\begin{array}{l}3.810 \\
3.810 \\
3.810 \\
3.810 \\
3.810 \\
3.810\end{array}$ & $\begin{array}{l}51 \\
51 \\
49 \\
49 \\
49 \\
49\end{array}$ \\
\hline
\end{tabular}


TABLE B-VIII

MONITOR LOOP CALIBRATION AND IRIS VSWR DATA

\begin{tabular}{|c|c|c|c|c|c|c|c|c|c|c|c|c|}
\hline COLn & -220 & --221 & -222 & --223 & -224 & --225 & --234 & -----235 & --236 & -----237 & --239 & -----2 \\
\hline $\begin{array}{l}\text { MOO } \\
\text { NO. } \\
. \\
: \\
:\end{array}$ & $\begin{array}{l}\text { TANK } \\
\text { ND. } \\
\text { AND } \\
\text { SECT. } \\
C-221 \\
.\end{array}$ & $\begin{array}{l}\text { COUP. } \\
\text { PACT. } \\
\text { U.5. } \\
\text { LOOP } \\
\text { (OB) }\end{array}$ & $\begin{array}{l}\text { TANK } \\
\text { NO. } \\
\text { ANO } \\
\text { SEC I. } \\
\text { C-223 } \\
\quad\end{array}$ & $\begin{array}{l}\text { COUP. } \\
\text { FACT. } \\
\text { CTR. } \\
\text { LOOP } \\
\text { (DE) }\end{array}$ & $\begin{array}{l}\text { TANK } \\
\text { NO. } \\
\text { AND } \\
\text { SECT. } \\
\text { C-225 } \\
\quad .\end{array}$ & $\begin{array}{l}\text { COUP. } \\
\text { FACT. } \\
D .5 . \\
\text { LOOP } \\
\text { (DB) }\end{array}$ & $\begin{array}{l}\text { USWR. } \\
\text { B.C. } \\
\text { TUNING } \\
: \\
:\end{array}$ & $\begin{array}{c}\text { DATE } \\
C-234 \\
\bullet \\
\bullet \\
(M-0-Y)\end{array}$ & $\begin{array}{l}\text { YSWR. } \\
\text { IRI } 5 . \\
\text { LOW } \\
\text { PUR. } \\
.\end{array}$ & $\begin{array}{c}\text { DATE } \\
C-221 \\
C-223 \\
C-225 \\
C-236 \\
(M-D-Y)\end{array}$ & $\begin{array}{l}\text { USWR. } \\
\text { W.G. } \\
\text { MIGH } \\
\text { PWR. } \\
\text { G-PCT } \\
\text {. }\end{array}$ & $\begin{array}{c}\text { DATE } \\
C-23 B \\
\vdots \\
(H-D-V)\end{array}$ \\
\hline $\begin{array}{r}5 \\
6 \\
7 \\
8 \\
9 \\
10\end{array}$ & $\begin{array}{l}18 \\
5 A \\
7 A \\
13 A \\
17 A \\
218\end{array}$ & $\begin{array}{r}\text { DU } \\
\text { DU } \\
\text { UU } \\
91.4 \\
\text { DU } \\
\text { DU }\end{array}$ & $\begin{array}{r}28 \\
58 \\
108 \\
148 \\
108 \\
228\end{array}$ & $\begin{array}{r}\text { DU } \\
\text { DU } \\
\text { DU } \\
48.6 \\
\text { DU } \\
\text { DU }\end{array}$ & $\begin{array}{l}6 A \\
8 A \\
12 A \\
16 A \\
20 A \\
24 A\end{array}$ & $\begin{array}{r}\text { Du } \\
\text { Du } \\
\text { Du } \\
52.6 \\
\text { Du } \\
\text { Du }\end{array}$ & $\begin{array}{l}1.3 \\
1.6 \\
1.1 \\
1.4 \\
1.3 \\
1.2\end{array}$ & $\begin{array}{r}\text { DU } \\
\text { OU } \\
\text { DU } \\
\text { DU } \\
5-01-72 \\
5-01-72\end{array}$ & $\begin{array}{l}\text { DU } \\
\text { DU } \\
\text { DU } \\
1.3 \\
\text { Du } \\
\text { OU. }\end{array}$ & $|1-01-7|$ & $\begin{array}{l}\text { DU } \\
\text { DU } \\
\text { DU } \\
\text { DU } \\
\text { DU } \\
\text { DU }\end{array}$ & \\
\hline $\begin{array}{l}11 \\
12 \\
13 \\
14 \\
15 \\
16 \\
17\end{array}$ & $\begin{array}{l}75 B \\
270 \\
33 \mathrm{~B} \\
35 C \\
37 C \\
39 C \\
41 C\end{array}$ & $\begin{array}{r}\text { DU } \\
\text { DU } \\
53.6 \\
\text { DU } \\
48.5 \\
48.2 \\
52.2\end{array}$ & $\begin{array}{l}268 \\
308 \\
330 \\
350 \\
370 \\
390 \\
410\end{array}$ & $\begin{array}{c}\text { DU } \\
D U \\
53.2 \\
D U \\
48.7 \\
48.1101 \\
48.5\end{array}$ & $\begin{array}{r}28 A \\
32 A \\
340 \\
368 \\
348 \\
1408 \\
428\end{array}$ & $\begin{array}{r}\text { DU } \\
\text { DU } \\
52.5 \\
\text { DU } \\
48.8 \\
47.8 \\
50.9\end{array}$ & $\begin{array}{l}1.4 \\
1.0 \\
1.0 \\
1.5 \\
1.3 \\
1.3 \\
1.6\end{array}$ & $\begin{array}{l}5-01-72 \\
5-02-72 \\
4-12-72 \\
4-12-72 \\
4-21-72 \\
4-11-72 \\
4-3-72\end{array}$ & $\begin{array}{l}0 u \\
0 U \\
1.2 \\
0 u \\
1.6 \\
1.2 \\
\text { ou }\end{array}$ & $\begin{array}{r}4-27-72 \\
4-14-72 \\
12-3-71 \\
10-27-71\end{array}$ & $\begin{array}{l}\text { DU } \\
\text { DU } \\
1.2 \\
1.3 \\
1.5 \\
1.4 \\
1.8\end{array}$ & $\begin{array}{r}8-18-71 \\
4-25-72 \\
4-19-72 \\
11-16-71 \\
5-1-72\end{array}$ \\
\hline $\begin{array}{l}18 \\
19 \\
20 \\
21 \\
22 \\
23 \\
26\end{array}$ & $\begin{array}{l}430 \\
450 \\
47 C \\
490 \\
510 \\
530 \\
550\end{array}$ & $\begin{array}{l}29.1 \\
48.7 \\
48.3 \\
48.1 \\
48.3 \\
48.0 \\
49.1\end{array}$ & $\begin{array}{l}430 \\
450 \\
470 \\
490 \\
510 \\
530 \\
550\end{array}$ & $\begin{array}{l}49.4 \\
48.7 \\
48.5 \\
48.6 \\
48.3 \\
48.1 \\
50.1\end{array}$ & $\begin{array}{l}44 B \\
468 \\
48 B \\
50 B \\
52 B \\
54 B \\
56 B\end{array}$ & $\begin{array}{l}49.2 \\
48.1 \\
48.2 \\
48.2 \\
48.6 \\
48.4 \\
48.4\end{array}$ & $\begin{array}{l}1.4 \\
1.7 \\
1.3 \\
1.2 \\
1.2 \\
1.2 \\
1.3\end{array}$ & $\begin{array}{r}4-28-72 \\
11-4-71 \\
10-26-71 \\
11-9-71 \\
1-4-72 \\
1-20-72 \\
12-17-71\end{array}$ & $\begin{array}{l}1.3 \\
0 u \\
1.6 \\
1.3 \\
1.3 \\
1.3 \\
1.3\end{array}$ & $\begin{array}{r}12-10-71 \\
10-29-71 \\
12-10-71 \\
1-6-72 \\
1-17-72 \\
1-17-72 \\
1-7-72\end{array}$ & $\begin{array}{l}1.5 \\
1.5 \\
1.7 \\
1.5 \\
1.5 \\
1.3 \\
1.5\end{array}$ & $\begin{array}{r}1-10-72 \\
11-11-71 \\
1-11-72 \\
1-19-72 \\
2-3-72 \\
2-3-72 \\
1-21-12\end{array}$ \\
\hline $\begin{array}{l}25 \\
26 \\
27 \\
28 \\
29 \\
30\end{array}$ & $\begin{array}{l}570 \\
590 \\
610 \\
630 \\
650 \\
570\end{array}$ & $\begin{array}{l}49.2 \\
50.0 \\
48.1 \\
48.1 \\
48.1 \\
48.1\end{array}$ & $\begin{array}{l}570 \\
590 \\
610 \\
630 \\
650 \\
670\end{array}$ & $\begin{array}{l}48.7 \\
48.3 \\
48.2 \\
48.0 \\
48.1 \\
48.7\end{array}$ & $\begin{array}{l}58 B \\
60 B \\
628 \\
64 B \\
668 \\
68 B\end{array}$ & $\begin{array}{l}49.9 \\
48.4 \\
48.2 \\
48.2 \\
48.2 \\
48.1\end{array}$ & $\begin{array}{l}1.0 \\
1.3 \\
1.3 \\
1.2 \\
1.4 \\
1.4\end{array}$ & $\begin{array}{r}1-21-72 \\
1-3-72 \\
1-26-72 \\
1=4-72 \\
\text { DU } \\
\text { DU }\end{array}$ & $\begin{array}{l}1 \cdot 1 \\
1 \cdot 3 \\
1 \cdot 3 \\
1.5 \\
1.7 \\
1.6\end{array}$ & $\begin{array}{l}1-7-72 \\
1-17-72 \\
1-17-72 \\
1-17-72 \\
1-27-72 \\
1-27-72\end{array}$ & $\begin{array}{l}1.1 \\
1.6 \\
1.6 \\
1.5 \\
1.7 \\
1.6\end{array}$ & $\begin{array}{l}1-30-72 \\
1-27-72 \\
1-31-72 \\
2-9-72 \\
2-10-72 \\
2-11-72\end{array}$ \\
\hline $\begin{array}{l}31 \\
32 \\
33 \\
34 \\
35 \\
36\end{array}$ & $\begin{array}{l}690 \\
710 \\
730 \\
750 \\
770 \\
790\end{array}$ & $\begin{array}{l}48.1 \\
48.3 \\
48.3 \\
48.3 \\
49.0 \\
48.6\end{array}$ & $\begin{array}{l}6.90 \\
710 \\
730 \\
750 \\
770 \\
790\end{array}$ & $\begin{array}{l}50.5 \\
48.4 \\
51.7 \\
47.5 \\
49.4 \\
43.5\end{array}$ & $\begin{array}{l}70 B \\
72 B \\
76 B \\
76 B \\
78 B \\
80 B\end{array}$ & $\begin{array}{l}49.2 \\
48.4 \\
49.8 \\
48.3 \\
48.5 \\
48.9\end{array}$ & $\begin{array}{l}1.4 \\
1.1 \\
1.2 \\
1.3 \\
1.3 \\
1.3\end{array}$ & $\begin{array}{l}1-18-72 \\
2-1-72 \\
1-21-72 \\
2-16-72 \\
2-14-72 \\
2-16-72\end{array}$ & $\begin{array}{l}1.6 \\
1.2 \\
1.4 \\
1.3 \\
1.5 \\
1.5\end{array}$ & $\begin{array}{l}1-27-72 \\
1-27-72 \\
1-27-72 \\
2-25-72 \\
2-25-72 \\
2-28-72\end{array}$ & $\begin{array}{l}1.7 \\
1.5 \\
1.3 \\
1.5 \\
1.6 \\
2.0\end{array}$ & $\begin{array}{l}2-16-72 \\
2-17-72 \\
2-24-72 \\
3-1-72 \\
3-2-72 \\
3-3-72\end{array}$ \\
\hline $\begin{array}{l}37 \\
38 \\
39 \\
40 \\
4.1 \\
42\end{array}$ & $\begin{array}{l}81 C \\
9.7 C \\
85 C \\
87 C \\
89 C \\
91 C\end{array}$ & $\begin{array}{l}48.3 \\
48.3 \\
48.5 \\
48.7 \\
48.4 \\
48.5\end{array}$ & $\begin{array}{l}\text { B1D } \\
\text { B3D } \\
250 \\
870 \\
89 D \\
910\end{array}$ & $\begin{array}{l}48.7 \\
48.5 \\
48.2 \\
48.6 \\
48.5 \\
48.2\end{array}$ & $\begin{array}{l}82 B \\
848 \\
65 B \\
88 B \\
90 A \\
928\end{array}$ & $\begin{array}{l}48.6 \\
49.2 \\
48.5 \\
49.0 \\
48.5 \\
48.5\end{array}$ & $\begin{array}{l}1 \cdot 3 \\
1 \cdot 5 \\
1 \cdot 5 \\
1 \cdot 4 \\
1 \cdot 3 \\
1 \cdot 5\end{array}$ & $\begin{array}{l}2-17-72 \\
2-29-72 \\
3-1-72 \\
3-3-72 \\
3-15-72 \\
5-12-72\end{array}$ & $\begin{array}{l}1.5 \\
1.5 \\
1.5 \\
1.5 \\
2.0 \\
1.5\end{array}$ & $\begin{array}{l}2-28-72 \\
3-13-72 \\
3-13-72 \\
3-13-72 \\
3-13-72 \\
4-3-72\end{array}$ & $\begin{array}{l}1.4 \\
1.8 \\
1.7 \\
1.8 \\
1.6 \\
1.6\end{array}$ & $\begin{array}{l}3-13-72 \\
3-14-72 \\
1-24-72 \\
4-4-72 \\
3-28-72 \\
4-6=72\end{array}$ \\
\hline $\begin{array}{l}4.3 \\
44 \\
4.5 \\
48 \\
4.7 \\
4.7\end{array}$ & $\begin{array}{l}93 \mathrm{C} \\
75 \mathrm{C} \\
970 \\
99 \mathrm{C} \\
101 \mathrm{C} \\
103 \mathrm{C}\end{array}$ & $\begin{array}{l}48.9 \\
48.6 \\
48.6 \\
48.6 \\
48.6 \\
48.2\end{array}$ & $\begin{array}{l}930 \\
950 \\
970 \\
990 \\
1010 \\
1030\end{array}$ & $\begin{array}{l}48.4 \\
48.8 \\
48.6 \\
48.3 \\
48.3 \\
48.8\end{array}$ & $\begin{array}{l}94 \mathrm{~B} \\
96 \mathrm{~B} \\
98 \mathrm{~B} \\
100 \mathrm{~B} \\
1028 \\
104 \mathrm{~B}\end{array}$ & $\begin{array}{l}48.4 \\
48.6 \\
48.7 \\
48.4 \\
48.5 \\
48.3\end{array}$ & $\begin{array}{l}1.5 \\
1.6 \\
1.4 \\
1.4 \\
1.6 \\
1.2\end{array}$ & $\begin{array}{l}5-19-72 \\
5-19-72 \\
5-3-72 \\
5-3-72 \\
5-19-72 \\
5-19-72\end{array}$ & $\begin{array}{l}1.3 \\
1.6 \\
1.3 \\
1.4 \\
1.4 \\
1.1\end{array}$ & $\begin{array}{l}4-3-72 \\
5-4-72 \\
4-21-72 \\
4-21=72 \\
4-21-72 \\
5-4-72\end{array}$ & $\begin{array}{l}1.6 \\
1.6 \\
1.5 \\
1.4 \\
1.5 \\
1.3\end{array}$ & $\begin{array}{l}4-10-72 \\
5-17-72 \\
4-27-72 \\
5-4-72 \\
5-10-72 \\
5-17-72\end{array}$ \\
\hline
\end{tabular}

DII = DATA UNAYAilagle (*) CDUP. FACTOR MEASURED 12-13-71. 
Table C-I gives a program for finding the average resonant frequencies for interior accelerating cavities of a section or tank. Table C-II gives a program for calculating the frequencies to which end and interior accelerating cavities are to be set. The latter program used the average data found by the former, together with end cavity frequencies and the $\pi / 2$-mode frequency of the whole section or tank. These programs are for the Hewlett-Packard $9100 \mathrm{~A}$ calculator. The program in Table $C-I$ was recorded on side $A$ of a magnetic program card; in Table $C-I I$, on side $B$. The tuners were given the following instructions for using these programs:

(1) After calculator has been turned on and has warmed up, check that only $O N$ and $y$ buttons on printer are depressed.

(2) Set DECIMAL DIGITS wheel to 2.

(3) Push go to ( ) ( ), 0, 0 .

(4) inscrt $A$ end of magnetic program in slot and pust in.

(5) Press ENTI? button.

(6) Push ro то ( ) ( ), 0, 0 .

(7) Enter interfor cell frequencies for one tank from Main Cell Data Sheet - Freq. Before Tuning in the following manner:

- Key in value in $\mathrm{kHz}$, push CONT. The printer will print in the form 805999.01, where 805999 was the value entered, and 01 designates segment $1-2$.

- Key in subsequent values, pushing CONT after each. Only the part of the value that is changing needs to be keyed in. For example, if the previous value was 805999 and the present value is 806111 , only key $6,1,1,1$, CONT.

- If the printer does not print after you have pushed CONT, check the value displayed in the $z$ register.

If the value displayed is correct, push CONT. If the value displayed is not correct, key in correct value (in $x$ register), push CONT.
- If the last value entered and printed is incorrect, it may be corrected as follows. Push CLEAR, CONT. Then key in correct value, push CONT. The procedure works only for the last value entered. If an error is discovered farther back than the last value, you should start over.

After all interior cavity frequencies have been chtered, check segment number of last printed value (the 2 digits to the right of the decimal point). This should be 2 less than the tatal number of accelerating cavities for this tank.

Push the PAPER button on the printer to feed out the tape. Tear of $f$ tape, mark tank number and date on it, and file in ellvelope attached to back of previous page in looseleaf notebook. Then do second part of calculation:

(1) Set DECIMAL DIGITS wheel to 0 .

(2) Push ClEAR, go To ( ) ( ), 0, 0 .

(3) Insert $B$ end of magnetic program card in slot and push in.

(4) Press ENTER button.

(5) Push go to ( ) ( ), 0,0 .

(6) Key in upstream head cavity frequency in $\mathrm{klz}$, push 4.

(7) Key in downstream head cavity frequency, push $\uparrow$.

(8) Key in $\pi / 2$-mode frequency before tuning, push CONT. Program will print 11 numbers.

(9) Feed out tape, trim off and attach in the box on Checklist "1. An example of a Checklist "1 and the listing printed out by the $\mathrm{HP} 9100 \mathrm{~A}$ calculator is shown in Fig. 23 on page 27 of the main text of this report. The checklist gives the meaning of the 11 numbers printed.

The desired -12 -mode frequency is found in the program in Table C-It at steps 5.1 through 5.6. This may be changed as required for different temperames or atmospheres in the cavities.

sles C-III through C-V list programs for generating forms for tuning data (FFTD) used in the final tuning. The program in Table C-III is for septum bending; in Table C-IV, for nose stretching. These programs are written in FLEA, an extension of 
TABLE C-I

HP $9100 A$ PROGRAM TO FIND AVLRAGE INTERIOR ACCELERATING CAVITY FREQUENCY

\begin{tabular}{|c|c|c|c|c|c|}
\hline Step & Instruction & Code & Step & Instruction & Code \\
\hline 0.0 & rollt & 31. & 3.0 & 2 & 02 \\
\hline 0.1 & 0 & 00 & 3.1 & $\mathrm{rcl}$ & 61 \\
\hline 0.2 & $x \rightarrow()$ & 23 & 3.2 & if $x, y$ & 53 \\
\hline 0.3 & a & 13 & 3.3 & 4 & 04 \\
\hline 0.4 & $x \rightarrow(1)$ & 23 & 3.4 & 0 & 00 \\
\hline 0.5 & $d$ & 17 & 3.5 & - & 34 \\
\hline 0.6 & $x+()$ & 23 & 3.6 & roll $\hat{\imath}$ & 22 \\
\hline 0.7 & 9 & 11 & 3.7 & swap $x, y$ & 30 \\
\hline 0.8 & $x+()$ & 23 & 3.8 & $x$ & 36 \\
\hline 0.9 & c & 16 & 3.9 & roll + & 22 \\
\hline $0 . a$ & roll $\uparrow$ & 22 & $3 . a$ & swap $x, y$ & 30 \\
\hline $0 . \mathrm{b}$ & $x+()$ & 23 & $3 . b$ & go to - & 44 \\
\hline $0 . c$ & $\mathrm{~b}$ & 14 & $3 . c$ & 3 & 03 \\
\hline $0 . \mathrm{d}$ & clear & 20 & $3 . d$ & 2 & 02 \\
\hline 1.0 & $b$ & 14 & 4.0 & $\downarrow$ & 25 \\
\hline 1.1 & if $x=y$ & so & 4.1 & b & 14 \\
\hline 1.2 & 7 & 07 & 4.2 & + & 33 \\
\hline 1.3 & 8 & 10 & 4.3 & e & 12 \\
\hline 1.4 & $\log x$ & 75 & 4.4 & $\uparrow$ & 27 \\
\hline 1.5 & int $x$ & 64 & 4.5 & swap y, - & 24 \\
\hline 1.6 & $\uparrow$ & 27 & 4.6 & 9 & 11 \\
\hline 1.7 & 1 & 01 & 4.7 & if $x<y$ & 52 \\
\hline 1.8 & + & 33 & 4.8 & 6 & 06 \\
\hline 1.9 & 1 & 01 & 4.9 & 7 & 07 \\
\hline $1 . \mathrm{a}$ & 0 & 00 & $4 . a$ & $x+()$ & 23 \\
\hline $1 . b$ & $x$ & 36 & $4 \cdot b$ & 9 & 11 \\
\hline $1 . c$ & $\mathrm{acc}+$ & 60 & $4 . c$ & $\downarrow$ & 25 \\
\hline $1 . d$ & $\uparrow$ & 27 & 4.d & $y \rightarrow()$ & 40 \\
\hline 2.0 & a & 13 & 5.0 & a & 13 \\
\hline 2.1 & roll $\downarrow$ & 31 & 5.1 & d & 17 \\
\hline 2.2 & if $x>y$ & 53 & 5.2 & + & 33 \\
\hline 2.3 & 3 & 03 & 5.3 & $y \rightarrow()$ & 40 \\
\hline 2.4 & 1 & 01 & 5.4 & $d$ & 17 \\
\hline 2.5 & - & 34 & 5.5 & swap y, - & 24 \\
\hline 2.6 & roll $\uparrow$ & 22 & 5.6 & c & 16 \\
\hline 2.7 & swap $x, y$ & 30 & 5.7 & . & 21 \\
\hline 2.8 & $\therefore$ & 35 & 5.8 & 0 & 00 \\
\hline 2.9 & swap $x, y$ & 30 & 5.9 & 1 & 01 \\
\hline $2 . a$ & $\ln t x$ & 64 & 5.2 & + & 33 \\
\hline $2 . b$ & roll $\downarrow$ & 31 & 5.b & $y \rightarrow()$ & 40 \\
\hline $2 . c$ & go to -- & 44 & $5 . c$ & c & 16 \\
\hline $2 . d$ & 2 & 02 & 5.d & roll $t$ & 31 \\
\hline
\end{tabular}

Step Instruction Code

$6.0 \quad$ swap $x, y \quad 30$

$6.1+33$

6.2 print 45

6.3 stop 41

6.4 go to -- 44

6.5000

6.6 b 14

6.7 stop 41

6.8 swap y, - 24

$6.99 \quad 11$

6.a swap $x, y \quad 30$

6.b swap $x, y \quad 30$

6.c If $x>y \quad 53$

6.d 000

$7.0 \quad b \quad 14$

7.1 if $x<y \quad 52$

7.200

7.3 b 14

7.4 pause 57

7.5 go to -- 44

$\begin{array}{lll}7.6 & 4 & 04\end{array}$

7.7 a 13

7.8 swap $y,-\quad 24$

7.9 c $\quad 16$

$7 . a \quad 21$

7.b $0 \quad 00$

7.c $1 \quad 01$

$7 . \mathrm{d}-34$

$8.0 y \rightarrow() \quad 40$

$8.1 \mathrm{c} \quad 16$

$8.2 \mathrm{~d} \quad 17$

$8.3 \uparrow 27$

8.4 a 13

$8.5-34$

$8.6 y \rightarrow() \quad 40$

8.7 d 17

8.8 go to -- 44

8.9606

8.a 303

8.b end 46 
TABLE C-II

HP 9100A PROGRAM TO CALCULATE DESIRED ACCELERATING CAVITY FREQUENCIES

\begin{tabular}{|c|c|c|c|c|c|c|c|c|}
\hline Step & Instruction & Code & Step & Instruction & Code & Step & Instruction & Code \\
\hline 0.0 & roll & 31 & 2.b & 1 & 01 & 5.8 & $\mathbf{a}$ & 13 \\
\hline 0.1 & $\operatorname{acc}+$ & 60 & $2 . c$ & swap $x, y$ & 30 & 5.9 & $\mathrm{~d}$ & 17 \\
\hline 0.2 & rcl & 61 & $2 . d$ & - & 34 & $5 . a$ & swap $x, y$ & 30 \\
\hline 0.3 & print & 45 & 3.0 & $y \rightarrow()$ & 40 & $5 . b$ & set $f l a g$ & 54 \\
\hline 0.4 & rollt & 22 & 3.1 & $b$ & 14 & $5 . c$ & go to -- & 44 \\
\hline 0.5 & print & 45 & 3.2 & 2 & 02 & $5 . d$ & 2 & 02 \\
\hline 0.6 & print & 45 & 3.3 & $\vdots$ & 35 & 6.0 & 7 & 07 \\
\hline 0.7 & $x=()$ & 23 & 3.4 & 1 & 01 & 6.1 & $y \rightarrow()$ & 40 \\
\hline 0.8 & $\mathbf{a}$ & 13 & 3.5 & swap $x, y$ & 30 & 6.2 & $e$ & 12 \\
\hline 0.9 & ro11 & 22 & 3.6 & - & 34 & 6.3 & 1 & 01 \\
\hline $0 . a$ & print & 45 & 3.7 & $\mathrm{a}$ & 13 & 6.4 & swap $x, y$ & 30 \\
\hline $0 . b$ & $\mathrm{c}$ & 16 & 3.8 & swap $x, y$ & 30 & 6.5 & $\mathrm{~b}$ & 14 \\
\hline $0 . c$ & rollt & 22 & 3.9 & $\sqrt{x}$ & 76 & 6.6 & - & 34 \\
\hline $0 . d$ & enter exp & 26 & $3 . a$ & $x$ & 36 & 6.7 & $a$ & 13 \\
\hline 1.0 & 2 & 02 & $3 . b$ & print & 45 & 6.8 & swap $x, y$ & 30 \\
\hline 1.1 & $x$ & 36 & $3 . c$ & continue & 47 & 6.9 & $\sqrt{x}$ & 76 \\
\hline 1.2 & print & 45 & $3 . d$ & continue & 47 & b.a & $x$ & 36 \\
\hline 1.3 & 2 & 02 & 4.0 & if flag & 43 & $6 . b$ & print & 45 \\
\hline 1.4 & swap $x, y$ & 30 & 4.1 & 6 & 06 & $6 . c$ & $y \rightarrow()$ & 40 \\
\hline 1.5 & + & 33 & 4.2 & 1 & 01 & $6 . d$ & f & 15 \\
\hline 1.6 & print & 45 & 4.3 & 2 & 02 & 7.0 & $\mathrm{~b}$ & 14 \\
\hline 1.7 & $y-()$ & 40 & 4.4 & $x$ & 36 & 7.1 & swap $x, y$ & 30 \\
\hline 1.8 & $\mathrm{c}$ & 16 & 4.5 & e & 12 & 7.2 & enter exp & 26 \\
\hline 1.9 & swap $x, y$ & 30 & 4.6 & - & 34 & 7.3 & 6 & 06 \\
\hline $1: a$ & $\mathrm{~d}$ & 17 & 4.7 & $\mathrm{E}$ & 15 & 7.4 & $x$ & 36 \\
\hline $1 . b$ & swap $x, y$ & 30 & 4.8 & - & 34 & 7.5 & print & 45 \\
\hline 1. c & $:$ & 35 & $4 . ?$ & $c$ & 16 & 7.6 & print & 45 \\
\hline $1 . d$ & print & 45 & $4 . a$ & $\div$ & 35 & 7.7 & stop & 41 \\
\hline 2.0 & $y \rightarrow()$ & 40 & $4 . b$ & $\mathbf{a}$ & 13 & 7.8 & end & 46 \\
\hline 2.1 & $\mathrm{~d}$ & 17 & $4 . c$ & + & 33 & & & \\
\hline 2.2 & continue & 47 & $4 . d$ & print & 45 & & & \\
\hline 2.3 & continue & 47 & 5.0 & print & 45 & & & \\
\hline 2.4 & continue & 47 & 5.1 & 8 & 10 & & & \\
\hline 2.5 & continue & 47 & 5.2 & 0 & 00 & & & \\
\hline 2.6 & $a$ & 13 & 5.3 & 4 & 04 & & & \\
\hline 2.7 & $\div$ & 35 & 5.4 & 8 & 10 & & & \\
\hline 2.8 & $\downarrow$ & 25 & 5.5 & 3 & 03 & & & \\
\hline 2.9 & $\uparrow$ & 27 & 5.6 & 4 & 04 & & & \\
\hline $2 \cdot a$ & $x$ & 36 & 5.7 & $x \rightarrow()$ & 23 & & & \\
\hline
\end{tabular}


FORTRAN which permits top-down structured programming. Table $C-V$ lists a corresponding program for dinging and nose stretching, after the program was translated by the FLEAS preprocessor to standard FORTRAN. (Data cards are not shown. These are similar to the data cards shown in Table C-IV.) See Fig. 22 on page 25 for an example of the form generated by the program in Table C-ILI; and Fig. 24 on page 28 , by Table $\mathrm{C}-\mathrm{V}$.
Table C-VI lists a program ior comparing measured individual cavity data for sections compared with tanks (SCWT). The section data was from the measurements after brazing; the tank data, from measurements in the tunnel before final tuning. The calculation was made to check for large frequency errors in the measurements before the $f$ inal tuning was done. For an example of the output, sec Fig. 25 on page 29.

TABLE. C-[I]

PROGRAM FFTD, VERSION FOR SEPTUM BENJINO LASL Icientification No. LP-1070

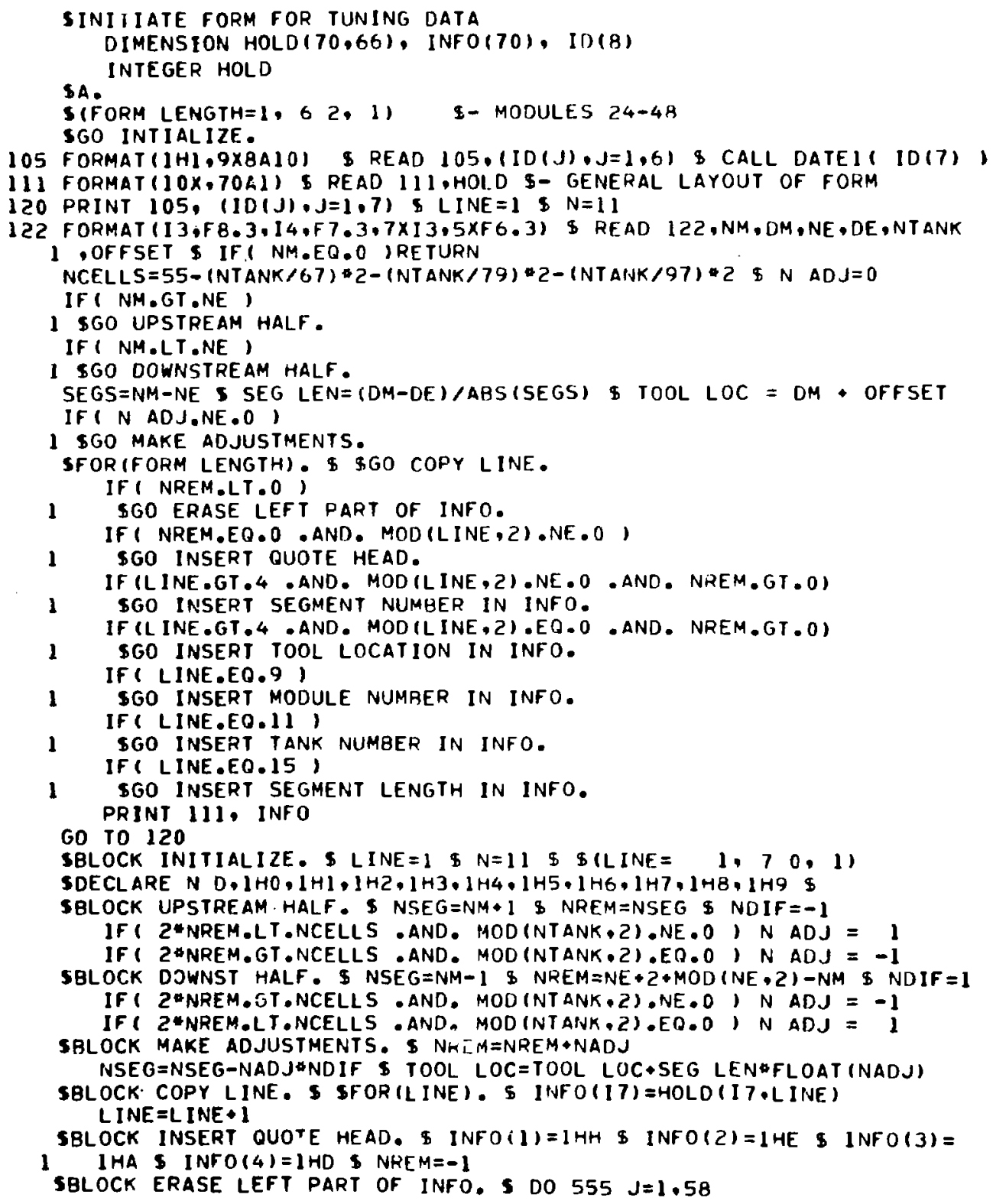


SBLOCK INSERT SEGMENT NUMBER IN INFO. \$N=3 \$ NDIG=2 \& NFRAC=0

$\checkmark A L U E=N S E G$ S \$GO INSERT VALUE IN INFO. \$ NSEG=NSEG+NDIF NREM $=$ NREM-1

SBLOCK INSERT TOOL LOCATION IN INFO. \& N=11 \$ NOIG=3 \$ NFRAC=2 VALUE $=$ TOOL LOC $\$$ BGO INSERT VALUE IN INFO. \$ TOOL LOC=TOOL LOC

1 - SEG LEN

SALOCK INSERT MODULE NUMBER IN INFO. S N=66 \$ NDIG=2 \& NFRAC=0 VALUE $=$ (NTANK・1 $1 / 2-4 \$ \$ G O$ INSERT VALUE IN INFO .

\$BLOCK INSERT TANK NUMBER IN INFO. \$N=60 \$NDIG=3 S NFRAC $=0$

VALUE =NTANK \$\$GO INSERT VALUE IN INFO.

IF (NDIF.LT * O) INFO $(64)=$ IHA S IF (NDIF.LT.O) INFO $(65)=1 \mathrm{HB}$

IF (NDIF.GT.0) INFO $(64)=1 H C \$$ IF (NDIF . GT . O) INFO $(65)=1 \mathrm{HD}$

SBLOCK INSERT SEGMENT LENGTH IN INFO. \$N=60 \$ NDIG=2 \$ NFRAC $=4$ VALUE =SEG LEN \$\$GO INSERT VALUE IN INFO.

SBLOCK INSERT VALUE IN INFO. S POWER=10.0* (NDIG-1)

VALUE $=A B S(V A L(U E)+0.5 *(10.0 *(-N F R A C)) \$-R O U N D$ LAST DIGIT $\$ M=0$

IF (POWER.LT.1. AND. POWER.GT.0.05) INFO(N) $=1 \mathrm{H}$.

IF (POWER.LT.1. AND. POWER.GT.0.05) $N=N+1$ S J=VALUE/POWER

IF (J.GT.O)M=1 \$-PAST IST NONZERO DIG \$ IF (M.GT.O) INFO $(N)=$

1

ND $(J+1)$ IF $(J \cdot G T .9)$ INFO $(N)=1 H * \$ N=N+1$ S VALUE =VALUE -

2 FLOAT $(J)$ OPOWER \& POWER=POWER/10.0

IF (2.0*POWER.GT. 10.0*(-NFRAC) ) GO TO 777

C

TO INSERT 9.99, SET NOIG=1 NFRAC $=2$ VALUE $=9.99$ (POS, VAL. ONLY)

SENO

SUBROUTINE STARTER(OUMMY) \$ RETURN \$ END

5. STOP PROCESSING

0000000000000000000000

1

01 SEGMENT TOOL

03

NUMBER

LOCATION

29

>... 11.11

28

$>-1 .-11.11$

0

10.11 .11

0

$1-\ldots 11.11$

0

$1 \ldots . .11$

$>--\infty$

$12 .-11.11$

0

10.11 .11

0

$>--.11 .11$

0

$10-11.11$

0

$1-\cdots \quad 11.1$

0

$>---$

0

$>-\infty-$

0

$>-\infty-$

0

$>--$

0

>-D...

0

r...-

0

$>-\infty-$

.11

.11

.11

.11

.11

.11
MAIN CELL DATA SHEET

FRER.,

C.C.SHORTED

FREQ. BEF ORE

TUNING
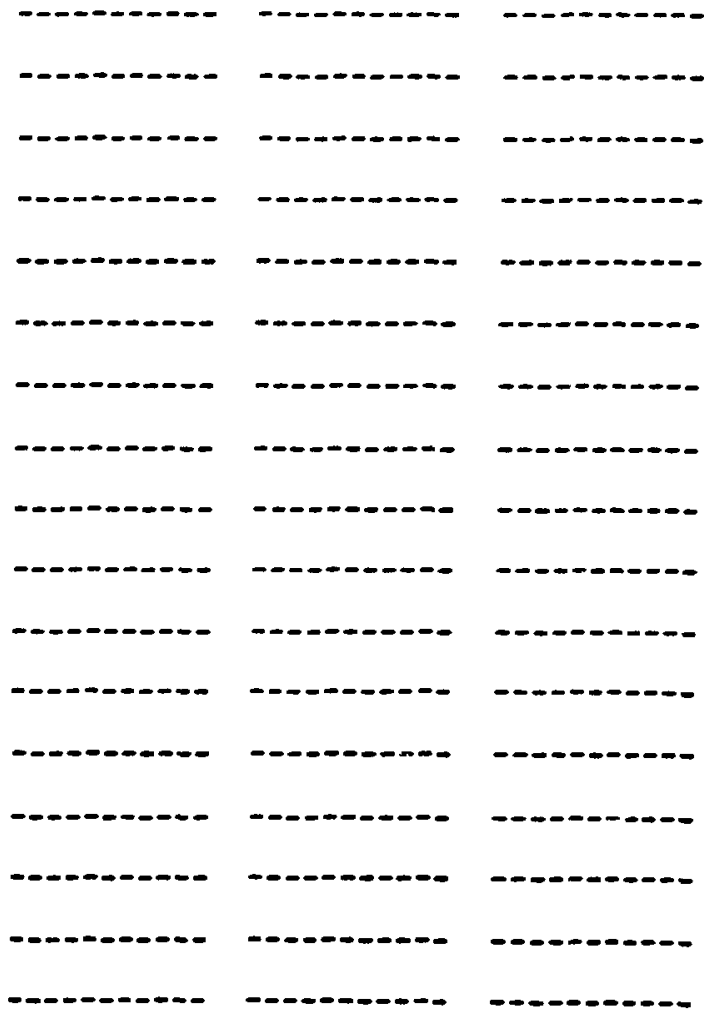

FINAL FREQ. C.C.SHORTED

DATE

INITIALS

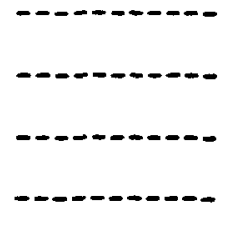

MODULE

TANK NO.

\section{SEGMENT LEN}
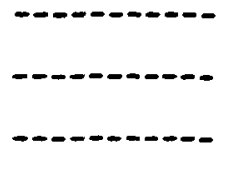

TEMPERATURE

DEG $F$ DEG $C$

PI/2 BEFORE

TUNING

\section{MHZ}

TUNE TO THIS

FREOUENCY

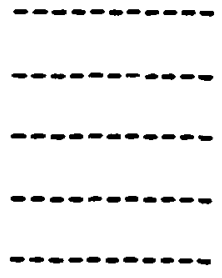

MHZ

TUNE HEAD

CELLS TO

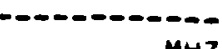




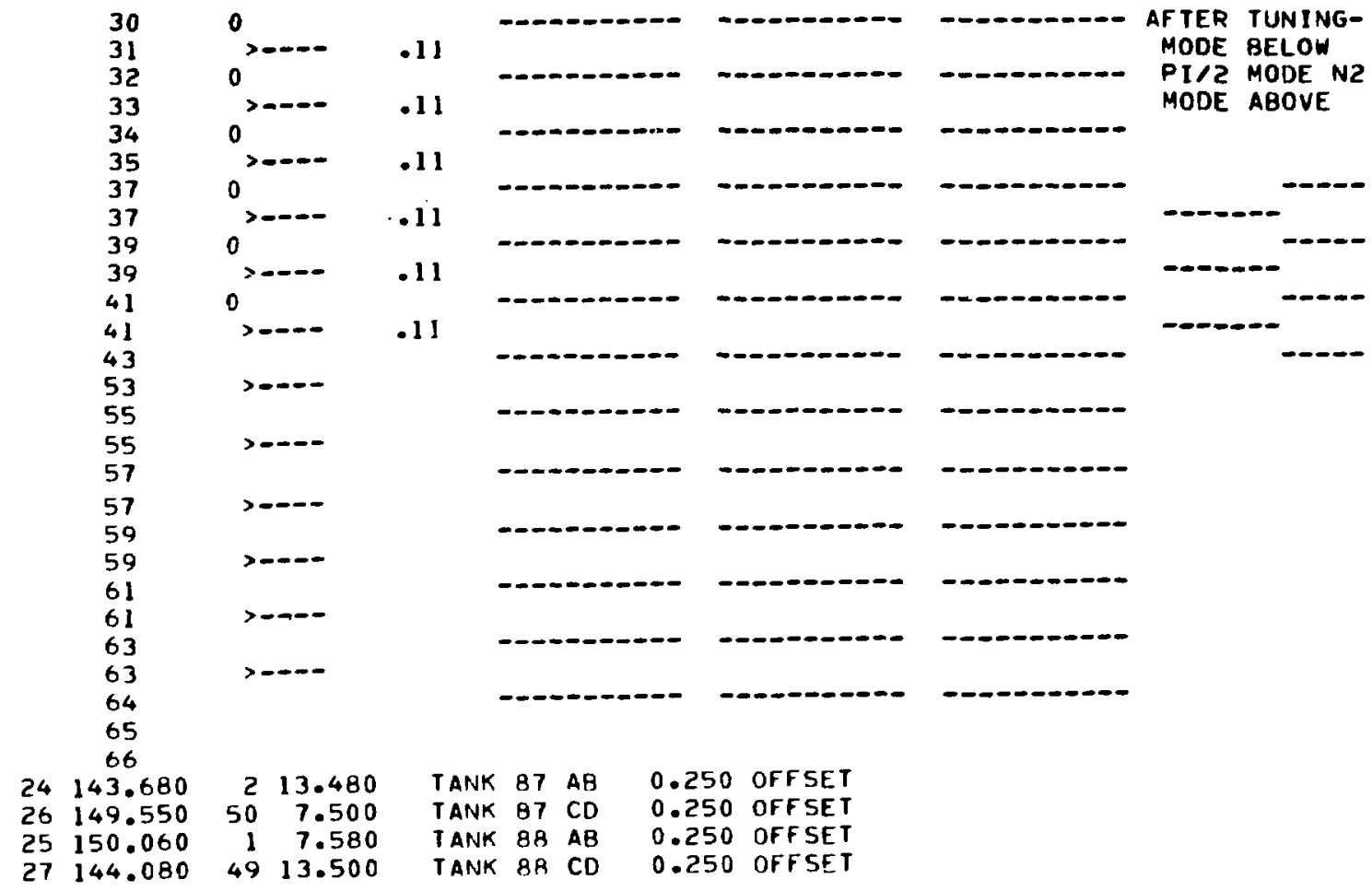

0000000000000000000000

TABI.E C-IV

PROGRAM FFTD, VERSION FOR NOSE STRETCHING

SINITIATE FORM FOR TUNING DATA

DIMENSION HOLD $(70,66)$, INFO $(70), 10(8)$

INTEGER HOLD

S(FORM LENGTH=1, 6 2, 1) \$- MODULES 24-48

SGO INT JAL JZE.

105 FORMAT(1H1.9X8A10) \$READ 105.(ID(J).J=1.6) \$ CALL DATEII IO(7),

111 FORMAT (10X,70AL) \$ READ 111 , HOLD \$- GENERAL LAYOUT OF FORM

120 PRINT 105 (IO(J),J=1,7) S LINE=1 \& $\mathrm{N}=11$

122 FORMAT (I3,F 8.3.14.F7.3.7X13.5XF6.3) \$ READ 122,NH,DM,NE,DE, NTANK

1 OFFSET S IF ( NM.EQ.0 IRETURN

NCELLS $=61-($ NTANK/35) 2-(NTANK/45):2 \$IF (NTANK.GT.54)

1 NCELLS $=55-(N T A N K / 67) * 2-(N T A N K / 79) * 2-(N T A N K / 97) * 2$ S N ADJ $=0$

IF ( NM.GT.NE )

1 SGO UPSTREAM HALF.

IF ( NM.LT.NE)

1 SGO DOWNSTREAM MALF.

SEGS $=N M-N E$ S SEG LEN=(DM-DE)/ABS (SEGS)

TOOL LOC=DM + 0.5\$SEG LEN - HG (4*NTANK-160) +1. - 3.18. 5-T41-84

IFI $N$ ADJ.NE.O)

1 SGO MAKE ADJUSTMENTS.

SFOR (FORM LENGTH) \& \$GO COPY LINE.

IF ( NREM.LT.O I

1 \$GO ERASE LEFT PART OF INFO.

IF ( NREM.EO.O . AND. MOD (LINE, Z) .NE.O )

1 SGO INSERT QUOTE HEAD.

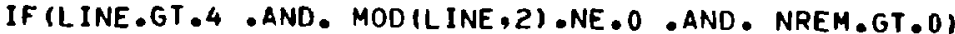

1 SGO INSERT SEGMENT NUMBER IN INFO.

IF (LINE,GT,4 . AND. MOD (LINE, 2) EEQ.0 . AND. NREM,GT,0)

1 SGO INSERT TOOL LOCATION IN INFO.

IF ( LINE.EQ.9)

1 SGO INSERT MODULE NUMBER IN INFO. 
If ( LINE.EO.II)

SGO INSERT TANK NUMBER IN INFO.

IF ( LINE.EQ.15)

SGO INSERT SEGMENT LENGTH IN INFO.

PRINT 111. INFO

GO TO 120

SBLOCK INITIALIZE. \$ LINE=1 \& N=11 \& \$(LINEx 1, 70,11

SOECLARE N D,1HO, 1HI, 1H2,1H3,1H4,1H5,1H6,1H7,1H8,1H9 \&

5- TANKS 41 - 84 SDATA HALF GAP.

$.949, \quad .949, \quad .949, \quad .949 . \quad .960$.

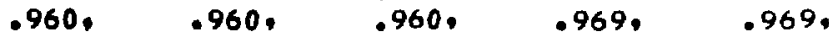

$.969, \quad .969, \quad .981 .0981 .0 .981$.

$.981 . \quad .987, \quad .987, \quad .987, \quad .987$.

$.992, \quad .992, \quad .992, \quad .992, \quad 1.000$.

$1.000,1.000,1.000,1.009,1.009$,

$1.009,1.009 .1 .028,1.028,1.028$,

$1.028,1.035,1.035,1.035,1.035$,

1.043, 1.043, $1.043,1.043,1.051$.

$1.051 .1 .051 .1 .051 .1 .058,1.058$.

1.058, 1.058, 1.066, 1.066, 1.066 ,

$1.066 .1 .096,1.096 .1 .096,1.096$.

$1.103,1.103,1.103,1.103,1.110$.

$1.110 .1 .110,1.110 .1115,1.15$.

$1.115,1.115,1.120 .1 .120,120$.

$1.120,1.129,1.129,1.129,129$,

$1.134,1.134,1.134,1.134,1.141$.

$1.141 .1 .141,1.141,1.147,1.147$.

$1.147,1.147,1.155,1.155,1.156$.

$1.155,1.167,1.167 .1 .167 .167$.

$1.174, \quad 1.173,1.172,1.172,1.177$.

$1.178,1.178,1.178,1.1845,1.1845$,

$1.1845, \quad 1.1845,1.1905,1.1905,1.189$,

$1.189,1.195,1.195,1.195,1.195$,

$1.200 .1 .200,1.200,1.200 .1 .205$,

1.205, 1.205, 1.205, 1.211. 1.211.

$1.211 .1 .211,1.215,1.215 .1 .215$.

1.215. 1.220. 1.220, 1.220 .1 .220$.

$1.224 .1 .225,1.225 .1 .225 .1 .268$.

$1.268,1.2675,1.2675,1.272,1.272$.

1.272 .1 .272 .1 .278 .1 .278 .1 .278$.

$1.278,1.283,1.284,1.284,1.284$,

$1.288,1.287,1.2885,1.2885,1.291$,

$1.291, \quad 1.291,1.291,1.295,1.293$,

$1.293,1.293,1.296,1.296,1.297$.

$$
1.297 \mathrm{~s}
$$

SBLOCK UPSTREAM HALF - S NSEG=NM+1 \& NREM=NSEG $\$$ NDIF $=-1$

IF( 2*NREM.LT.NCELLS .AND. MOD(NTANK.2).NE.0, $N A D J=1$

IF ( 2-NREM.GT.NCELLS.AND. MOD (NTANK.2).EQ.0, N ADJ = -

SBLOCK DOWNST HALF. S NSEG $=N M-1$ S NREM $=N E+2+M O D(N E, 2)-N M$ S NOIF $=1$

IF ( 2*NREM.GT.NCELLS - AND. MOD (NTANK,2).NE.0 IN ADJ = - I

IF( 2 NNREM.LT.NCELLS .AND. MOD (NTANK,2).EQ.0, NADJ = 1

SBLOCK MAKE ADJUSTMENTS. S NREM=NREM+NADJ NSEG=NSEG-NADJ*NDIF \& TOOL LOC*TOOL LOC+SEG LEN*FLOAT (NADJ)

SBLOCK COPY LINE. S SFOR(LINE). S INFO(17)=HOLD(17,LINE) LINE $=$ LINE + I

SBLOCK INSERT OUOTE HEAD. S INFO(1)=IHH \$ INFO(2) 1 IHE \$ INFO(3)=

1 IHA $\$$ INFO $(4)=1$ HD 5 NREM $=-1$

SBLOCK ERASE LEFT PART OF INFO. S DO $555 \mathrm{~J}=1.58$ INFO $(J)=1 H$

SBLOCK INSERT SEGMENT NUMBER IN INFO. \$N=3 \$NDIG=2 \$NFRAC=0 VALUE $=N S E G$ S 5 GO INSERT VALUE IN INFO. S NSEG=NSEG+NDIF NREM $=$ NREM-1

SBLOCK INSERT TOOL LOCATION IN INFO. \$ N=11 \$ NOIG=3 \$ NFRAC=2 VALUE $=T O O L$ LOC $\$ \$ G O$ INSERT VALUE IN INFO. \$ TOOL LOC $=T O O L$ LOC 1 - SEG LEN

SBLOCK INSERT MOOULE NUMBER IN INFO. S N=66 \$ NDIG=2 \& NFRAC=0 VALUE $=(N T A N K+1) / 2-4 \$ \$ G O$ INSERT VALUE IN INFO

SBLOCK INSERT TANK NUMBER IN INFO. \$ NE60 5 NDIG=3 S NFRAC 0 VALUE $=$ NTANK $\$$ SGO INSERT VALUE IN INFO. IF (NDIF.LT.O) INFO (64) =IHA \$ IF (NDIF.LT.0) INFO (65) =IHB IF (NDIF.GT.0) INFO $(64)=1 H C$ IF (NDIF.GT.0) INFO $(65)=1 \mathrm{HD}$ 
SBLOCK INSERT SEGMENT LENGTH IN INFO. \$ N=60 S NDIG=2 \$ NFRAC=4

VALUE $\times S E G$ LEN $\$$ SGO INSERT VALUE IN INFO.

SBLOCK INSERT VALUE IN INFO. S POWER=10.0**(NOIG-1)

$\checkmark A L U E=A B S$ (VALUE) $+0.5 *(10.0 *(-N F R A C)$ S-ROUND LAST DIGIT $\$$ M=O

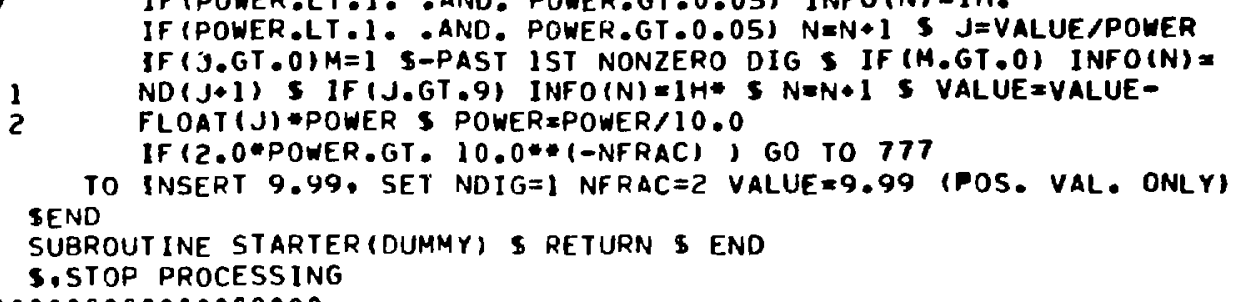

MAIN CELL DATA SHEET - FOR NOSE STRETCHING

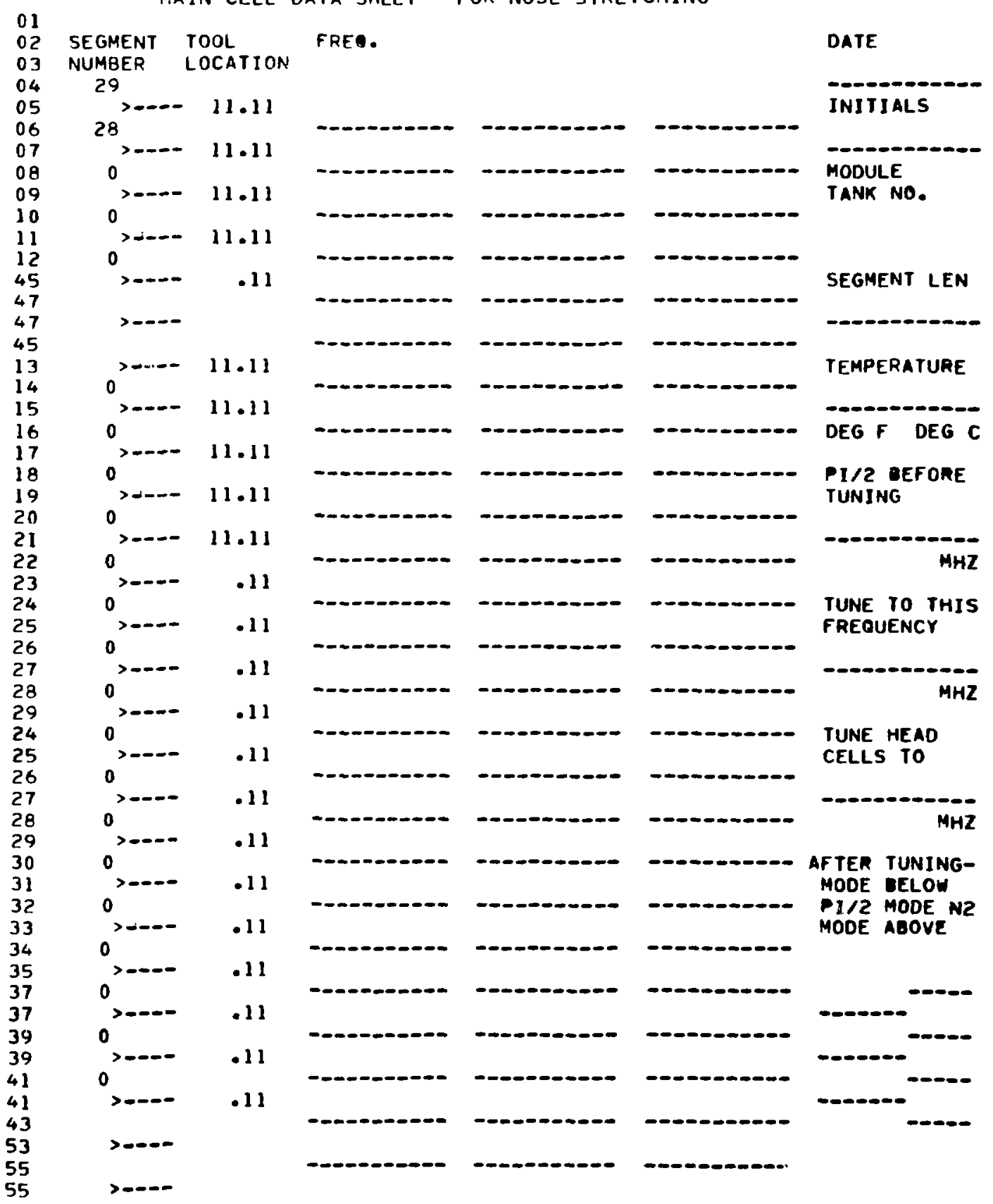



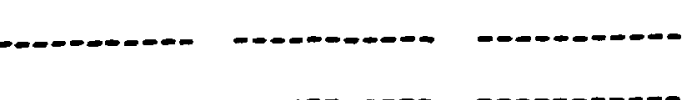

211.580

$56 \quad 6.620$

16.630

5511.660

211.780

$56 \quad 6.700$

16.710

5511.810

211.910

$56 \quad 6.750$

16.800

5511.930

212.100

$54 \quad 6.860$

16.900

5312.160

212.250

$54 \quad 6.950$

16.960

5312.330

\section{TANK 49 AB}

TANK 49 CD

TANK 50 AB

TANK $50 \mathrm{CD}$

TANK 51 AB

TANK 51 CD

TANK $52 A B$

TANK 52 CD

TANK 53 AB

TANK $53 \mathrm{CD}$

TANK 54 AB

TANK $54 \mathrm{CD}$

TANK 57 AB

TANK 57 CD

TANK 58 AB

TANK $5 B C D$

TANK 59 AB

TANK 59 CD

TANK $60 A B$

TANK $60 \mathrm{CD}$
0.250 OFFSET

0.250 OFFSET

0.250 OFFSET

0.250 OFFSET

0.250 OFFSET

0.250 OFFSET

0.250 OFFSET

0.250 OFFSET

0.250 OFFSET

0.250 OFFSET

0.250 OFFSET

0.250 OFFSET

0.250 OFFSET

0.250 OFFSET

0.250 OFFSET

0.250 OFFSET

0.250 OFFSET

0.250 OFFSET

0.250 OFF SET

0.250 OFF SET

0000000000000000000000

TABLE C-V

PROGRAY FFTD, VERSION FOR DINGING AND NOSE STRETCHING

PROGRA:AFFTD(INPUT , OUTPIIT , TAPEG=OUTPUT, TAPEID=INPUT, TAPEB) DCOMMON/O IUT6C/NOUTSC. NOCOLS, NOHEAD, NAMECOL $(6,7)$, NDUMMY $(19)$ SD IMENSIONHOLD $(70$ $1,56)$. INFO $(70), 10(3), F M C(56)$, FMC2T $(66)$ \$ INTEGERHULUEDIMENSIONND $(10)$

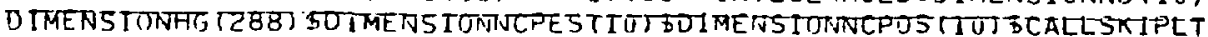
CALLSTARTERI2UHFFTO $03 / 03 / 72$ I SNTRACE $=200$ \$NOUTGC=O\$NTANKL $=0$ GOTOY5I

901 CONTINUE SFPN $=R 04.834$

105 FORMAT $(1 \mathrm{HI}, 9 \times 8 A I 0)$ READI05, (ID $(J), J=1,6)$ SCALLDATEI(ID ( 7$)$ )

111 FORMAT $(10 \times, 70 A 1)$ READI11,HOLO

120 PRINT $105,($ ID (J), J $=1,7) \$ L$ INE $=1 \$ N=11$

122 FORMAT (13.F . 3.I4.F 7.3.7XI3,5XF6.3)

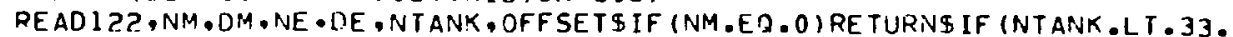
10R. NTANK. GT . 104) GOTOI 99DNCELLS=61-(NTANK/35)*2-(NTANK/45) 2\$IF (NTA INK.GT.54) NCELLS $=55-(N T A N K / 67) * 2-(N T A N K / 79) * 2-(N T A N K / 97) * 2 \$ N A D J=0 \$ N$ 1 ICELLS $=N C E L L S-1 \$ C N=0 . \$ N G R O U P=10-(N C E L L S-49) / 2 \$ C E L L S=N C E L L S \$ I F$ INTAN $1 \mathrm{~K}$.EO.NTANKL) GOTOL $26 \$ N R E A D=N C E L L S+5 \$ R E A D 125$. (FMC (I), I =1, NREAU)

125 FORMAT (16F5.0)

DO800I I =1 . NREAD, I I IF (19OD (NTANK.2). NE.0.ANU.FMC (I1).GT.104.)FMC(II) $1=.001$ FMC (II) +800.\$FMC2I (II) =FMC (II)\$IF (MOD (NTANK, 2$)$. EO.U.AND.FMCI 111 . . GT .104.)FMC2T (II) $=.001$ \#MC (II)+800.

SOO CONTINUE

126 SUM $1=0 . \$ S U M 2=0 . \$ U O \$ 01$ I I $=2$. N ICELLS, $1 \$ J=I 1 \$ S U M 1=S U M 1+F M C(J) \$ S U M 2=S U M$ $12+F M C 2 T(J) \$ C N=C N+1$.

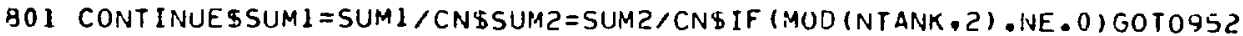

902 CONTINUE I IF (MOO (NTANK, 2).ED.0) GOTO953

903 CONTINUE \$DCE $=1 .-(F I / F P U) * 2 \$ F E E=F P U * S O R T(1 .-.5 * D C E) \$ F P C=F P U+(2 . F E$ $1 E-F 1 C E L L-F N C E L L) /(C N+2$. ) \$DC=1. $-(F I / F P C) * 2 \$ F E N=F P N * S Q R T(1 .-.5 * D C)$ $F$ IN=FPN SORT ( I. -DC) IIF (NM.GT.NE) GOTO954 


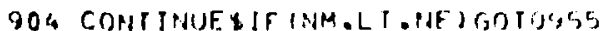

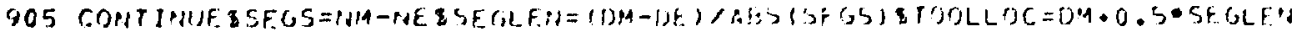

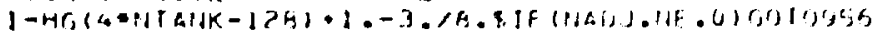

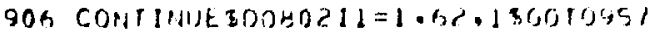

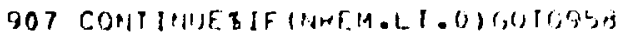

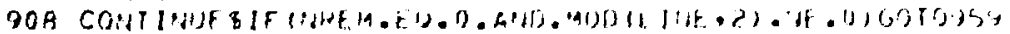

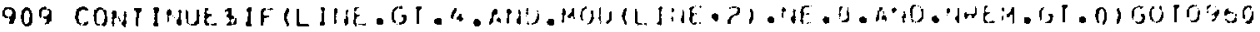

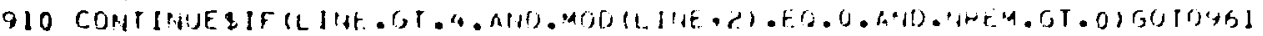

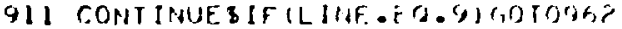

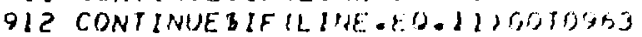

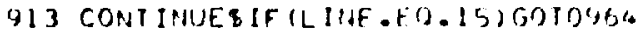

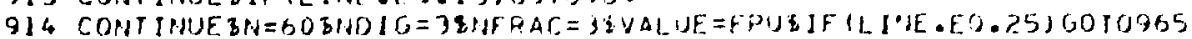

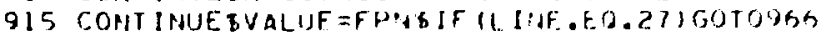

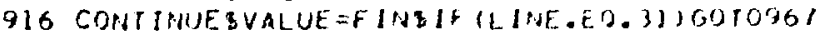

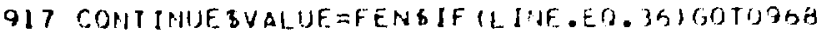

918 CONIINUE \$IF ILINE.EO-39)GOTOS6O

919 CONTINUEZIF IL INE.EO.40IGOTO970

920 CONT INUE SPRINTI11, INFO

gOz CONTIPUNE

199 NTARKL =NT ANKSCOT!120

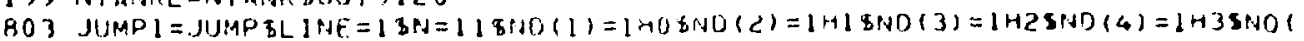

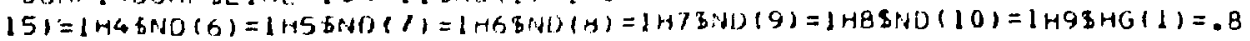
$1563 \mathrm{Hr},(2)=.8565 \mathrm{HG}(3)=$

$145 \mathrm{HG}(286)=1.3735 \mathrm{HG}(287)=1.3729 H G(288)=1.3723 \mathrm{HCPES}(1)=182 N C P E S(2)=1$ 17 SNCPES $(3)=16$ SNCPES $(4)=16$ SNCPES $(5)=14 \$ N C P E S(6)=15$ FNCPES $(7)=133+N C P E$ $15(8)=14$ NCPE $5(9)=123 N C P E S(10)=13 \$ N C P O S(1)=18$ SNCPOS $(2)=17$ SNCPOS $(3)=$ 1165 HCPOS $(4)=15 \$ N C P O S(5)=15$ \&NCPOS $(6)=14$ BNCPOS $(7)=14$ SNCPOS $(8)=135 N C P$ $10 S(9)=13 \$ N C P O S(10)=12$ \&UMP $=J U M P]$ SGOTOY400

804 JUMPZ $=$ JUMP \$,FPI $=$ FMC (NCELLS.4) \$IF (FMC (INCELLS+?). NE. FLOAI (NIANK) ) GOTO

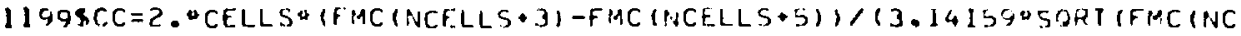

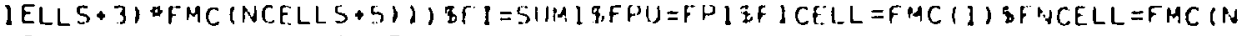
1 CELLS) \& JUMP = JUAF\% $\$, 60 T 09900$

805 JUMP $3=$ JUMP \&FP2 =FMC2 I (NCELLS+4) B IF $(F M C 21$ (NCEI_LS + 2) . NE. . FLOAT (NTANK))

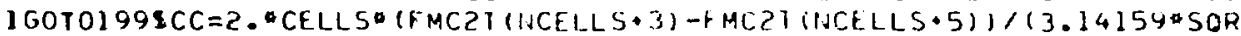

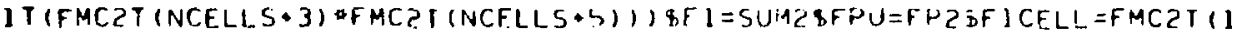
1) SFNCFLL =FMC2I (INCELLSI \$ JUMP = JUMF $3860 T 09900$

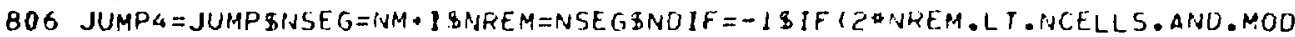

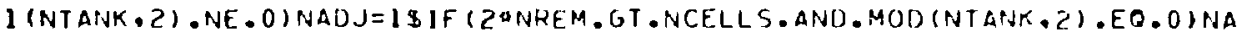
$10 J=-1 \$ J U M P=J U M P 4 \$ G O T 09900$

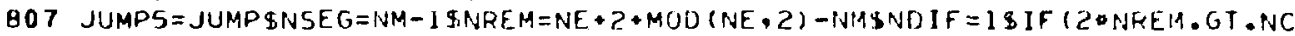
1ELLS. ANT). MOD (NTAINK. 2). NE . O) NADJ =-I IIF (2 INREM.L T. NCELLS. AND. MOU (NTA INK, ?) . E(J.O INADJ $=1 \$$ JUMP = JUMP5\$GOTO 9900

$B O B$ JUMPG $=J U M P \$ N P E M=? N R E M+N A D J Q N S E G=N S E G-N A D J N D I F \$ T O O L L O C=T O O L L O C \cdot 5 E G L$ IFN"FLOAT (NAOJ) \& JUMP = JUMPG\$GOTO9900

B09 JUMP $7=J U M P \$ O O B 10 I 7=1 \cdot 70,1 \$ 1 N F O(17)=$ HOLD $(17 \cdot$ LINE )

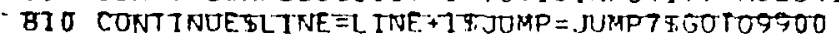

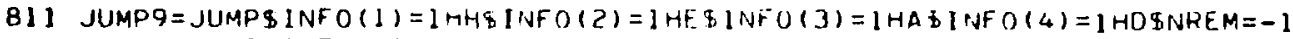
JUMP = JUMPQ\$GOT 09900

812 JUMPB $=J U M P \$ D O 555 J=1,5 B$

555 INFO $(J)=1 \mathrm{H}$ \$JUMP = JUMPB\$GOTO9900

813 JUMP $10=J U M P \$ N=1$ SND I G= $2 \$ N F R A C=0 \$$ VALUF $=N S E G \$ G 0 T 0971$

921 CONT INUE SNSEG =NSEG + NDI F \$NREM =NREM-1\$ JUMP = JUNP $10 \$ 60 T 09900$

814 JUMP I $1=$ JUMP \$N $=7 \$ N D I G=3 \$ N F R A C=2 \$$ VALUE $=70 O L L O C \$ G 010972$

922 CONT INUESTOOLLOC $=T$ OOLLOC-SEGLEN\$IS=NSEGSIF (NDIF . LT 0 ) N=N+ I\$VALUE=FM IC (N) S J=NSIF (MOD (NT ANK, Z).EO.0) J=NCELLS+1-N\$IF $(M O D(J-N C P E S$ (NGROUP), INCPOS (NGROUP) ).EO.0) INFO (5) =1HJ\$IF (MOU (NTANK, 2$). E Q .0) \cup A L U E=F M C Z T$ (N I) $S N=16 \$ M S I G N=1 \mathrm{H}$ \$IF (FIN.LT.VALUE) MSIGN=1H-\$CHANGE = ABS (F IN-VALUE) SN $1 D I G=3$ SNFRAC $=3 \$$ GOTO973

923 CONTINUE $\$$ INFO $(24)=M S I$ GNS $V A L U E=C H A N G E \$ N=25 \$ N D I G=13 N F R A C=3 \$ 60 T 0974$

924 CONT INUE $\$$ JUMP $=$ JUMP 1 I \$GOT09900

815 JUMPI $2=J U M P \$ N=66 \$ N D I G=2 \$ N F R A C=0$ S ALUE $=(N T A N K+1) / 2-4 \$ G 0 T 0975$

925 CONTINUE \$ JUMP $=$ JUMP $12 \$$ GOTO 9900

816 JUMPI $3=$ JUMP $\$ N=60$ \$NDIG $=3 \$ N F R A C=0 \$ \vee A L U E=N T A N K \$ G 0 T 0976$

926 CONTINUESIF (NDIF.LT.O) INFO (64)=1HASIF (NDIF.LT.O INFO (65) =1HE\$IF (ND 1IF.GT.0) INFO $(64)=1 \mathrm{HC} \$ I F(N D I F . G T .0)$ INFU $(65)=1 \mathrm{HD} \$ J U M P=J U M P I 3 \$ 6010990$ 10

817 JUMP $14=J U M P \$ N=60 \$ N D 1 G=2 \$ N F R A C=4 \$ V A L U E=S E G L E N \$ G 0 T 0977$

927 CONT INUES JUMP $=$ JUMP $14 \$$ GOTO9900

818 JUMP $17=J U M P \$ N=63 \$ N D I G=1 \$ N F P A C=6 \$ V A L U E=D C \$ 60 T 097 \mathrm{~B}$

928 CONT INUE SJUMP $=$ JUMP $17 \$ 60109900$ 


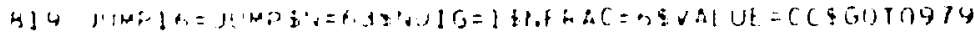

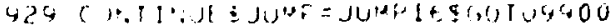

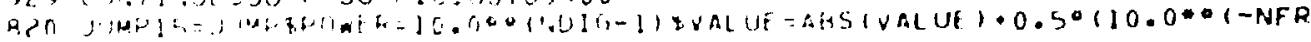

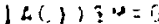

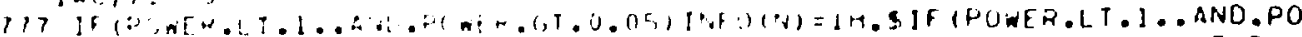

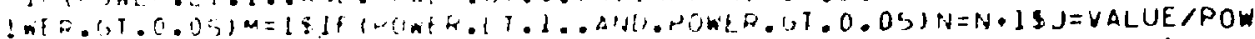

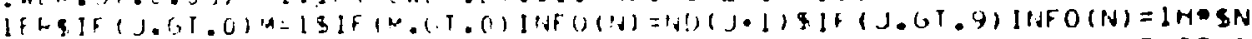

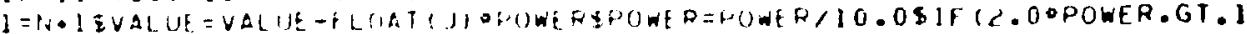

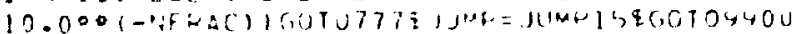

Q5 JUMF' $=156,50503$

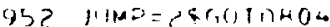

प53 JUMP $=30 \%$ TOTOC

054 JMI: $=496,170+\mathrm{GH}$

(15,5 N1+1:-53

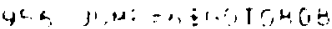

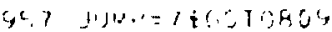

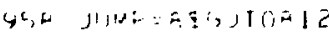

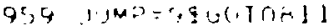

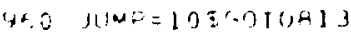

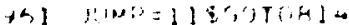

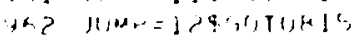

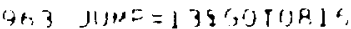

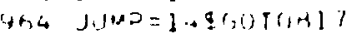

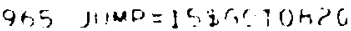

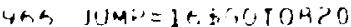

YS7 JUMD $=1755010420$

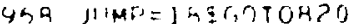

Q., 9 JUMH $=1750,0,70819$

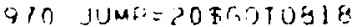

471 JUME $=21 \$ 2050926$

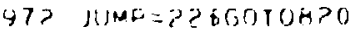

973 JUM:

47 U UNE $=7491,070$ T20

$475 \quad$ KMU $=2555010420$

475 JIM: $=36959$ I

477 JU? $=275,0 T \cup R 20$

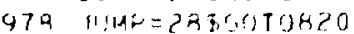

914 Jusp $=>90,950$ TU5?0

$99005,751401,702.903 .904 .405,406,907,905,909.910,911.912,913,914,415,9$

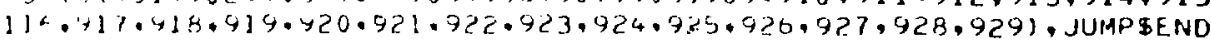
S'ADOIJT'.ESIADTEK(IJUMMY) IPE TURINBENA)

TABI: C - V I

PROCRAS SCh']

PROGRAMSCWT I INPUT OUTPUT , TAPEG=OUTPUT. TAPE IO=INPUT - TAPEB) SCOMMON/O IUTGC/NOUTGC. NOCOL S, NOHEAO. NAMECUL (6.7). NDUMMY (19) \$OIMENSIONFMC (66) 1. HOLD (12) , FAE (66). TEE (4), TTE (4), DA (4) SCALLSK IPLT SCALLSTARTER(2OHSC $1 W T \quad 02 / 15 / 72$ ISNTRACE $=2008 N C U T 6 C=0 \$ F P N=804.930$ SNTANKL $=105$

111 LINE $=\mathrm{LINE}+1$

112 FORMAT (14.R1,A5,14F5.0)

RE ADI 12 , NTAHK, LS, DATE, FPU, DCC, HULDSIF (NT ANK.ED. O) RE TURNSSUM=O. SCN= 10.

114 FORMAT $(40 X *$ TANK*I4)

IF (NTANK.GT.NTANKL) CALLPAGERSIF (NTANK. NE.NTANKL) PRINT I $14, N T A N K S I F I$ INT ANK. NE.NT ANKL) NSTORE=0SIF (NTANK.NE.NTANKL.AND.MOD(NTANK,2).EO.O) INSTORE=NSTORE+1\$IF (NTANK.NE. NT ANKL.AND.MOO (NTANK, Z).EO.O)FAE (NSTOR

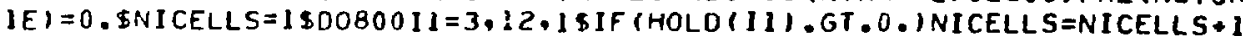

800 CONTINUE $\$ N=N I C E L L 5+1 \$ 00801 I 1=1 . N \cdot 1 \$ H O L D(11)=001 * H 0 L D(I 1)+800 . \$ N S T$ IORE =NST ORE + I \&F AE (NSTORE =HOLD (II)

801 CONTINUESNSTORE $=N S T O R E+1 \div$ - AE (NSTORE $)=0 . \$ F P U=.001 * F P U+800 . \$ D C C=.000$ $1001 * 0 C C \$ D O 802 I 1=2$.NICELLS, I $\$ S U M=S U M+H O L D(I) \$ C N=C N+1$.

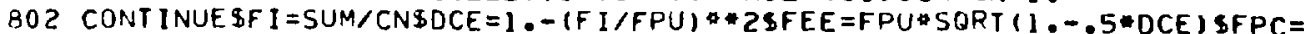
$1 F P U+(2 . F E E-H O L D(1)-H O L D(N)) /(C N+2$. $) \$ D C=1 .-(F I / F P C) \# \& 2 \$ F E N=F P N * S A R$ $1 \mathrm{~T}(1 .-5 * D C) \$ F I N=F P N * S O R T(1 .-D C) \$ D A(L S)=D A T E S T T E(L S)=F$ INSTEE (LS) =FE INSNI $=1 \$$ IF (LS.EO.1. AND.MOD (NTANK, 2). NE. O) NI=2\$NZ=N\$IF (LS.EO.4.AND.M

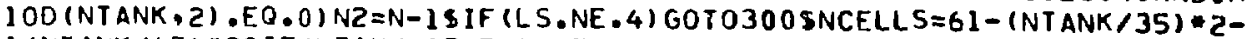
I (NTANK/45) ZSIF (NTANK.GT.54) NCELLS=55-(NTANK/67) 2-(NTANK/79) Z2- (N 


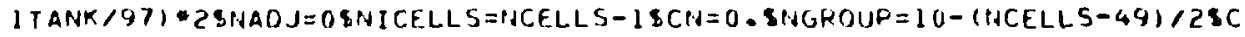

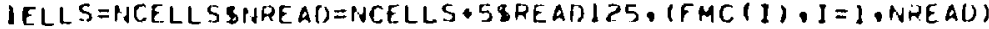

125 FORMAT (16F5.0)

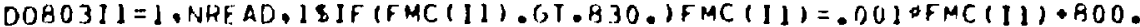

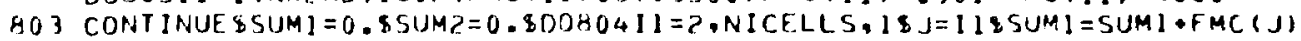
$\mathrm{CN}=\mathrm{CN}+1$

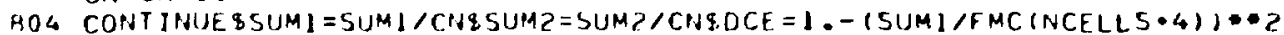

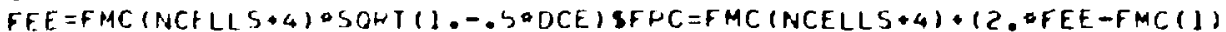
$1-F M C(N C E L L S)) /(C N+2) \$ U C T=.1 .-($ SIMA) $/ F P C) * 28 F E T=404.834 * S O R T(1 .-.5 *$

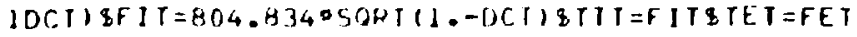

243 FORMAIIJOXODAIE C TUINF IO ERHON FREO.. FREO. FPEO.. EPROR 1 TUPE TO ERRA/IOX NO ETLA ETLE ETLB DPOP TUNNE 2L TUNNEL TUNNEL DIF\#/IOX*-. - 3-- - -

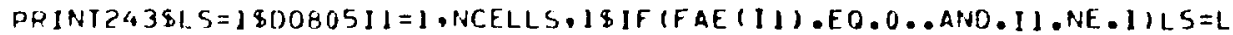

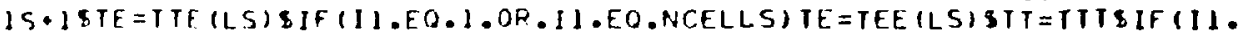
IEO.1.OR. 11.EQ.NCFLLSITT=TET\&EE =FAE $(111-T E S F Q=F A E(11)-F M C I 11)$ SE I =FM

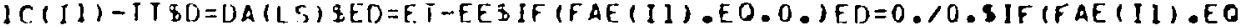
$1.0 .10=5 H \quad \$ 1 F(F A F(11) . E O .0) E E=.0.10 . \$ 1 F(F A E(I)$. E . 0.) FD $=0.10$. PAINT244,D,II, TE, EE, FAE (I) , FD,FMC II I), E , T I, ED

RQS CONTINUE.

244 FORMAI (SXA5, I4,F 9.3,F7.3,F9.9,F6.3,F9.3,F 7.3,F9.3,F6.3)

300 NTANKL = NTANK\&GOTO111 QEND

SUBPOUTINE PAGER

C PAGE = CURRENT PAGE NUABER

C LINE=FREE LINES REMAINING ON THIS PAGE COMMON IPAGES/ LINE, PAGE, INFO PG(16), IIOTPT $P A G E=P A G E+1$

WRITE 19,11$)$ (INFO PG(J),JEI,16), PASE

11 FORMAT (IHI,A9,7A10/7A10,A7,F 3.0/1H) I 1 OTPI $=0$

\section{RE TURN}

SUBROUTINE SKIPLI \$ HETUR'A \& ENO

SUTHROUTIINE STARTERITHAO)

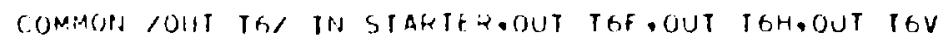

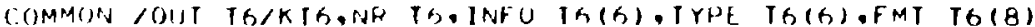

COMMUI: /PAGES/ LINE, PAGE, INFO PG(16), IIOTPT

(I) TMERSTON INAOO(S)

$\operatorname{INF}(\rho)(1)=1 \mathrm{H}$

WHITE (H) IAJ O) $P G(1)$

$$
\text { HACFSFACL H }
$$

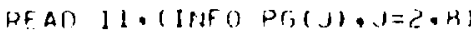

MACKSPACF I

11 FUHMAT (IAIO)

INFO PUI QI $=1 \mathrm{H}$

CALL DATE] I INFO PG(10),

CALL CLOCKII INFO $P(, 111)$,

INFO $P G(12)=10 \mathrm{H}$ CODE-

INFO $P(O(13)=I N F O(1)$

INFO $P G(14)=1 N F O(2)$

INFO $P G(15)=10 H S W A \mid N M P-9$

INFO PI(16) $=7 H \quad$ PACE

FMT $T G(1)=3 H(8 X$

FMT $T 6(t)=I H I$

LINE = ]

$$
P A G E=0
$$




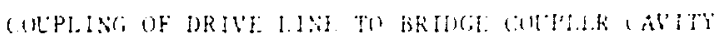

The following dorluation is hased on a mete sy E. Knapp (1968). The coupling toutlirient ot a transatssion liak syster do a resonant avity in outbined in many aicrowave axts, and is piven by

$$
\because=Q_{0 \times t}
$$

where gext is the erpulvalent loss to the resonant cavity systam introduced by the natched fenerator driving the line. For ravity mateh $=1$. For i cavity system with beam loasing, ?o varies as a function of beam current and roergy sain as

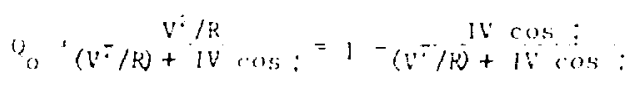

where $V$ is the eiteretive civity voltake, $\mathrm{B}$ is the shune inpedance, 1 is the beam turrent, and a is the phase between $v$ and 1 . If a is delined as a beari loading parameter

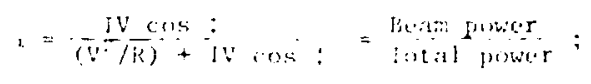

then

and

$$
\therefore=1+\frac{1}{1+1}(1, \cdots)
$$

$$
\text { ?o }=(1-1) \text {; }
$$

thus the coupling parameter wartes as

$$
\therefore=\ddots_{0}(1-t)
$$

In terms of the usual1: measured cavity parameters, field levels and current,

$$
\imath=\frac{1}{1+\left(\mathrm{E}_{\mathrm{o}} \mathrm{T}\right) /(\mathrm{ZT} \cdot \cos \cdot \mathrm{I})}
$$

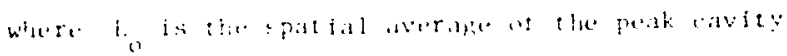
sin. 1.1

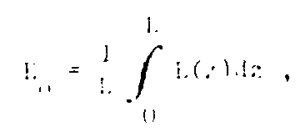

Fis live transit time fale or, and : is the syn-

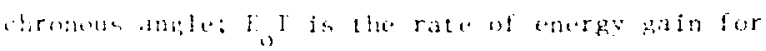
a pertilele erossing, the center of the gap at perak ! i. 1.1 .

Thin tor tosilf we have $\mathrm{E}_{0} \mathrm{~T}=$ constant $=$

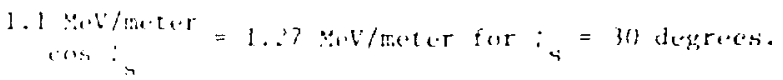
For i = li we we wht $:=1.000$ :

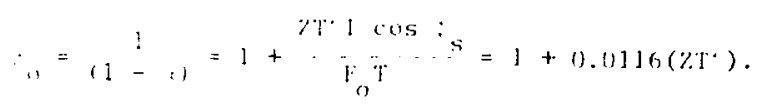

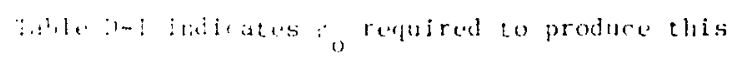

TABL: D-I

COLPJING FACTOR

$\begin{array}{cc}\because y . j / m) & \therefore 0 \\ 20 & 1.23 \\ 25 & 1.29 \\ 30 & 1.35 \\ 35 & 1.41 \\ 40 & 1.46 \\ 45 & 1.52\end{array}$

The coupling hole should be cut to give a VSWR $=\Sigma_{0}$, overcoupled, and varied along the accelerator to match the local shunt impedance. 


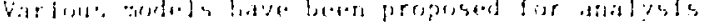

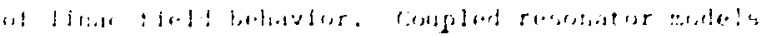

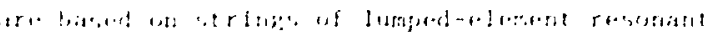

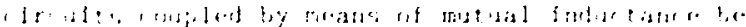

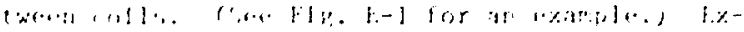

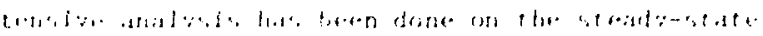

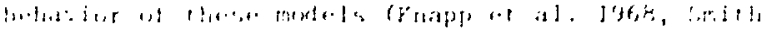

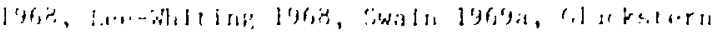

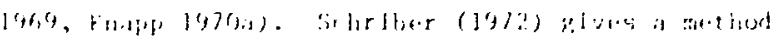

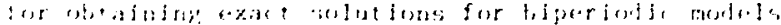

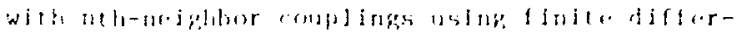

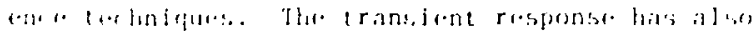

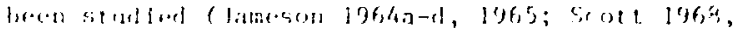

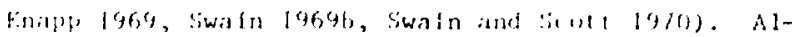

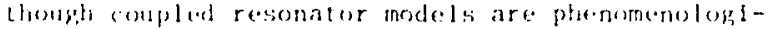
aal In niture, they have proved to bre at isfoful ana-

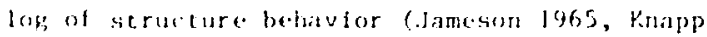

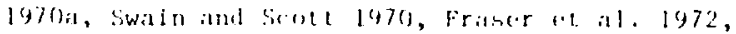
Sebrtber 1975).

in alosther approash, equivalent circule: iave been derived from Maxwell's equations with the ficld expanded in appropriate normal modes for crampla. rilukstern 1965a-b, Julc ind lilukstoru 1973). The?te models are destgnated field modols in this refort. For the yry-MHz linac, the passhands of the structure at or noar the operat ing frequency are narrow enough that the choice of model is not critical - similar results are obtained. Further information on the various equivalent cireuit approaches may be found in the survey by Dome (1970) and tho roforences therein.

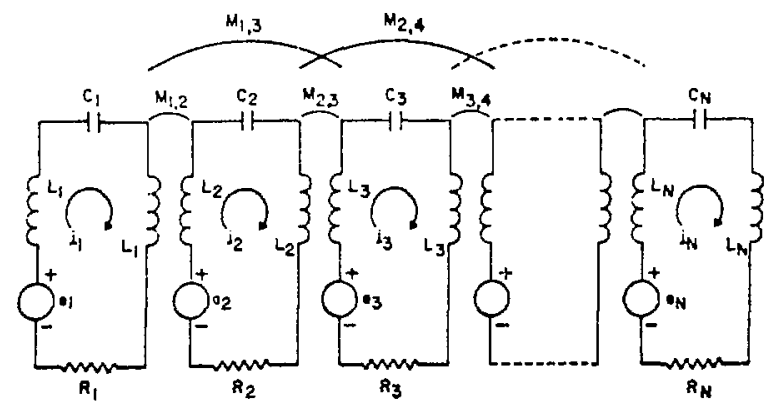

Fig. E-1. Coupled resonator equivalent circuit with nearest and next-nearest nelghbor coupling and full resonator terminations.

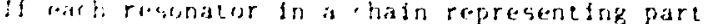
if a llate seruetire is assuged to be crupled only

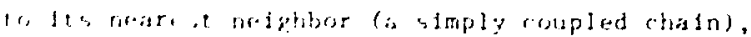

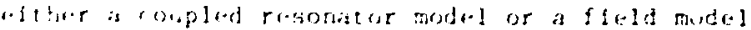

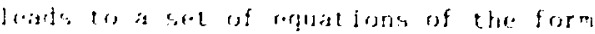

$-{ }_{n} \%_{n}+y_{n-1}+z_{n+1}=0, n=1,2, \cdots,(5-1)$

ia allith Lhe ${ }_{\text {n }}$ are nurmal joed phasors represent 1 ng liee resonator amplitudes and phases, and the an ontals various frequency and circuit parameters. idd mantered resonators represent accelerating caviticos; even mumbereal rasomators, roupling cavities. Kosonater number one is the and of the ctatin; the drive is consifreres] to be it a resonator with $n$ greater than the range used in Fq. (E-1). At the end of the chain, the first resonator is coupled to other resonators enly on one side and hhus $y_{0}=0$ in th. (k-1) for $n=1$. (Thls is known as a full-resonator Lerminalion, as opposed to the halt-resonator termination in which the last resonator ends at a flane of reflective symmetry. Half resunator terminations art not considerui in this report. Half-resonator termination: were considered by potzer (MP I)ivision $1971(1)$.

The dependence of $x$ on the parameters varies with the approach or model chosen. For the D-mode field midel (losses neglected),

$$
\frac{-(1-k)\left(\omega_{0} / \omega_{j}\right)^{2}}{(k / 2)\left(\omega_{0} / \omega\right)^{2}}
$$

while for the coupled resonator model with uniform coupling

$$
\alpha_{n}=(2 / k)\left[1-\left(\omega_{n} / \omega\right)^{2}-j \omega_{n} /\left(\omega Q_{n}\right)\right]
$$

where $\omega$ is the operating frequency, $\omega_{0}$ or $\omega_{n}$ characterfze the individual resonator frequency, and $k$ is the amount of coupling between resonators.

For the $\pi / 2-$ mode, $\alpha$ is small. Then one may use mathematical induction to verify that the approximate values of the phasors $x_{n}$ at any position along the chain in terms of $X_{2}$ at the end are 


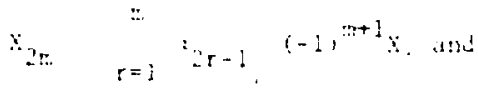

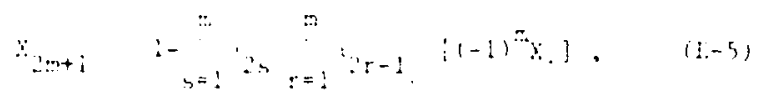

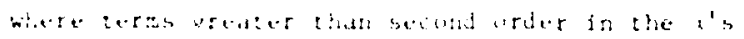

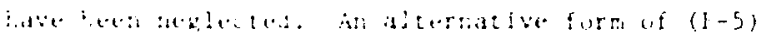

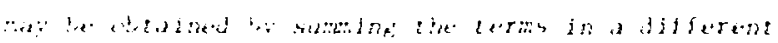

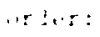

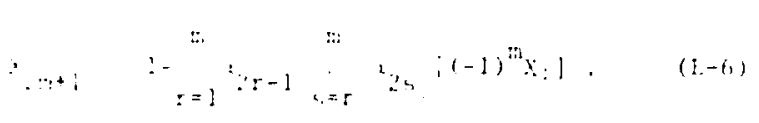

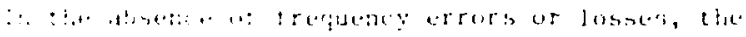

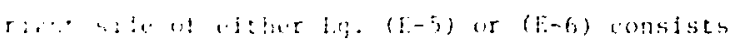

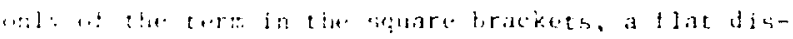

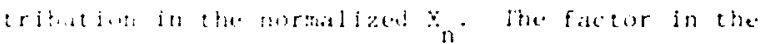

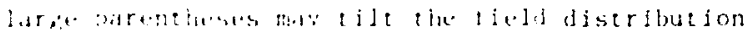

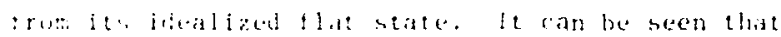

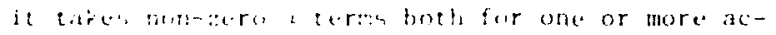

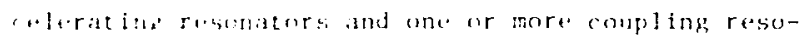
raiders lo prortuce a lili.

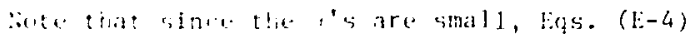
and $(n-5)$ blow that $\ddot{x}_{2 n} \cdots \ddot{2 n+1}_{2 n+1}$, al least when is smali. In other words, the siored energy in the coupling cavitics is shall compared with the stored energy in the acelerating cavities provided the structure is not made too long;

bien the resonators are coupled to nejghboring resonators beyond just the nearest resonator in the structure, it is more difficult to calculate the form of the field distribution for the $r / 2$-mode (Swain 1969, lee-Whit ing 1968, Schriber 1972). However, one finds that if the resonator irequencies are set correctly, a nearly flat field distribution in the normalized $x_{n}$ can again be obtained. In particular, for the coupled resonator model with nearest and next nearest neighbor coupling only, one has

$$
\begin{gathered}
-x_{n} k x_{n}+k\left(x_{n-1}+x_{n+1}\right)+k_{n}\left(x_{n-2}+x_{n+2}\right)=0 \\
n=1,2, \ldots,
\end{gathered}
$$

where $a_{n}$ is as in Eq. $(E-3), k$ is the nearest neighbor coupling, and

$$
\begin{aligned}
& k_{n}=r_{11}, \quad n \text { u.t. } \\
& k_{n}=k, n \text { enem, }
\end{aligned}
$$

wit th $k$ a represent ank the coupling between acceleratinp: cavitice and $k$. lle coupling between coupling avities. It une notes that for the desired condi(1) I. S

$$
\therefore n+1 \quad(-1)^{n+a}
$$

an:

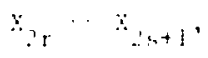

then the raal part uf lect (b-7) leads to the tuning conel it ions

$$
n_{n+1}=\ldots 1-k_{a}, n_{1}=1,2, \ldots
$$

fur interiur alleleraljeg cavitios and

$$
.=.1-10.5 \mathrm{k}
$$

for the end acelerating avity.

A more complete analysis (Swain 1969) shows that a relation similar to liq. (E-9) holds for the coupling cavities:

$$
{ }_{2 m}=\ldots \sqrt{1-\bar{k}}
$$

In general, the field distribution is found to be stable if the dispersion curve is linear in the vicinity of the $\pi / 2$ mode (Dôme 1970, Andreev et a1. 1973, Beringer and Gluckstern 1964). This makes nearby modes approximately symmetrical about the operating point. The coupled resonator model with resonators tuned according to Eqs. (E-9), $(E-10)$, and $(E-11)$ is found to have such a dispersion curve.

Values for the various coupled resonator model parameters for the $805-\mathrm{MHz}$ linac are given in Table B-III of $A$ ppend $i x$ B. The mo.iel used assumes fullresonator terminations, and includes next-nearest as well as nearest neighbor couplings. 


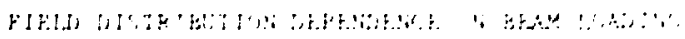

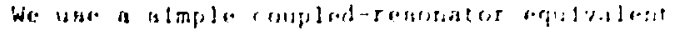

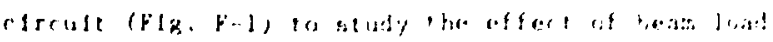

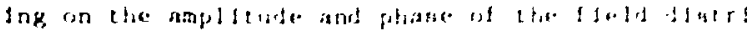

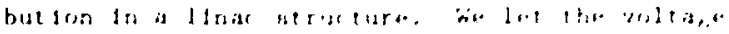

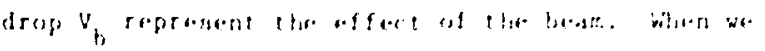

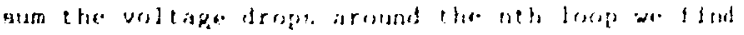

$$
\begin{aligned}
& \left.1.1 .1_{n}+9.2 i_{n-1}+1_{n} / 19.1\right)+31 n \\
& +1 . .1 .1_{n}+1 . M n_{n+1}+v_{n}=0 .
\end{aligned}
$$

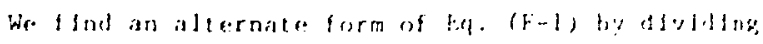
e.very tarm i,y 2$\} \cdot \ldots$. :

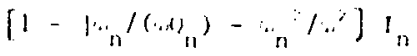

$$
\begin{aligned}
& +3 k 1_{n-1}+i k l_{n+1}-j v_{b} /(2 \cdot 1)=0(k-2)
\end{aligned}
$$

where ${ }^{\prime . .}:=: /(21,0)$

$$
\eta_{n}=2 i n n
$$

and $\quad k=M / l$.

Now

$$
\begin{aligned}
& V_{b} /\left(2 i_{\omega} L\right)=\left[V_{b} I_{n} I_{n}^{\star} R /\left(2, L, I_{n} I_{n}^{\star} R\right)\right] \\
& \left.\left.=\left[{ }^{a}\right)_{n} V_{b} I_{n}^{*} /(w a)_{n}\left|I_{n}\right|{ }^{2} R\right)\right] I_{n} \text {, }
\end{aligned}
$$

where $I_{n}^{*}$ is the complex conjubate of $I_{n}$. Since $\left|I_{n}\right|^{2} R$ is the power lost in the cavity, $P_{c}$, and $\operatorname{Re}\left(V_{b} I_{n}^{*}\right)$ is the power transferred to the beam, $P_{b}$, we may write

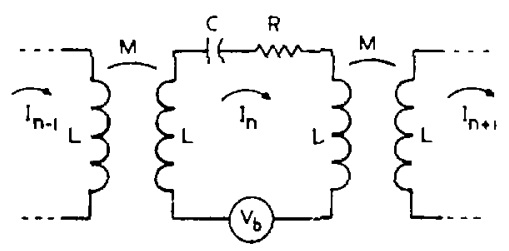

Fig. F-1. Equivalent circuit for the nth resonator in a Iinac structure.

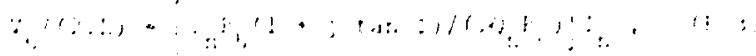

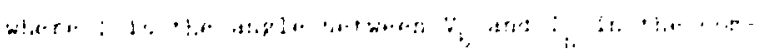

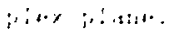

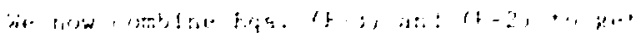

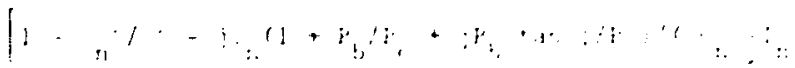

$$
\begin{aligned}
& +2+z_{n-1}+2 \times 1_{n+1}=1 .
\end{aligned}
$$

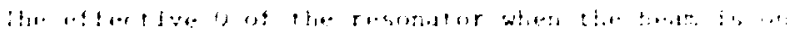

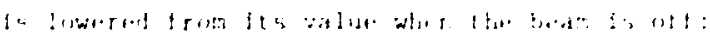

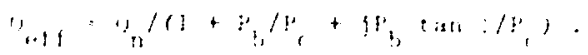

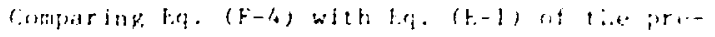
viende inperiti $\%$, wh f Ind

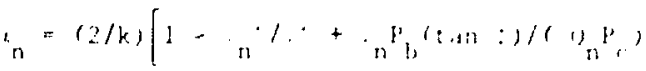

$$
\begin{aligned}
& -i n_{n}\left(1+p_{n} / n^{\prime}, 1\left(1, n_{n}\right)\right) \text {. }
\end{aligned}
$$$$
(r-)
$$

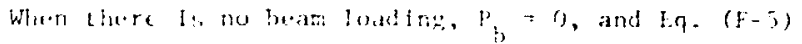
reduresi in Eq. $(\mathrm{I}:-3)$.

From lif. (t)-6) of Appendix E, we find the field diseribution is given by

$$
x_{2 n+1} \doteq\left(1+s_{m}\right)(-1)^{m} x_{1}
$$

where $S_{m}=-\because_{r=1}^{m} 2 r-1 \sum_{s=r}^{m} 2 s$.

If $\left.\right|_{\mathrm{m}} \mid \cdots 1$, we may interpret

Re $S_{m}=$ amplitude droop of $X_{1}$ with respect to $x_{2 m+1}$,

- In $S_{m} \doteq$ pirase error (radians) of $x_{1}$ with respect to $x_{2 m+I}$.

We assume all accelerating cavities are alike and all coupling cavities are alike. Then using the accelerating cavity $\alpha_{2 r-1}$ given by $\mathrm{Eq} .(\mathrm{F}-5)$ and the coupling cavity $\alpha_{2 s}$ given by Eq. (E-3), we find the droop $\Delta A$ and phase error $\Delta \phi$ are approximately given 


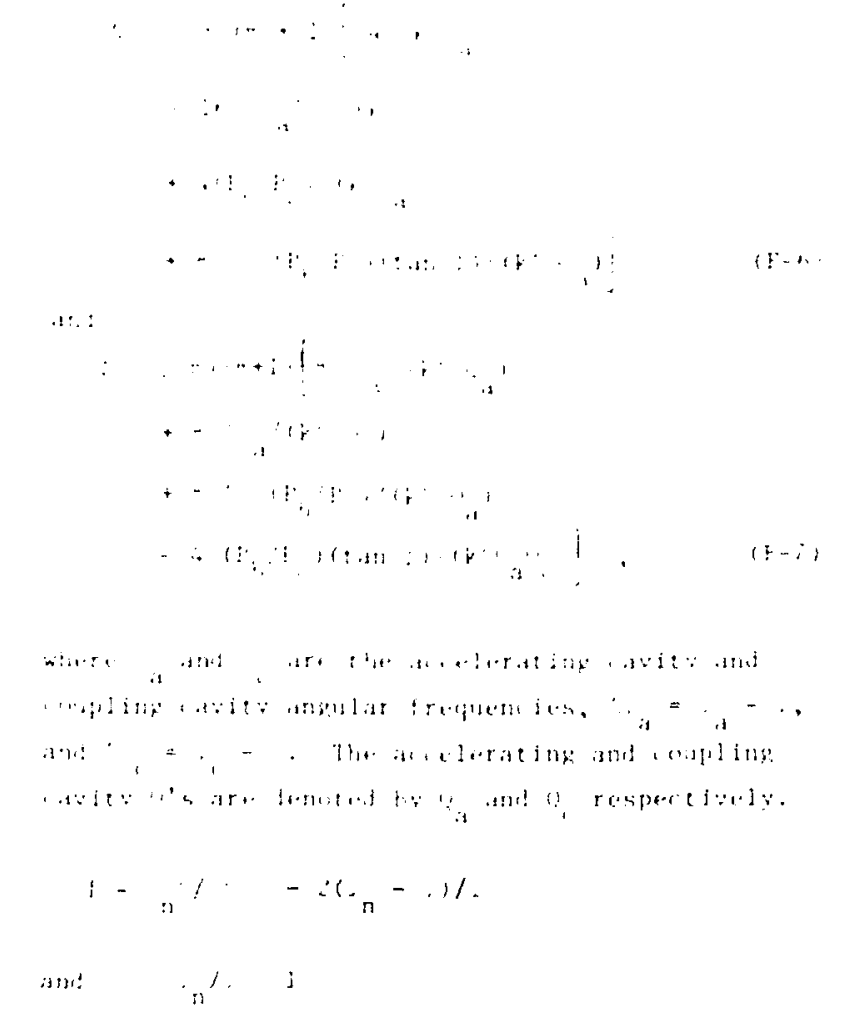

were used lesimblity the results in lqge $(f-6)$ and $(\mathrm{F}-\mathrm{i})$.

b. now ronsider the cuntributions to droop of the various ierms in liq. $(F-f)$. The term

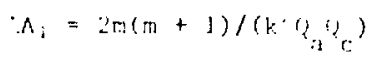

represents a troop that is independent of beam loading. In practice, this droop is masked by the variation in field due to ron-uniformities in the couplings $k$ between resonators. The term

$$
A_{i}=-8 m(m+1) \therefore a_{c} a_{c} /\left(k{ }^{2}\right)
$$

may be ignored for the 805-Mbz linac since liw $\mathrm{c}$ is small (smali stopband) and $t_{t h}$ is very small. (Since most of the stored energy is in the accelerating cavities, the resonant frequency, and hence the operating frequency, is very close to the accelerating cavity frequency.)

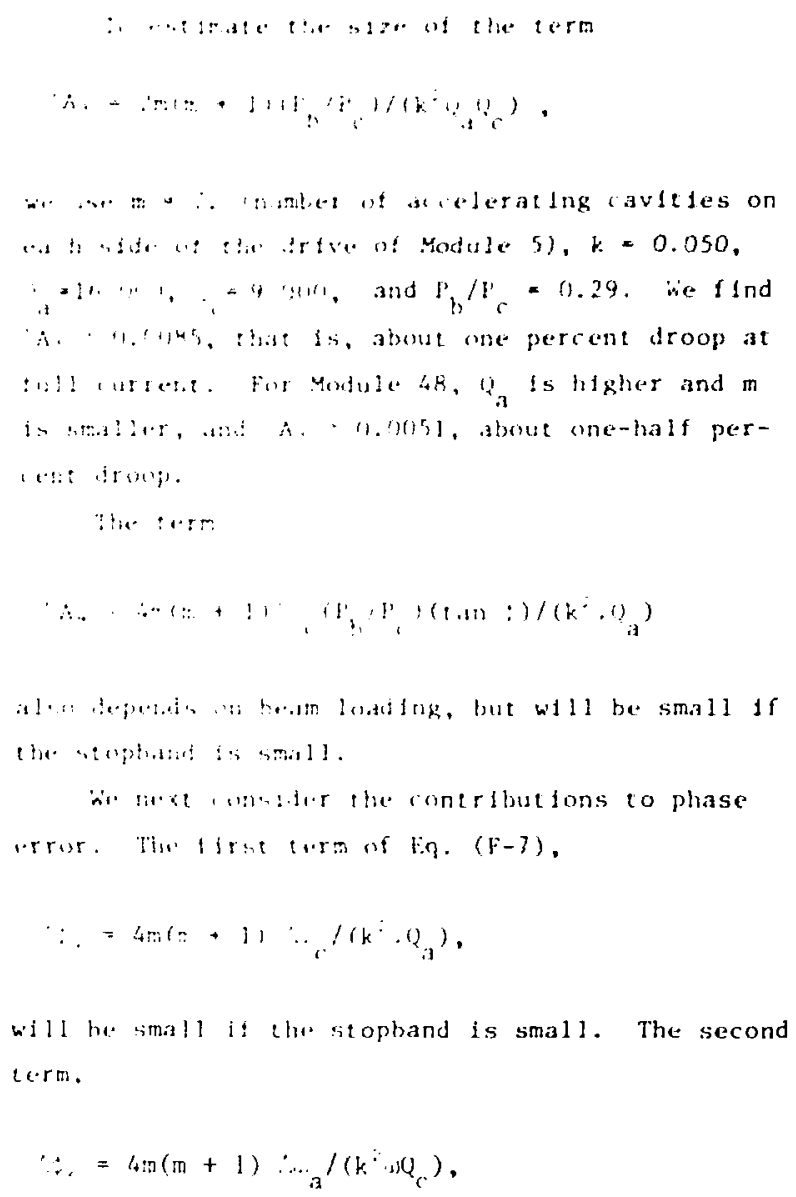
$P_{b} / P_{c}=0.29, k=0.05$, and $Q_{a}=16000$. We find the phase error for this beam loading is about 0.5 degree.

The final term,

$$
A_{4}=-2 m(m+1)\left(P_{b} / P_{c}\right)(\tan \phi) /\left(k^{2} Q_{a} Q_{c}\right)
$$

also depends on beam loading. For $\left|\left(P_{b} / P_{c}\right) \tan \phi\right|$ 0.29 for Module 5, $\left|\Delta \phi_{4}\right|<0.0085$ radians, which is less than 0.5 degree. 
It has been observed on Module 5 of the LAMPF accelerator structures that opt imum high-power stabllity appears to be achleved wth the stophand set slighely hiph. A posisible explanation of this effect and some crude ast imates of the magnitude of lue effert are discussed in this Appendix, which it based on work by E. knapp (J970h).

l'sing b.qs. (F,-f) and (F-3) for a lossless complees resonator modrel, we find the tilt sensitivity for a tank with rend cavity perturbations is

$$
\begin{aligned}
& x_{2 n+1}=(-1)^{n}\left[1-n \alpha_{c}{ }_{c}\right] x_{1},
\end{aligned}
$$

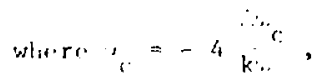

$$
\begin{aligned}
& \therefore{ }_{r}={ }_{{ }_{0}}-{ }=\text { stoptiand, }
\end{aligned}
$$

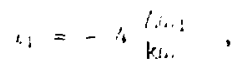

$$
\begin{aligned}
& \therefore n_{1}-\cdots 1-\cdots=\text { end cavity frequency errot. }
\end{aligned}
$$

The field distribution for varjous combinations of frequency errors is shown in fig. $(;-1$. The field at cavity $2 n+1$ is held constant by the $r$ amplitude control system. With a negative stopband, a negative frequency error fin tilts the distribution toward the $n=1$ end ravity, which induces a greater field in that cavity. This, in turn, can induce an additional negative frequency error due to excess power dissipation in that cavity. Thus if the stopband is negative, a feedback mechanism exists to inrrease tilt, and if the stopband is positive, a feedback mechanism exists to decrease tilt. :iow the initial tht may be produced by unbalance in coupling, rather than freguency errors. In this case, the orloinal frequency errors may be zero except for a stophand. Then the addition of power will producse relative frequency errors in the cavitirs whjrb would not be present in a flat tank at high-power. If the scopband is high, the ereguency errors will be surch as to reduce the fields in accelerating cavities which have high initial fielets, and raise the fields in cavitics bith low initial field values, of fetting the effects of coupling arror's. With the stopband low, the coupling constant fjold arrors are increased by the frequenry errors. In the case of stopband opened high (positive), the tanks are driven to a flat distribution, c.g., stable. In the stopband low (negative) (ase, the situation may become divergent and large tilts develop.

To estimate the order of magnitude of the ef fect under consileration, consider the field distribution producer by a tank which has a frequency distribution as shown in Fig. (j-2: one-half the module $\therefore$ a high in accelerating cavities, other half $-{ }^{\prime}$. stopband $\therefore c^{\circ}$. Then

$$
\begin{aligned}
& x_{2 r-1}-x_{a}=\frac{4 u_{a}}{k(n)} \text { for } r=1,2, \ldots, n ; \\
& x_{2 s}-x_{c}=\frac{4 \therefore c}{k w} \text { for } s=1,2, \ldots, n ;
\end{aligned}
$$

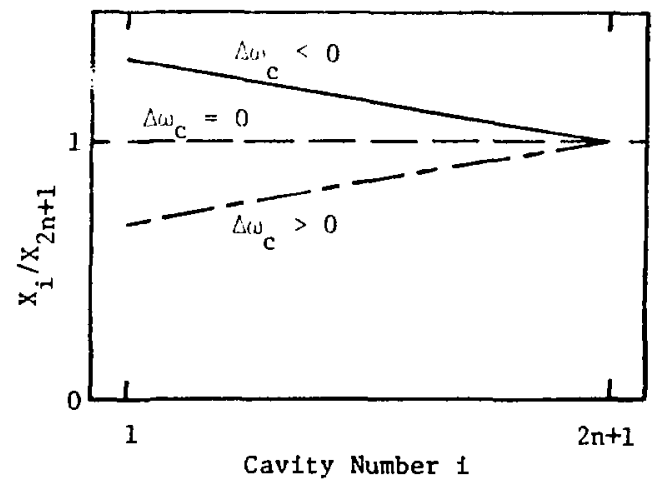

Fig. G-1. Field distributions for $\Delta w_{1}<0$ and various stopband conditions.

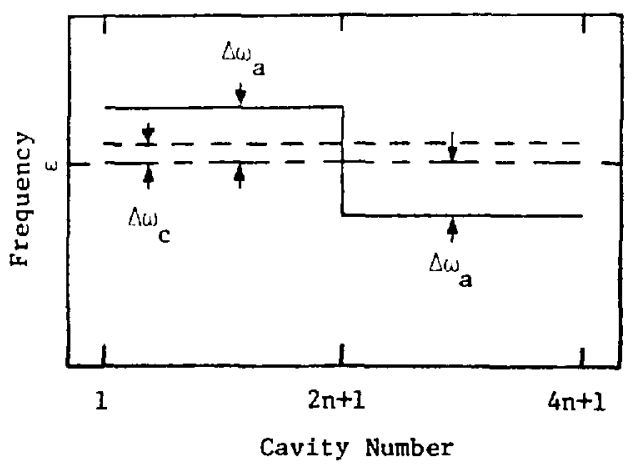

Fig. G-2. Assumed frequency distribution in a module. 
and we find using $t q$, $(i-f)$ that

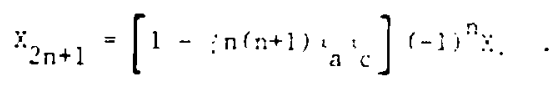

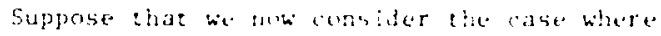

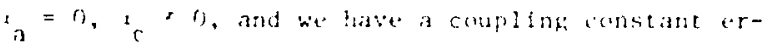
ror fn the center lavily bo that une-hale the nodwe is initially high, the wher balf initially low, by 1): for n nuthertan list. Ghen, the d: ferential heating will profere a treglency error distribution as indisaled in Fig. (i-2. The mandlude of the freriseney error an be est imated from che water temperature gersab average ra pewer data frow Yodule 5. A tewperature shite of $4^{\circ} \mathrm{C}:\left(7^{\circ} \mathrm{F}\right)$ is

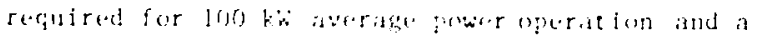

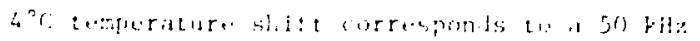
thinge in astity reriuenge Thus

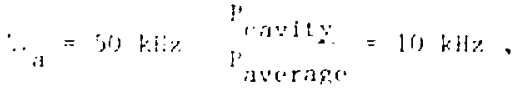

$$
\begin{aligned}
& 2 n+1=145,
\end{aligned}
$$

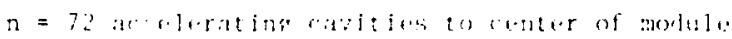

$$
\begin{aligned}
& k=11.1 \% \text {. }
\end{aligned}
$$

and for a lor the stophind we find the accelerating

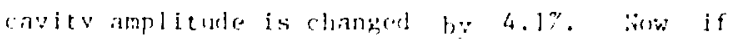
the stophand is ponstive, this redaces the frequency error, and a second icoration cassuming the end ell perturbation is in every cell in the system, which is definitely not true, but which can be used eatsily in calculations) violds a shift from zero power of $2.5 \%$

If the stophand is negative, the frequency error is increased. Doing this iteration with the same assumptions gives a final field shift of $7.5 \%$.

The results for scveral stopbands are shown in Fig. $(;-3$.

While these estimates are very crude, they do seem to give at least order of magnitude agreement

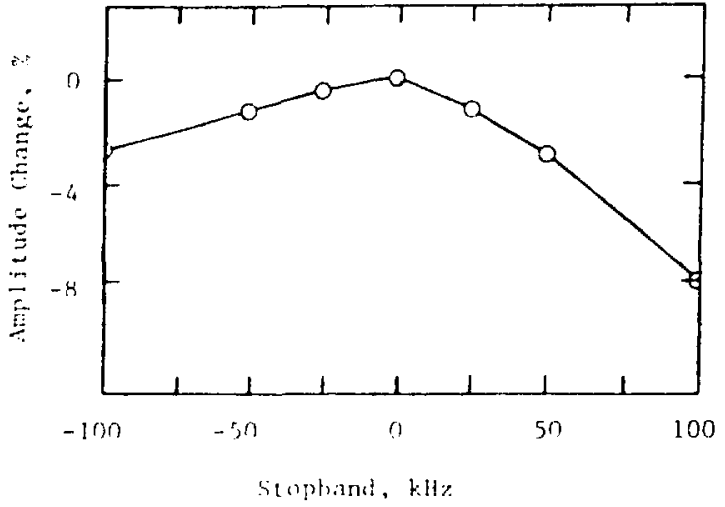

Fig. li-3. Field distribution ciange for half the molule initially ten per ecent high and hall lea ner cont low.

with the observed hehavior. These ralculations can be made on a distial computer without the assumptions made bere, and may lead to a more complete understanding of the offect, It appears that:

(1) Remuing initial coupling cavity errors would redure the stopband offset effect.

(2) Seleing the average value of the tanks accurately will help alleviate this problem.

(3) Some additional stability will always be afforded by operating with a small positive stopbind.

(4) The stophand in each tank should be set, for this can be a loral, as well as a general efsect.

(5) As we progress to higher : modules, the effect should decrease as heat transfer from the drift tubes in the accelerating cavities becomes better, and the number of cavities per module decreases.

Calculations of this effect using the coupled circuit model including $r$ fosses confirmed tho type of behavior shown in Fig. G-3, but indicated the amplitude changes were smaller than shown above (Swain 1970c). 


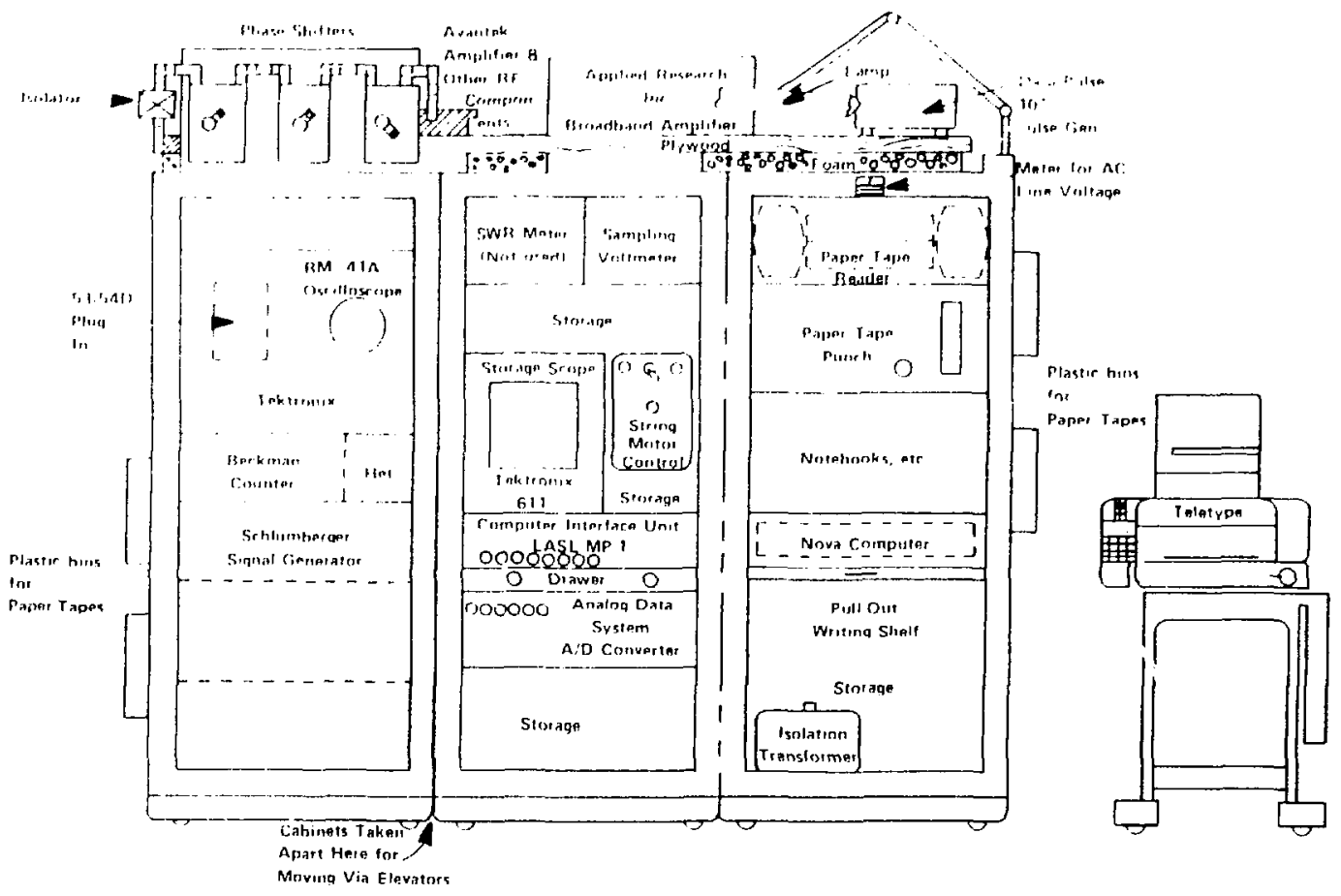

fig. H-1. Portable rack with inmputerized headpull measurement equipment. 

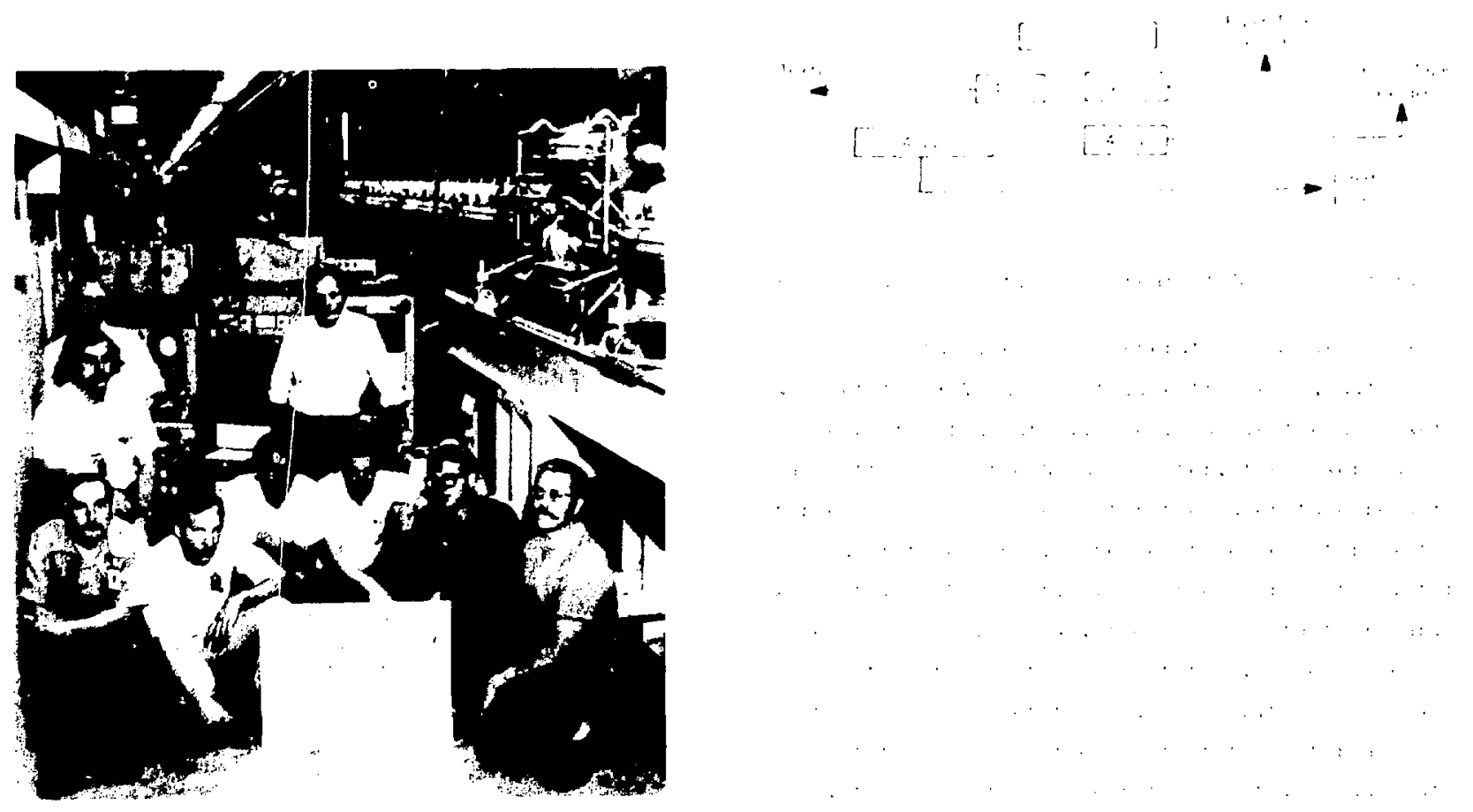


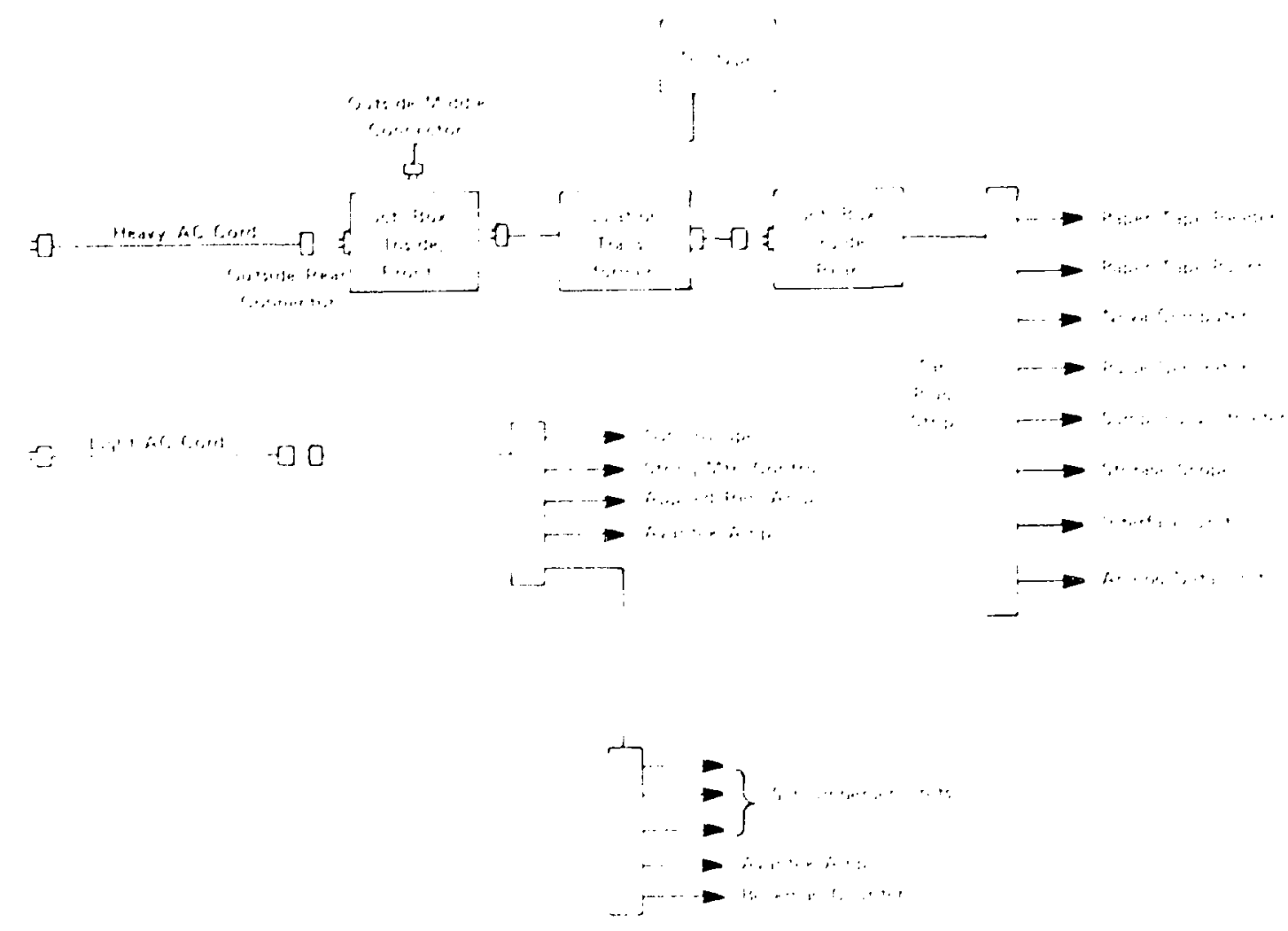

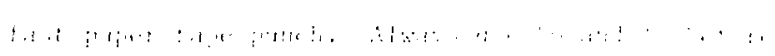

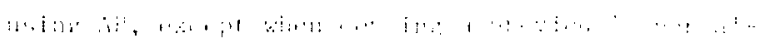

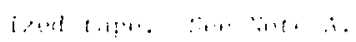

\%

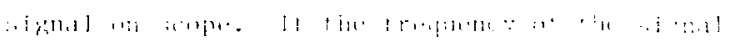

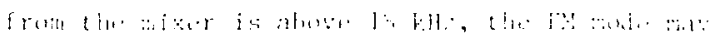

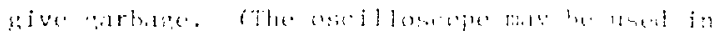

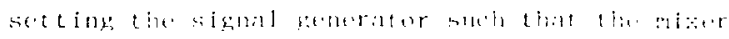

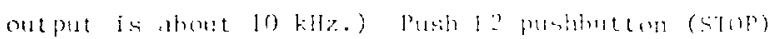

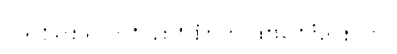





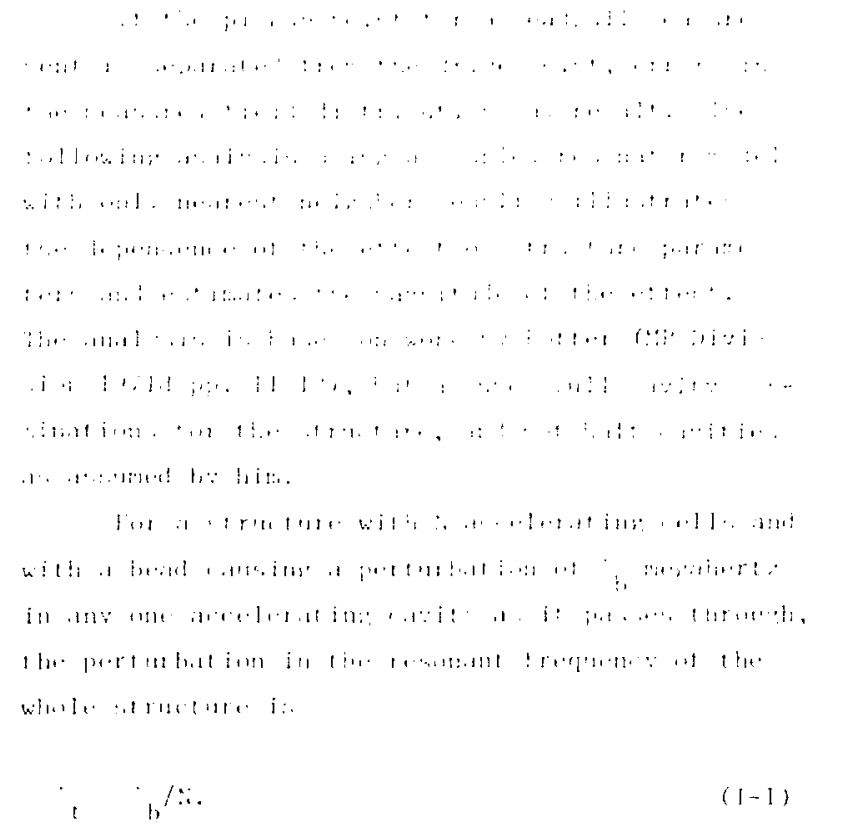

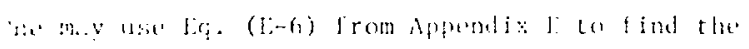
thects of these freguene perturbations on the fieldsi in the strueture.

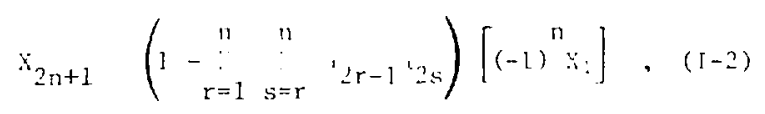

provided no can determine ${ }^{2} 2 r-1$ and ' ${ }^{2} 2 s^{\circ}$ Primed quantities are used in the expressions to follow

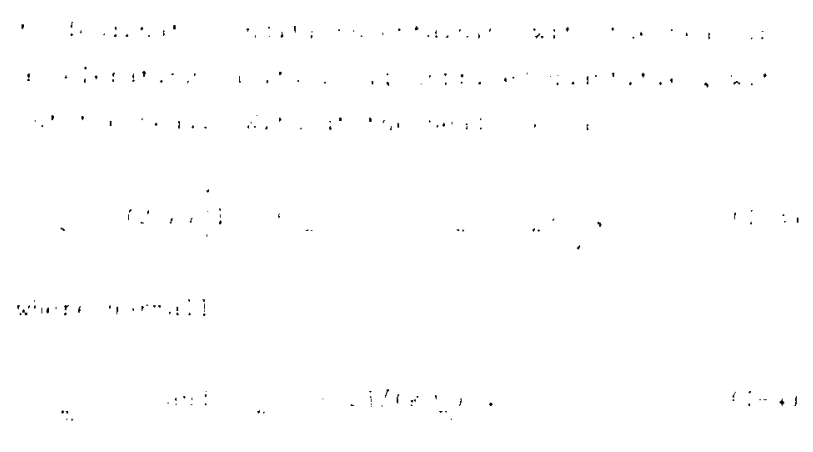

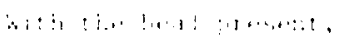

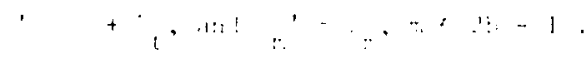

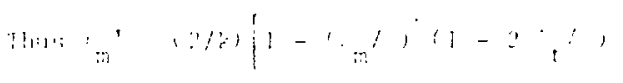

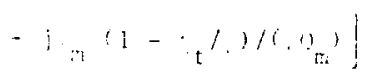

ind

$$
{ }^{\prime}{ }^{\prime}+{ }_{\mathrm{t}} /(\mathrm{k})-2 \mathrm{j} /\left(\mathrm{k} \mathrm{q}_{\mathrm{r}}\right)
$$

For i 0.002 :14:, k .05, . $805 \% \mathrm{~Hz}$, and 1) 20000 , the magnitude of the sucond term in fig. (1-5) is about 10 times that of the first. These values are typical for accelerating cavities. For coupling cavities, the ? is lower, and the ratio of the terms is even larger. Consequently. from Eqs. $(I-4)$ and $(1-5)$ 


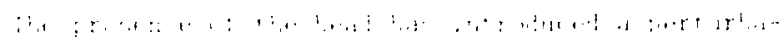

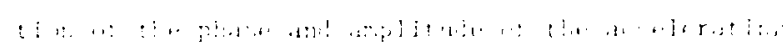

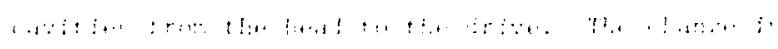

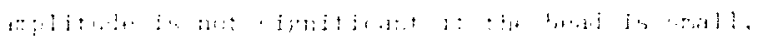

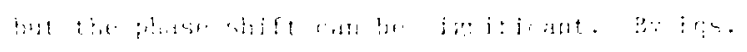

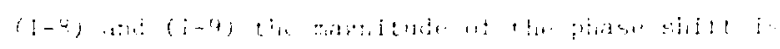

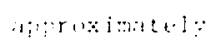

$$
:=a(n-b+1) /(k) \quad i-i), n \text { in }
$$

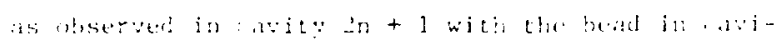

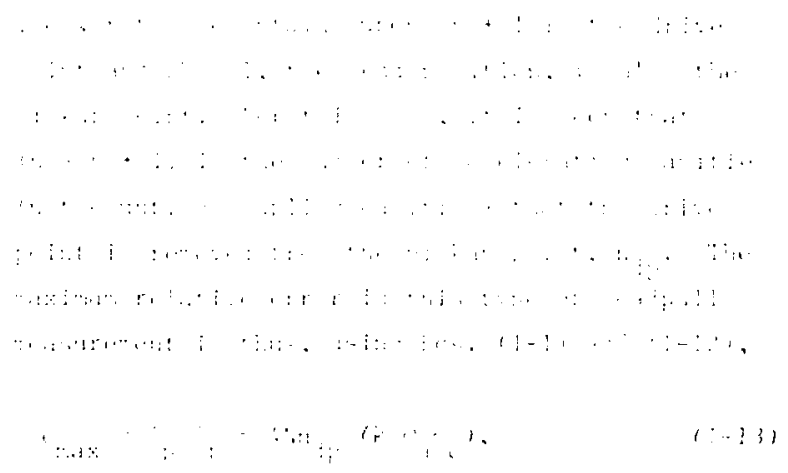

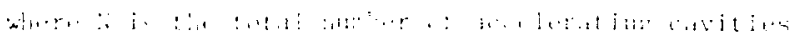

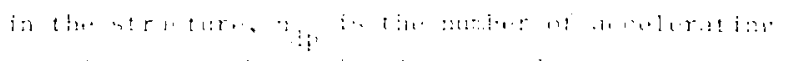

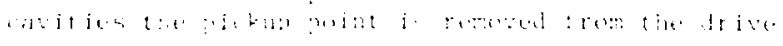

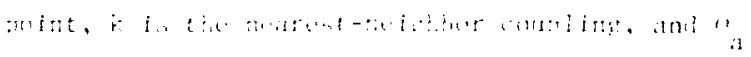

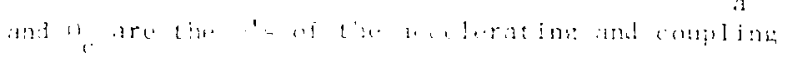
i.: it it in: 


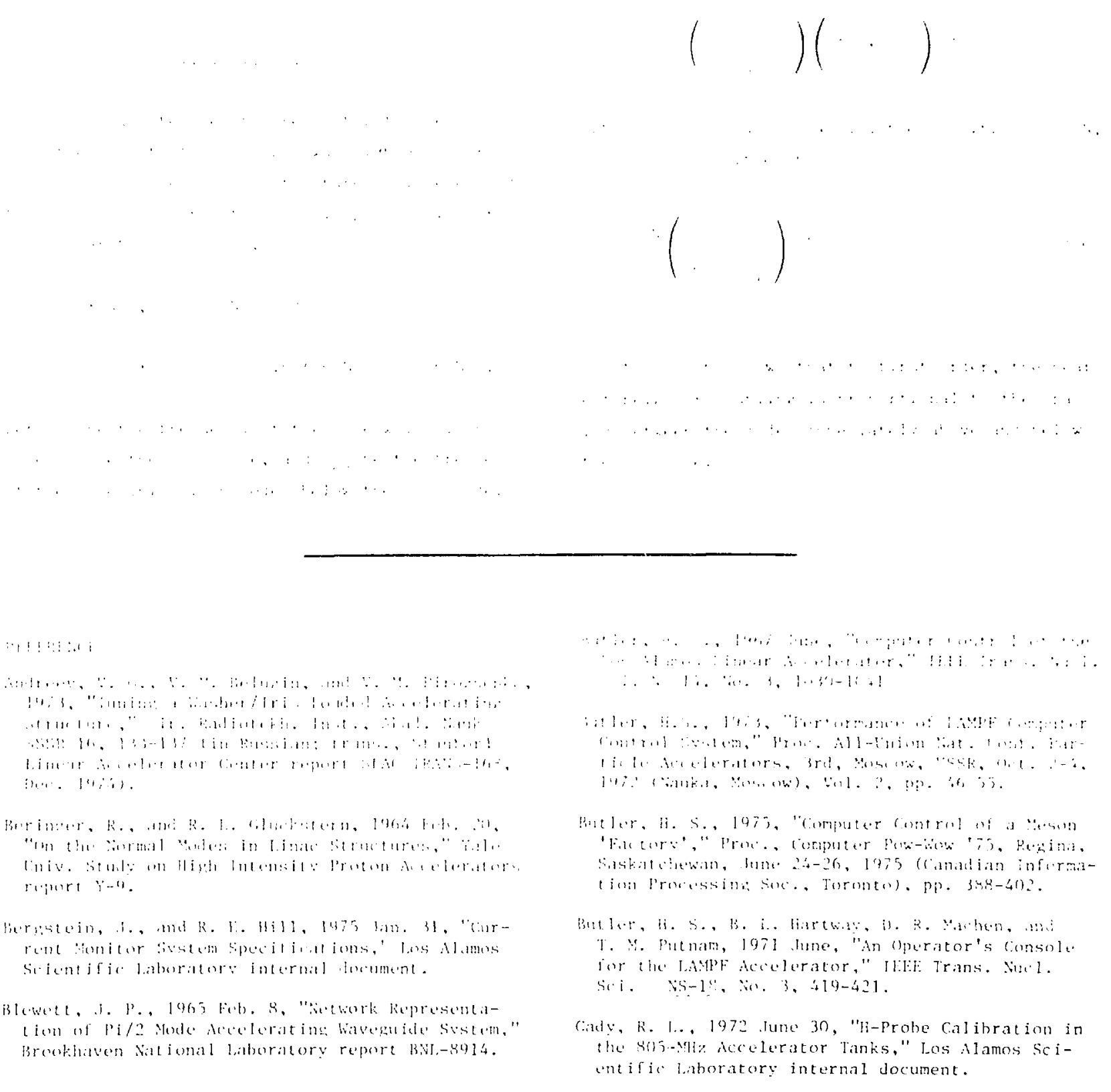




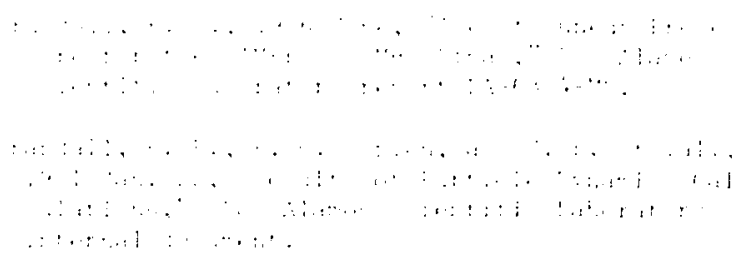

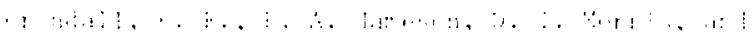

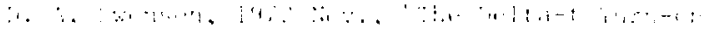

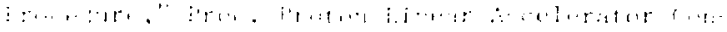

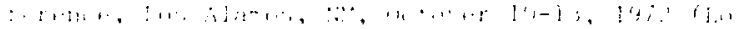

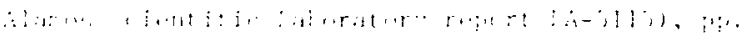
1. $\therefore ? \cdots$

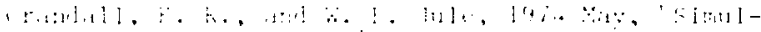

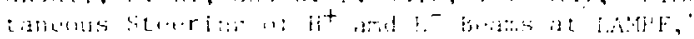

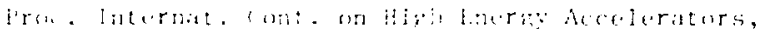

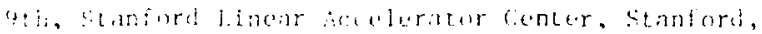

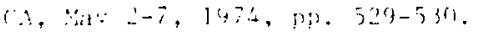

Crandall, $\ddot{t}$. F.. and i) A. Sivenson, 1970 Feb. "s, "Sic. Coupled l.inal iurn un Problen." Los Alinos seigntific laboratory internal docunent.

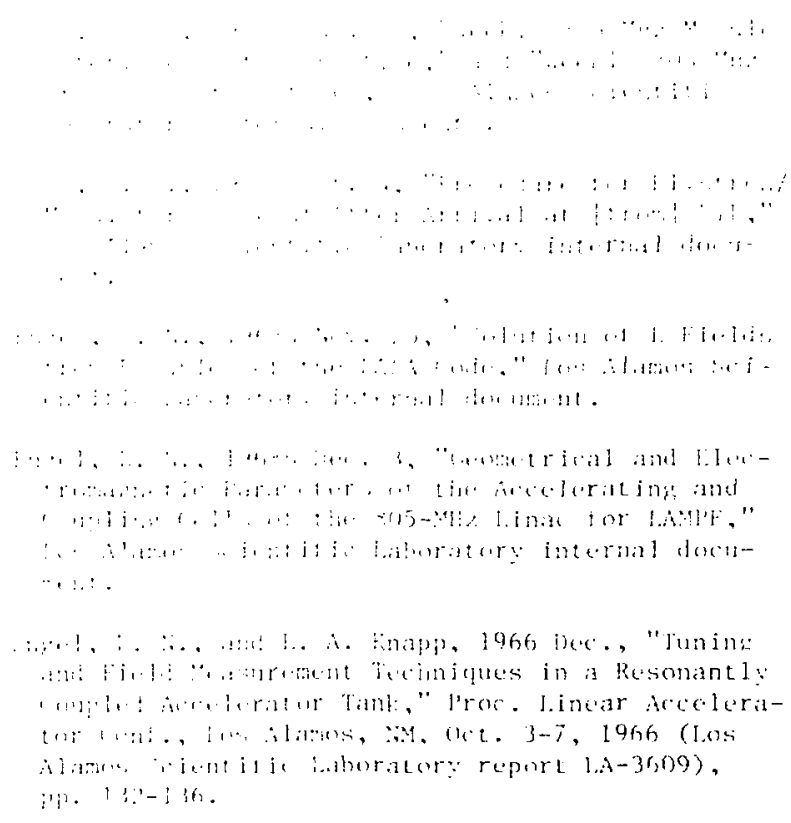

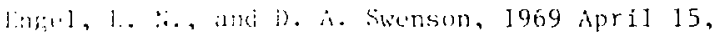

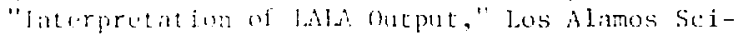
ent if ir baburatury internal dociment.

Fraser, A. S., S. H. Kidner, f. Ackeown, and 6 , E. Mychace, is72 inv., "The Chalk River Hectron Test Acreleratur," Proce proton linear Accelerator conf., los hlanos, $:$, w tober 10-13, 1972 (los Alamos Seicntiris laboratory report $1 \Lambda-5115$ ), ip. $224-232$.

ciluckstern, R. I., 1964 Sept., "Cavity-Bean Interactions," in "Al lroposil for a High-Flux Vleson 


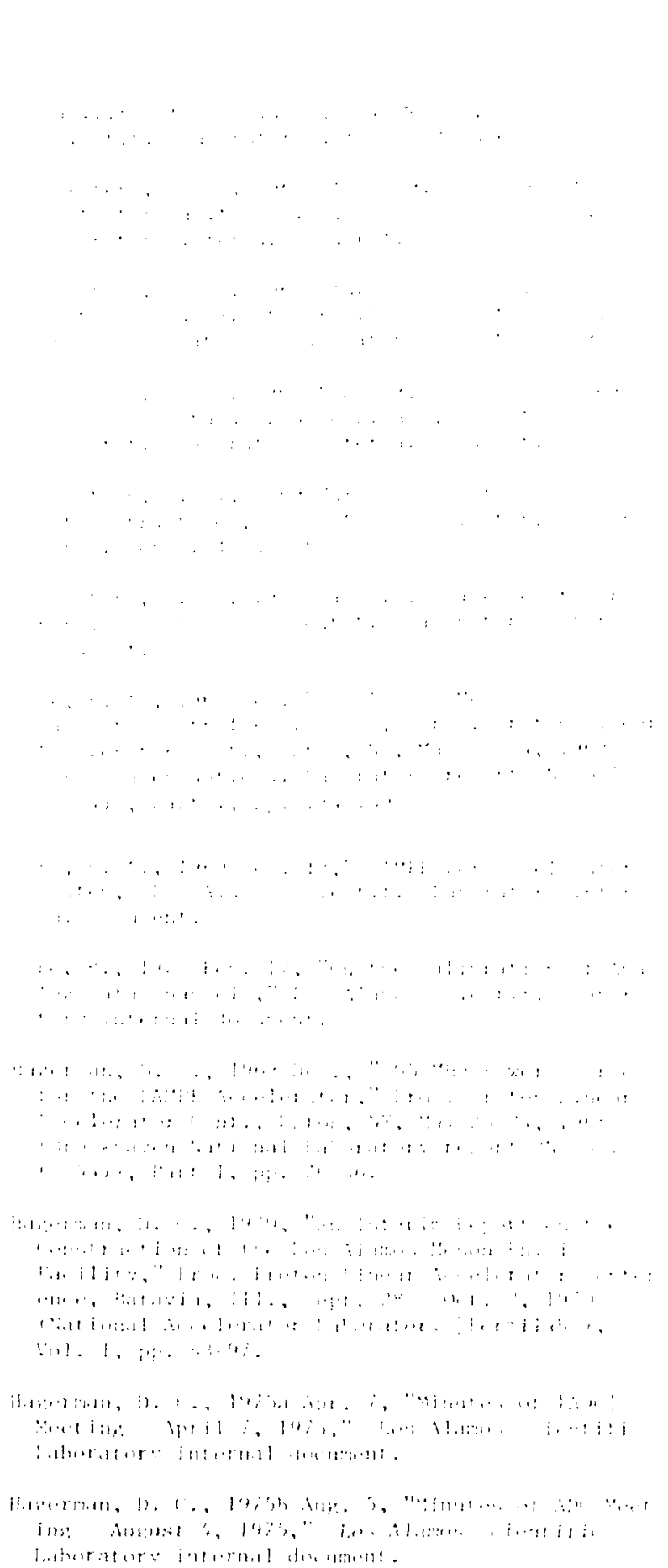

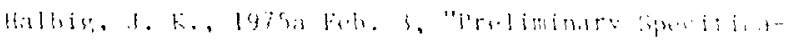

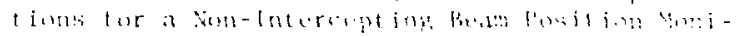

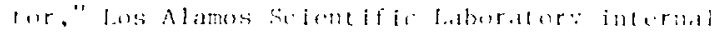
duenent.

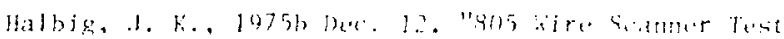

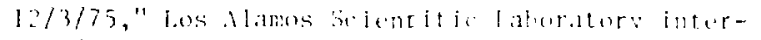
nal document.

Harrison, R., and V. E. Harl, 19it Der. 5, "summmente

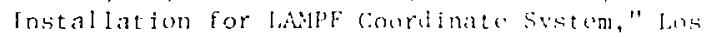
Alamos Seicntific laboratory internal doemene.
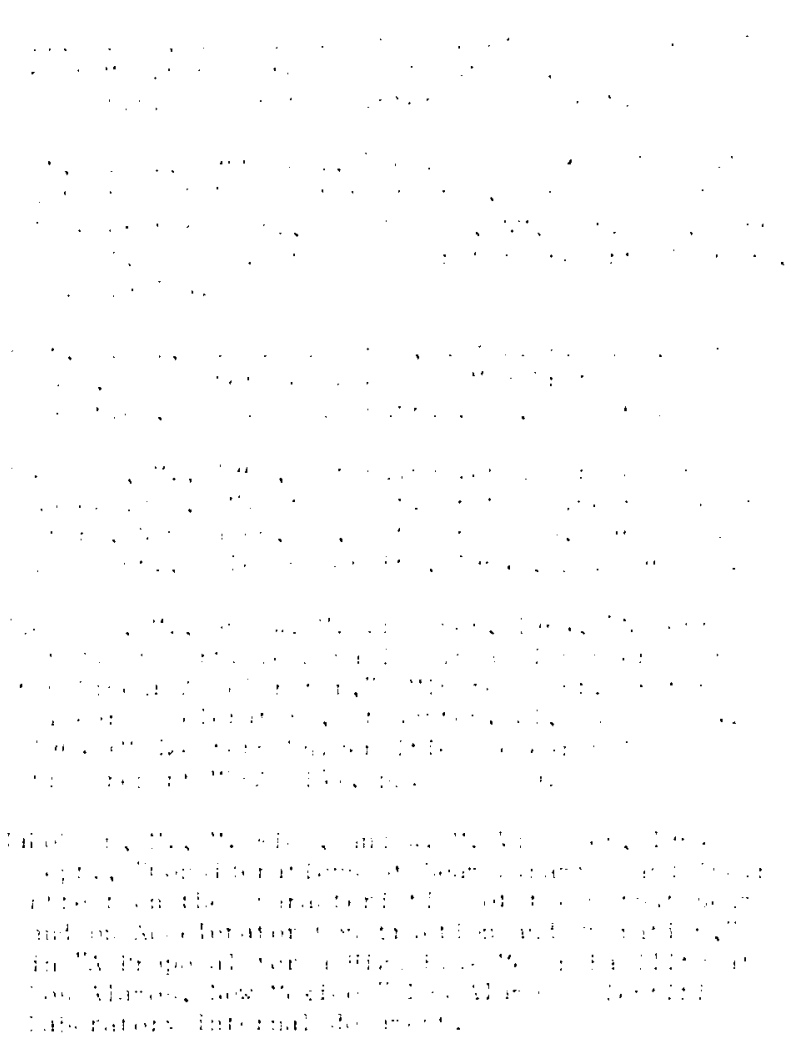

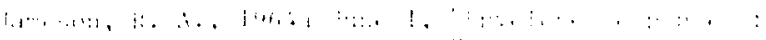

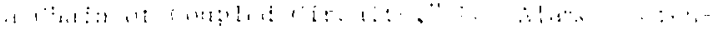

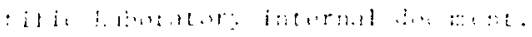

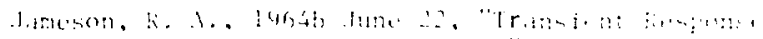

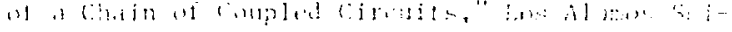

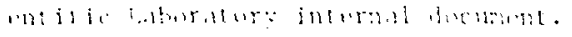

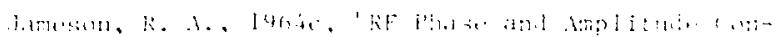

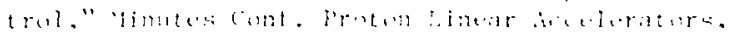

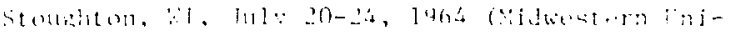

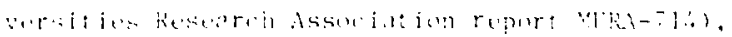
'ir). 


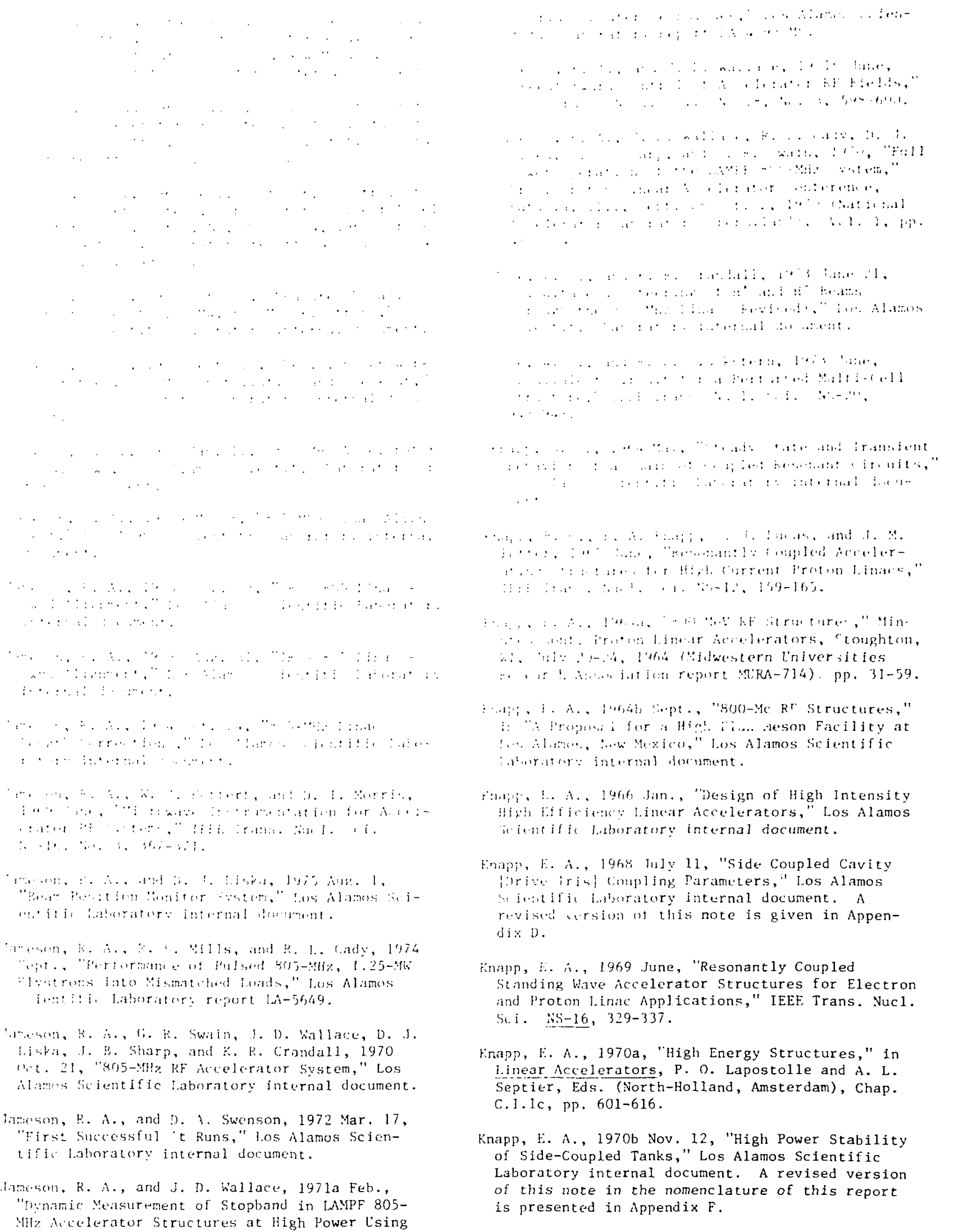




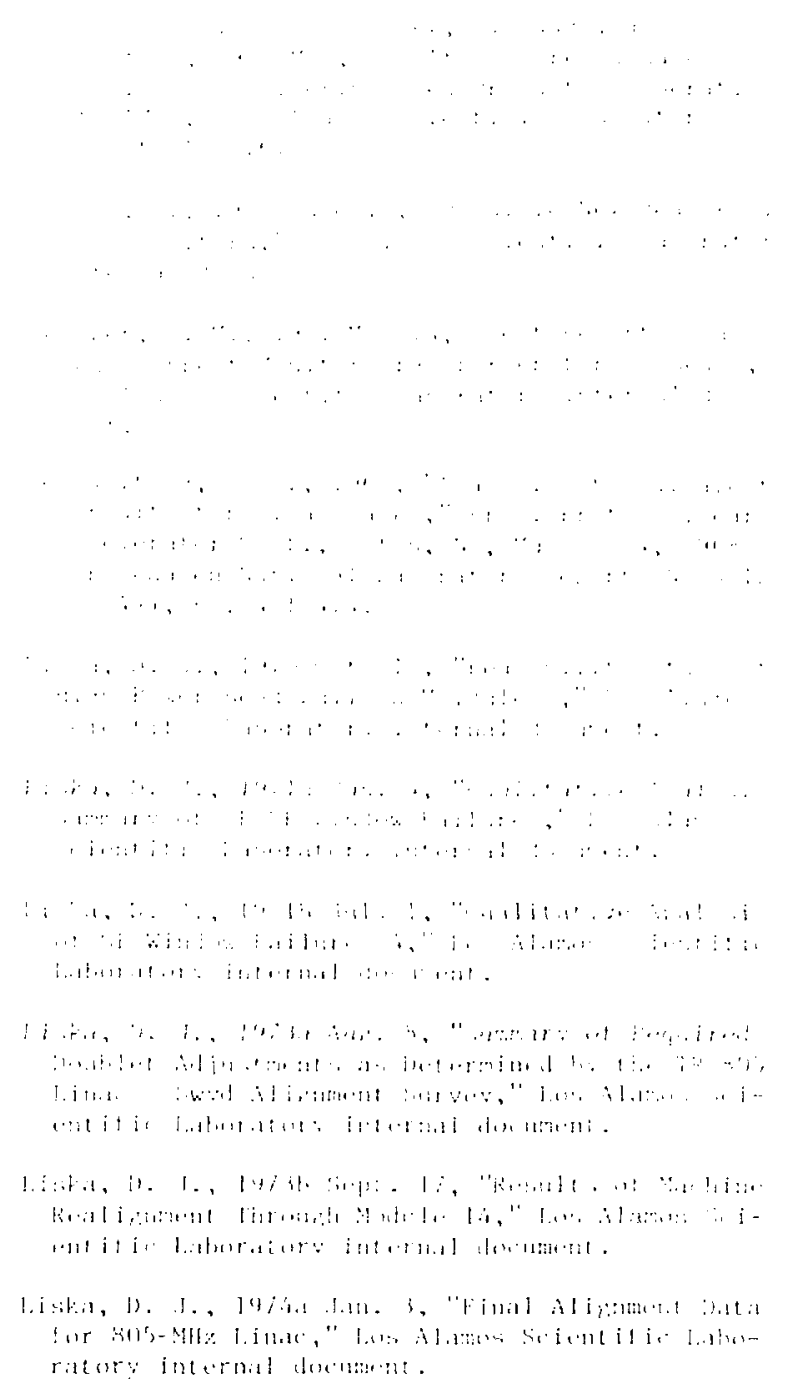

1.iskia, 1). J., 1074l, Jan. 7. "Final Vertian! Ai iqul-

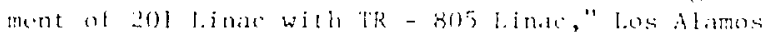
Sicientifj. laboratury inlernal doentrent.

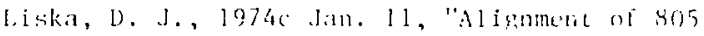

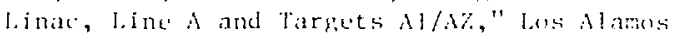
seicutific laboratory internal docment.

liska, 1). I., 1974d May 22, "[Procedures for] Me.surements on Module lengths for Period lay 2931, 1974," Los $A 1$ anc: Selentilic laboralory internal document.

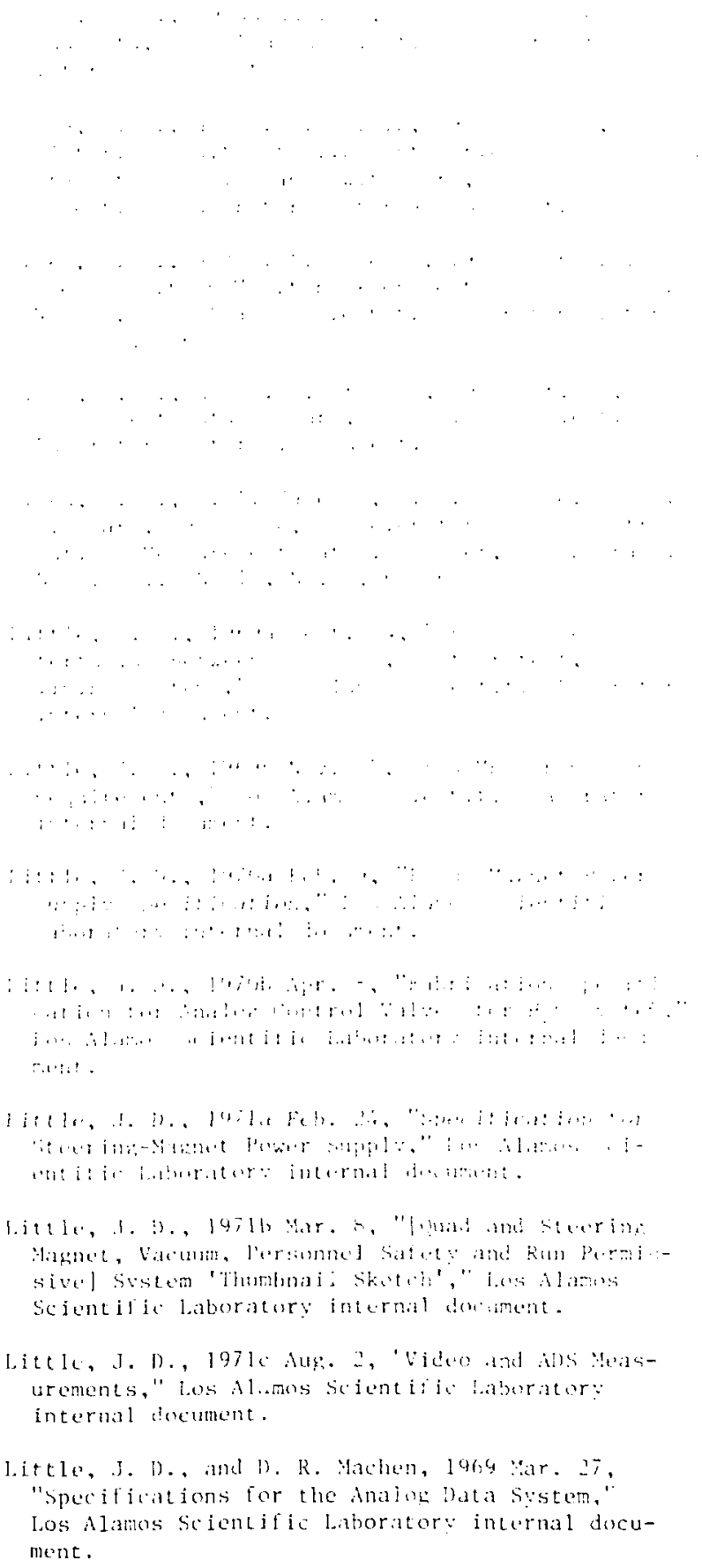

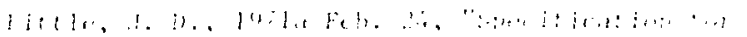

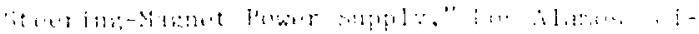

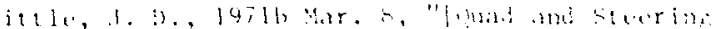

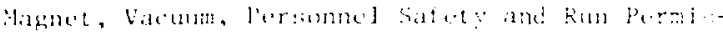

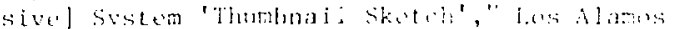
seientilie laboratury intermal dorement

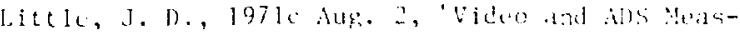
urenents," tos illanos Sicientitio laberator:

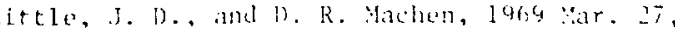
Los Alamos Soiembje laborator" inlernal document. 


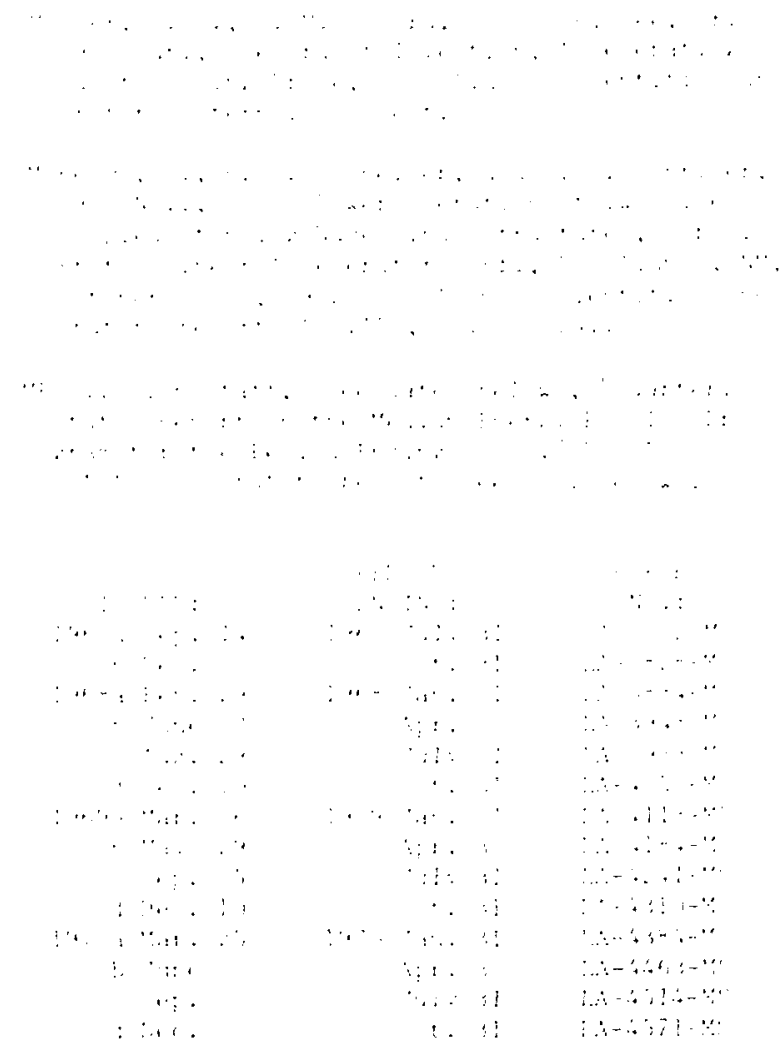

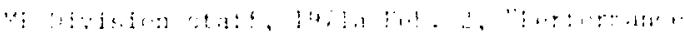

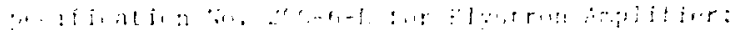

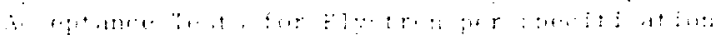

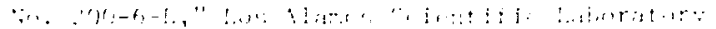

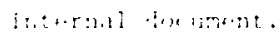

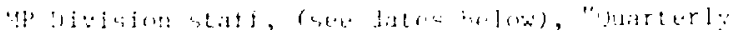

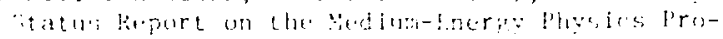

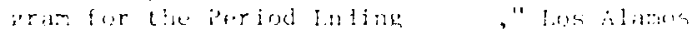

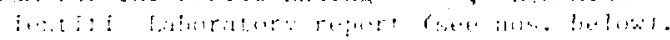

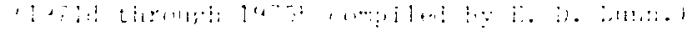

0.175

15. (1):

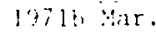

" $\because a \%$

is Sip.

(c) i) e.c.

1972 a sor.

b Ju] $\because$

c Sep.

\section{and $[1]$}

(E) li:;:

1973 ian. 3]

Apr. 30

. $111 \div 31$

oct. 31

1972 Jan. 31

Apr. 39

Ju $: \because 31$

\section{RIPORT}

(i) $:$

$1,1-4639-15$

$1,4-4692-45$

$1 . \lambda-4753-95$

$1 A-4850-P R$

$A A-4899-P R$

$[A-4982-P R$

$1, A-5 \cap 1+P-P R$

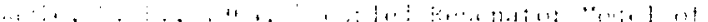

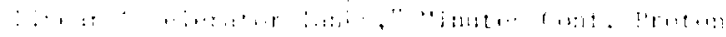

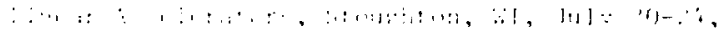

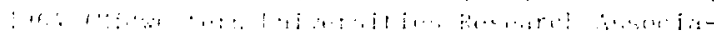

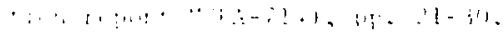

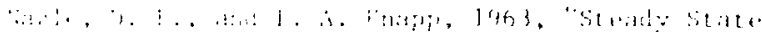

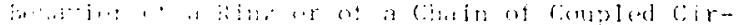

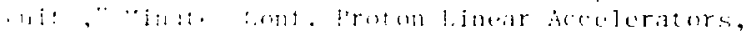

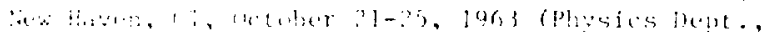

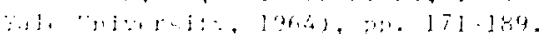

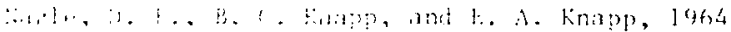

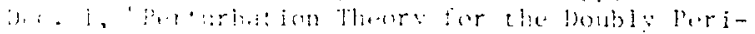

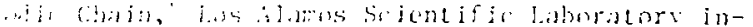

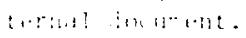

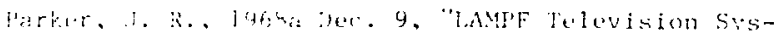

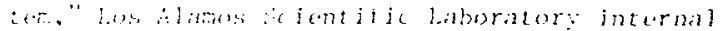
downt

Park.r, i. K., 196eb ber. la, "Rad-sate sustom,"

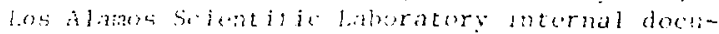
mint.

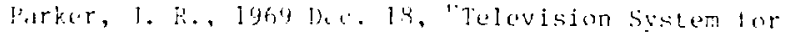

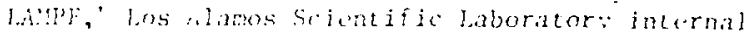
dociugent.

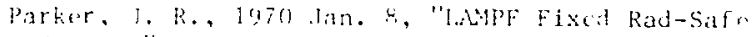
System," los alamos sojent if ic laboratory jnturnal document. 

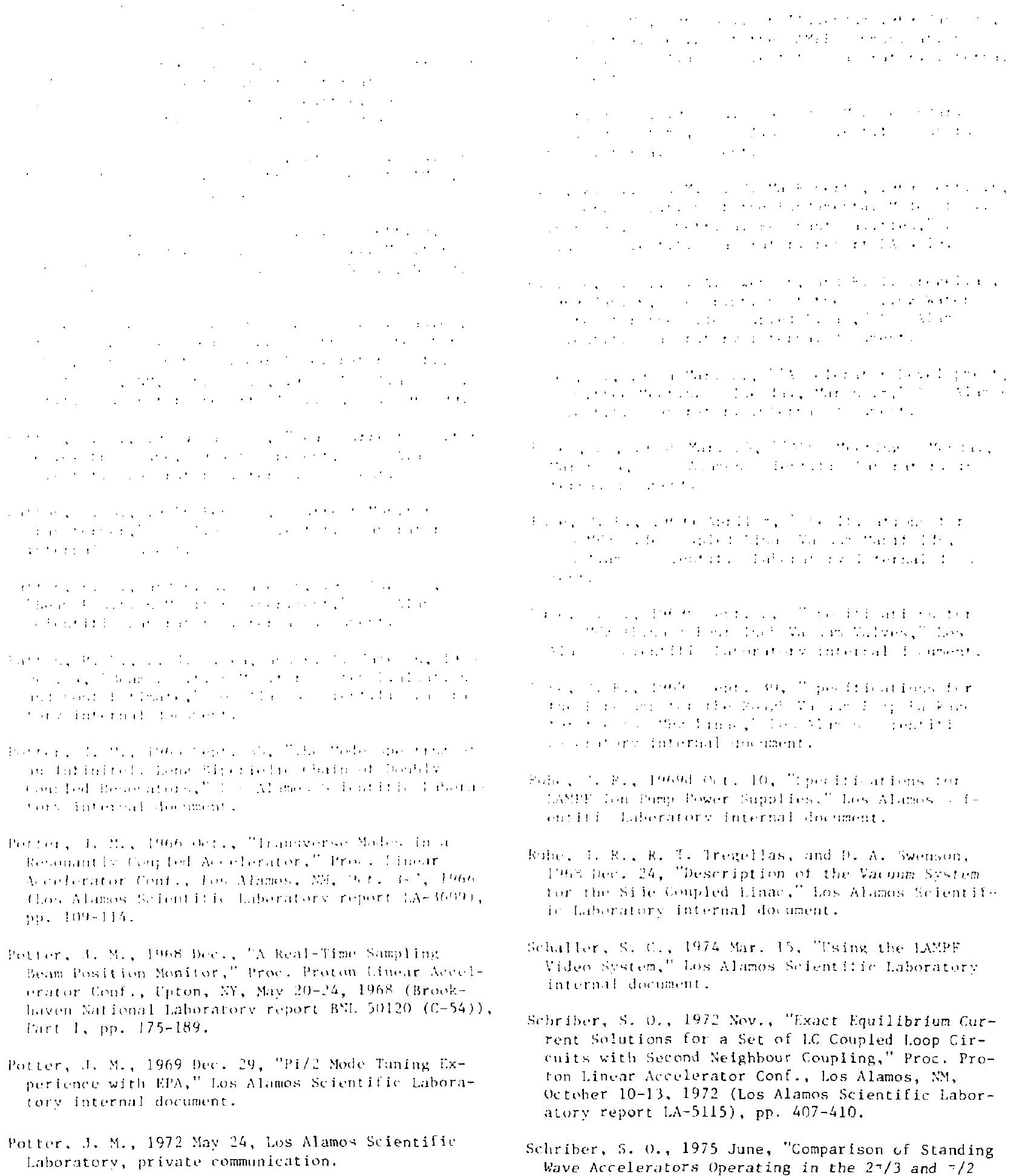


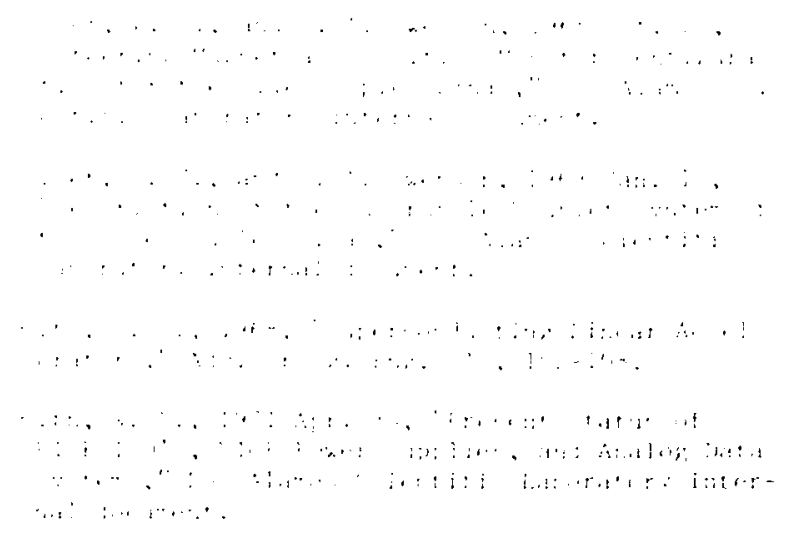

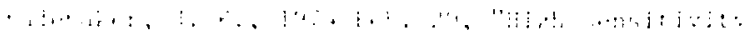

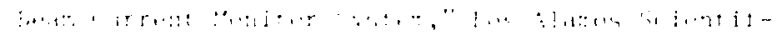

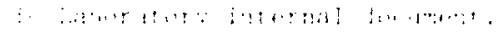

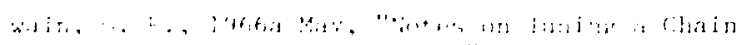

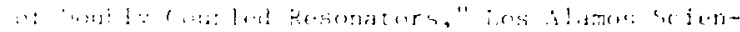

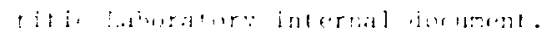

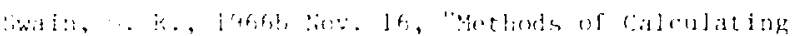

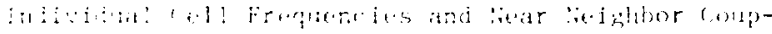

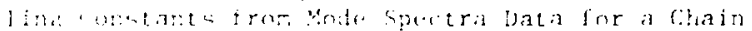

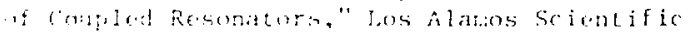
laborator $\because$ internal Horitnent.

win, r. R., I96fi der., "riruit Analog Techniques for Analysis of Resonant ly-Coupled linear Accel"rator Structures," Pror. l.inear Accelerator Cone., Los ilanos, iM, Oct. 3-7, 1966 (Los Alamos Scientific Laborator $\because$ report 1 A-3609), pp. 125-131.

Swain, G. R., 19660 d Dec. 2, "Degradation of Long Tank Performance with Tuning Frrors - Summary of
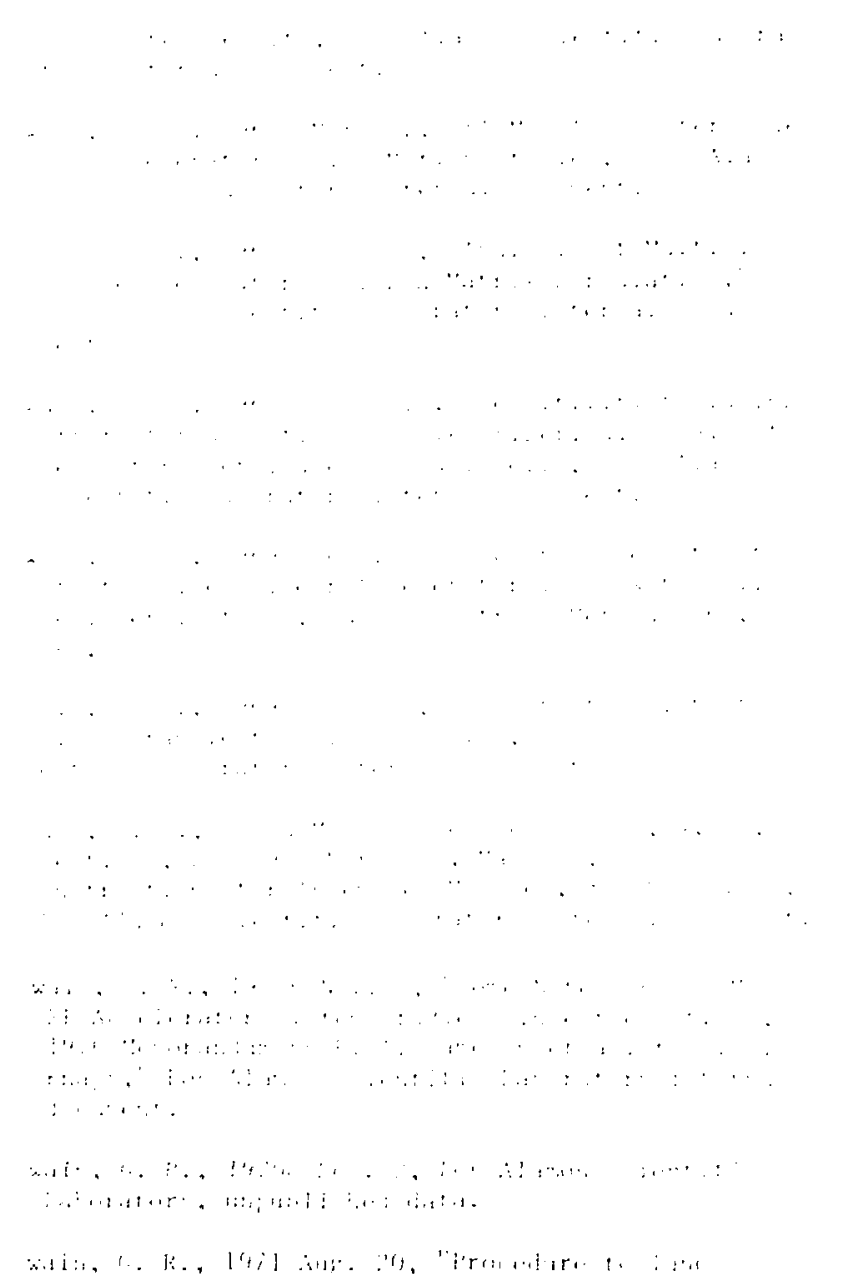

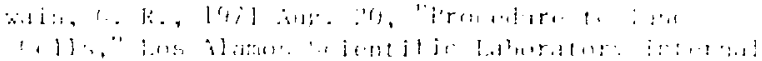
$\because 1,1, \cdots, \cdots+1$.

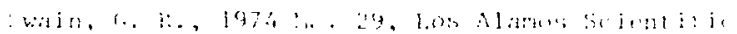

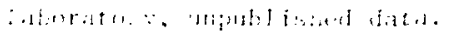

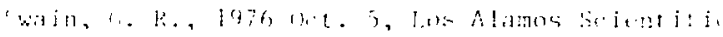

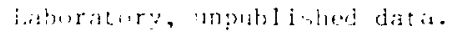

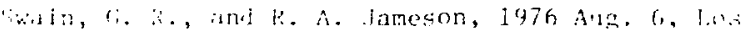

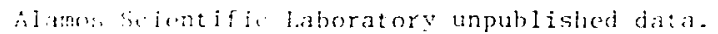

Waiti, G. R., R. A. Jameson, R. Fandarian, N. I. l.iska, $\because$. k. Yartin, and i. :1. Potter, 1972 :iov. "cavit: tuning for the IAtuF Bos litz Linac," Pror protot Linear Aceclerator Conf., Los Alamos, s.? lictoher 10-13, 1972 (Los Alamos Sijentifix fahoratury report $(.1-5115)$, P. $242-249$.

Swan, (i. K., R. A. Jameson, E. A. knapn, D. J. I.iski, I. M. Potter, and J. D. Wallace, 1971 June, "luning and Pre-Beam Chcckout of 805 shle SideCoupled Prolon Linac Structures," IEFE Trans. Nucl. Sci. 3.s-18, No. 3, 614-618.

Swain, C. R., D. J. L.iska, J. D. Wallace, I. B. Sharp, and R. A. Jameson, 1970 July 16, "Yodule" 5 Fxperiment," Los Alamos Scientific laboratory internal doctument. 


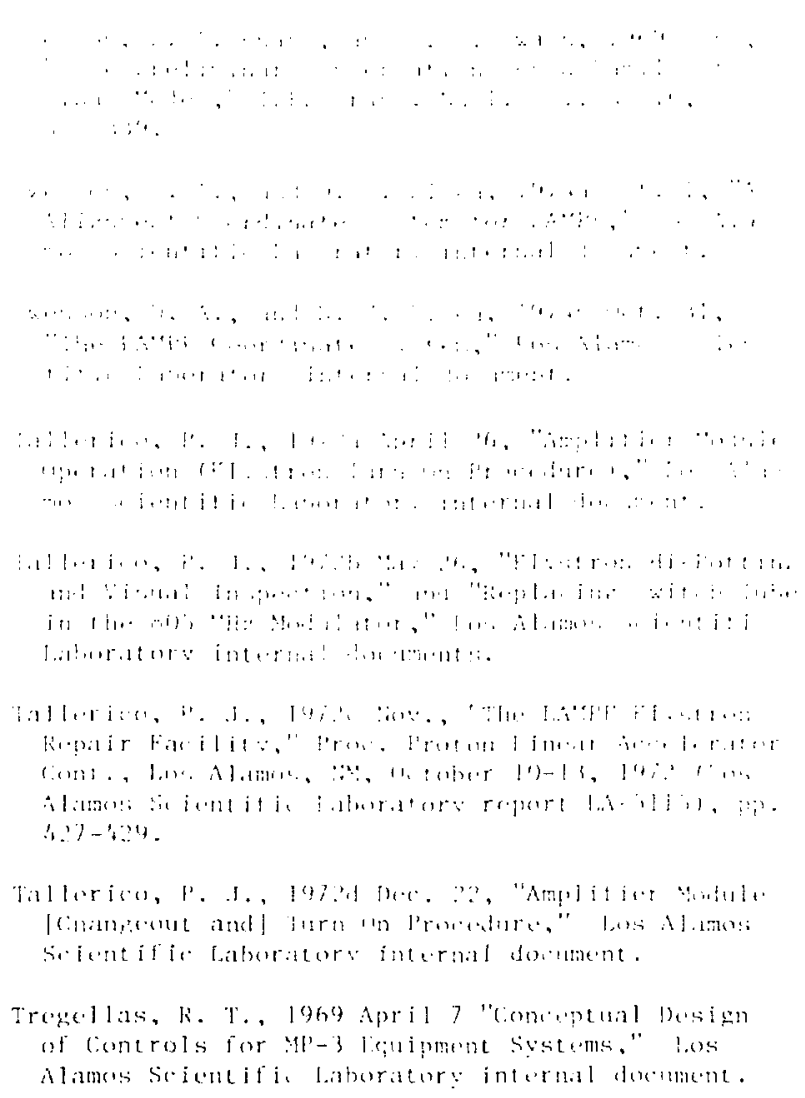

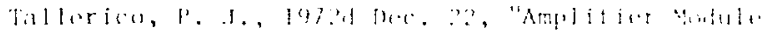

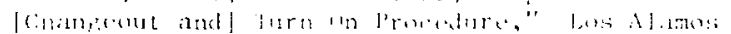

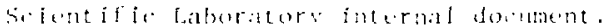

Tregellas, R. T., 1969 April 7 "comerptual design

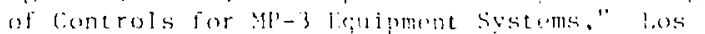

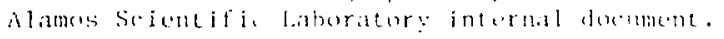

